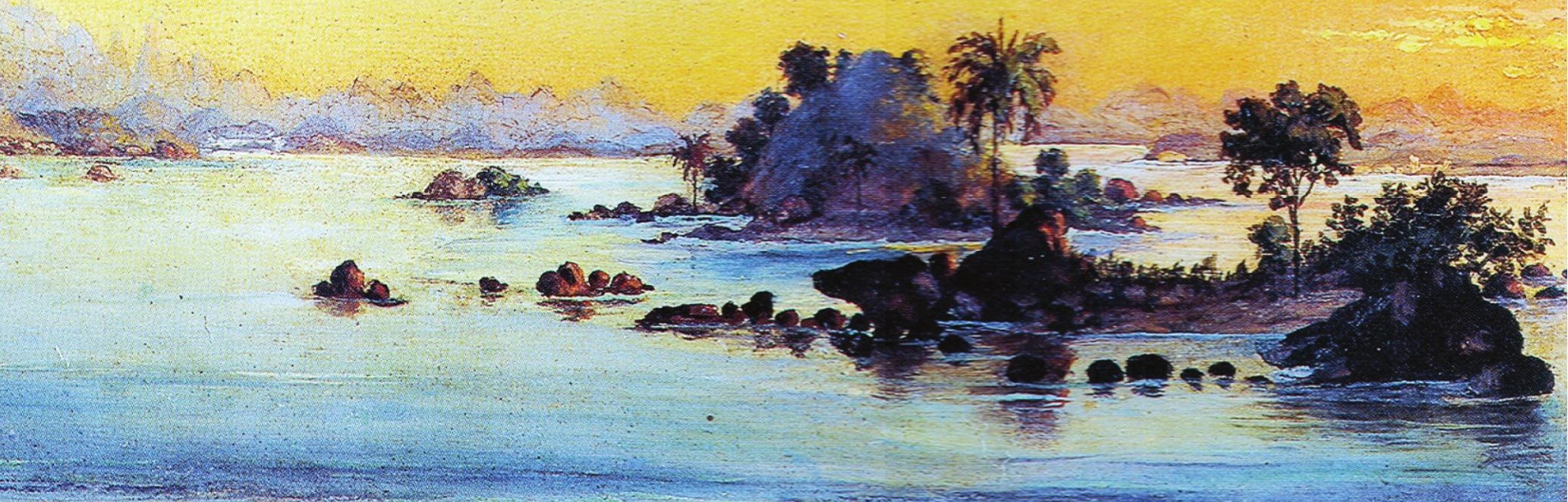


História

da Historiografia issn 1983-9928 


\section{Conselho Executivo}

Alejandro Eujanian (UNR . Rosário . Argentina)

Arthur Lima de Àvila (UFRGS . Porto Alegre . RS. Brasil)

Helena Mollo (UFOP. Mariana . MG . Brasil)

Fábio Franzini (UNIFESP . Guarulhos . SP . Brasil)

\section{Consellho Editorial}

Arthur Alfaix Assis (UnB . Brasília . DF . Brasil)

Claudia Beltrão (UNIRIO . Rio de Janeiro . RJ . Brasil)

Durval Muniz de Albuquerque (UFRN . Natal . RN . Brasil)

Fabio Wasserman (UBA. Buenos Aires . Argentina)

Fernando Nicolazzi (UFRGS . Porto Alegre . RS . Brasil)

Helena Mollo (UFOP . Mariana . MG . Brasil)

Julio Bentivoglio (UFES . Vitória . ES . Brasil)

Lucia Maria Paschoal Guimarães (UERJ . Rio de Janeiro . RJ . Brasil)

Pedro Meira Monteiro (Princeton University . Princeton . Estados Unidos)

Pedro Spinola Pereira Caldas (UNIRIO . Rio de Janeiro . RJ . Brasil)

Raquel Glezer (USP . São Paulo . SP . Brasil)

Rebeca Gontijo (UFRRJ . Seropédica . RJ . Brasil)

Ricardo Salles (UNIRIO . Rio de Janeiro . RJ . Brasil)

Rodrigo Turin (UNIRIO . Rio de Janeiro . RJ . Brasil)

Sérgio da Mata (UFOP . Mariana . MG . Brasil)

Temístocles Cezar (UFRGS . Porto Alegre . RS . Brasil)

Tiago C. P. dos Reis Miranda (Universidade de Évora . Évora . Portugal)

Valdei Lopes de Araujo (UFOP . Mariana . MG . Brasil)

\section{Consellho Consultivo}

Astor Diehl (UPF . Passo Fundo . RS . Brasil)

Carlos Fico (UFRJ . Rio de Janeiro . RJ . Brasil)

Carlos Oiti (UFG . Goiás . GO . Brasil)

Cássio Fernandes (UNIFESP . Guarulhos . SP . Brasil)

Chris Lorenz (VU University Amsterdam . Amsterdã . Holanda)

Denis Bernardes - in memoriam (UFPE . Recife . PE . Brasil)

Edgar De Decca (UNICAMP . Campinas . SP . Brasil)

Eliana Dutra (UFMG . Belo Horizonte . MG . Brasil)

Estevão de Rezende Martins (UnB . Brasília . DF . Brasil)

Ewa Domanska (Adam Mickiewicz University . Poznañ . Polônia)

Fábio Franzini (UNIFESP) . Guarulhos . SP . Brasil)

Fernando Catroga (Universidade de Coimbra . Coimbra . Portugal)

Francisco Murari Pires (USP . São Paulo . SP . Brasil)

François Hartog (EHESS . Paris . França)

Frederico de Castro Neves (UFC . Fortaleza . CE . Brasil)

Guillermo Zermeño Padilla (Colegio del México . Cidade do México . México)

Hans Ulrich Gumbrecht (Stanford University . Stanford . Estados Unidos)

Hayden White (Stanford University . Stanford . Estados Unidos)

Iris Kantor (USP . São Paulo . SP . Brasil)

José Carlos Reis (UFMG . Belo Horizonte . MG . Brasil)

Jörn Rüsen (KI/ UWH . Witten . Alemanha)

Jurandir Malerba (PUC-RS . Porto Alegre . RS . Brasil)

Keila Grinberg (UNIRIO . Rio de Janeiro . RJ . Brasil)

Luiz Costa Lima (PUC-Rio . Rio de Janeiro . RJ . Brasil)

Manoel Salgado Guimarães - in memoriam (UFRJ . Rio de Janeiro . RJ . Brasil)

Marco Morel (UERJ . Rio de Janeiro . RJ . Brasil)

Marlon Salomon (UFG . Goiânia . GO . Brasil)

Pascal Payen (Université de Toulouse II - Le Mirail . Toulouse . França)

Sanjay Seth (University of London . Londres . Reino Unido)

Sérgio Campos Matos (Universidade de Lisboa . Lisboa . Portugal)

Silvia Petersen (UFRGS . Porto Alegre . RS . Brasil)

\section{Secretario}

Rodrigo Machado (UFOP . Ouro Preto . MG . Brasil) 


\section{Ediitoração, revisão técnica e capa}

João Carlos Furlani (UFES . Vitória . ES . Brasil)

Rodrigo Machado (UFOP . Ouro Preto . MG . Brasil)

\section{Revisão de Língua Portuguesa}

Adriana Carina Camacho Álvarez “Lecttura traduções”

\section{Revisão de Língua Espanhola}

Adriana Carina Camacho Álvarez “Lecttura traduções”

\section{Revisão de Língua Inglesa}

Adriano Moraes Migliavacca “Lecttura traduções”

\section{Realização}

Sociedade Brasileira de Teoria e História da Historiografia (SBTHH)

Programa de Pós-Graduação em História da Universidade Estadual Federal do Rio de Janeiro (UNIRIO)

Programa de Pós-Graduação em História da Universidade Federal de Ouro Preto (UFOP)

\section{Apoio}

Conselho Nacional de Desenvolvimento Científico e Tecnológico (CNPq)

Coordenação de Aperfeiçoamento de Pessoal de Nível Superior (CAPES)

Fundação de Amparo à Pesquisa do Estado de Minas Gerais (FAPEMIG)

\section{Contato}

Rua do Seminário, s/n • Centro • Mariana - MG • 35420-0oo • Brasil

www.historiadahistoriografia.com.br • historiadahistoriografia@hotmail.com • (31) 3557-9400

\section{Missão}

História da Historiografia publica artigos, resenhas, entrevistas, textos e documentos historiográficos de interesse para os campos da história da historiografia, teoria da história e áreas afins. Tem por missões divulgar textos de teoria da história e história da historiografia, e promover o intercâmbio de ideias e resultados de pesquisas entre investigadores dessas duas áreas correlatas. Num momento em que, no cenário brasileiro, o crescimento do número de periódicos científicos apenas espelha (se bem que de forma algo distorcida) a ampliação dos programas de pós-graduação, é consenso que o próximo passo a ser dado é o da verticalização e especialização do perfil das publicações. $H H$ foi fundada em 2008 exatamente a partir desse diagnóstico, e é hoje um periódico de referência para os especialistas das áreas de teoria da história e história da historiografia no mundo de língua portuguesa e espanhola. O periódico é uma publicação da Sociedade Brasileira de Teoria e História da Historiografia, do Programa de Pós-Graduação em História da Universidade Federal do Estado do Rio de Janeiro e do Programa de Pós-Graduação em História da Universidade Federal de Ouro Preto.

\section{Ficha Catalográfica}

História da Historiografia. Ouro Preto / Edufop, 2016, número 21, agosto, 2016, 163 p.

Quadrimestral

ISSN 1983-9928

1. História - Periódicos

CDU 930(05) 


\section{EDITORIAL EDITORIAL}

\section{ARTIGOS ARTICLES}

Historical Narrative as a Moral Guide and the Present as History as an Ethical Project María Inés Mudrovcic

Historicismo fraco: sobre hierarquias de virtudes e de metas intelectuais Weak Historicism: On Hierarchies of Intellectual Virtues and Goods

Herman Paul

No Future: esboços para uma ação política no "novo tempo do mundo"

No Future: sketches for political action in the "new time of the world"

Danilo Araujo Marques

"Na mais ilustre de todas as cidades, tão miserável tipografia": antiquariato, imprensa e epigrafia a partir de André de Resende (c. 1500-1573)

"In the most illustrious of all cities, so miserable a press": antiquarianism, printing and epigraphy in André de Resende (c. 1500-1573)

Pedro Telles da Silveira

French erudités and the construction of Merovingian history

Dmitri Starostin

Elena Kuleshova

Desde la justicia al abordaje historiográfico: los expedientes judiciales-criminales decimonónicos del Archivo Nacional Histórico

From justice to historiographical approach: nineteenth-century criminal court records of the

Chilean Historical National Archive

Víctor Mauricio Brangier Peñailillo

Germán Adolfo Morong Reyes

Miradas historiográficas sobre los obispos. Abordajes de un sujeto histórico complejo a través de la historiografía argentina en el periodo colonial y temprano-independiente

Historiographical points of view the bishops. Approaches to a complex historical subject through Argentinian historiography in colonial and early independent times

\section{RESENHAS}

\section{REVIEW ESSAYS}

$\mathrm{O}$ (des) encontro entre História e memória

The (dis) agreement between History and memory

CATROGA, Fernando. Memória, História e Historiografia. Rio de Janeiro: Editora FGV, 2015. 10op.

96

Diego José Fernandes Freire 
O tempo das expectativas decrescentes, ou os efeitos políticos do presentismo

The time of decreasing expectations, or the political effects of presentism

ARANTES. Paulo E. O novo tempo do mundo: e outros estudos sobre a era da emergência.

São Paulo: Boitempo, 2014. 464p.

Guiherme Bianchi

Mundo Rural e Historiografia Brasileira

Rural World and Brazilian Historiography

MOTTA, Márcia Maria Menendes. O Rural à la Gauche: campesinato e latifúndio nas

interpretações de esquerda (1955-1996). Niterói: Editora da UFF, 2014. 278p.

148

Marcos Nestor Stein

\section{PARECERISTAS DESTE NÚMERO \\ REVIEWERS OF THIS ISSUE}

\section{NORMAS DE PUBLICAÇÃO \\ EDITORIAL GUIDELINES}

\section{DIRETRIZES PARA AUTORES GUIDELINES FOR AUTHORS}


Editorial

editorial 
O número 21 da revista História da Historiografia traz a regularização de sua publicação, e esse é um motivo de comemoração, em tempos tão turbulentos como esses que vivemos. Ressaltamos a crescente internacionalização da Revista História da Historiografia, vista, aqui, pela maioria de seus artigos publicada em espanhol e inglês.

Um novo grupo de editores, ao qual damos boas-vindas, realiza seu primeiro trabalho. Que a caminhada seja sempre benfazeja.

Os artigos reunidos nesse número demonstram a força que determinados temas têm na construção da historiografia neste início do século XXI. Podemos destacar, entre eles, a indagação sobre os giros historiográficos, presentes desde a segunda metade do século XX, e como os passados práticos articulam-se nesses movimentos. Destaca-se, assim, o primeiro artigo do número 21 , intitulado Historical Narrative as a Moral Guide and the Present as History as an Ethical Project, de Maria Inéz Mudrovcic.

O artigo de Herman Paul, Historicismo fraco. Sobre hierarquias de virtudes e de metas intelectuais, traduzido por Arthur Assis e Pedro Caldas, apresenta uma leitura da sensibilidade que se encontra no Historicismo aliada a um "comportamento intelectualmente virtuoso", necessário para a operação historiográfica: a construção do objeto da pesquisa e de sua interpretação.

Danilo Marques, em No Future: esboços para uma ação política no "novo tempo do mundo", se debruça sobre as novas possibilidades de experiência do tempo vividas no início do século XXI e como se vê seu transbordamento na elaboração do tempo histórico.

"Na mais ilustre de todas as cidades, tão miserável tipografia": antiquariato, imprensa e epigrafia a partir de André de Resende (c. 1500-1573). Nesse artigo, Pedro Telles busca compreender a relação existente entre a prática antiquária na Idade Moderna e a introdução da imprensa, através de um personagem: o humanista português André de Resende.

Em French erudités and the construction of Merovingian history, Dmitri Starostin e Elena Kuleshova apresentam como problema a elaboração do tempo histórico, na relação de distanciamento e aproximação entre a idade média e o início da modernidade, pelos eruditos franceses.

Desde la justicia al abordaje historiográfico: los expedientes judiciales-criminales decimonónicos del Archivo Nacional Histórico. Víctor Mauricio B. Peñailillo e Germán Adolfo Morong Reyes se debruçam sobre a pertinência de metodologias mobilizadas pela historiografia chilena do final do século XX e início do XXI e como se dão as possibilidades de estudo das fontes judiciais.

Miradas historiográficas sobre los obispos. Abordajes de un sujeto histórico complejo a través de la historiografía argentina en el periodo colonial y temprano-independiente, de Maria Laura Mazzoni, traz como discussão principal as novas linhas de pesquisa que tiveram lugar a partir da década de 1990, na Argentina, e iluminaram certos objetos, como o lugar da história da hierarquia eclesiástica.

As resenhas se referem a obras de grande fôlego de alcance. Na primeira, seu autor Diego José F. Freire, salienta a importância de um tema clássico, a ser visitado sempre: a relação entre a memória, a história e a historiografía. $O$ 
(des) encontro entre História e memória é uma ótima oportunidade para (re) encontrar esse tema.

Guilherme Bianchi, em $O$ tempo das expectativas decrescentes, ou os efeitos políticos do presentismo visita a obra de Paulo Arantes, que reúne artigos publicados ao longo de dez anos e traz dois outros inéditos. Ao longo desse trabalho, a questão constante repousa na reflexão sobre o tema do passado recente e o presente global.

A última resenha, escrita por Marcos Nestor Stein, apresenta o livro de Marcia Menendes Motta e ressalta a importância da história rural - e aí a força da obra apresentada - para a compreensão do mundo agrário e, tanto no Brasil quanto na América Latina - as atávicas relações de desigualdade no campo.

Os editores lançam a proposta e desejam uma excelente leitura. 
Artigos 


\title{
Historical Narrative as a Moral Guide and the Present as History as an Ethical Project ${ }^{*}$
}

\author{
María Inés Mudrovcic \\ mmudrovcic@gmail.com \\ Profesora titular de Filosofía de la Historia del Departamento de Filosofía \\ Universidad Nacional del Comahue-CONICET \\ Saavedra, 249 - Cinco Saltos \\ 8303 - Río Negro \\ Argentina
}

\begin{abstract}
The aim of this paper is to explain why the many turns that historiography has undergone from the middle of the twentieth century to the present are related to the "living experiences" that have occurred outside of academia. Trying to grasp the concept of "practical past" from Oakeshott and White, it will be argued that the disciplinary transformations such as "gender history" or the "historiography of decolonization" that accompany "living experiences" outside of academia are the result of the "practical attitude" that accompanies historical narratives and function as a moral guide to the present. Finally, it will be discussed that if historians assume a critical attitude toward the "living experiences" and regard the "present as history," then the different transformations of the discipline can be explained by a critical attitude and go together with an ethical project.
\end{abstract}

\section{Keywords}

Historical narrative; Historical time; Temporalities.

Recibido el: $16 / 2 / 2016$

Aceptado el: 14/6/2016

\footnotetext{
* Universidad Nacional del Comahue-CONICET. I want to thanks to the referees' comments that helped to improve the final version of the manuscript.
} 
The International Conference "History of the Twentieth-Century Historiography" was held at the University of Peloponnese, Athens, from June 18 th to 20 last year. This paper concurs with the diagnosis of the call for papers of that Conference: the various turns that historiography has undergone from the middle of the twentieth century to the present are related to the "living experiences" that have occurred outside of academia. That is, there is a connection and interrelation between the various experiences of the century, not only those considered "catastrophic" but also those arising from feminism or decolonization, for example, and the various "turns" of historiography. I believe that this diagnosis is correct.

My aim in this paper is to explain why this is so-specifically, why there is an interrelation between the experiences of the century and the turns in historiography, between the "outside" and the "inside" of academia. I will attempt to show that this interrelation is due to the narrative form of the historical discourse. My argument will show that there will be no distinction between the practical past and the historical past if academic historiography is cast in a narrative form. The past of historical narratives is historical insofar as it is practical.

The teleological retrospective movement of the plot of the narrative helps build an intelligible past. This way of linking events is characteristic of narratives and constructs continuities between the present and the past. It also favors the transformation of these continuities into present subjects who understand themselves as coming and resulting from the past. The narrative structure prioritizes continuities over discontinuities. Because the present works as a discursive closure, the historical narrative tends to favor an "arch of solidarities" with the past. The result is a past that helps the present be more livable- i.e., a practical past. Like other ways of addressing the past, academic narrative historiography helps answer the question of what we must do (i.e., provides a practical -moral- answer).

Trying to grasp the concept of "practical past" from Oakeshott and White, I will argue that the disciplinary transformations such as "gender history" or the "historiography of decolonization" that accompany "living experiences" outside of academia are the result of the "practical attitude" that accompanies historical narratives and function as moral guide to the present. Finally, I will try to show that if historians assume a critical attitude toward the "living experiences" and regard the "present as history", then the different transformations of the discipline can be explained by a critical attitude and go together with an ethical project.

\section{Oakeshott and the Present}

In the first part of his article, "The Activity of being an Historian", written in 1955, Oakeshott refers to the common places where the "activity of being an historian" was understood in those times. The historian is one who understands the past, who makes that past intelligible, who verifies his statements, and who addresses "historical events" in which we are warranted in believing because they are conclusions of a "certain" method of inquiry. The historian raises a 
special "kind" of questions about the past. The recent past is not appropriated for this sort of activity because it can lead to moral approval or disapproval. In short, a number of features were present in the theoretical and methodological reflections on history at that time. Nevertheless, to Oakeshott, the activity of being a historian is not about the past but about the present.

The "historical past" is the result of the attitude that certain people (in this case, historians) have toward the world around us. Every event that occurs around us can arouse different responses on our parts. The example Oakeshott gives is the demolition of an old building. Given this fact, we can have several responses: we can run and preserve ourselves; we can recognize it as an act of vandalism and complain; we can understand it as a sign of progress; or we can simply contemplate it as an image, like a picture whose design can delight us or not. We are not indifferent to the happenings around us, and the events cause various types of reactions that depend on whether we recognize them as this or that. For Oakeshott, our responses to the world can be of two kinds: first, the happenings do not arouse any response in us-they are mere "images"or second, we can consider them as evidence of something that happened or will happen. Oakeshott calls the first of these attitudes "contemplative", and although he does not give to the second a precise name, he does say that it has an internal variety of different attitudes, among which one can distinguish the practical attitude and the scientific attitude, among others. The contemplation is, essentially, the attitude of an artist or a poet, for example. For anyone who 12 adopts the contemplative attitude, the events are not "signs" of other events but rather images of delight that do not refer beyond the present of themselves. They do not cause moral approval or disapproval, and the categories "real" or "fictitious" are inapplicable. Unlike the "contemplative" attitude, the second attitude regards the events before us as signs of other events. The signs, unlike the images, are events that we interpret as "evidence" of other events. Oakeshott calls this the "practical" attitude.

In the practical attitude, we recognize what is happening around us in relation to ourselves, our wishes and our activities. The partner of the "practical" attitude is the perception of a "practical" event. We see a tree in a desert, for example, and hasten our steps toward it to protect us from the sun. The tree is the "sign" of the future shadow that we will obtain from it. The tree is "practical" insofar as it is useful or beneficial to someone. "We want to be at home in the world, and (in part) this consists in being able to detect how happenings will affect ourselves and in having some control over their effects" (OAKESHOTT 1962 , p. 143). To attain this feeling of being at home, we use our senses. We see, touch, smell, etc., what is happening, and these activities allow us to act "in what we judge to be an appropriate manner". We understand the events as "signs" that may be friendly or hostile, useful or useless, but in all of these, the appreciation of the distinction between "cause" and "effect" is present. In the practical life, for Oakeshott, we recognize an event as a "cause" when we understand it as a sign of other events that will follow (the comfort I will feel when I am protected by the shadow of the tree, in our example). In the "practical 
attitude", we understand the world in its direct relationship with us, that is, in its habitability. We perceive the events as useful or beneficial. The practical event is something that we can use. This is what Heidegger referred to as a "tool", i.e., something that is "ready-to-hand".

However, Oakeshott acknowledges that there is another attitude by which events are interpreted as "signs" of "causes" and "effects"; however, unlike in the practical attitude, these causes and effects are not considered by taking into account either the habitability of the world or the relationship between the events and ourselves. Oakeshott calls this kind of attitude the "scientific attitude". He says the scientist has a more precise notion of these concepts because they are the necessary and sufficient conditions of "hypothetical situations", and as such, they are useless for us. Finally, there is a third kind of attitude by which the world surrounding us is understood as the evidence or sign of another event that happened: Oakeshott calls it the "historical attitude". To understand the happenings of the present world as "evidences" of other events is a characteristic that the "historical attitude" seems to share with the "practical attitude" and the "scientific attitude"; therefore, Oakeshott has to be very careful to distinguish between the different attitudes. The activity of being a historian "is pre-eminently that of understanding present events -things that are before him- as evidence for past happenings" (OAKESHOTT 1962, p. 150). However, this attitude toward the present that sends us to the past is also present in the "practical attitude" and the "scientific attitude". The point is that the past is only a certain way of reading the present (i.e., there is not a past independent of the present). The present is only what exists and the past is a way of "reading" the present. In this way, there will be many pasts as results of our different ways of understanding the present.

For example, for an individual who considers the present world from a "practical attitude", the past appears only in relation to the consequences that the past would have for him, in its usefulness. The example that Oakeshott gives of a "practical past" is that of a lawyer who says to his client that "under this will you may expect to inherit 1000 pounds" (OAKESHOTT 1962, p. 147). The lawyer is interested in the past for the consequences that this past will have for his client. Another way in which the "practical past" appears is when we read backward from the present or toward the past to the present, i.e., when we look for the "origins" of the present in the past and make moral judgments about it. In these sorts of cases, the past is practical insofar as it has moral consequences, i.e., it is a practical-as-moral past.

We can also talk about a "scientific past" but with certain caveats. For Oakeshott, this past is independent of our interest, remains "unassimilated to the present", and reflects the scientific language that does not speak about causes and effects but about necessary and sufficient conditions. There is, strictly speaking, no "scientific attitude" toward the past because the "scientific attitude" is a-temporal.

The "historical past" seems to be the activity of a historian, and Oakeshott asks whether the historical past has a characteristic that could distinguish it from 
the pasts that are results of "scientific attitude" or the "practical attitude". The "practical past" appears when we are placed in front of our daily vicissitudes and wonder whether these events are evidence of some past. That is, the past is presented in a haphazard and uncritical way because it appears only when the interest in the present is understood as a result or consequence of a past. However, for the historian, the past is very different; it does not appear for him in a "casual" way. His "inquiry into the past is not determinate by chance encounters with current happenings" (OAKESHOTT 1962, p. 155). The present for the historian consists of things and events (documents, for example) that he considers for reasons of "appropriateness and completeness". Considered in this way, the events of the "historical past" seem to represent an interest for "their own sake", like the events of the "scientific attitude". However, although the "historical attitude" and the "scientific attitude" were born together in modern Europe, the attitudes differ. To the question so common in the time in which Oakeshott wrote this article, is history a science? he would answer, no. The understanding that the historian has is neither "casual" nor "necessary" or "inevitable". The historian, unlike the practical man or the scientist, considers past events to be "intelligible happenings". For Oakeshott, the historian should decline to seek the "origins" of present events because this would mean reading the past backward and thus assimilate it to the present. The expression "the origin of the French Revolution", for example, belongs to a practical-as-moral attitude that seeks to disguise itself as a historical attitude. Historians adore a dead past that is not offered for aesthetic delight, practical understanding or scientific recognition.

\section{Hayden White and the Past}

In a recently published book, $\mathrm{H}$. Kellner explains that when he was a student of Hayden White, White cancelled one of his seminars in 1967 (KELLNER 2013). When pupils asked him where he had gone, he replied that he had been speaking at a biology conference. The lecture given in 1967 was titled "What is a Historical System?", and White's objective was to establish "some crucial distinctions between biological and historical systems". For White, the fundamental difference between both systems is that the historical systems "are inconceivable without the act of retrospective ancestral constitution that gives them their specific contents" (WHITE 2010, p. 133). The objective of this retrospective act is to replace old ancestors with new ones who help legitimize the present in a better way. Historians are responsible for establishing the connection between the new ancestors and the present of the historical system. Unlike the past of a biological system, the past of a historical system is a result of the conscious choices of its members. They can choose their own ancestors and treat them as genetic progenitors. "The historical past is plastic in a way that the genetic past is not" (WHITE 2010, p. 132). Historians quite often use biological language to refer to historical systems. In this way, they speak of the "origin" of a nation, of the "evolution" of a society, or of the "birth" of an epoch. However, this sort of language obscures because historical systems do not have a "life"; only their members have life and only they are able to make choices 
that can destroy the system: "when individuals cease to choose a given way of life, this way of life ceases to exist" (WHITE 2010, p. 129). Animal behavior can be explained as a legacy of the animal's genetic code and mutations in response to the environment; the animal cannot choose its genetic heritage. However, historians, through "a process of retroactive ancestral constitution", provide ancestors for the sociocultural system who are chosen to legitimate the new ends of the present. "The historical, unlike the biological past, is not given" (WHITE 2010, p. 135).

This retrospective movement necessary for building an intelligible past is present in the plot of the narrative discourse. As Danto points out an event gets its "meaning" because of its significance for later events (DANTO 1985, p. 167). The last event gives retrospective closure to the sequence of events. This is what White, many years later, called "figuralism": a way of linking events that is characteristic of narrative and resulting in it being understood as comedy, tragedy or romance, for example. In "Auerbach's Literary History: Figural Causation and Modernist Historicism", White points out that:

A given historical event can be viewed as the fulfillment of an earlier and apparently utterly unconnected event when the agents responsible for the occurrence of the later event link it "genealogically" to the earlier one. The linkage between historical events of this kind is neither causal nor genetic (WHITE 1999, p. 89).

He gives an example of the linkage established between the Italian Renaissance and the Greek-Latin culture. This linkage is purely retrospective, consisting of the decision of a group of Dante's contemporaries to choose to regard themselves as if they were descended from Greco-Latin culture. In this sense, for White, Auerbach's Mimesis "is not to be understood as the effort to produce a verbal mirror image of some extraverbal reality". What Auerbach offers is "the figure-fulfillment [...] to provide the diachronic plot of the history of Western literature" (WHITE 1999, p. 94). This idea is also reflected by Kellner: "White 's figuralism is a choosing backwards". The plot of the narrative creates the meaning, because the end of the story gives a backward sense to the narrative as a whole (KELLNER 2013, p. 160). This is what Foucault, in criticizing other historians of medicine, calls "illusion", because it "functions as a retrospective justification" (FOULCAULT 2003, p. 125).

Thus far, White seems to be at odds with Oakeshott's position, because for the latter any past that is a result of hindsight is not a "historical past" but rather a "practical-as-moral past." For Oakeshott, it is inappropriate for the historian to talk about the "origins" or "ancestors" of a nation because this presupposes a retrospective attitude from the present to the past. This would transform the activity of being a historian into a practical-as-moral activity. For White, however, the choice of ancestors or the finding of origins are the appropriate activities of the historian. ${ }^{1}$

\footnotetext{
${ }^{1}$ White explicitly recognizes the practical-as-moral dimension of professional historiography because, in the
} 
For Oakeshott, there exists an insurmountable barrier between the practical and the historical past. There is something avant la lettre in Oakeshott's article of 1955, which brings him to White, that is considering the historical past as built by or a product of some kind of attitudes that some kind of persons (in this case, historians) have toward the present.

Oakeshott is genuinely convinced that the historical past is different from the practical past, and he believes this because, even if he thinks that historians are not scientists, he believes, like White, in the founding gesture that historians made to distinguish historiography from both literature and practical activities. To White, the historical past arises from the radical gap that Western culture poses between the past and the present and the creation of a "scientific discipline" to bridge this gap (WHITE 2005, p. 334). Professional historians needed that gap because they believed that it would preserve them from subjectivity. That gap would guarantee them the "objective" knowledge proper to a "science". P. Novick summarizes the consensus about the objectivity of historians as follows: "The assumptions on which it rest include a commitment to the reality of the past, and to truth as correspondence to that reality; a sharp separation between knower and known, between fact and value, and, above all, between history and fiction" (NOVICK 1988, p. 2). ${ }^{2}$

To this point, some ambiguity should be noted in the use of the concept "practical" that leads to confusion about the semantic scope of the term. We can distinguish three meanings: "practical" as useful, "practical" as moral and "practical" as ethical. On the one hand, the word "practical" refers to "usefulness". Something is "practical" if it can be used or if it "serves" us. This is the sense that we mainly find in Oakeshott's essay. On the other hand, the concept "practical" can relate to actions. In this sense, the term may be understood morally. Morality defines a world of obligations that appears when we try to answer the question what must I do? However, "practical" can also be understood ethically. This is the case when Kant asks what should I do? Unlike the moral world of obligations, the ethical world offers no map to follow. Both of these latter scopes of the concept "practical" are found in White's latest book, The Practical Past (WHITE 2014).

In his recent book, ${ }^{3}$ White seems to adhere to the distinction between the "practical past" and the "historical past" proposed by Oakeshott, which would lead, according to some, to question of what White had so far held. 4 "The practical

nineteenth century, historians were endowed "with the task of providing genealogies for the new national estate formations, and charged with of providing genealogies for the new national estate formations, and charged with providing an antidote to the appeal of the future-oriented and socially transformative ideologies" (WHITE 2005, p. 334).

2 Novick points to the opposition between fiction and history, having in mind Metahistory. However, in 2014, White recognized that it was misleading to suggest that historiography "could best be understood as literature and therefore as fiction". History writing and literary writing are two modes of written discourse. Some literary writing may be fictional, focusing on purely imagined entities, or it may not be, like biographies, historical novels, etc. (WHITE 2014, p. xii).

${ }^{3}$ The distinction between the practical past and the historical past is also present in two articles "The Practical Past", Historein, 10 (2010) and "Politics, History, and the Practical

Past", Storia della Storiograia, 61, 1 (2012) and in a discussion with Dirk Moses in History and Theory, 2005.

${ }^{4}$ For Lorenz, to accept that the practical past is different from the historical past implies, first, denying the retrospective relationship between events that is present in social and cultural systems and the figuralist 
past" in the title of his book has to do with a past that Koselleck named "space of experience". ${ }^{5}$ On the one hand, it is, for White, the past constructed by historical novelists who, in the context of the eighteenth and nineteenth centuries, helped the new middle classes address the new modes of work and labor, the new modes of love and the new sensibilities. This past was a practical-as-moral past. The modern novel transformed the romance "into a range of "how to live" manuals directed at middle-class women left at home and seeking instruction on "what must be done"" (WHITE 2014, p. 11). Nevertheless, on the other hand, the practical past is also the past of historical postmodernist writers who, in the context of the twentieth century, tried to help in "coming to terms with pasts" with "modernist events" such as, for example, crimes against humanity. Understood in this way, the practical past has ethical consequences because it tries to cope with a past that has been "ignored, suppressed, repressed or hidden" without ruling anything or indicating the road to follow. In both these senses, the practical past is "the other" of the historical past of historiography. The historical past is a construction of history as a scientific or para-scientific discipline. It is the object of study for historians and, as such, it pretends to be studied "for itself alone" and as "an end in itself" detached from the present. Conceived in this way, the historical past has no value for present actions and has no practical-(moral-ethical) consequences.

The professional history would recognize only practical-as-useful consequences. As White stated, professional historiography served "the interests of the nation-state, to help in the work of creating national identities, and was used in the training of educators, politicians, colonial administrators" (WHITE 2014 , p. 15). For White, this utility of historiography was consonant with the contemporary ideology of science that was considered both "disinterested" and "practical" or "social beneficial at one and the same time". The other way in which professional history can be practical-as-useful for the present is "in the extent to which it can correct or neutralize or dissolve the distortions, myths, and illusions about the past" (WHITE 2013, p. xiv). As the historical past is about "pure facts" detached from the present, historians could "identify and neutralize ideological distortions of the past". These utilities or social benefits are the only "practical" dimensions that historians are willing to recognize for historiography because it maintains their pretentions to purport an objective and detached knowledge of the past.

Nevertheless, evil appeared insofar as the "historical past" is cast in narrative form. The separation between the past and the present, which would guarantee the objectivity of the "professional" historian and give him/her freedom from the interests of daily life, is only a gesture to repress the inherent practical-moral dimension of historiography. It is a necessary repression for a discipline with

understanding and, second, denying the inevitable ideological implications of historiography, all of which was clearly stated in Metahistory. As Lorenz wrote "How, then, can there be a historical past distinct from the practical past if all history writing is somehow ideological?" (LORENZ 2014, p. 37).

${ }^{5}$ It is a "warehouse of archived memories, ideas, dreams, and values which we go to as a kind of "old curiosity shop" in search of intimations of where we came from in order to grasp, ..., what we are to do with all the detritus left to us a legacy of dubious relevance to the solution of current "practical" problems" (WHITE 2014, p. 10). 
pretensions to be a science. Historiography "reads us moral lessons, whether we would have it or not, simply by virtue of the casting of its accounts of the past in the form of stories". To White, this point is "hard to swallow if you are committed to telling the truth, the whole truth, and nothing but the truth in what you say" (WHITE 2014, p. 20).

\section{The Moral Dimension of the Practical-historical Past}

One of the consequences of the "discursive turn" was unmasking the practical-as-moral dimension of historical narrative and thus allowing an account of why twentieth-century historical experiences have determined the study of the past, i.e., why the experience of feminism gave birth to a history of feminism.

Living in a present with multiple sexualities that can exist without a sexual identity, Fabienne Brugère chooses the ancestors for a French History of Feminist Philosophy. Her historiography has all the elements of a narrative that departing from the present, finds backward its "origin" (in 1942), predecessor moment (in 1673), and moment of consolidation (mid-1970s) that all lead to a "close" in the present. In an article that was published in April 2015 (BRUGERE 2015) she recognizes Simone de Beauvoir's Duxième Sexe, published in 1949, to be the foundation stone of French feminism. Her predecessor would have been the Cartesian Poulaine de la Barre who wrote, in 1673, De légalité des sexes. Simone de Bouvoir's legacy would be developed from the 70s, when genres studies were consolidated with Chistine Delphy and Colette Guillaumin, until the present when the French feminist denounces, along with Judith Butler, any sexual distinction because it is too binary. Fabienne Brugère, as a member of a specific and small social group (the feminist French philosophers), chooses her ancestors and elects the ideal "founders of the family" from whom she wishes to have descended.

Examining the narratological structure of four different historiographies of the Weimar Republic, Jan Eckel shows how they construct very different relationships between the past and the German present. For Eckel, the four historiographies offer a picture of the Weimar Republic as a "negative contrast" that allows "German post-war society to assess the current political and social conditions of the Federal Republic" (ECKEL 2010, p. 44).

Historical narratives are the written expression what $M$. Mandelbaum calls "historicism" and Z. B. Simon calls "developmental view of historical thinking" (SIMON 2015, p. 820). Mandelbaum defines historicism as "the belief that an adequate understanding of the nature of any phenomenon and an adequate assessment of its value are to be gained through considering it in terms of the place it occupied and the role which it played within a process of development" (MANDELBAUM 1971, p. 42). According to Ankersmit historicism considers that "the nature of a thing lies in its history; if we wish to grasp the nature of a nation, a people, an institution or an idea, the historicist will require us to consider its historical development" (ANKERSMIT 1995, p. 144). On the other hand, the "developmental view" stresses the continuity that is established through time. This temporal continuity retains the self-identity of the subject amid all changes. The retrospective movement of the choosing the ancestors establishes the 
subject identity through time. The choice of the origins, the continuity through time and the possibility of retrospective recollecting from the present to the past are all elements for constituting an historical identity. This developmental view is evolved in the nineteenth century when historical discipline is consolidated as science, being historical narrative its written counterpart. In this way, historiography helps to build identities through narratives being one of its first task to build the identity of modern states through nation.

Narrative configuration creates historical identities relating beginning, middle and end which, all together, are temporal coherent wholes. ${ }^{6}$ Belonging to historical identities -a nation, a church, a group- allows people to think and act in specific "concrete" situations and it serves as a "practical-moral guide" of future actions "insofar as it is the very same subject whose past and future is at stoke" (SIMON 2015, p. 825). And it is this element, first, exposes the inherent moral dimension of historiography and, second, explains why "disciplinary turns" (feminist history or decolonial history, for example) are linked to different experiences in the present. Historiography is a "way of providing an event with a past from which it must have derived" (WHITE 2007, p. 225), and, in doing so, it provides a moral guide for what the group must do, considering its heritage. Morality is what is imposed as mandatory and marked by rules, obligations, prohibitions characterized both by a requirement of universality and by an effect of coercion. It tells us "what we must and must not do in a given situation of choice" (WHITE 2005, p. 338). If I belong to a certain church, a group or a certain institution, for example, I know what I have to do or not, what norms and rules I have to follow. ${ }^{7}$ To use the above example, "Weimar" served as a "counter-image" to the new democracy, as a "symbol" that must not be followed. Fabienne Brugère's Feminist genealogy serves as a model which shows her not only where she had come from but also who is she and what future she had a right to choose for herself. Thus considered, historiography would fulfill the same role as other practical activities such as historical biography, witness literature, and the historical industry. In this sense, $\mathrm{H}$. White affirms:

This genealogical connection is a perfect example of how historians produce historical accounts of the past which serve practical rather than scientific ends ... This is the social and political or, I wish to say, ideological function of "the historical past" (WHITE 2014, p. 98).

\footnotetext{
${ }^{6}$ Louis Mink speaks about the "configurational mode of comprehension" of the narratives which transforms the events in coherent wholes (MINK 1978, p. 142). From a phenomenological point of view, Paul Ricoeur and David Carr point to the role of the emplotment in transforming the events of a story by "grasping them together" (RICOEUR 1983, p. 105, CARR 1986, p. 64-65).

7 The temporal continuity of the historical identity established through narrative allowed, for example, that Pope John Paul II admitted the Catholic Church's culpability for past crimes against different groups and communities. On March 15, 2000, The International Council of Christians and Jews issued a press that regretted the Church's apparent difficulty admitting responsibility and historical guilt: "not only those Catholics in general but also those responsible for leading the Church through centuries must be included". The Catholic Church is the self-identical subject of history that remains the same through all of the transformations in the development of its stages. The Catholic Church is the subject (substance) that results of the historical narrative which is built backwards from the present. Cf.: http://www. sacredheart.edu/faithservice/centerforchristianandjewishunderstanding/documentsandstatements/ internationalcouncilofchristiansandjewsstatementinresponsetopapalapologymarch $152000 /$.
} 
The practical-moral dimension of the historical past of historical identities helps us in considering the people, institutions, and groups of our present as substances: stable entities whose deep rootedness is built backward by professional historians who look for the linkages that would show a temporal continuity between the present and the past. In this way, historians become the guardians of social identities. In revealing the origins of social identities, historians help naturalize the stability of the world that surrounds us. In The Archaeology of Knowledge, Michel Foucault clearly exposes this idea:

Continuous history is the indispensable correlative of the founding function of the subject, the guarantee that everything that has eluded him will be restored to him ...Making historical analysis the discourse of the continuous and making human consciousness the original subject of all historical development and all action are two sides of the same system of thought (FOUCAULT 1972, p. 12).

Discontinuities are "repugnant" to a historiography so conceived. To this sort of historiography, accustomed to find the "origins", to trace the line of ancestry, to reconstruct evolutionary curves and to turn endlessly to metaphors of life, is difficult to conceive the difference, the singular, the contingence instead the identity. The "historical past" of the "historical narratives" is very far from the past as such or "in itself" that pretended to establish the basis of a scientific discipline.

\section{"Present as History" as an Ethical Project}

The call for papers for the International Conference: History and Historiography in the $20^{\text {th }}$ Century noted that the twentieth century was not only "the age of the extremes" but also the age of feminism, decolonization and techno-scientific evolution. ${ }^{8}$ The organizers developed questions such as how can we relate these phenomena with historiography? Is there a connection between these rivers running outside academia and those flowing within it? In a word, is there a relation between history (as the course of events) and historiography (as written discourse)? The answer is yes. Most disciplinary turns of academic historiography have to do with the attempt to address the political and cultural transformation of the age. This was translated in gender historiography, decolonization historiography, audiovisual historiography and so on. Each of these new trends in academic disciplines offered a "practical-asmoral" answer to those epochal turns. In trying to address the new problems, most historians intended to look for their origins, i.e., to show how we arrived at the present, casting the answer in a narrative form.

When the "practical past" and the "historical past" are no longer the blind spots of historiography, the "historical attitude" unfolds as a way of relating to the present that in Nietzsche's words, "living comes to harm and finally is destroyed, whether it is a person or a people or a culture (NIETZSCHE 2000, p. 
39). The living is radically contingent; it is not an original unity reconstructed by a narrative. What historical narrative offers us is the "illusion" of the stability of the living. The reconstruction of the origins of practices, institutions and groups (subalterns, women, etc.) that exist in the present gives them a retrospective temporal continuity. This retrospective temporal continuity legitimizes the naturalized stability of the present. Any taken-for-granted idea or established fact is understood to be an inevitable consequence of the march of time that historiography (re)creates backward.

Following Oakeshott's idea that different pasts are the result of the different ways we relate with our present, the following question arises: what is the attitude that historians should adopt toward the world in which we live to display the living "as such" (i.e., essentially contingent)? And, therefore, what kind of present would be the correlate of such an attitude?

In Discipline and Punish, Foucault writes the following:

I would like to write the history of this prison, with all the political investments of the body that it gathers together in its closed architecture. Why? Simply because I am interested in the past? No, if one means by that writing a history of the past in terms of the present. Yes, if one means writing a history of the present (FOUCAULT 1977, p. 30-31).

To Foucault "writing a history of the past in terms of the present" is writing about the past to legitimate the present. It is constructing a historical past for the things of the world that surround us. ${ }^{9}$ In doing so, it shows the living as "natural" things proceeding from the past (i.e., from the dead) instead of showing that death is the future of the living. Showing death to be the future of the living is showing the irreducible historicity of all things. It is to disconnect the future from the present and from the past. It is to begin to think that what will happen in the future will not be similar at all neither with the present nor with the past. ${ }^{10}$ As Chakrabarty pointed out: "The discipline of history exists on the assumption that our past, present, and future are connected by a certain continuity of human experience. We normally envisage the future with the help of the same faculty that allows us to picture the past" (CHAKRABARTY 2009, p. 197). However, if historians consider the "present as history"-as White recognizes for the "practical-as-ethical past" of the postmodernist writersthey are reversing the historical attitude of the historical narratives. In this sense, "the present as history" is what Joan W. Scott calls "history as critique". Resuming the work of Foucault, Scott tries to show that none of the concepts which surround us, like "the home, the individual, the self, [...] incest, even bodily experiences such as fever" (SCOTT 2007, p. 30) is stable. All what is now

\footnotetext{
${ }_{9}$ Cf.: Michael S. Roth: "Writing a history of the present means writing a history in the present...Foucault uncovers the past to rupture the present into a future that will leave the very function of history behind it, a future that will have no need of a past to be endlessly recaptured" (ROTH 1981, p. 43-44).

${ }^{10}$ At this point we can think in what Z. B. Simon has named an "unprecedent change" [...] "this change, by definition, cannot be explained by studying the past, because [...] has no past and no origin in the past" (SIMON 2015, p. 827). An unprecedented change is so entirely new that we can hardly think about it. And this sort of change can only be envisage if we considers the present as history.
} 
present will die, which means not that our present will be the past of our future but that our present will die for ever. It means that will not be a "future past" of any "future present".

Hayden White describes it thusly: "critique means attention to the evanescent immanence of everything" (WHITE 2007, p. 225). This is the reversal of the temporal regime of historiography: instead of looking to the past, "history as critique" is looking to the present. Because critique means the denial of substances as perennial, the reification of the world or established facts, critique enables us to think that the present can be changed, that the present can be overcome, and that the living will die. Writing about Adorno's critical theory, Hoy affirms: "The intent is to make certain the present is still open to the future despite its problematic connection to the past" (HOY 1994, p. 139). Unlike the moral dimension of the practical-historical past of professional historiography, the idea of "present as history" or "history as critique" defines an ethical project insofar as the present is considered historically. Unlike morality that defines a field of obligations, ethic aims to a life fulfilled of actions that we consider good for us. Instead a world of "musts", ethic delimits a field under the sign of what we should do or not to do. Joan Scott defends the ethical dimension of "history as critique" as it does not offer a map or a road to follow. Ethics is found in history's purely negative side. Only in this way will the present show us its emancipator face; because of its undetermined past, its future cannot be prescribed. Although the social history 22 of the 60 s, of which she acknowledges being part, was revolutionary in the sense of bringing the stories of common people into consideration, it was not really emancipatory. For Joan Scott, in those times, "the emphasis was on our similarity with the past, not on our difference from it; on continuity; and on the universality of categories such as class, race and gender" (SCOTT 2007, p. 21). The questioning of these categories that inhabit our present institutions and theories as natural citizens would reveal their historical foundation, lift the veil of their necessity, and suggest that there could be another route to escape from them (WHITE 2007, p. 225).

To conclude, both the "historical past" with its practical-as-moral dimension and the "historical present" with its critical attitude, even when they show relationships with living experiences, make experiences the discovering of two different worlds. The past of historical narratives shows a world where living is composed of substances and essences related to a past that legitimized them in their continuity with it. On the contrary, the "critical attitude to the present", or the "present as history", displays the living experiences of our world in their naked contingency. It is a world that invites us to act, to transform it for the future. Nevertheless, if we focus on the present as history, then we have to abandon the historical past and its partner "the activity of being an historian", at least such as it has been narrativized till now. 


\section{Bibliography}

AMKERSMIT, Frank. Historicism: An Attempt at Synthesis. History and Theory, v. 34. n. 3, p. 143-161, 1995.

BRUGÈRE, Fabienne. La philosophie féministe ne se contente pas d'interroger les rapports entre hommes et femmes, elle questionne I'altérité et I'identité. Philosophie aujourd' hui, n. 270, 2015.

CARR, David. Time, Narrative, and History. Indianapolis: Indiana University Press, 1986.

CHAKRABARTY, Dipesh. The Climate of History. Four Theses. Critical Enquiry, v. 35, p. 197-222, 2009.

DANTO, Arthur. Narration and Knowledge. New York. Columbia University Press, 1985.

ECKEL, Jan. "Narrativizations of the Past: The Theoretical Debate and the Example of the Weimar republic. In: BERGER, Stefan; LORENZ, Chris. Nationalizing the Past. Historians as Nation Builders in Modern Europe. London: Palgrave Macmillan, 2010.

FOUCAULT, Michel. The Archaeology of Knowledge. New York: Pantheon, 1972

Discipline and Punish. The Birth of the Prision. New York: Pantheon, 1977.

. The Birth of the Clinic. An Archaeology of Medical Perception. Oxford; New York:Taylor \& Francis e-Library, 2003.

HOY, David Couzens. A Descontructive Reading of the Early Frankfurt School. In: Hoy, David Couzens and McCarthy, Thomas. Critical Theory. Cambridge: Blacwell, 1994, p. 103-143.

KELLNER, Hans. Hopeful Monsters or, The Unfulfilled Figure in Hayden White's conceptual System. In: Doran, Robert. Philosophy of History after Hayden White. London; New Delhi; New York; Sidney: Bloomsbury, 2013, p. 151-170.

LORENZ, Chris. "It Takes Three To Tango. History between the "Practical" and the "Historical" Past". Storia della Storiografia, v. 65, n. 1, p. 29-46, 2014

MANDELBAUM, Maurice. History, man and reason: a study in nineteenth century thought. Baltimore, Md.: The Johns Hopkins Ugniversity Press, 1971.

MINK, Louis. "Narrative Form as a Cognitive Instrument". In: CANARY, Robert; KOZICKI, Henry (ed.). The Writing of History. Literary Form and Historical Understanding. Madison: University of Wisconsin Press, 1978, p. 129-149. 
NIETZSCHE, Friedrich. Sobre la utilidad y los perjuicios de la historia para la vida. España: EDAF S.A., 2000.

NOVICK, Peter. That Noble Dream. The "Objectivity question" and the American historical Profession. Cambridge: Cambridge University Press, 1988.

RICOEUR, Paul. Temps et Récit. Paris: Seuil, 1983. . Soi-meme comme un otre. Paris: Seuil, 1990.

ROTH, Michael. Foucault's "History of the Present". History and Theory, v. 20, n. 1 , p. $32-46,1981$.

SIMON, Zoltán Boldizsár. History Manifested. Making Sense of Unprecedented Change. European Review of History - Revué européenne d ' histoire, v. 22, n. 5, p. 819-834, 2015.

SCOTT, Joan Wallace. History-writing as critique. In: KEITH, Jenkins; MORGAN, Sue; MUNSLOW, Alun. Manifestos for History. New York: Routledge, 2007, p. 19-38.

WHITE, Hayden. Auerbach's Literary History. Figural Causation and Modernist Historicism. In: . Figural Realism. Studies in the Mimesis Effect. Baltimore; London: The Johns Hopkins University Press, 1999, p. 87-100.

- The Public Relevance of Historical Studies: A Reply To Dirk Moses. History and Theory, v. 44, n. 3, p. 333-338, 2005.

. Afterword. Manifesto time. In: KEITH, Jenkins; MORGAN, Sue; MUNSLOW, Alun. Manifestos for History. New York: Routledge, 2007, p. 220-231.

. What is a Historical System? In:

- The Fiction of the

Narrative. Essays on History, Literature, and Theory, 1957-2007. Baltimore: Johns Hopkins University Press, 2010 [1972], p. 126-135.

. Comment. In: Doran, Robert. Philosophy of History after Hayden

White. London; New Delhi; New York; Sidney: Bloomsbury, 2013, p. 2009-2013.

The Practical Past. Evanston: Northwestern University Press, 2014. 


\title{
Historicismo fraco: sobre hierarquias de virtudes e de metas intelectuais*
}

\author{
Weak Historicism: On Hierarchies of Intellectual Virtues and Goods
}

\author{
Herman Paul \\ h.j.paul@hum.leidenuniv.nl \\ Professor associado \\ Departamento de História, Universidade de Leiden, Holanda \\ Leiden University \\ 95002300 RA - Leiden \\ Holanda
}

\begin{abstract}
Resumo
Este artigo busca reconciliar a sensibilidade historicista em relação à forma como o comportamento intelectualmente virtuoso é moldado por contextos históricos, de um lado, e uma abordagem nãorelativista da pesquisa histórica acadêmica do outro. Para tanto, distingue-se entre hierarquias de virtudes intelectuais e hierarquias de metas intelectuais. A primeira hierarquia rejeita um modelo único de virtuosidade histórica em favor de um modelo que permite significativas variações no peso relativo que os historiadores atribuem às virtudes intelectuais, de modo a obter conhecimento histórico fundamentado. Esta hierarquia situa as bases para tais diferenças não nas preferências ou interesses dos historiadores, mas nas suas situações historiográficas, de maneira que as hierarquias de virtudes são uma função das demandas feitas pelas situações historiográficas (definidas como o intercâmbio de gênero, questões de pesquisa, e estado da arte). Da mesma maneira, a segunda hierarquia concede espaço para que sejam perseguidas várias metas intelectuais, mas afasta o espectro do relativismo ao tratar a compreensão histórica como uma meta intelectual fundamental para a pesquisa histórica e que, por consequência, merece prioridade diante de metas alternativas. A posição daí emergente é classificada como uma forma de historicismo fraco.
\end{abstract}

\section{Palavras-chave}

Epistemologia da virtude; Virtudes intelectuais; Virtudes epistêmicas.

\begin{abstract}
This article seeks to reconcile a historicist sensitivity to how intellectually virtuous behavior is shaped by historical contexts with a non-relativist account of historical scholarship. To that end, it distinguishes between hierarchies of intellectual virtues and hierarchies of intellectual goods. The first hierarchy rejects a one-size-fits-all model of historical virtuousness in favor of a model that allows for significant varieties between the relative weight that historians must assign to intellectual virtues in order to acquire justified historical understanding. It grounds such differences, not on the historians' interests or preferences, but on their historiographical situations, so that hierarchies of virtues are a function of the demands that historiographical situations (defined as interplays of genre, research question, and state of scholarship) make upon historians. Likewise, the second hierarchy allows for the pursuit of various intellectual goods, but banishes the specter of relativism by treating historical understanding as an intellectual good that is constitutive of historical scholarship and therefore deserves priority over alternative goods. The position that emerges from this is classified as a form of weak historicism.
\end{abstract}

Keywords

Virtue epistemology; Intellectual virtues; Epistemic virtues.

Recebido em: 10/6/2016

Autor convidado

* Do original: Weak Historicism: On Hierarchies of Intellectual Virtues and Goods. Journal of the Philosophy of History, v. 6, 369-388, 2012. Traduzido por Arthur Assis e Pedro Caldas. Os tradutores agradecem ao autor e editores do periódico Journal of the Philosophy of History por terem liberado esta tradução e possibilitado sua publicação. 
Imagine dois historiadores a realizarem complexas pesquisas acadêmicas. Uma historiadora trabalha em uma biografia de Leopold von Ranke. O outro historiador participa de um projeto destinado à reconstrução das contabilidades nacionais (isto é, de indicadores abrangentes relativos à produção, receitas e despesas) de vários países europeus no século XIX. Ambos os historiadores enfrentam tarefas assustadoras, mas por diferentes razões. A biógrafa de Ranke se vê confrontada com uma vasta quantidade de literatura especializada abrangendo a juventude de Ranke, a sua formação luterana, a nomeação como professor em Berlim, as tarefas docentes, o seu perfil filosófico, as viagens para os arquivos de Veneza e o seu envolvimento com a Academia Bávara de Ciências e Humanidades. Com base nesta riqueza bibliográfica, a historiadora elabora uma biografia que almeja juntar os fios que perpassam a vida e a obra de Ranke, sem jamais se esquecer de que uma tal obra de síntese não somente pressupõe profunda familiaridade com a bibliografia existente, mas também exige bastante do seu poder imaginativo, da sua inteligência e da sua capacidade de julgar. O segundo historiador, por outro lado, nada tem a sintetizar. No seu recente e emergente campo de pesquisa, toda a atenção está dirigida à busca por informações que permitirão generalização estatística. Mesmo que a agricultura e a pecuária sejam setores econômicos bem documentados, dados precisos sobre a produção da horticultura no século XIX são notoriamente escassos (SMITS; HORLINGS; ZANDEN 1999, p. 59). Felizmente, o segundo historiador tropeçou em algumas contas maravilhosamente detalhadas que 26 foram mantidas por horticultores flamengos. Sua tarefa, então, é apurar deste material dados relevantes relativos à produção e a despesas. Com isso poderá estimar a participação destes produtores no mercado através da comparação com outros horticultores do país, e, com base nisso, poderá também calcular, com o máximo de fiabilidade possível, a contribuição do setor para o produto interno bruto da Bélgica.

Imagine agora que ambos os projetos de pesquisa apareçam como estudos de caso em uma investigação filosófica sobre virtudes intelectuais. Dado que atualmente os especialistas em virtudes epistêmicas estão cada vez mais interessados não somente em formas de conhecimento estritamente vinculadas ao raciocínio lógico-matemático, mas também em complexas formas de compreensão, tais como as exigidas para apreciar Os Irmãos Karamazov, de Dostoievski, ou para perceber as nuances da personalidade de uma outra pessoa, este tipo de experimento não é de todo irreal. Se especialistas em virtudes epistêmicas, tais como Linda Zagzebski, Robert C. Roberts, e W. Jay Wood, argumentam que as virtudes intelectuais são especialmente relevantes para "tipos ambiciosos de conhecimento como descobertas científicas, a compreensão sutil de textos difíceis, [e] autoconhecimento moral" (ROBERTS; WOOD 2007, p. 8), ${ }^{1}$ eles terão motivo para examinar as virtudes intelectuais exercitadas por historiadores que se dediquem a biografias de Ranke ou à pesquisa 
sobre contabilidades nacionais. Imagine então estes filósofos perguntando a si mesmos: que virtudes intelectuais a biógrafa de Ranke e o estudioso dos ganhos da horticultura flamenga precisam pôr em prática para fazerem uma contribuição valiosa para a pesquisa histórica erudita ou acadêmica? Devem eles pôr em prática o mesmo conjunto de virtudes intelectuais, na mesma ordem, e no mesmo grau? Ou, será que devem praticar diferentes tipos de comportamento intelectualmente virtuoso para poderem contribuir para uma melhor compreensão do passado?

Pesquisas recentes no campo da historiografia - aquele em que se estuda como os historiadores estudam o passado - conferiram uma certa urgência a essas questões. Tem-se argumentado que nem todos os historiadores concordam quanto ao que seja um comportamento intelectualmente virtuoso. Vem sendo apontado que diferentes tradições historiográficas - por exemplo, a história econômica tal como praticado pelo estudioso especializado na contabilidade nacional belga do século XIX e a história intelectual representada pela biógrafa de Ranke podem ter percepções diferentes sobre o tipo de comportamento intelectual que os historiadores devem ter. Embora tais percepções tendam a se sobrepor umas às outras, as diferenças entre ambas podem ser suficientemente significativas para nos levar à conclusão de que, em termos empíricos, os historiadores nem sempre são unânimes sobre o que se deve entender como comportamento intelectualmente virtuoso (PAUL 2011a). Além disso, mesmo que os historiadores concordem sobre a importância de virtudes intelectuais como a "precisão", não se pode afirmar de maneira inequívoca o que significa, para eles, ser preciso nas suas pesquisas e nos seus textos. Tais definições dependem, entre outras coisas, do peso relativo que eles atribuem a esta virtude em particular; isto é, de como eles relacionam a precisão com outras virtudes intelectuais, tais como a firmeza, a coragem e a cautela. Esta é a razão pela qual somente descrições densas descrições de virtudes intelectuais sensíveis às particularidades do contexto e da situação do historiador - podem esclarecer o que significa ser intelectualmente virtuoso. ${ }^{2}$ Isto se torna ainda mais evidente quando enfim expandimos o raio da nossa análise para além do mundo acadêmico atual e passamos a incluir historiadores de outros tempos e lugares. Quando nos confrontamos com as práticas historiográficas da China da época da dinastia Han ou dos anos mais remotos do Reino dos Francos, e essas diferem significativamente de tudo aquilo que, hoje em dia, poderia ser reconhecido como erudição histórica, é difícil, quando não impossível, deixar de concluir que aquilo que os historiadores consideram como comportamento intelectualmente virtuoso é, em grande medida, "moldado por contextos históricos" (cf. PAUL 2011a, p. 11).

A questão daí emergente é a seguinte: em que medida estas diferenças que atravessam o tempo e as situações podem ser justificadas? Deixem-

\footnotetext{
2 Isto foi belamente ilustrado pelo balanço contextual ricamente matizado feito por Daston e Galison sobre o que a "objetividade" significou para várias gerações de pesquisadores no fim do século XIX e no início do século XX. Ver Daston; Galison (2007). Concentrando-me aproximadamente no mesmo período, tentei mostrar como virtudes tão apreciadas como a honestidade e a cautela adquiriram significados específicos dependendo, entre outras coisas, de constelações de virtudes nas quais elas supostamente deveriam estar integradas (PAUL 2011b; PAUL 2012).
} 
me esclarecer, logo de início, que uma "justificação", neste contexto, não é um atalho para "justificação epistemológica". Afinal de contas, a justificação epistemológica está centrada nas razões que as pessoas têm para manter certas crenças sobre o mundo. De acordo com William P. Alston, "dizer que é justificado que S. creia em $p$ é dizer que está tudo bem que $\mathrm{S}$ creia em $p$; que isso é satisfatório, está de acordo com o modo como as coisas devem ser, " (ALSTON 1989, p. 83). Ainda assim, no caso dos historiadores que privilegiam certas virtudes intelectuais em detrimento de outras, a questão não é sobre em que medida estes acadêmicos têm justificação para acreditar em certas coisas sobre o passado. Em vez disso, a questão que se coloca é a seguinte: em que medida "é satisfatório e está de acordo com o modo como as coisas devem ser" o fato de os historiadores privilegiarem certas virtudes e não outras nas suas tentativas de contribuir para uma melhor compreensão do passado. A questão que aqui está em jogo não diz respeito a crenças sobre o mundo, mas a comportamentos intelectualmente virtuosos.

Falo de justificação, no entanto, devido às conotações normativas desta palavra. Justificação refere-se a estados de coisa que são satisfatórios; a algo que se considera estar "em ordem", ou a práticas que estão "de acordo com o modo como as coisas devem ser". O termo pressupõe "dever", "obrigação", e "exigência" (PLANTINGA 1993, p. 4). Falar que os historiadores estão justificados ao privilegiarem certas virtudes e não outras, então, é falar sobre a pertinência relativa de uma tal conduta. Isto levanta a questão das razões pelas quais é apropriado que certas virtudes sejam priorizadas por um estudioso da contabilidade nacional belga e que as mesmas não o sejam pela biógrafa de Ranke. Mais especificamente, isto levanta a questão sobre quando e com que motivos alguém pode argumentar que ambos os historiadores fazem uma contribuição valiosa, desejável e apropriada para a compreensão do passado, mesmo que eles atribuam pesos distintos para virtudes distintas.

Ao equiparar "conduta justificada" a "contribuições valiosas, desejáveis e pertinentes para a compreensão do passado", gostaria de ser entendido não somente como alguém que está empregando justificação num sentido mais amplo do que o de costume na epistemologia, mas também como alguém que se dissocia de abordagens fundacionalistas da justificação. Dizer que os historiadores têm justificação para privilegiar certas virtudes sobre outras não implica que tal ato de privilegiar esteja justificado a ponto de produzir conhecimento justificado do passado. Dado que eu não avalio desejo e pertinência em termos de conhecimento justificado, mas em termos de valor das contribuições para a compreensão do passado, o padrão que utilizo pode ser bem descrito como nãofundacionalista e contextual. Não é fundacionalista na medida em que o que conta como uma contribuição valiosa para a compreensão do passado depende não somente da habilidade para dar sentido para o corpus documental, mas também da habilidade para fazer avanços em relação à bibliografia especializada já existente. Além disso, o padrão é contextual na medida em que avanços dependem do estado da arte, isto é, da situação (historicamente contingente) na qual o historiador se encontra. E ainda, como devo explicar mais adiante, 
a despeito da sua alta sensibilidade para contextos, o padrão que utilizo para avaliar pertinência também é não-relativista, no sentido de que a biógrafa de Ranke e o estudioso da contabilidade nacional belga, uma vez que queiram fazer uma contribuição valiosa para a compreensão do passado, não são livres para escolher as virtudes que quiserem.

Num certo sentido, então, este artigo tenta reconciliar a ênfase historicista na relação entre as virtudes intelectuais e os contextos históricos em que se formam, de um lado, com uma abordagem não relativista da pesquisa histórica acadêmica, do outro. Argumentarei que os dois historiadores no centro dos nossos estudos-de-caso têm boas razões para empregar diferentes hierarquias de virtudes intelectuais, uma vez que estão envolvidos no que eu chamo de situações historiográficas diferentes. Da mesma forma, em reação às tradições historiográficas significativamente diferentes daquilo que, atualmente, pode ser reconhecido como erudição histórica sólida, defenderei que os historiadores têm todas as justificativas para buscar quaisquer metas intelectuais que desejarem, mas que, como historiadores acadêmicos, não estarão justificados caso priorizem uma destas metas em detrimento da compreensão histórica - a meta intelectual que considero como fundamental para a erudição histórica.

\section{$\mathbf{I}$}

Vamos começar com a questão sobre em que medida a biógrafa de Ranke e o historiador da economia partilham do mesmo conjunto de virtudes intelectuais. Partindo do princípio de que ambos fazem o que for necessário para se destacarem em seus trabalhos, os conjuntos das virtudes que exercitam estão propensos a se sobrepor. Entre outras coisas, ambos historiadores farão o seu melhor para serem exatos, no sentido de estarem atentos à precisão. Ambos tentam ser justos, no sentido de considerar de maneira ponderada todas as fontes e todos os fatores relevantes. Ambos também tentam pôr em prática a virtude da coragem intelectual, algo indispensável para abordar o papel do providencialismo luterano na filosofia da história de Ranke, bem como para estimar a fatia de mercado das companhias horticultoras flamengas no respectivo setor da economia belga (na ausência de outros dados exatos). Ao mesmo tempo, estas virtudes parecem ser diferentes. Compreender os aspectos intrincados do caráter de Ranke exige uma dose de empatia, caridade e humildade, algo que não é normalmente necessário quando se trata de calcular perdas e ganhos monetários. Da mesma forma, sintetizar um corpo significativo de literatura secundária exige a habilidade para negociar um equilíbrio delicado entre autonomia e generosidade com relação aos autores que já se dedicaram ao mesmo tema, algo com o que o primeiro especialista em horticultores flamencos não precisa se preocupar.

Isto poderia implicar, então, que os conjuntos de virtudes empregados pelos nossos dois historiadores não são idênticos? Tal conclusão seria precipitada. Pois mesmo que o historiador da economia não tenha que capturar as sutilezas do caráter de uma pessoa, nem tenha que se referir a uma pilha de literatura secundária, isto não significa que ele possa se permitir ignorar virtudes tais como a empatia, a caridade e a generosidade. Ele precisa, por exemplo, de uma 
certa quantidade de empatia para dar sentido a dados que foram lançados de maneira amadora e confusa. Da mesma forma, uma dose saudável de humildade o prevenirá de confiar de modo desmedido no significado e na fiabilidade das suas generalizações estatísticas. Assim, o fato de que historiadores diferentes, em situações diferentes, atribuam pesos distintos para virtudes distintas não confirma a conclusão de que seus conjuntos de virtudes seriam não-idênticos. As diferenças entre eles talvez não sejam de tipo, mas antes de grau e ênfase.

Será que alguém poderia, então, argumentar que as tarefas enfrentadas pela biógrafa de Ranke e pelo especialista em agricultura são tão diferentes a ponto de requererem diferentes hierarquias de virtudes intelectuais? Enquanto a lista de virtudes necessárias para a biógrafa de Ranke pode começar pela empatia e pela firmeza, as virtudes mais importantes para o historiador da economia podem ser a precisão e a atenção. Isto significa que os nossos dois historiadores devem priorizar algumas virtudes sobre outras, com o fito de exercitar as virtudes mais importantes para a sua pesquisa com mais dedicação e num grau mais elevado do que aquelas menos cruciais para a tarefa a ser desempenhada. Calcular os lucros e perdas monetárias de um horticultor flamengo é uma tarefa tão diferente de compreender a mente de um historiador alemão do século XIX, que um historiador que se dedique ao primeiro projeto precisa priorizar virtudes intelectuais diversas daquelas que são mais importantes para o historiador envolvido no segundo projeto.

Sob quais circunstâncias, então, seria justificado priorizar certas virtudes 30 sobre outras? O que diferencia as tarefas dos dois historiadores a ponto de justificar, na execução de cada uma delas, a atribuição de pesos distintos para virtudes distintas? Eu gostaria de sugerir que hierarquias de virtudes intelectuais dependem de situações historiográficas, isto é, da interação entre (1) o gênero da escrita, (2) o problema de pesquisa do historiador, e (3) o estado da literatura especializada. Gêneros de escrita incluem o artigo monográfico, baseado em pesquisa extensiva de fontes primárias; o balanço bibliográfico, que analisa as pesquisas recentes em um campo específico de investigação; e o manual, que sintetiza o estado atual dos estudos em um tema ou período em particular. Por mais rudimentar que seja, esta tipologia - uma mais detalhada seria desejável - ilustra que as hierarquias de virtudes intelectuais não podem ser idênticas em todas as circunstâncias. O autor de um manual, normalmente, precisa ter um grande poder de síntese - o que pode corresponder à virtude da firmeza intelectual - do que o autor de um artigo baseado em pesquisa detalhada. Além disto, a questão que move a pesquisa do historiador, ou o problema que ele ou ela pretende ajudar a resolver, desempenha um papel crucial. Um capítulo sobre a questão "a que horas os assassinos de Júlio César se reuniram nos Idos de Março, em 44 A.C.?" se ligará a um tipo de pesquisa diferente do que um livro sobre "China, Europa e a formação da economia mundial moderna" (RAMSAY 2008; POMERANZ 2000). Enquanto o primeiro projeto busca resolver um problema factual ("quando"), a segunda pesquisa remete a tipos complexos de explicação ("por quê"). Da mesma maneira, o historiador que tenta reconstruir a contabilidade nacional belga ("quanto") deve realizar um trabalho intelectual 
diferente do que é realizado pela sua colega que busca compreender os aspectos intrincados da personalidade de Ranke ("como era o ser humano").

Finalmente, o estado da arte, da literatura secundária existente sobre um dado assunto, também é um elemento constitutivo das situações historiográficas. Como é diferente a tarefa da nossa biógrafa de Ranke, cuja pesquisa precisa se debruçar sobre dezenas de antigas monografias e centenas de artigos já publicados sobre o "pai da historiografia moderna", se comparada com o trabalho pioneiro que o nosso segundo historiador conduz nos arquivos dos negócios flamengos. Enquanto aquela está, explicitamente ou não, em diálogo constante com várias interpretações alternativas, este não tem o benefício nem o fardo representados por um tal corpus de literatura especializada. Quando eu defendo a ideia de que nossos dois historiadores se encontram em diferentes situações historiográficas, este termo se refere a uma interação entre gênero, problema de pesquisa e o estado da arte, interação esta que funciona de maneira distinta para cada um destes historiadores.

O meu argumento, portanto, é o de que as diferentes hierarquias de virtudes intelectuais se justificam em razão das diversas situações historiográficas. Dependendo da sua situação historiográfica, os historiadores deverão priorizar certas virtudes perante outras, ou concentrar-se em algumas virtudes mais do que em outras. Os historiadores têm razões para fazê-lo, porque não é possível aprimorar a compreensão do passado sem que haja uma sintonia fina entre as suas virtudes e a sua situação. Assim, aprimorar a compreensão histórica depende, no final das contas, do gênero, do problema da pesquisa, e do estado da arte. Não se pode especificar o quanto se aperfeiçoou o conhecimento histórico sem prestar atenção às demandas de uma situação historiográfica específica. Historiadores que tentam contribuir para uma melhor compreensão do passado não somente podem priorizar virtudes à luz da sua situação historiográfica. Na verdade, eles necessariamente têm de proceder assim. Hierarquias diferentes de virtudes intelectuais tornam-se justificadas em função das diferentes situações historiográficas. ${ }^{3}$

\section{II}

Tudo isto sugere pelo menos duas razões pelas quais seria inapropriado abordar os nossos historiadores com um questionário em mãos, checando quais virtudes eles necessitam e quais eles não necessitam. Em primeiro lugar, a prática da virtude intelectual - ou virtude moral, no caso - jamais pode ser

\footnotetext{
${ }^{3}$ Não defendo a ideia de que diferentes hierarquias intelectuais se justificam tendo como base os interesses ou preferências pessoais do historiador, embora tais fatores geralmente exerçam uma influência considerável sobre como a pesquisa histórica acadêmica é conduzida. Isto, por sua vez, não retira a legitimidade dos historiadores que seguem as suas preferências ou interesses, mas, antes, permite reconhecer que tais preferências ou interesses não contribuem para a justificação da compreensão histórica. Em outras palavras: mesmo quando os historiadores, como ocorre normalmente, no seu trabalho, são fortemente influenciados por seus interesses e preferências pessoais, somente as suas situações historiográficas podem justificar a hierarquia de virtudes intelectuais que se estabelece. Em termos mais práticos: quando um resenhista julga que os autores de uma certa publicação deveriam ter tido mais cautela e tato nas suas explicações de eventos passados, este julgamento está baseado no que os autores deveriam ter feito a partir da sua situação historiográfica - e não na questão de se os autores apreciam virtudes como o tato e a cautela, ou se teriam capacidade para tal. Isto implica que o resenhista opera a partir da premissa de que as hierarquias de virtudes intelectuais não podem ser justificadas tendo como base interesses ou preferências pessoais.
} 
descrita em termos binários ("sim" ou "não"). Se é verdade que a biógrafa de Ranke e o historiador da economia têm muitas virtudes intelectuais em comum, mas empregam estas virtudes de maneira diferentes - cada um do seu jeito, priorizando certas virtudes em relação a outras, de acordo com as suas respectivas situações historiográficas - , então, em primeiro lugar, dizer que os dois historiadores são justos e precisos não é dizer muita coisa. Seria mais revelador aprender como eles praticam estas virtudes, cada um à sua maneira, na sua própria situação. Isto implica, em segundo lugar, que a abordagem-questionário inevitavelmente resulte em descrições "ralas" do comportamento intelectual virtuoso. Ralas são as descrições que não prestam atenção às demandas específicas que se colocam aos historiadores nas situações historiográficas em que se encontram. Descrições "densas", por contraste, tentam especificar o que, numa dada situação historiográfica, os historiadores precisam fazer para aperfeiçoar a sua compreensão do passado (quais virtudes intelectuais são mais cruciais em sua situação e com quanto esforço estas virtudes devem ser praticadas com o objetivo de se obter uma compreensão adequada do passado). Por isso, somente descrições densas podem explicar a diferença entre a biógrafa de Ranke e o historiador especializado em horticultura, no que diz respeito às suas virtudes intelectuais. ${ }^{4}$

Mais uma razão - a terceira - para rejeitar a abordagem por questionário é que o comportamento virtuoso jamais é uma questão de "ou isto, ou aquilo", mas sempre uma questão de grau. Cuidado, por exemplo, não é algo que 32 alguém possui ou não, mas, antes, uma virtude que alguém pode praticar em maior ou menor medida. Ninguém é perfeitamente cuidadoso ou completamente negligente, da mesma maneira que não há ninguém que seja ou perfeitamente bom ou totalmente desprovido de bondade. Claro que alguém pode se esforçar em ser mais cuidadoso, no sentido de praticar uma virtude em particular com mais afinco do que antes, da mesma forma como alguém pode se tornar uma pessoa moralmente melhor. Virtudes são medidas em uma escala, mais do que por um questionário limitado a "sim" e "não". Ao invés, portanto, de perguntar se os historiadores exercem a virtude da cautela, devemos perguntar: o quão cautelosos eles são?

Por essas três razões, não estou particularmente interessado na questão sobre se há virtudes intelectuais "universais", isto é, se há virtudes intelectuais que todos os historiadores devem praticar. Mark Day, por exemplo, defende a precisão e a consensualidade (ou a acurácia e a justiça, para usar a minha terminologia) como as duas virtudes mais importantes para os historiadores (DAY 2008, p. 42). Embora a sua investigação sobre que virtudes os historiadores devem prezar resulte numa lista impressionantemente longa, Day condensa deliberadamente as suas descobertas empíricas num duplo imperativo: "maximize o escopo do material abordado, sem prejuízo ao sentido de unidade e maximize a precisão sem prejuízo da clareza" (DAY 2008, p. 24). Não se sabe, porém, qual seria o propósito de identificar tais virtudes intelectuais

\footnotetext{
${ }^{4}$ A terminologia, é claro, deve ser creditada a Clifford Geertz (1973).
} 
"universais" - aquelas exigidas por todos os historiadores em todas as situações historiográficas - quando as diferenças entre nossos dois historiadores, no que diz respeito às suas virtudes intelectuais, não parecem residir no tipo de virtudes que eles devem praticar, mas, antes, na maneira ou no grau com os quais eles devem praticá-las. Além disso, de que serve apresentar a precisão e a consensualidade como sendo as virtudes mais essenciais ao historiador sem especificar as posições ocupadas por essas virtudes nas hierarquias de virtudes intelectuais? Não se pode presumir que estas hierarquias sempre são, em todas as situações, encimadas por virtudes como a acurácia e a justiça. Enquanto o historiador especialista em horticultura pode precisar dar prioridade à primeira em relação à segunda, o reverso talvez valha para o biógrafo de Ranke.

Com base no que foi exposto, alguém pode argumentar que os historiadores precisam, universalmente, não de uma virtude, mas de uma "meta-virtude". O que os historiadores necessitam, em todas as situações historiográficas, é uma certa dose de phronesis, que Ihes permita perceber quais são as demandas postas a cada situação. Phronesis, ou o ato de invocar a palavra correta na hora e no lugar certos, é o que os historiadores necessitam quando precisam estabelecer hierarquias de valores intelectuais sintonizadas com a situação em que estão. E é precisamente na medida em que as diferentes situações historiográficas se ligam a diferentes exigências que os historiadores precisam da meta-virtude aristotélica da phronesis- isto é, da virtude que Ihes ajuda a discernir o que é necessário, em cada uma destas situações, para se fazer uma contribuição para uma melhor compreensão do passado. ${ }^{5}$

\section{III}

Imagine agora que a população que compõe o experimento, em vez de se restringir aos dois acadêmicos há pouco mencionados - o biógrafo de Ranke e o historiador imerso em registros comerciais flamengos -, abarca também historiadores de outras épocas e regiões, como são Gregório de Tours, o bispo galo-romano conhecido pela sua Historia francorum, e SimaQian, também conhecido como "o pai da historiografia chinesa", cujos Shiji, ou Relatos do magnífico historiador apareceram por volta de 90 a.C. ${ }^{6}$ Em que medida esse acréscimo da população sob investigação irá afetar as conclusões já alcançadas?

Especialistas em historiografia não tardarão em assinalar que esses historiadores se dedicaram a formas de investigação histórica que são dificilmente comparáveis às que se praticam no mundo acadêmico moderno. Em se tratando de virtude intelectual, poderiam argumentar que historiadores da Antiguidade

\footnotetext{
${ }^{5}$ Sobre a phronesis em Aristóteles, ver Moss (2011). Sobre o tato como "uma sensibilidade para situações e para a maneira de lidar com elas, para o que o conhecimento de princípios gerais não basta", ver também Gadamer (1998, p. 16).

${ }^{6}$ Ao classificar ambos os autores como "historiadores", não tenho a intenção de lhes atribuir qualquer outra qualidade em comum a não ser a de que ambos estudaram o passado. Por razão semelhante, um levantamento global sobre o pensamento e a prática históricas, recentemente realizado, identifica os historiadores como aquelas pessoas "que registraram ou representaram o passado, seja por motivos ligados a interesses pessoais, seja em razão de propósitos sociais ou políticos mais alargados". Essa definição inclui contadores de estórias da África subsaariana, além daqueles que na América andina pré-colombiana costumavam usar o quipu como um dispositivo para registrar memórias comunais. Ver: Woolf (2011, p. 5).
} 
e da Idade Média, cada um ao seu modo, se comprometiam com ideais de individualidade e erudição, além de noções de virtuosidade intelectual, que hoje em dia apenas poucos historiadores aceitariam. Por essa razão, eles podem sugerir que aquilo que conta como comportamento intelectualmente virtuoso se altera em função do tempo e do espaço. Afinal de contas, nenhum acadêmico contemporâneo poderá concordar com SimaQian quando este assume que a fortuna e os infortúnios dos povos seriam explicáveis por referência à noção confuciana de uma ordem cósmica (dao) e que, por conseguinte, os historiadores teriam de possuir a habilidade de perceber se os povos terão ou não vivido em consonância com o dao (MUTSCHLER 2007, p. 197). Do mesmo modo seria difícil encontrar um defensor contemporâneo da visão de Gregório de que a fé cega naquilo que a Bíblia ensina em matéria de história é uma virtude que contribui para o bom entendimento do passado (BEUKELAAR 1994, p. 52-54). Portanto, falando empiricamente, o que conta como sendo um comportamento intelectualmente virtuoso não está gravado em pedra: diferentes tradições nutrem diferentes percepções quanto ao assunto.

A questão mais importante é, então, em que medida SimaQian e Gregório tinham justificativa para empregar virtudes, ou conjuntos de virtudes intelectuais, que diferem daquelas usadas pelo nosso biógrafo de Ranke ou pelo nosso historiador da economia. Penso que essa é uma questão de grande relevância porque ela parece nos colocar diante do desagradável dilema de termos que escolher entre (1) a ideia de que diferentes padrões de virtuosidade 34 intelectual podem coexistir de maneira legítima - uma ideia que muitas vezes é adotada implicitamente pelos historiadores da historiografia - e (2) o argumento de que SimaQian e Gregório não podem ser qualificados como historiadores intelectualmente virtuosos por estarem fora dos padrões que para nós definem a virtuosidade intelectual. A primeira ideia dificilmente pode ser reconciliada com o meu argumento de que o que pode variar de maneira justificada de uma situação à outra são apenas as hierarquias de virtudes intelectuais. Além disso, parece também abraçar um relativismo com respeito ao tema da virtuosidade intelectual, o qual provavelmente não resistiria a um exame mais minucioso (BEVIR 1999, p. 106-124). A segunda ideia, contudo, não é muito mais atraente. Parece deixar de lado que aquilo que motiva os historiadores em primeiro lugar, ou seja, a possibilidade de aprendermos com aqueles que viveram antes de nós, de nos enriquecermos a nós próprios com as percepções deles e, assim, superarmos alguns dos nossos defeitos e limitações. Em outras palavras, será que, neste segundo caso, não estamos assumindo aprioristicamente que temos uma melhor compreensão de virtuosidade intelectual do que SimaQian ou Gregório tinham? Sendo assim, por que nos interessaríamos pelas visões de virtuosidade deles? E, por outro lado, se evitarmos julgar, abrindo-nos para o que os historiadores chamam de "alteridade" ou "estranheza" do passado, como faríamos para não adotar tacitamente uma posição relativista similar à que foi explicada em (1)?

De modo a escapar desse dilema, gostaria de introduzir uma outra categoria conceitual. Enquanto os dois historiadores discutidos na seção anterior 
trabalhavam meramente em situações historiográficas distintas, empregando consequentemente diferentes hierarquias de virtudes intelectuais, o grupo mais heterogêneo de historiadores que agora atrai a nossa atenção também nos coloca defronte a diferentes hierarquias de metas intelectuais (intelectual goods). Metas (goods) apontam para as finalidades que dirigem as investigações intelectuais, ou, no contexto deste artigo, para os bens que a pesquisa histórica supostamente deve distribuir (ROBERTS; WOOD 2007, p. 32-58). Um exemplo óbvio dessas metas é a compreensão histórica, algo que pode ser definido de maneira algo imprecisa como um olhar para uma ordem de coisas do passado. Historiadores cujo objetivo primário é compreender algo historicamente procuram incrementar a sua habilidade para falar do passado de modo fidedigno. A sua preocupação principal não é atingir juízos morais, prazer estético, ou reconhecimento social, mas compreender como o mundo era antigamente. ${ }^{7}$

A compreensão, no entanto, não é a única meta associada à investigação histórica. Isso se torna evidente quando consultamos o Shiji de SimaQian provavelmente o mais influente texto de história já escrito (WOOLF 2011, p. 63). Se tomarmos o autor ao pé da letra, a sua meta mais importante era demonstrar, com meios históricos, a legitimidade do dão confuciano. Como explica um especialista em historiografia chinesa, SimaQian tentou continuamente "dar à tradição uma unidade confuciana organizada", para, assim, ilustrar que o "caminho do céu" é sempre adequado e justo (DURRANT 1995, p. 27). Uma vez que nem todos os eventos e situações discutidas no Shiji correspondem bem àquilo que o confucionismo tradicionalmente entende como o caminho do céu, aparece no Shiji uma tendência para a "teodiceia", isto é, para dar explicações sobre por que o caminho do céu nunca é injusto. Portanto, a meta perseguida por SimaQian não era compreender o passado sob uma ótica confuciana, nem era compreender o dao enquanto tal. O que ele buscava, antes de mais nada, era uma justificação para o caminho do céu perante as aparentes incompreensibilidades da história humana. Além disso, SimaQian tinha em vista contribuir para aquilo que se poderia chamar de preservação do passado. Ele registrava eventos pretéritos, numa escala que não pode ser comparada com a dos seus antecessores, "de modo a prevenir que o passado caia para sempre na escuridão" (DURRANT 1995, p. 7). Um tal ímpeto para registrar eventos não apenas respondia ao propósito de compreender o passado, mas também, e mais essencialmente, preenchia a necessidade confuciana de honrar os ancestrais e de impedir que os nomes destes caísses no esquecimento. Em terceiro lugar, o Shiji pretendia servir a uma finalidade didática ao tratar personagens e situações históricas como exemplos morais - ainda que, como afirma Stephen W. Durrant, tal finalidade amiúde fosse mitigada pelo apetite insaciável do autor por histórias bem amarradas, algo que Ihe permitiu criar "um caleidoscópio de personagens

\footnotetext{
7 Por conveniência, eu emprego aqui "compreensão" como uma categoria abrangente que vale tanto para verstehen quanto para erklären - termos com os quais historiadores e teóricos da história têm habitualmente definido quais são as metas da investigação histórica. Ver D'Oro (2009). Não vou aqui tentar resolver o problema de como a compreensão se relaciona com o conhecimento. Note-se apenas que a primeira é normalmente considerado como pressuposto do segundo e o segundo é considerado uma extensão da primeira. Ver, por exemplo, Kvanvig (2003, p. 185-203) e Riggs (2003).
} 
difíceis de classificar e de converter em exemplos inequívocos" (MUTSCHLER 2007, p. 199-200; DURRANT 1995, p. 143).

Observações parecidas podem ser feitas sobre a Historia francorum, ou História dos francos, escrita por Gregório de Tours no final do século VI. Que metas intelectuais Gregório tinha em vista? Para além da compreensão histórica, ele claramente esperava obter uma espécie de orientação temporal, ou seja, uma ideia acerca de onde estaria a humanidade dentro da linha do tempo que vai desde a criação até o juízo final. Quase todos os capítulos do seu livro se dedicam a contar o número de anos passados desde Adão e Eva, para que o leitor venha a saber quantos anos faltam para que se completem os 6.000 anos concedidos por Deus à história humana. Mesmo que tal orientação obviamente carecesse de elementos relacionados com a compreensão, Gregório, que era, lembremos, bispo, realizava os seus cálculos com um propósito mais pastoral em mente ("para aqueles que estão perdendo as esperanças, à medida que veem o fim do mundo a chegar cada vez mais perto") (GREGÓRIO DE TOURS 1974, p. 67). Para ele, portanto, orientação temporal não era em primeiro lugar uma questão de compreensão histórica, mas uma questão de natureza religiosa, ligada à garantia da salvação. Tal como SimaQian, Gregório também concedeu um valor considerável à função didática da historiografia. "Tenho de dedicar muito do meu espaço às querelas entre os perversos e os justos", afirmou ele, para nas páginas seguintes ressaltar de modo estridente como aos perversos está destinada à punição eterna, enquanto os que seguem Cristo reinarão em 36 glória (GREGÓRIO DE TOURS 1974, p. 63). A educação da audiência era um item claramente importante na lista de metas intelectuais de Gregório. ${ }^{8}$

\section{IV}

Como esses exemplos mostram, metas intelectuais normalmente aparecem no plural. Isso vale não apenas para historiadores que atuaram em épocas que hoje nos parecem longínquas. Pode ser, por exemplo, que o estudioso de Ranke não apenas queira ganhar uma compreensão detalhada da vida e da obra do historiador alemão. Ele pode querer aprender com Ranke sobre como ser um bom historiador. No espírito do famoso comentário de Burckhardt, de que cabe à investigação histórica "tornar-nos mais sábios (para sempre), em vez de apenas mais astutos (para a próxima vez)" (citado por GOSSMAN 2000, p. 272), ele pode querer melhorar-se a si próprio por meio da reflexão contínua sobre uma figura tão grandiosa e complicada quanto a de Ranke. Ou, alternativamente, pode querer chegar a algum tipo de avaliação sobre o valor relativo das realizações de Ranke. Pode, então, tomá-las como exemplo de uma erudição intelectualmente virtuosa; pode ainda tentar se dissociar das premissas eurocêntricas que subjazem à maior parte da obra de Ranke.

Eu não vejo motivos para que qualquer uma dessas metas intelectuais seja descartada como uma meta ilegítima. Quem quer que queira confinar a investigação histórica à procura da compreensão histórica, quem quer que

\footnotetext{
${ }^{8}$ Sobre esse tipo de metas intelectuais na historiografia medieval, ver Schmale (1985, p. 143-164).
} 
despreze o desejo de avaliar, julgar, aprender com o passado, tão comum entre os historiadores, rejeita automaticamente muito daquilo que dá certo na pesquisa histórica. Eu estou, portanto, preparado para aceitar que existe uma variedade de metas intelectuais (para não falar de metas não-intelectuais, como obter reconhecimento pessoal, ascender na carreira, ou ganhar dinheiro).$^{9} \mathrm{E}$ estou preparado para defender que os historiadores podem, legitimamente, correr atrás de qualquer uma dessas metas intelectuais ou não-intelectuais. Rejeito, contudo, a ideia de que todas essas metas sejam igualmente significativas. Não penso que os historiadores com pretensão à seriedade acadêmica estejam livres para priorizar a meta que bem quiserem (por exemplo, para colocar a aprendizagem com o passado à frente da compreensão). Por isso, discordo do argumento relativista de que, do ponto de vista da erudição histórica, o Shiji e a Historia francorum são tão aceitáveis quanto uma moderna biografia de Ranke ou uma reconstrução da contabilidade nacional belga.

A chave para essa posição encontra-se na premissa de que existem hierarquias de metas intelectuais, da mesma maneira que há hierarquias de virtudes intelectuais. Compreender, aprender e julgar qualificam-se como metas intelectuais, mas não funcionam como objetivos de igual importância para a erudição histórica. Pode-se imaginar que a estudiosa de Ranke priorize a aprendizagem (o que ela pode aprender com Ranke?) em vez do juízo valorativo (por que ela discorda dele?), ao mesmo tempo em que subordina ambos esses objetivos àquilo que ela corretamente identifica como sendo a mais importante meta da erudição histórica: a compreensão do passado. Outros historiadores, por trabalharem com temas que tendem a gerar objeções morais (escravidão, genocídio, etc.), podem ficar mais inclinados para julgar do que para aprender com o passado investigado, mas também subordinam esses dois objetivos à meta da compreensão histórica. Em contraste, o que faz com que SimaQian e Gregório de Tours apareçam, ao olhar moderno, como historiadores "não profissionais" é o fato de que eles parecem priorizar metas tais como a aprendizagem e o juízo, em detrimento da compreensão. Não é que eles pratiquem de modo insuficiente virtudes como o cuidado e a precisão - isto é, virtudes que estão no cerne da atitude crítica da qual a historiografia moderna frequentemente se orgulha. $\mathrm{O}$ problema é que eles deixam que a aprendizagem e o juízo valorativo ganhem precedência sobre a compreensão. Por mais que inegavelmente a compreensão histórica também se encontre entre as metas que eles procuram perseguir, a compreensão não aparece no lugar proeminente que ocupa nos nossos dois casos anteriores. Uma coisa está clara: o que distingue os nossos historiadores dos dias de hoje dos seus colegas da Antiguidade e da Idade Média não é que

\footnotetext{
9 Tais metas não-intelectuais são exemplos vívidos do que AlasdairMacIntyre chama de "metas ou bens externos" (externalgoods), ou seja, metas ou bens que derivam de uma prática cuja razão de ser é definida por uma "meta ou bem interno" (internalgood). O meu conceito de "metas intelectuais" é, entretanto, mais abrangente do que o conceito de "metas internas" de MacIntyre. Ainda que eu concorde com ele que as diferentes práticas humanas (como a da erudição histórica) normalmente sejam constituídas por apenas uma meta intelectual (como a compreensão histórica), não acho que tal circunstância transforme todas as demais metas em metas "externas". Quero crer que o desejo de aprender com o passado é menos externo para a prática da erudição histórica do que outras metas como, por exemplo, progredir na carreira ou ganhar dinheiro. Ver Macintyre (1981).
} 
aqueles, diferentemente destes, se dediquem exclusivamente à compreensão do passado. Argumentar assim implica negligenciar o grau em que os historiadores de hoje também se aplicam, conscientemente ou não, em avaliar e julgar o passado que investigam. ${ }^{10} \mathrm{O}$ ponto crucial aqui é que a compreensão seja a prioridade número um nas suas hierarquias de metas intelectuais.

Ainda que nunca se possa fazer cumprir tais prioridades à força, acredito que as hierarquias de metas intelectuais têm necessariamente de ser encabeçadas pela meta da compreensão, quando se pretende que uma investigação histórica seja reconhecida como pesquisa erudita. A compreensão histórica é fundamental para a erudição histórica. Por tal razão, a compreensão deve receber prioridade sobre todas as outras metas intelectuais (e também as não intelectuais) para que uma investigação histórica se qualifique como erudição. Isso implica que outras metas apenas podem ser perseguidas legitimamente na medida em que não atrapalhem a busca do historiador pela compreensão. Toda vez que as metas intelectuais ameaçam a colidir umas com as outras - por exemplo, quando o propósito de fornecer esclarecimento moral parece incompatível com o objetivo de compreender um mundo no qual o claro e o escuro estão estreitamente entrelaçados - deve-se dar precedência à compreensão. Historiadores que eventualmente optem por outras maneiras de resolver um conflito como esse podem estar agindo de maneira legítima, mas ao fazê-lo deixam de estar fazendo um trabalho acadêmico ou erudito. 0 mesmo critério de demarcação permite com que os historiadores neguem ao Shiji e à Historiafrancorum o status de trabalhos históricos eruditos. Exatamente na medida em que esses trabalhos subordinam a compreensão histórica à prossecução de outras metas intelectuais, deixam de poder pretender ser exemplos de trabalhos acadêmicos.

Perceba que nada disso quer dizer que os historiadores que priorizem outras metas que não a compreensão estejam a dedicar-se a um trabalho ilegítimo. Não quero contestar a legitimidade de um trabalho histórico preparado de acordo com os modelos fornecidos por SimaQian ou Gregório. Apesar de um tal trabalho não se qualificar como uma contribuição para a erudição histórica, pode o mesmo aspirar ter, por exemplo, valor literário. Assim como o Shiji hoje pode, com proveito, ser lido como um clássico literário (DURRANT 1995, p. 117), ${ }^{11}$ um trabalho atual nele inspirado pode almejar fins intelectuais virtuosos distintos da compreensão. De fato, um romance histórico como Terra d'água (Waterland), de Graham Swift é uma realização intelectual de primeira linha precisamente, porque, não muito diferentemente do Shiji, ousa subordinar a compreensão histórica (tal como definida acima) a uma reflexão sobre coisas como a natureza das tradições e a margem de manobra

\footnotetext{
10 Mark Day diferencia algumas formas específicas de "relação com o passado" (epistêmica, preservadora, dialógica e prática). Mesmo que se possa discordar de Day quanto à quantidade e à natureza dessas relações, é inegável que ele identifica um aspecto importante ao afirmar que "a relação crítico-epistêmica como o passado está envolvida nas outras formas de relação com o passado" (DAY 2008, 9).

11 "Frequentemente revisitamos os Registros do historiador [o Shiji, NT], porque este texto é tão difícil e inextrincável como a própria vida. As nuvens no espelho de SimaQian correspondem aos padrões de um ser humano completo e intrincado; são as mesmas nuvens que, de um jeito ou de outro, nos incomodam a todos nós (DURRANT 1995, p. 147).
} 
de que as pessoas dispõem para se libertar de crenças e práticas herdadas. A quem quer que queira compreender a história dos Fens - a região ao leste da Inglaterra na qual Swift situa a sua narrativa - recomenda-se que procure uma monografia acadêmica. Mas um leitor que esteja à procura, por exemplo, de uma visão sobre as peculiaridades humanas fará bem em passar algumas noites na companhia de Terra d'água (SWIFT 1983). ${ }^{12}$ Portanto, a precedência da compreensão histórica sobre outas metas intelectuais não é absoluta; serve meramente como um critério de demarcação entre as do passado que têm pretensão acadêmica e as que não podem ter. Explica, todavia, porque os historiadores de hoje corretamente rejeitam o Shiji e a Historia francorum como contribuições sérias à erudição histórica.

Por último, gostaria de assinalar que não é possível especificar de antemão que tipo de finalidade deveria ocupar a segunda, a terceira, ou a quarta posições na hierarquia de metas intelectuais do historiador, nem tampouco os motivos à luz dos quais tais hierarquias podem ser justificadas. Dos historiadores que se dedicam à pesquisa erudita pode-se esperar apenas que deem prioridade à compreensão, de maneira a evitar que a persecução de metas intelectuais alternativas não comprometa aquele objetivo fundamental. Por sorte, contudo, esse requisito é forte o suficiente para permitir que os historiadores eruditos se dissociem de SimaQian, Gregório de Tours, ou qualquer outro historiador que priorize, por exemplo, a aprendizagem ou o juízo em detrimento da compreensão. É forte o suficiente para colocar em causa a ideia relativista de que a historiografia antiga ou medieval é simplesmente tão boa quanto a historiografia acadêmica contemporânea. Contrapõe-se a esse relativismo ao privilegiar a compreensão histórica em detrimento de outras metas intelectuais. Ainda que possa haver diferentes hierarquias de metas intelectuais, é característica fundamental da erudição histórica a precedência da compreensão sobre as demais metas, não podendo essa compreensão ser obstaculizada pela vontade de aprender com o passado ou pelo desejo de julgar os méritos relativos daqueles que vieram antes de nós.

\section{V}

Ambas as formas de hierarquia acima discutidas - hierarquias de virtudes intelectuais e hierarquias de metas intelectuais - servem ao propósito de conciliar uma descrição não relativista da erudição histórica com a percepção historicista de que o comportamento intelectual virtuoso se forma dentro do seu contexto histórico. O primeiro tipo de hierarquia contribui para tal propósito ao rejeitar um modelo uniformizado de virtuosidade histórica em favor de um modelo que permite variações significativas no peso que os historiadores conferem a cada uma das virtudes intelectuais de que lançam mão para promover uma melhor compreensão do passado. Além disso, essas diferenças não são relacionadas aos interesses e preferências pessoais dos historiadores, mas antes às suas situações historiográficas, de tal modo que as

\footnotetext{
12 Agradeço a Madeleine Karsten por me ter exortado a ler esse maravilhoso romance.
} 
hierarquias de virtudes intelectuais, em vez de serem meramente arbitrárias, passam a ser vistas em função das demandas que cada situação impõe ao historiador. Da mesma forma, o segundo tipo de hierarquia deixa espaço para que diversas metas intelectuais sejam perseguidas - inclusive aquelas que são preferidas por historiadores que trabalham dentro de tradições que hoje dificilmente seriam reconhecidas como erudição histórica -, mas ao mesmo tempo cria uma barreira de contenção contra o espectro do relativismo, uma vez que trata a compreensão histórica como uma meta intelectual prioritária quando o assunto é pesquisa histórica erudita.

Por essa razão, a posição que é advogada no presente texto não é uma posição fortemente historicista. Historicismo forte corresponderia à ideia de que a investigação histórica "é total e necessariamente determinada pela realidade finita da circunstância histórica". Ao operar a partir do pressuposto da "paroquialidade total e inevitável da razão", o historicismo forte exclui a possibilidade de definir a erudição histórica de modo situacionalmente transcendente (PAGE 1995, p. xi, 3). Apesar de a minha posição permanecer simpática ao impulso historicizante que perpassa a maior parte dos trabalhos recentes de história da historiografia, eu rejeito um tal historicismo forte em nome de uma descrição não relativista da erudição histórica. Afirmo serem não relativistas tanto o meu argumento de que a compreensão histórica é fundamental para a erudição histórica quanto a conclusão de que a meta da compreensão deve ter prioridade sobre as demais metas (pelo menos no plano da erudição).

HO A minha posição pode então ser descrita como historicista em sentido fraco. O historicismo fraco é historicista na medida em que rejeita descrições de comportamentos intelectualmente virtuosos que sejam "magras" ou inespecíficas do ponto de vista situacional, e em que aponta para as demandas intelectuais encaradas pelos historiadores em diferentes situações historiográficas. Além disso, é também historicista uma vez que aceita como um dado da realidade que os historiadores frequentemente se colocam metas que são distintas da compreensão histórica, e porque, desde um ponto de vista normativo, autorizaos a assim proceder. Todavia, ao endossar a tese forte de que a compreensão histórica deve ser a prioridade número um de qualquer historiador que queira realizar um trabalho acadêmico, o referido historicismo fraco deixa de trazer consigo as implicações relativistas típicas do historicismo forte. Para resumir: o historicismo fraco adota uma postura categórica quanto àquilo que qualifica um trabalho de história como um trabalho erudito ou acadêmico, ao mesmo tempo em que admite de modo mais generoso que o comportamento intelectualmente virtuoso é marcado pelos contextos históricos. Será presunçoso pensar que, nesse historicismo fraco, aumentam as probabilidades para que os historiadores da historiografia interessados em descrições densas de comportamentos intelectualmente virtuosos e os teóricos da história desejosos de evitar o espectro do relativismo se aproximem uns dos outros? ${ }^{13}$

\footnotetext{
${ }^{13}$ Agradeço a Mark Bevir e Allen R. Dunn pelos comentários que fizeram a uma versão preliminar deste artigo.
} 


\section{Referências bibliográficas}

ALSTON, William P. Concepts of epistemic justification. In: ALSTON. Epistemic Justification: Essays in the Theory of Knowledge. Ithaca: Cornell University Press, 1989, p. 81-114.

BEUKELAAR, Adriaan H. B. Historiography and Episcopal Authority in Sixth-Century Gaul: The Histories of Gregory of Tours Interpreted in their Historical Context. Göttingen: Vandenhoeck \& Ruprecht, 1994.

BEVIR, Mark. The Logic of the History of Ideas. Cambridge: Cambridge University Press, 1999.

DASTON, Lorraine; GALISON, Peter. Objectivity. New York: Zone Books, 2007.

DAY, Mark. The Philosophy of History: An Introduction. London: Continuum, 2008.

D'ORO, Giuseppina. Historiographic Understanding. In: TUCKER, Aviezer (org.).

A Companion to the Philosophy of History and Historiography. Chichester: Wiley-Blackwell, 2009, p. 142-151.

DURRANT, Stepehn W. The Cloudy Mirror: Tension and Conflict in the Writings of Sima Qian. Albany: State University of New York Press, 1995.

GADAMER, Hans-Georg. Truth and Method. New York: Continuum, 1998.

GEERTZ, Clifford. Thick Description: Toward an Interpretative Theory of Culture. In: The Interpreation of Cultures: Selected Essays. New York: Basic Books, 1973, p. 3-30.

GOSSMAN, Lionel. Basel in the Age of Burckhardt: A Study in Unseasonable Ideas. Chicago: University of Chicago Press, 2000.

GREGÓRIO DE TOURS. The History of the Franks. Harmondsworth: Penguin Books, 1974.

KNANVIG, Jonathan. The Value of Knowledge and the Pursuit of Understanding. Cambridge: Cambridge University Press, 2003.

MACINTYRE, Alasdair. After Virtue: A Study in Moral Theory. London: Duckworth, 1981.

MOSS, Jessica. 'Virtudes Make the Goal Right': Virtue and Phronesis in Aristotle 's Ethics. Phronesis, v. 56, p. 204-261, 2011.

MUTSCHLER, F. -H. Sima Qian and His Western Colleagues: On Possible Categories of Description. History and Theory, v. 46, n. 2, p. 194-200, 2007.

PAGE, Carl. Philosophical Historicism and the Betrayal of First Philosophy. University Park: Pennsylvania State University Press, 1995.

PAUL, Herman.The Scholarly Self: Ideals of Intellectual Virtue in NineteenthCentury Leiden. In: BOD, Rens; MAAT, Jaap; WESTSTEIJN, Thijs (orgs.). The Making of the Humanities. Amsterdam: Amsterdam University Press, 2012, p. 397-412. v. II. 
. Performing History: How historical scholarship is shaped by epistemic virtudes. History and Theory, v. 50, n. 1, 2011, p. 1-19, 2011 a.

. Distance and Self-Distanciation: Intellectual Virtude and Historical Method around 1900. History and Theory, v. 50, n. 4, 2011, p. 104116, 2011b.

PLANTINGA, Alvin. Warrant: The Current Debate. Oxford: Oxford University Press, 1993.

POMERANZ, Kenneth. The Great Divergence: China, Europe, and the Making of the Modern World Economy. London: Princeton University Press, 2000.

RAMSEY, John. At What Hour Did the Murderers of Julius Caeser Gather on The Ides of March 44 B.C.W. In: HEILEN, Stephan et al. (orgs.). In Pursuit of Wissenschaft: Festschrift für William M. Calder III zum 75. Geburtstag. New York: Georg Olms Verlag, 2008, p. 351-363.

ROBERTS, Robert C.; WOOD, W. Jay. Intellectual Virtues: An Essay in Regulative Epistemology. Oxford: Clarendon Press, 2007.

RIGGS, Wayne D. Understanding 'Virtue' and the Virtue of Understanding. In: DEPAUL, Michael; ZAGZEBSKI, Linda (orgs.). Intellectual Virtues: Perspectives from Ethics and Epistemology. Oxford: Clarendon Press, 2003, p. 203-226.

SCHMALE, Franz-Josef. Funktionen und Formen mittelalterlicher Geschichtsschreibung: Eine Einführung. Darmstadt: Wissenschaftliche Buchgesellschaft, 1985.

SMITS, Jan-Pieter, HORLINGS, Edwin; ZANDEN, Jan Luiten van. Sprekende cijfers! De historische nationale rekeningen van Nederland, 1807-1913. NEHA-Jaarboek, n. 62, p. 51-110, 1999.

SWIFT, Graham. Waterland. London: William Heinemann, 1983.

WOOLF, Daniel. A Global History of History. Cambridge: Cambridge University Press, 2011.

ZAGZEBSKI, Linda. Recovering Understanding. In: STEUP, Mathias (org.). Knowledge, Truth, and Duty: Essays on Epistemic Justification, Responsibility, and Virtue. Oxford: Oxford University Press, 2001, p. 235251. 


\title{
No Future: esboços para uma ação política no "novo tempo do mundo"
}

\author{
No Future: sketches for political action in the "new time of the world"
}

\author{
Danilo Araujo Marques \\ danilomarques.his@gmail.com \\ Mestre em História \\ Universidade Federal de Minas Gerais \\ Av. Elísio de Brito, 845 - Boa Vista \\ 31060-535 - Belo Horizonte - Minas Gerais \\ Brasil
}

\begin{abstract}
Resumo
Neste início de século, uma nova dinâmica temporal parece irromper no Ocidente. Nas mais diversas acepções desta nova experimentação do tempo histórico, um presente autocentrado toma lugar de destaque, em detrimento de experiências passadas e projetos de futuro. Mas o que dizer a respeito das implicações políticas dessa configuração temporal? Este artigo pretende explorar duas diferentes indicações de alternativas para ação política neste que seria um "novo tempo do mundo", tendo em conta os possíveis arranjos entre experiência e expectativa nos dias de hoje: de um lado, a "hipótese comunista"; de outro, o "pós-socialismo". Animado pela concepção de crise enquanto abertura de possibilidades, ao final do texto pretende-se formular um esboço próprio de ação, que sintetize o moderno impulso para o futuro (porvir) e a contemporânea - por vez estagnante - onipresença de um "regime de historicidade presentista", conjugando a noção de um "regime de urgência" com elementos dos pensamentos de Ernst Bloch e Walter Benjamin.
\end{abstract}

\section{Palavras-chave}

Temporalidades; Presentismo; Política.

\begin{abstract}
In this new century, a new temporal dynamics seems to arise in the West. In several senses from this new experimentation of historical time, a self-centered present takes a prominence place, at the expense of the past experiences and future projects.But, what to say about the political implications from this temporal setting? This article intends explore two different sketches of alternatives for political action on this that would be a "new time of the world", taking into account the possible arrangements between experience and expectation in our days: on the one hand, the "communist hypothesis"; on the other, the "post-socialism". Excited by the concept of crisis like a while of opening possibilities, when finalizing the text we intend to formulate our own action outline, making a synthesis between the modern impulse for the future and the contemporary sometimes stagnant - omnipresence of a "presentist regime of historicity", combining the notion of a "urgency regime" with elements from the Ernst Bloch and Walter Benjamin's thoughts.
\end{abstract}

\section{Keywords}

Temporalities; Presentism; Policy.

Recebido em: 16/11/2015

Aprovado em: 15/7/2016 
Em sua clássica Introdução à leitura de Hegel, Alexandre Kojève afirma que apenas uma categoria de tempo interessava ao autor da Fenomenologia do Espírito: "o tempo da ação consciente e voluntária que realiza no presente um projeto para o futuro". Trata-se do tempo histórico e, de acordo com Kojève, "o presente só é histórico [para Hegel] porque nele há uma relação com o futuro, ou, mais exatamente, porque ele é uma função do futuro" (KOJÈVE 2002, p. 349). Reinhart Koselleck já nos ensinou que esta definição do tempo histórico é característica sui generis da modernidade, e, tratando-se de Hegel a primazia conferida pela ação no presente a um projeto de futuro, um "horizonte de expectativas", não poderia ser diferente (KOSELLECK 2006).

Ora, mas se considerarmos aqui esta definição "futurocentrada" - nos termos de François Hartog -, podemos concluir que hoje o tempo histórico está em crise, ou que ao menos "o futuro não é mais o que era" (MARQUES et al. 2013; VALÉRY 1991). As muitas designações contemporâneas para essa nova condição dão o tom daquilo que Paul Valéry já denonimava no século passado como "o problema de nosso tempo": fala-se em "regime de historicidade presentista", "cronótopo do presente amplo", "presente perpétuo", "presente contínuo", "presenteísmo" e assim por diante (HARTOG 2013; GUMBRECHT 2012; BAUMAN 1998; MAFFESOLI 2003). "A busca do presente", para citar outro poeta, desta vez Octávio Paz, faz irromper a força e a onipresença de uma nova categoria temporal (PAZ 1990). E, assim como nos últimos versos da não menos poética - embora mais barulhenta - God Save the Queen, da britânica

44 The Sex Pistols, um causticante No Future é repetido à exaustão no que ainda resta de "consciência histórica" no Ocidente.

O filósofo Paulo Arantes argumenta que vivemos hoje em um Novo Tempo do Mundo. Gestado na virada dos anos 70 para os anos 80 do século passado, seu principal atributo seria um corolário do congelamento da agitação social no Ocidente e da intensificação daquele discurso que Krzysztof Pomian denominou "a crise do futuro" (POMIAN 1999). De acordo com Arantes,

a certa altura do curso contemporâneo do mundo, a distância entre expectativa e experiência passou a encurtar cada vez mais e numa direção surpreendente, como se a brecha do tempo fosse reabsorvida e se fechasse em nova chave, inaugurando uma nova era que se poderia denominar das expectativas decrescentes, algo "vivido" em qualquer que seja o registro, alto ou baixo (ARANTES 2014, p. 67, grifos no original).

Apreendido pelo que se convencionou chamar de presentismo, este "novo tempo do mundo", segundo palavras da historiadora Ludivine Bantingny, "traduz seguramente um certo ar do tempo onde predomina o sentimento de um futuro vacilante"; uma nova e "essencialmente pessimista" condição para a experimentação do tempo (BANTIGNY 2013, p. 23). Mas, em vez de apenas apresentar aqui uma espécie de patchwork dos conhecidos estudos que, mais ou menos nessa direção, alegam a irrupção contemporânea de uma nova ordem do tempo, consideremos enquanto filão de nossa reflexão a sugestão segundo a qual é "bem mais à maneira de uma ideologia que é 
preciso analisar o presentismo, e portanto explorar suas implicações políticas" (BANTIGNY 2013, p. 24).

Neste sentido, Jérôme Baschet defende que "o reino de um presente perpétuo que nega o antes e o depois, e faz do hoje o novo altar em que todos devem se sacrificar "trata-se de um autêntico produto da chamada "lógica neoliberal". Para ele, desde que a chamada Era Reagan-Tatcher acenou com a mão invisível o princípio TINA - There Is No Alternative - do livre mercado, o presente surgiu como "este novo tirano que, para melhor assegurar sua dominação, faz desaparecer o passado no esquecimento e obnubila toda perspectiva de um futuro que não seja a repetição ou a amplificação da dominação presente" ${ }^{1}$ (BASCHET 2001, p. 63). Assim, nada mais representativo do que a polêmica declaração de que, ao final do século XX, a História atingira o "ponto final na evolução ideológica da humanidade", figurado pelo triunfo hegemônico dos princípios políticos e econômicos do liberalismo em detrimento de seus rivais ideológicos (FUKUYAMA 1989). A teoria fukuyamiana do "fim da História" seria, portanto, uma genuína expressão do que o filósofo Pierre-André Taguieff chamou de "a sacralização do mundo tal como ele vai", um recorrente ethos no mundo ocidental contemporâneo (TAGUIEFF 2000, p. 10-11).

Diante do "mal-estar" causado por essa condição, argumenta-se que aquele profundo e indiferente niilismo do jovem Meursault, em O Estrangeiro, de Albert Camus, teria atingido o nível globalizado de um sintoma da consciência histórica na lógica cultural do capitalismo tardio. Ao fim do século $X X$, enquanto o futuro saía, melancólico, pela porta dos fundos da História, o presente era recebido com a intensa e cínica repetição de duas efusivas frases: "tanto faz" e "não me importo" (CAMUS 2013). Assim se afigurava o que, conforme palavras de Zygmunt Bauman,

é o colapso gradual e o rápido declínio da antiga ilusão moderna: da crença de que há um fim do caminho em que andamos, um telos alcançável da mudança histórica, um Estado a ser atingido amanhã, no próximo ano ou no próximo milênio, algum tipo de sociedade boa, de sociedade justa e sem conflitos em todos ou alguns de seus aspectos postulados (BAUMAN 2001, p. 37).

Todavia, longe de reiterar aqui a inflexão trágica por trás do "ar essencialmente pessimista" ou mesmo aquela expressão pré-fabricada de melancolia e resignação por parte de alguns pós-modernos, propomos assumir a crise do momento atual como uma oportunidade prenhe de novas possibilidades e desdobramentos. É neste sentido que nos cumpre considerar algumas reflexões que enfrentam a angústia proclamada pelo "horizonte-dique" de um "presente hipertrofiado" - para usar alguns termos de José Carlos Reis e apontam possíveis caminhos para ação política neste chamado "novo tempo do mundo" (REIS 2012, p. 54).

\footnotetext{
${ }^{1}$ Eis o leitmotiv da tese sustentada por Fredric Jameson, que concebia o pós-modernismo "como a dominante cultural da lógica do capitalismo tardio" (JAMESON 1996, p. 72). Para ele, a dita "condição pós-moderna" estimula um rearranjo temporal no qual uma "nova relação com nosso próprio presente inclui elementos anteriormente incorporados à experiência do 'futuro' e bloqueia, ou impede, qualquer visão global deste último como um sistema diferente, radicalmente transformado" (JAMESON 1996, p. 291).
} 


\section{A "hipótese comunista": pela reativação crítica do futuro (porvir) emancipatório}

Na reedição da Dialética do Esclarecimento, em 1969, os fundadores da Escola de Frankfurt, Theodor Adorno e Max Horkheimer, admitiam que, decorridos mais de vinte anos desde sua publicação, "não são poucas as passagens em que a formulação não é mais adequada à realidade atual". Por outro lado, a força que havia animado a escrita da obra de modo algum parecia ultrapassada. "O pensamento crítico, que não se detém nem diante do progresso", diziam, "exige hoje que se tome partido pelos últimos resíduos de liberdade, [...] ainda que pareçam impotentes em face da grande marcha da história" (ADORNO; HORKHEIMER 1985, p. 9). Reivindicando para si a tradição desse "pensamento crítico", intelectuais de uma renovada esquerda, pós-queda do Muro de Berlim, procuram atualmente tomar "partido pelos últimos resíduos de liberdade" e refletir sobre as possíveis formas de reconfiguração da práxis revolucionária sem uma realidade social dita "unidimensional", na qual, segundo Stanley Aronowitz, "a vida política já não se fundamenta numa concepção de um mundo qualitativamente melhor" (HOLLANDA 1992, p. 155).

Um pouco à maneira de como agia Lênin nos primeiros anos do século passado - guardadas as devidas proporções históricas de tempo e espaço - , a principal questão que anima estes pensadores no início do século XXI é: que fazer diante de uma "ordem" que, voltada para o prosaísmo do "mundo tal como ele vai", orgulha-se de decretar diariamente o luto político das metateorias propositivas de horizontes alternativos? Para o filósofo Slavoj Žižek,

É fácil rir da noção de "fim da história" de Fukuyama, mas o ethos dominante hoje é "fukuyamiano": o capitalismo democrático-liberal é aceito como a fórmula da melhor sociedade possível que finalmente se encontrou - só resta torná-lo mais justo, mais tolerante etc (ŽIŽEK 2011, p. 416).

Nesse sentido, não sem uma boa dose de provocação, pergunta:

se o capitalismo democrático-liberal funciona obviamente melhor do que todas as alternativas, se o capitalismo democrático-liberal, se não é a melhor forma de sociedade, pelo menos é a menos pior, por que simplesmente não nos resignamos, como adultos que somos, e o aceitamos de todo o coração? (ŽIŽEK 2011a, p. 81)

Movido pelo princípio de "reativação crítica" do que Miguel Abensour denominou "o novo espírito utópico", Žižek apresenta-se como um dos principais representantes dessa vertente téorica que, em maior ou menor grau, propõe uma releitura dos discursos políticos de emancipação sem perder de vista os desafios lançados pelo "novo tempo do mundo" (ABENSOUR, 1990). ${ }^{2}$ Crítico da contemporânea sociedade de "últimos homens", de "indivíduos 'pós-modernos' que rejeitam como terroristas todos os objetivos 'mais altos' e dedicam a 
própria vida a sobreviver, a uma vida cheia de prazeres menores cada vez mais refinados e artificialmente excitados", Žižek empenha-se na reformulação do "desejo emancipatório" entendendo que:

Embora momentos sublimes como o climax jacobino da Revolução Francesa e a Revolução de Outubro permaneçam para sempre como parte fundamental de nossa memória, o arcabouço geral tem de ser superado e tudo deve ser repensado, a partir do zero (ŽIŽEK 2003, p. 108; 2011, p. 80 , grifos nossos).

Assim, tomando como ponto de partida de sua crítica este presente autorreferenciado - o "grau zero da ideologia", como gosta de dizer -, Žižek alerta para a necessidade de se enfrentar o atual "deserto do real" e toda a crise de seu vazio substancial. Não para seguir em frente e continuar "[sobre]vivendo no fim dos tempos", mas a fim de que se compreenda a crise do atual momento como real oportunidade de sua superação (ŽIŽEK 2012).

Rapidamente comentada acima, a concepção do "novo espírito utópico" proposta pelo filósofo Miguel Abensour ${ }^{3}$ tende a captar muito bem o ethos que anima boa parte dos pensadores que atualmente agem de acordo com o postulado da VI tese benjaminiana sobre o conceito de história, segundo o qual "cada época deve tentar sempre arrancar a tradição da esfera do conformismo que se prepara para dominá-la" (BENJAMIN 2013, p. 11-12). Tratam-se de intelectuais que, na melhor acepção deste tão desgastado termo, buscam repensar, hoje, o lugar social dos discursos de emancipação, e, não raro, recorrem ao arcabouço teórico de Karl Marx. Conservando, contudo, a crítica como princípio fundador, os "partidários do novo espírito utópico" não são, nas palavras de Abensour, "como o herdeiro que prossegue um movimento". Oriundos de correntes heterodoxas ou marginais no interior do marxismo, eles

Não querem repetir ou recomeçar a utopia (ou, o que daria no mesmo, completar Marx com a utopia) mas redescobrir o programa comunista que está no coração da teoria radical [...] não querem permanecer aquém da teoria de Marx nem ir além dela, mas tomar posição no centro mesmo da teoria. Implícita ou explicitamente, o novo espírito utópico se inspira na ideia de que a crítica revolucionária real das utopias formuladas por Marx e Engels foi deformada, pior ainda invertida pelos epígonos, ocultando uma dimensão fundamental da teoria [...]: a tensão para o futuro comunista (ABENSOUR 1990, p. 59-60).

E é justamente neste sentido que, ao apontar o "problema no paraíso"4 e sugerir "que tudo tem de ser superado e repensado, a partir do zero", Žižek

\footnotetext{
${ }^{3}$ Agradeço ao colega Wilkie Buzatti Antunes por esta certeira sugestão de leitura.

${ }^{4}$ Esta é a expressão que intitula um dos livros de Žižek, que leva como subtítulo "Do fim da história o fim do capitalismo". De acordo com suas palavras: "O 'paraíso' do título deste livro faz referência ao paraíso do Fim da História (tal como elaborado por Francis Fukuyama: o capitalismo liberal-democrata como a melhor ordem possível enfim encontrada), e o 'problema', evidentemente, é a crise permanente que levou o próprio Fukuyama a abandonar sua ideia de Fim da História. Minha premissa é que aquilo que Alain Badiou chama de 'hipótese comunista' é o único arcabouço adequado ao diagnóstico da crise" (ŽIŽEK 2015, p. 11). A respeito daquela guinada no argumento de Francis Fukuyama, ver: "Do fim ao futuro da História" (MARQUES 2014).
} 
defende que "sem dúvida, esse começo é o que Badiou chama de 'hipótese comunista'" (ŽIŽEK 2011, p. 80).

O filósofo Alain Badiou é outro representante desta esquerda (auto)crítica, que tomamos a liberdade de denominar aqui, por razões óbvias, como "pósqueda do Muro de Berlim". ${ }^{5}$ Sua proposta política de releitura da concepção marxiana de mundo é clara:"no campo da ideologia e da história, convém fazermos nosso próprio balanço do século $X X$, de modo a reformular a hipótese da emancipação de acordo com as condições de nossa época, após o fracasso dos Estados socialistas". A urgência desse balanço seria imposta, hoje, pelo fato de, em uma "escala de conjunto, a forma moderna, dita 'democrática', do Estado burguês, cujo suporte é o capitalismo globalizado, [...] se apresentar como sem rival no campo ideológico" (BADIOU 2012, p. 146). Diante disso, nosso momento histórico é definido em suas palavras como "a época da reformulação da hipótese comunista" (BADIOU 2012, p. 40-41).

Para Badiou, o termo "comunismo" ou foi completamente esquecido, após a proclamação do "fim das ideologias", ou historicamente identificado com as práticas tirânicas e criminosas de um Josef Stalin ou um Pol Pot. Todavia, alguns sinais indicariam o iminente fim desse "período reativo", visto que estaríamos, hoje, mais próximos das questões enfrentadas na primeira metade do século XIX do que dos problemas herdados do século XX. "Como por volta de 1840", diz ele,

estamos diante de um capitalismo cínico, certo de ser a única via possível de organização das sociedades. [...] Os revolucionários são desunidos e frouxamente organizados, amplos setores da juventude foram tomados por um desespero niilista, a grande maioria dos intelectuais é servil (BADIOU 2012, p. 147).

Em outras palavras, o atual momento de crise não poderia ser mais propício para a releitura da "Ideia comunista". Não no sentido do mero resgate e transposição ahistórica de um modelo para a ação política, mas de uma reavaliação contemporânea, contrária ao formato dogmático de grande parte do século XX. Conforme o argumento de Badiou, acima de tudo,

É preciso derrubar o velho veredito que diz que chegamos ao "fim das ideologias". [...] A razão para emancipação da humanidade não perdeu sua força. A palavra "comunismo", que durante muito tempo deu nome a essa força, foi aviltada e prostituída. Mas hoje seu desaparecimento serve apenas aos detentores da ordem, aos atores febris do filme catástrofe. Vamos ressucitá-la em sua nova clareza. Que é também sua antiga virtude, quando Marx diz que o comunismo é a ruptura, "do modo mais radical, com as ideias tradicionais" e faz surgir uma "associação na qual o livre desenvolvimento de cada um é a condição para o livre desenvolvimento de todos" (BADIOU 2012, p. 59-60, grifos nossos).

\footnotetext{
5 Podemos, talvez, trabalhar com a hipótese de que, no caso de Badiou, a necessidade de uma releitura do pensamento de esquerda tenha se originado no fracasso e subsequente isolamento histórico dos movimentos sociais de 1960 no decorrer das décadas de 1970 e 1980. Alain Badiou foi um militante da juventude maoista no fatídico Maio de 1968 francês. Para mais informações sobre a proposta de releitura do evento e do pensamento de esquerda no Ocidente, verr o texto "Maio de 1968 revisitado, quarenta anos depois" (BADIOU 2012).

${ }^{6}$ É nesta direção que Slavoj Žižek vai propor um retorno à leitura de Hegel em seu Menos que nada (ŽIŽEK 2013).
} 


\section{O "pós-socialismo": por uma ação política calcada na autorreferenciali -dade do presente}

Por outro lado, convém considerar a proposta de reflexão que o sociólogo Alain Touraine esboça a respeito da ação política no "novo tempo do mundo" - dado que nela subjaz uma outra concepção de porvir. De acordo com sua leitura, para uma justa compreensão da realidade presente, é preciso ter em mente o esgotamento do "horizonte de expectativas" da esquerda socialista. ${ }^{7}$ Dessa maneira, trata-se, portanto, de dar boas-vindas a uma nova condição, caracterizada em suas palavras pelo "desaparecimento de um certo modo de ação política, de um tipo de relação entre os valores culturais, os interesses ou os movimentos sociais e a ação propriamente política" (TOURAINE 1988, p. 73).

Para Touraine, a sociedade que emerge no que ele chama de"pós-socialismo' é definida por uma capacidade de ação autorreferente. "Em todo caso", diz,

ela não se volta mais para o céu, mas, sim, para si mesma. Ela não acredita mais nem na vida eterna nem nos amanhãs que cantam. Responsável por ela mesma, descobre que as opções sociais e políticas são antes opções morais, uma certa maneira de compreender a capacidade de criar que nos define agora de forma total (TOURAINE 1988, p. 53).

Neste sentido, Touraine sustenta que

Hoje, como ontem, os homens fazem a sua história, mas agora sabem que a fazem. Sabem também que sua ação não desembocará na mudança, progressiva ou abrupta, do reino da necessidade para o reino da liberdade. Nunca haverá paraíso reencontrado (TOURAINE, 1988, p. 209-210).

Tendo em vista, portanto, a problemática de uma ação política que se instale em uma nova forma de experimentação do tempo histórico, em um presente autocentrado, ${ }^{8}$ Touraine sugere afinar a sensibilidade para a práxis democrática dos novos movimentos sociais que surgem na cena pública. Segundo ele, os

atuais movimentos, 0 das mulheres, nacionalistas, ecologistas, antinucleares, estes vivem no imediato, decididamente no fim do mundo: é agora que é preciso por termo ao poder nuclear; amanhã será muito tarde. Mas esse tempo sem profundidade, que torna a escatologia uma dimensão da vida cotidiana, combina-se a uma ampliação quase infinita do espaço. [...] Os novos movimentos sociais são planetários; seus militantes, nômades e cosmopolitas (TOURAINE 1988, p. 140).

\footnotetext{
7 É interessante notar que Žižek também concebe o fracasso do socialismo justamente como o momento de propor a "hipótese comunista" como alternativa radical ao capitalismo. Para ele, há que se diferenciar "socialismo" de "comunismo". O primeiro seria facilmente reinventado pelo capitalismo sob a forma de comunitarismo, populismo, capitalismo de valores asiáticos ou qualquer configuração que o valha. Enquanto "o capitalismo representa a propriedade privada e o socialismo, a propriedade estatal", afirma Žižek, "o comunismo representa o fim da propriedade como tal nas áreas comuns. "Assim, muito além de ser concebido como a "infame 'fase inferior'" do comunismo, o socialismo, para Žižek, deve ser visto como "seu verdadeiro concorrente, sua maior ameaça. [...] Portanto, o complemento do título de [Antônio] Negri deveria ser: Adeus, sr. Socialismo... e bem-vindo, camarada Comunismo!" (ŽIŽEK 2011, p. 86)

8 É claro que há a iminência de um risco no caso de excesso dessa autorreferência. E ele está relacionado às "tentações da decadência" de um "culto do presente". De acordo com Touraine, "o enclausuramento no presente significa, quase sempre, a recusa de todo projeto coletivo, de toda capacidade de ação política" (TOURAINE 1988, p. 78).
} 
Compreendendo, assim, a irrupção social de um novo momento histórico, no qual as categorias de tempo e espaço são profundamente reconfiguradas, a proposta de Touraine é sepultar o socialismo - o "fantasma que já deixou de convencer e mobilizar" -, e viver neste "novo tempo", agindo de acordo com as novas situações e comportamentos dos movimentos sociais democráticos. É preciso voltar os olhos para o presente, a fim de se desembaraçar do passado e reencontrar novas esperanças para "um futuro que criamos, mas mal começamos a descobrir" (TOURAINE 1988, p. 220). Os combates devem ser acima de tudo pela democracia. "Deixemos os nostálgicos e os ambiciosos à margem", sugere,

é preciso inventar uma nova maneira de vivermos juntos, num planeta tumultuado, no meio dos poderosos e perigosos instrumentos de nosso conhecimento e no bojo dos perigos por que passam as liberdades em qualquer período de crise. Governar, calcular, planificar, sim; mas inicialmente ter suficiente confiança para caminhar de passo com o que muda e acreditar na importância dos novos movimentos sociais para construir uma nova imagem da liberdade e da responsabilidade coletivas, para devolver força, voz e esperança à maioria (TOURAINE 1988, p. 219).

\section{O ainda-não-consciente de Ernst Bloch e o tempo-de-agora de Walter Benjamin: dilatar o presente com "possíveis-reais" - ou "Sobre a função utópica"}

Próxima da noção de "imediatismo" dos movimentos sociais de que fala Touraine, a expressão "novo tempo do mundo" de Paulo Arantes, que vimos utilizando até aqui, busca captar este novo "estado de perpétua emergência" como "um fato consumado de [nossa] época". "Salvo na sua dimensão cronológica trivial", diz Arantes, em "uma sociedade rigorosamente sem futuro, como todas as sociedades securitárias de risco, [...] a urgência se tornou a principal unidade política de medida temporal" (ARANTES 2014, p. 258; p. 337). É neste sentido, portanto, que compreendemos as duas propostas de ação política consideradas aqui sob uma égide histórica e social comum: a despeito de suas flagrantes divergências, ambas falam a partir do estado de emergência do "novo tempo do mundo". E, de acordo com Arantes, nós, que vivemos nesta configuração temporal, "carecemos é de uma antipolítica que saiba decifrar o renascimento paradoxal de expectativas que se abram para outras dimensões temporais" (RODRIGUES 2014, grifos nossos).

Deste ponto de vista, Boaventura de Sousa Santos dá um primeiro passo ao sugerir aquilo que denomina como uma "sociologia das emergências". Tal proposta - uma via que consideramos no limiar das duas concepções de ação política descritas acima, e que, por isso mesmo, corroboramos neste artigo -, "busca uma relação mais equilibrada entre experiência e expectativa, o que nas atuais circunstâncias, implica dilatar o presente e contrair o futuro". Assim, a sociologia das emergências - enquanto "fragmento de uma nova teoria da história que nos permita voltar a pensar a emancipação social" - propõe investigar alternativas que caibam no horizonte de possibilidades concretas. Portanto, não se trata de minimizar as expectativas, mas radicalizá-las no que Ihes há de assente, em capacidades reais no aqui-agora (SANTOS 2006, p. 53). Neste sentido, como 
proposta de ação em um "regime de urgência", ${ }^{9}$ a principal conduta da sociologia das emergências é ainda a do desejo emancipatório. Sua raison d'être deriva de um novo inconformismo, animado pela concepção de que hoje e não amanhã podemos viver em um mundo melhor. "Afinal, [...] se só vivemos o presente, não se compreende que seja tão passageiro" (SANTOS 2006, p. 135).

O conceito que regula a sociologia das emergências é o "ainda-nãoconsciente" - noch-nicht-bewußte - de Ernst Bloch. Por se tratar de uma categoria que exprime a latência de um movimento no processo de sua manifestação e investiga a tendência do "possível-real" que emana do "instante vivido", o "aindanão-consciente" descreve o modo como o futuro irrompe no presente e o dilata, "este futuro [que] é em si nada mais que a expansão do nosso obscuro, nada mais que nossa obscuridade gerando o que é grande, expandindo sua latência"10 (BLOCH 1977, p. 244). Portanto, em vez de referendar um futuro indeterminado e longínquo, o conceito blochiano, inscreve no presente a perspectiva do novum: uma possibilidade incerta, embora jamais neutra. E é esta incerteza não neutra que dá forma à concepção segundo a qual cada momento está repleto de possiblidades, e que, por isso mesmo, é importante não desperdiçar a chance específica de transformação oferecida em cada instante vivido. ${ }^{11}$

Eis aí o que Walter Benjamin descreve como o "tempo-de-agora" - Jetztzeit - em suas teses Sobre o conceito de história. Na medida em que dá forma a um cairológico tempo histórico - um devir perpassado pelo átimo em que a iniciativa humana colhe a oportunidade favorável e decide a própria liberdade -, a fresta aberta pelo "tempo-de-agora" representa o "material explosivo" do instante de ação, com toda a dimensão revolucionária de sua apocatástase. Assim, o conceito benjaminiano coloca-se a serviço da reflexão e da prática no "instante vivido", visto que "na realidade, não há um só instante que não carregue consigo a sua chance revolucionária" (BENJAMIN apud LÖWY 2005, p. 134). E, a partir do momento em que essa "chance revolucionária" é definida como específica, "como chance de uma solução inteiramente nova em face de uma tarefa inteiramente nova", o Jetztzeit de Benjamin revela-se como meio fundamental para o alcance daquilo que Ernst Bloch chamou de "atividade consciente e ciente do ainda-não-consciente".

Chega-se assim ao ponto em que a esperança, esse autêntico afeto expectante no sonho para a frente, não surge mais como uma mera emoção autônoma [atravessada apenas por um sentido de urgência que almeja se desgarrar da condição presente], mas de modo consciente como função utópica (BLOCH 2005, p. 144, grifos no original). ${ }^{12}$

\footnotetext{
${ }^{9}$ O termo é de ZakiLaïdi (LAÏDI 1998; 1999).

10 No original: "ce futur n'est lui-même rien d'autre que l'agrandissement de notre obscur, rien d'autre que notre obscurité engendrant ce dont elle est grosse, agrandissant sa latence." (Tradução livre)

11 Pois uma coisa é certa: se com o "ainda-não-consciente" Bloch pretende tecer um conceito à altura da vontade utópica do "sonhar para a frente" e levar a filosofia até a esperança - "um lugar do mundo tão habitado quanto as terras mais cultivadas e tão inexplorado quanto a Antártida" -, a "vontade última", diz ele, "é a de estar verdadeiramente no presente" (BLOCH 2005, p. 16-17; p. 26). Isto porque, em suas palavras, a "vontade utópica autêntica não é de forma alguma um almejar infinito, ao contrário: ela quer que o meramente imediato e, dessa forma, o conteúdo não possuído do encontrar-se e do estar-aí [Dasein] finalmente mediado, aclarado e preenchido, preenchido de modo adequado à felicidade" (BLOCH 2005, p. 26).

12 Talvez seja neste sentido que, atentando para o postulado benjaminiano segundo o qual "a chance
} 


\section{Conclusão}

No início deste texto, sustentamos que aquele tempo histórico que animava as reflexões de Hegel e de tantos outros modernos parece estar, hoje, em profunda crise. Sob as mais variadas alcunhas, trata-se da chamada "crise do futuro". Momento de euforia para uns e de desalento para outros - já que no "fim da História" há muitas moradas -, talvez a mera permanência no nível dos juízos de valor sobre a presente situação seja ainda insuficiente, não propositiva. Como nas palavras de Benjamin: "A tendência só não basta [...] Certamente, as opiniões têm, apesar de tudo, grande importância, mas a melhor opinião de nada serve se não fizer alguma coisa de útil àqueles que a partilham" (BENJAMIN apud ABENSOUR 1990, p. 151) Sendo assim, em meio à difusão de sentimentos e opiniões em jogo no debate de uma questão tão contemporânea, talvez seja o momento de tomar nota do "estado de espírito" gramsciano e, ao menos, arriscar uma síntese para se alcançar "alguma coisa de útil" do ponto de vista propositivo. "Ser pessimista com a inteligência, mas otimista com a vontade" parece um caminho formidável (GRAMSCI 1987, p. 142-143).

Há pouco mais de vinte anos, num ciclo de conferências a respeito da polêmica tese de Fukuyama, Edgar Morin afirmava que "há na nossa época enormes fermentações possíveis - tanto para o pior quanto para o melhor", e que, mais do que apenas continuar, "a história se encontra diante de novos caminhos, de novas bifurcações". Neste sentido, concordamos com o complemento do sociólogo Jean-Luc Boilleau: "É o tempo difícil de se fazer uma boa escolha" (LEFORT 1994, p. 72; p. 82). Há que se enfrentar a crise do tempo histórico moderno como oportunidade de refletir sobre novas sendas para a ação política. Se é urgente ou não, cabe avaliar. Mas como dizia um velho revolucionário do século passado: "há uma grande desordem sob o céu, a situação é excelente" (ŽIŽEK 2012, p. 13).

\section{Referências bibliográficas}

ABENSOUR, Miguel; ARANTES, Urias (org.). 0 novo espírito utópico. Campinas: Ed. UNICAMP, 1990.

ADORNO, Theodor W.; HORKHEIMER, Max. Dialética do Esclarecimento: fragmentos filosóficos. Rio de Janeiro: Zahar, 1985.

AGAMBEN, Giorgio. Infância e história: destruição da experiência e origem da história. Belo Horizonte: Editora UFMG, 2012.

ARANTES, Paulo Eduardo. O novo tempo do mundo: e outros estudos sobre a era da emergência. São Paulo: Boitempo, 2014.

\footnotetext{
revolucionária própria de cada instante histórico se confirma a partir da situação política", John Holloway lança mão da necessidade de se pensar uma alternativa àquela "nova ordem mundial" de que fala Francis Fukuyama em sua tese sobre o "fim da História" e argumenta que, neste início de século, "há uma nova urgência, uma urgência do próprio tempo [...] as dimensões temporais do pensamento radical e revolucionário mudaram. [...] Não faz mais sentido falar em paciência como uma virtude revolucionária ou falar sobre "revolução futura". Que futuro? Precisamos da revolução agora, aqui e agora. Tão absurdo, tão necessário. Tão óbvio" (HOLLOWAY 2013, p. 8).
} 
BADIOU, Alain. A hipótese comunista. São Paulo: Boitempo, 2012.

BANTIGNY, Ludivine. Historicités du 20e siècle: quelquesjalons sur une notion.

Vingtième siècle - révued'histoire, n. 117, p. 13-25, 2013.

BASCHET, Jérôme. L'histoire face au présent perpétuel: quelques remarques sur la relation passé/futur. In: HARTOG, François; REVEL, Jacques (org.). Les usages politiques du passé. Paris, Ed. de I'EHESS, 2001, p. 59-63.

BAUMAN, Zygmunt. O mal-estar da pós-modernidade. Rio de Janeiro: Zahar, 1998.

Modernidade líquida. Rio de Janeiro: Zahar, 2001.

BENJAMIN, Walter. O anjo da história. Belo Horizonte: Autêntica, 2013.

BLOCH, Ernst. L'esprit de I'utopie. Paris: Éditions Gallimard, 1977.

. O princípio esperança. Rio de Janeiro: UERJ; Contraponto, 2005. v.1.

CAMUS, Albert. O Estrangeiro. Rio de Janeiro: Record, 2013.

FUKUYAMA, Francis. The End of History? The National Interest, n. 16, p. 3-18, 1989.

GUMBRECHT, Hans Ultich. Graciosidade e estagnação: ensaios escolhidos. Rio de Janeiro: Contraponto: Ed. PUC-Rio, 2012.

GRAMSCI, Antonio. Cartas do cárcere. Rio de Janeiro: Civilização Brasileira, 1987.

HARTOG, François. Regimes de historicidade: presentismo e experência do tempo. Belo Horizonte: Autêntica Editora, 2013.

HARVEY, David. Os limites do capital. São Paulo: Boitempo, 2013.

HOLLANDA, Heloisa Buarque de (org.). Pós-modernismo e política. Rio de Janeiro: Rocco, 1992.

HOLLOWAY, John. Fissurar o capitalismo. São Paulo, Publisher, 2013.

JAMESON, Fredric. Pós-modernismo: a lógica cultural do capitalismo tardio.

São Paulo: Editora Ática, 1996.

KOJÈVE, Alexandre. Introdução à leitura de Hegel. Rio de Janeiro: Contraponto, 2002.

KOSELLECK, Reinhart. Futuro Passado: contribuição à semântica dos tempos históricos. Rio de Janeiro: Contraponto; Ed. PUC-Rio, 2006.

LEFORT, Bernard (org.). Sobre o fim da história. Rio de Janeiro: Vozes, 1994.

LAÏDI, Zaki. L'urgence ou la dévalorisation culturelle de l'avenir. Esprit, n. 240, fév., pp. 8-20, 1998.

. La tyrannie de I'urgence. Montreal: Fides, 1999.

LÖWY, Michael. Walter Benjamin: aviso de incêndio: uma leitura das teses

"Sobre o conceito de história". São Paulo: Boitempo, 2005. 
MARQUES, Danilo; SOUZA, Débora Cazelato; RODRIGUES, Deise Simões. Entrevista com o Prof. Dr. François Hartog. Temporalidades, v. 5, n. 2, p. 10-15, 2013.

. Do fim ao futuro da História: uma análise acerca do percurso da teoria de Francis Fukuyama, de 1989 a 2012. Revista Historiador, ano 6, n. 6, p. 93-108, 2014.

MÉSZAROS, István. Para além do capital. São Paulo: Boitempo, 2002.

PAZ, Octavio. La busqueda del presente. Revista de Literatura Hispânica, v. 1, n. 32, p. 3-12, 1990.

POMIAN, Krzystof. Sur I'histoire. Paris: ÉditionsGallimard, 1999.

REIS, José Carlos. Teoria \& História: tempo histórico, história do pensamento histórico ocidental e pensamento brasileiro. Rio de Janeiro: FGV, 2012.

RODRIGUES, Carla. No tempo das emergências - uma entrevista com Paulo Arantes. Jornal Valor Econômico, caderno "Eu \& fim de semana", 9 de abril de 2014. Disponível em: http://blogdaboitempo.com.br/2014/05/11/ no-tempo-das-emergencias-uma-entrevista-com-paulo-arantes/. Acesso em: 15 nov. 2015.

SANTOS, Boaventura de Sousa. A gramática do tempo: para uma nova cultura política. São Paulo: Cortez, 2006.

TAGUIEFF, Pierre-André. L'Effacement de I'avenir. Paris: Galilée, 2000.

TOURAINE, Alain. O pós-socialismo. São Paulo: Editora Brasiliense, 1988.

VALÉRY, Paul. Variedades. São Paulo: Iluminuras, 1991.

ŽIŽEK, Slavoj. Bem-vindo ao deserto do real: cinco ensaios sobre o 11 de setembro e datas relacionadas. São Paulo: Boitempo, 2003.

. Vivendo no fim dos tempos. São Paulo: Boitempo, 2012.

. Em defesa das causas perdidas. São Paulo: Boitempo, 2011.

Primeiro como tragédia, depois como farsa. São Paulo: Boitempo, 2011a.

Menos que nada: Hegel e a sombra do materialismo dialético. São Paulo: Boitempo. 2013.

Problema no paraíso: do fim da história ao fim do capitalismo. Rio de Janeiro: Zahar, 2015. 


\title{
"Na mais ilustre de todas as cidades, tão miserável tipografia": antiquariato, imprensa e epigrafia a partir de André de Resende (c. 1500-1573)
}

\author{
"In the most illustrious of all cities, so miserable a press": antiquarianism, \\ printing and epigraphy in André de Resende (c. 1500-1573)
}

\author{
Pedro Telles da Silveira \\ doca.silveira@gmail.com \\ Doutorando em História \\ Universidade Federal do Rio Grande do Sul \\ Rua General Vitorino, 72, apto. 93 - Centro \\ 90020-170 - Porto Alegre - Rio Grande do Sul \\ Brasil
}

\section{Resumo}

Este estudo procura compreender a relação entre a prática antiquária na Idade Moderna e a introdução da imprensa através do trabalho do humanista português André de Resende. Partindo tanto da história do livro quanto da história da historiografia, busca-se entender como a permanência dos manuscritos, as dificuldades técnicas relacionadas à impressão e as limitações dos próprios antiquários faziam um conjunto de circunstâncias técnicas se tornarem problemas teóricos. Procura-se, então, problematizar a distinção proposta pelo historiador italiano Arnaldo Momigliano entre fontes "literárias" e "não-literárias" através de uma atenção mais detalhada aos procedimentos de estudo e comunicação dos antiquários modernos.

\section{Palavras-chave}

Antiquariato; Imprensa; História da Historiografia.

\begin{abstract}
This article seeks to understand the relationship between antiquarian practice in Early Modern Europe and the introduction of printing technologies based on the work of the Portuguese humanist André de Resende. Drawing upon both the history of the book and the history of historiography, the article discusses how the permanence of handwritten texts, the technical difficulties related to the printing process and the limitations of the antiquarians themselves turned a set of technical circumstances into theoretical problems. Therefore, the distinction between "literary" and "non-literary" historical sources proposed by the Italian historian Arnaldo Momigliano is questioned through a detailed observation of the study and communicational procedures devised by modern antiquarians.
\end{abstract}

Keywords

Antiquarianism; Print; History of Historiography. 
De retorno a Portugal após um périplo que Ihe fez passar por Salamanca, Aix-en-Provence, Paris, Lovaina, Bolonha e Roma, o viajado homem de letras português André de Resende (c. 1500-1573) foi convidado para, no dia primeiro de outubro de 1534, proferir a oração de abertura do ano acadêmico da então Universidade de Lisboa. De claro pendor humanista, o erudito exorta seu auditório, em determinado momento, para aprender as letras gregas (RESENDE 1956 [1534], p. 39-41); ao cabo da oração, ele faz uma breve digressão sobre a etimologia do nome Lisboa, no qual o $n$ dobrado grego e o I desempenha um papel fundamental no asseverar se a cabeça do reino lusitano tem de fato Ulisses como seu fundador (RESENDE 1956 [1534], p. 57). Esta atenção às minúcias dos caracteres gregos - decisiva para um sólido julgamento filológico - representaria apenas o interesse erudito de Resende, caso o antiquário, na dedicatória que faz do volume ao monarca d. João III, não afirmasse também:

A instâncias de amigos e de uma boa parte de escolares, mandei de mau grado imprimir a oração de sapiência que há pouco fiz e pronunciei na Universidade de Lisboa, entre muitas outras razões, mormente porque a custo encontraria caracteres tipográficos adequados para esta matéria,

e, logo depois,

Entendi que devia mostrá-la a Vossa mui Augusta Majestade, não porque esteja persuadido de que a obra é digna de tal honra, mas porque eu, vosso protegido, e quantos professam as letras, temos esta obrigação perante Vós, que sois o maior professor das letras e seus cultores. $E$ também diga-se de passagem, para que, depois de verdes, na mais ilustre de todas as cidades, tão miserável tipografia, Vos apresseis a darnos a que tínheis resolvido, quando neste assunto Vos falamos (RESENDE 1956 [1534], p. 31; grifo meu).

"Na mais ilustre de todas as cidades, tão miserável tipografia". A dedicatória não deixa de ser também uma espécie de recriminação ao rei e um pedido a ele, que descuidou de sua função de patrono das letras. A trajetória desta reclamação, entretanto, não termina aí. O comentador moderno da obra confirma "o péssimo apetrechamento tipográfico" português da época, salientando que, em alguns exemplares da obra, aqueles caracteres gregos mencionados acima simplesmente não existem, tendo sido deixados em branco. Noutro exemplar, por sua vez, o próprio André de Resende teve de preencher estas lacunas à mão, desenhando os caracteres que faltavam (RESENDE 1956 [1534], p. 65, nota 2).

A passagem revela, portanto, que aos homens de letras que viviam em Portugal no começo do século XVI, a imprensa e a tipografia eram questões sensíveis para o avanço de suas iniciativas. Em obras dependentes de detalhes tão minuciosos, onde a ausência - por erro mecânico ou humano - de algum caractere, uma ilustração pouco fiel às intenções de seu autor ou uma edição malcuidada poderiam jogar em risco a credibilidade duramente construída de seu autor, como garantir a fidelidade na passagem dos manuscritos às obras impressas? No caso dos antiquários, a questão se tornava ainda mais premente, uma vez que a imprensa era utilizada para publicar e, por conseguinte, preservar anotações 
fugazes de objetos que, muitas vezes, estavam em vias de desaparecimento. Ao mesmo tempo, muitos eruditos se valiam dos novos recursos para efeitos que iam além da mera reprodução fidedigna de inscrições, monumentos e outras evidências materiais existentes, inserindo suas atividades nos domínios da falsificação e da invenção. Por fim, a própria desconfiança de muitos antiquários com relação à imprensa, para os quais ela era tanto um meio de difusão do conhecimento quanto um veículo para sua distorção, criava um campo de usos e possibilidades em tudo ambíguo no que toca às relações entre a erudição e as novas tecnologias da época. Em todas estas alternativas, os antiquários e eruditos do século XVI, em Portugal ou em outros lugares da Europa, estavam atentos aos aspectos técnicos envolvidos tanto na produção quanto na reprodução do passado que, muitas vezes literalmente, desenterravam.

Este trabalho tem por objetivo estudar o cruzamento entre a prática antiquária no século XVI e as preocupações com a imprensa, nesta mesma época, a partir do trabalho de André de Resende. Um primeiro momento deste estudo será dedicado ao entendimento da introdução da imprensa em Portugal e na Europa, as reações a ela por parte dos eruditos e, em especial, ao exame do tratamento de um tipo específico de evidência, o livro. Num segundo momento, nos voltaremos ao estudo da epigrafia por parte de Resende e outros antiquários da época, de modo a compreender a operação que ia da observação à anotação e da anotação à publicação. O olho, o manuscrito e o livro impresso, nesse sentido, participavam de um conjunto de procedimentos que, em suas constantes tensões, revela aspectos importantes do fazer antiquário quinhentista. O que unifica estas duas seções dedicadas a objetos bastante diferentes - o livro e as inscrições epigráficas - é a indagação a respeito do estatuto das fontes utilizadas pelo antiquário. Por isso, uma seção preliminar tem de ser dedicada ao trabalho do historiador italiano Arnaldo Momigliano.

\section{A natureza das fontes antiquárias}

Não é exagero afirmar que o moderno estudo do antiquariato começa com o artigo de Arnaldo Momigliano intitulado "Ancient History and the Antiquarian", publicado nas páginas do Journal of the Warburg and Courtauld Institutes em 1950. Trata-se, conforme Ingo Herklotz, de um texto que "ainda goza da esplêndida reputação não apenas de ter feito uma contribuição inovadora em seu próprio tempo mas também de permanecer fundamental para o estudo do antiquariato até o presente" (HERKLOTZ 2007, p. 127). As circunstâncias biográficas em torno à escrita deste artigo, o enraizamento de seu autor numa instituição privilegiada, o Warburg Institute, e a própria erudição do autor, aliada ao estilo de sua escrita (MILLER 2007, p. 6-7), levaram o artigo a ser lido como "a história do antiquariato cuja ausência o próprio Momigliano havia lamentado" (MILLER 2007, p. 12). E, apesar de textos críticos recentes (PHILLIPS 1996; WOMERSLEY 2006; HERKLOTZ 2007), ele não deixa de ainda caracterizar os termos do debate, inclusive desta presente contribuição.

Segundo Arnaldo Momigliano, o antiquário teria desempenhado importante papel na elaboração do moderno método histórico baseado na distinção entre 
fontes primárias e secundárias, ou em suas palavras, "autoridades originais e derivadas" (MOMIGLIANO 2014, p. 21). Para isso, o autor diferencia o historiador do antiquário a partir de uma série de oposições. Enquanto os historiadores escrevem em ordem cronológica buscando uma narrativa de viés moral, o antiquário se entrega à descrição sistemática e sincrônica do passado (MOMIGLIANO 2014, p. 22); enquanto os historiadores lidam com "fatos que servem para ilustrar ou explicar uma situação", os antiquários "coletam todos os itens que estão conectados a um determinado assunto seja para resolver um problema ou não" (MOMIGLIANO 2014, p. 22); por último, enquanto os historiadores se valem sobretudo de narrativas elaboradas por outros historiadores, utilizando-se de fontes "literárias", os antiquários se dedicam ao estudo de evidências materiais e de arquivo com as quais podem oferecer outra imagem do passado (MOMIGLIANO 2014, p. 22).

Para o historiador italiano, o conjunto de procedimentos que os antiquários desenvolveram a fim de tornar possível analisar este conjunto diversificado de fontes foi apropriado pelos historiadores na passagem do século XVII para o XVIII, quando uma série de ataques céticos vindos das fileiras do pirronismo buscavam colocar em xeque não apenas a utilidade mas a própria possibilidade do conhecimento histórico (MOMIGLIANO 2014, p. 30-31). O antiquário sai de cena, portanto, dotando o historiador de ferramentas capazes de tornar seu saber mais confiável: o método histórico.

O arco argumentativo proposto por Arnaldo Momigliano insere-se numa tentativa de compreender a relação entre a historiografia produzida na Idade Moderna e seus desdobramentos disciplinares a partir do século XIX, daí a importância dada ao método na apreciação do trabalho de antiquários, filólogos e eruditos. Essa não deixa de ser uma argumentação marcada por idiossincrasias e escolhas muito pessoais (MILLER 2007, p. 4; 27). Procura-se aqui contribuir com a discussão de algumas delas.

Dentre todas as oposições elencadas por Momigliano, a principal parece ser aquela entre fontes literárias e não-literárias. Ainda que um dos primeiros antiquários modernos, o italiano Flavio Biondo (1392-1463), tenha combinado "evidências literárias, arqueológicas e epigráficas, preferindo os textos literários e epigráficos" (MOMIGLIANO 2014, p. 25), a ênfase do autor na atividade dos eruditos dos séculos XVII e XVIII acaba por distorcer a relação entre estes variados tipos de fontes históricas (HERKLOTZ 2007, p. 136-137; 141). Nestes séculos, caracterizados pelo ceticismo, de acordo com Momigliano, "Assumiase que documentos e outras declarações públicas, moedas, inscrições e monumentos eram evidências mais qualificados que as fontes literárias" (MOMIGLIANO 2014, p. 32), diferenciando-se entre os textos recebidos pela tradição e aquelas "outras evidências tais como diplomas, inscrições, moedas e estátuas" (MOMIGLIANO 2014, p. 32). Os testemunhos materiais, portanto, possuiriam maior legitimidade que a palavra dos historiadores passados.

A caracterização das fontes "literárias" como o conjunto da tradição textual recebida, em oposição à categorização detalhada das espécies de evidências materiais, denuncia certa ausência de uma reflexão acerca da linguagem no 
entendimento das fontes históricas. Este problema é apenas tangenciado por Momigliano. Segundo o autor, houve, no decorrer destes séculos, dois padrões de sucesso, pois

Quando traçamos um panorama dos feitos dos antiquários em formular as regras da interpretação adequada da evidência não literária, precisamos fazer uma clara distinção. O sucesso foi completo no que toca ao estabelecimento de regras seguras para o uso de diplomas, inscrições e medalhas, tanto no campo da autenticação quanto no da interpretação (MOMIGLIANO 2014, p. 39).

Por outro lado, "Vasos, estátuas, relevos e pedras falavam uma língua muito mais difícil" (MOMIGLIANO 2014, p. 40). Em outras palavras, onde existia a possibilidade de uma via de acesso por meio do texto e da leitura, o conhecimento era possível; onde as evidências não possuíam uma referência textual, o conhecimento antiquário encontrava seu limite (VINE 2010, p. 135). Isso mostra que a importância das categorias de fontes "literárias" e "nãoliterárias", assim como a própria diferenciação entre elas, era muito mais fluida do que Momigliano parece admitir.

Para além destas considerações teóricas mais amplas acerca do papel da linguagem na avaliação das fontes antiquárias e na criação das próprias categorias de Momigliano, é interessante compreender os argumentos levantados por Ingo Herklotz em sua "resenha crítica" ao texto aqui trabalhado. Estes argumentos nos encaminham para os problemas técnicos que influenciavam as perspectivas teóricas dos antiquários modernos.

De acordo com Herklotz, a distinção entre fontes literárias e não-literárias não pode ser tomada como absoluta enquanto um dos critérios que definem, de um lado, o antiquário e, de outro, o historiador, porque "o apelo do antiquário por evidências não-literárias nunca foi um apelo por objetos materiais ao invés de, mas mais apropriadamente, em adição a fontes literárias" (HERKLOTZ 2007 , p. 137). O antiquário estudava a cultura material não porque as fontes escritas não eram confiáveis, mas sim porque elas não eram suficientes quando se tratava de propor uma imagem completa da antiguidade. Em segundo lugar, lembra o autor, havia uma série de considerações logísticas que guiavam o trabalho antiquário. Um estudioso na Alemanha, por exemplo, que decidisse estudar as antiguidades romanas necessariamente teria de fazê-lo - com exceção da escassa oferta de ruínas presentes em seu entorno - a partir de evidências de segunda mão (HERKLOTZ 2007, p. 137). Pode-se dizer que, ao articular esta distinção como um princípio metodológico e não como uma circunstância prática de pesquisa, Momigliano acaba por deixar de lado outros mecanismos da prática antiquária que também dependiam da visão, ainda que fosse de modo vicário e não direto: a correspondência, através da qual os antiquários podiam trocar descrições de ruínas, objetos e o conteúdo de documentos antigos (VINE 2010, p. 82-83; MILLER 2005); a circulação de livros e imagens tanto manuscritos quanto impressos que reproduziam estas mesmas evidências. Por último, a argumentação do historiador italiano pode acabar forçando a desviar a atenção 
de um conjunto de objetos que encontra um estatuto ambíguo nesta divisão, tais como os livros.

Esta avaliação do trabalho de Arnaldo Momigliano não tem por objetivo questionar o modelo proposto pelo autor, mas sim refletir a seu respeito para torná-lo produtivo a outras espécies de análise. Em aspectos gerais, ela aponta, através da reflexão acerca da diferença entre fontes literárias e não-literárias, para alguns dos aspectos que serão analisados nas páginas seguintes: o estatuto de evidências que não se enquadram facilmente em nenhuma das categorias acima; o papel retórico dos dispositivos textuais dedicados a gerar credibilidade dos trabalhos antiquários; a possibilidade de estudar fontes antiquárias sem o apoio de evidências textuais, o que levanta a dúvida a respeito de se os antiquários estavam realmente interessados - ou eram capacitados - em estudar estas evidências por sua materialidade ou se eles não as viam apenas como suportes para textos recém-descobertos. Nas páginas a seguir, traçaremos o caminho de André de Resende nestas idas e vindas entre a textualidade e a matéria.

\section{Livros, antiquários e tipógrafos}

Não é preciso muito esforço para compreender que a Renascença se inaugura com uma valorização do livro (PETTEGREE 2010, p. 10). A atividade de procura de manuscritos empreendida entre os séculos XIV e XVI proporcionou a recuperação de uma parcela significativa do legado clássico, ampliado o

60 conjunto de textos antigos disponíveis aos homens do Renascimento em comparação com o período imediatamente anterior. Petrarca, em 1333, descobriu o Pro Archia, de Cícero, e, em 1345, as cartas a Ático, do mesmo autor; em 1392, sob inspiração do chanceler florentino Coluccio Salutati, foram encontradas as epístolas ad familiares, também de Cícero; em 1416, Poggio Bracciolini descobriu o texto completo das Instituições Oratórias, de Quintiliano; cinco anos depois, o bispo Gerardo Landriani encontrou o manuscrito de cinco tratados ciceronianos, incluindo o texto completo do De Oratore (GRENDLER 1989, p. 120-121). Estes textos, novamente disponíveis para o público letrado, imediatamente se tornavam modelos de escrita e cultura para os então nascentes studia humanitatis.

Esse cenário não se modificou, apenas se intensificou, com a introdução da imprensa, embora o novo meio tenha sido recebido tanto com admiração quanto desconfiança. Nesse sentido, não teria sido necessariamente a invenção da imprensa que impulsionou o conjunto de transformações que associamos com o Renascimento e/ou a Idade Moderna, como sugere a conhecida tese de Elisabeth Eisenstein (1998), mas sim "as novas formas de educação e as mudanças na natureza dos governos", além da ativa promoção do estudo, sobretudo entre as elites, dos textos clássicos, que "criaram o novo público leitor laico da Renascença" (GRAFTON 1980, p. 274-275).

A vida de André de Resende se desenrolou sobre esse pano de fundo. Nascido por volta de 1500 em Évora, onde inicia sua educação com o gramático Estevão Cavaleiro, autor de obras pedagógicas humanistas, ele estuda entre 
1513 e 1521, com intervalos, em duas prestigiosas instituições universitárias espanholas, a recém-criada universidade de Alcalá de Henares e a tradicional universidade de Salamanca (MATOS 2000, p. XVIII-XIX). Entre outros motivos, a estada castelhana de André de Resende é importante por causa de dois acontecimentos editoriais. Primeiro, a produção da Bíblia Poligota, iniciativa do inquisidor-mor da Espanha, Jímenez de Cisneros, e que apresentaria o texto da Escritura em suas versões latina, grega e hebraica; o segundo foi a introdução, em 1516, das obras de Erasmo no reino castelhano, onde ele gozaria de grande favor até o final da década seguinte. Um dos canais de sua entrada na Espanha foi a Universidade de Alcalá, a mesma onde a Bíblia estava sendo editada, em especial pela atuação de seu chefe de impressões, Miguel de Eguía. Entre 1516 e 1524, trinta edições de obras de Erasmo seriam publicadas na Espanha, das quais 24 saíram de Alcalá (MOREIRA DE SÁ 1977, p. 7; BATAILLON 1966, p. 279-315; COROLEU 2008, p. 83-84).

É um pouco por influência do humanista neerlandês que Resende empreende sua viagem pela Europa. Primeiro se direcionando para a França, onde recebe as honras de subdiácono da ordem dominicana (MATOS 2000, p. XXIX), ele segue para os Países Baixos, onde se inscreve no Collegium Trilingue, de inspiração erasmiana, em 1529 (MATOS 2000, p. XXXIV). Na cidade belga, ele se corresponde com Erasmo, a quem envia um poema encomiástico, o qual foi encaminhado para publicação - sem que o soubesse - por este, tendo saído do prelo, também pela oficina de Frobenius, em 1530. Logo em seguida, Resende entra para o serviço de D. Fernando de Mascarenhas, embaixador português na corte de Carlos V, onde atua como professor de latim. Sob a tutela de Mascarenhas, Resende tem a oportunidade de viajar pelo Leste europeu e pela Itália, onde passa por Bolonha e Roma, antes de ser chamado novamente ao Reino lusitano.

O "péssimo apetrechamento tipográfico português", no dizer do comentador Artur Moreira de Sá, quando do retorno de André de Resende, se explica por motivos que não são atribuídos necessariamente ao suposto "atraso" luso com relação ao restante da Europa. A pequena população do Reino português e, por conseguinte, o reduzido público leitor, que não compensaria os gastos com a cara atividade de impressão, assim como o fato de que a grande maioria dos membros da corte portuguesa eram, ao menos, bilíngües, sendo versados em castelhano, quando não conheciam também o latim, língua literária por excelência da época, e a proximidade com a Espanha, por onde muitos dos livros entravam, são causas da timidez inicial dos esforços tipográficos lusitanos (MUSSER 2012, p. 115). Além disso, seria apenas por um curto período de tempo que o Reino lusitano, sob o reinado de D. João III, procuraria promover o português como linguagem científica europeia e, logo, sua imprensa própria, em especial através dos trabalhos do cosmógrafo Pedro Nunes (TARRío 2002, p. 82).

Em Portugal, as primeiras atividades tipográficas locais estiveram ligadas à impressão de obras litúrgicas judaicas no final da década de 1480; com a expulsão dos judeus em 1496, porém, esta incipiente atividade, a qual produzira obras de grande qualidade, fora encerrada (ANSELMO 1981, p. 26-27; MUSSER 2012, 
p. 113-114). Concomitante a esta atuação da comunidade judaica, em 1489 foi impresso o primeiro incunábulo latino em Portugal (MUSSER 2012, p. 114). Em Évora, cidade natal de André de Resende, a primeira oficina tipográfica a se instalar o fez somente em 1526 (MATOS 2000, p. XXVI). Entre as primeiras obras impressas portuguesas e a introdução da tipografia em Évora, entretanto, deve-se destacar a entrada dos impressores estrangeiros em Portugal, como o alemão Valentim Fernandes e o francês Germão Galharde (ANSELMO 1981; MUSSER 2012, p. 119120). Estes impressores e a circulação de livros através das fronteiras portuguesas garantem a ligação entre as correntes intelectuais europeias, principalmente aquelas relacionadas ao humanismo, e os desdobramentos mais específicos da atividade lusitana da época, como as navegações (LOPES 2012). Expansão do Império e expansão das letras, nesse sentido, eram também mediadas pela imprensa.

O trabalho dos homens de letras, no geral, acompanhou, como um de seus primeiros beneficiários e agentes, a introdução da imprensa. Muitos dos primeiros impressores eram humanistas e as primeiras iniciativas de fôlego no novo meio, muitas vezes, foram levadas a cabo por eruditos (PETTEGREE 2010, p. 70-71). O relacionamento entre humanistas e impressores, todavia, não era sempre tão harmonioso e, mais de um século após a introdução da imprensa, essas tensões alcançavam a relação entre o interesse mercadológico dos editores, as necessidades de defesa e afirmação dos Estados modernos e os diferentes graus com que a cortesania erudita era respeitada de local a local. Algumas passagens de André de Resende são ilustrativas desta situação.

Em carta escrita e publicada em 1567 endereçada ao erudito castelhano Bartolomeu de Quevedo, André de Resende critica seu colega toledano por se valer de textos clássicos que, embora pouco confiáveis, ganham repercussão pelo ar de novidade que trazem ao introduzir modificações que outras edições ou manuscritos não possuem:

Mas vieram agora a lume, segundo dizes, uns escólios a Ptolomeu que trazem alguns topônimos alterados, outros com esclarecimentos, e onde se lê: "Libora, outrora Élvora, hoje Talábriga, vulgo Talavera". Para que hás-de acreditar em escoliastas como esses que, baseados em informação de ignorantes e sem qualquer exame do local, e para agradarem aos tipógrafos (para que o livro se venda melhor), assim nos enganam? (RESENDE 1988 [1567], p. 101-103).

Escoliastas ávidos por reconhecimento e tipógrafos sedentos por rendas geravam sombras sobre a empresa erudita, e a passagem revela que as edições modernas de textos clássicos e outros trabalhos não necessariamente eram mais confiáveis que outras versões anteriores, que podiam circular manuscritas ou que, ao menos, receberam o devido cuidado quando foram enviadas à oficina de impressão. André de Resende faz eco, portanto, ao princípio de que o manuscrito, ao possuir uma difusão mais controlada, era mais veraz e fidedigno que a obra impressa (BOUZA 2001, p. 59; WOOD 1998, p. 87-88).

Estes casos também afetavam a rede de confiança por trás do empréstimo mútuo de manuscritos e outras obras efetuado não apenas pelos cortesãos mas 
sobretudo pelos letrados (BOUZA 2001, p. 48-49). Resende, na mesma carta a Quevedo, reporta ter sido alvo de um desses ataques:

Há já muito tempo que anseio por ler Juliano Pomério. Tanto mais que o vosso santo bispo Juliano, discípulo de Eugênio II, sucessor de Quirico, manifestou por ele grande admiração nos livros Dos prognósticos dos tempos vindouros, que compôs para Idálio de Barcelona. Estes livros, que me foram furtados há mais de vinte anos apor um hóspede parisiense, vim a recebê-los, um dia, impressos, mas sem terem sido devidamente expurgados dos erros que pululavam por todo o lado.

E a passagem seguinte demonstra que se trata - provavelmente - de casos recorrentes:

Vi um dia, na Alemanha, um opúsculo com os seus poemas, mas estavam em poder de um indivíduo que nem sequer por um dia mos quis emprestar (RESENDE 1988 [1567], p. 155).

Estas passagens confirmam que, apesar de algumas relações entre autor e impressor terem se tornado emblemáticas na época, como a que se desenvolveu entre Aldo Manuzio e o círculo europeu de letrados que se reunia em seu entorno em Veneza, ou aquela entre Erasmo e Frobenius na Basileia entre as décadas de 1510 e 1530, estas relações "pouco têm a ver com as oficinas de impressão que a maior parte dos cidadãos da República das Letras conhecia melhor" (GRAFTON 1980, p. 275). Nestes ambientes, não apenas os tipógrafos podiam agir de má-fé, visando apenas os lucros, como também os humanistas. Imersos em carreiras altamente competitivas, podiam utilizar a possibilidade de ampla circulação de ideias ocasionada pela imprensa para defender suas reputações atacando a de seus colegas, ou falsear livros e documentos para interesse próprio ou dos senhores aos quais estavam empregados, quando não eram apenas descuidados no manejo das provas ou queriam ver suas obras impressas o mais rapidamente possível, reproduzindo erros que se tornavam canônicos. Nestas circunstâncias, "não é surpreendente que muitos eruditos sentissem que a associação com o comércio tinha arruinado o que poderia ter sido a arte liberal da impressão" (GRAFTON 1980, p. 278).

Os casos relatados por Resende também indicam que muitas abordagens recentes da história da recuperação e da difusão do legado clássico, assim como dos comentários modernos à sua volta, acabam por subsumir os textos ao seu conteúdo, esquecendo que "o livro", nas cidades e cortes europeias, "não era apenas uma fonte de informação ou um repositório de conhecimento, mas um artefato apreciado e valorizado" (PETTEGREE 2010, p. 20; cf. também BOUZA 2001, p. 53). Justamente o valor associado ao livro enquanto objeto físico muitas vezes único fazia a cortesania letrada encontrar no empréstimo de manuscritos um de seus pontos de tensão.

Duas passagens da obra do humanista eborense, ainda em momentos avançados do século XVI, ajudam a ilustrar o valor associado ao livro. Na primeira, a abertura de seu diálogo publicado postumamente, o Aegidius Scallabitanus, 
cujo fio condutor é a vida do santo português frei Gil de Santarém, Resende retrata a si mesmo com um precioso "tesouro" em mãos:

[...] depois de regressar à minha cidade e de me instalar em casa, estava eu certo dia sentado no meu pórtico, por volta do meio-dia, a confrontar o dito livro [uma hagiografia do referido santo que o antiquário decide reescrever em melhor estilo] com a minha nova história, eis senão quando chega o médico Luís Pires, pessoa que, pela exuberância de sua erudição e pela afabilidade do seu trato, considero meu amigo e um indivíduo encantador. Começou por congratular-me com o meu regresso e depois, ao ver um livro velhíssimo, escrito em pergaminho e meio roído das traças, exclamou:

- Continuas igualzinho a ti mesmo, Resende! Ora diz-me lá: a que antro foste tu desenterrar tão vetusto achado?

- Ao dos frades, Pires - respondi.

- Algum tesouro deve ser, assim o espero - acrescentou ele. Porque os teus achados são sempre, é o teu costume, do mais requintado que há.

- Bem Ihe podes chamar tesouro. Mas se estás à espera de algum requinte, então ouve (RESENDE 2000, p. 294, grifos meus).

Já em seu opus magnus, as Antiguidades da Lusitânia, publicadas também postumamente, no ano de 1593, o antiquário português descreve a cena de estudo de um manuscrito antigo de Plínio, o Velho:

Há cerca de quarenta anos, quando eu estava a estudar em Salamanca, discuti muito com Fernando Pinciano, professor público de Grego e de Plínio, por causa do seguinte: mostrou-me um códice muito antigo com o texto de Plínio, que conseguira fazer vir, depois de dadas garantias, da Sé de Toledo para fazer a sua colação, e um outro não tão antigo, mas escrito com grande exatidão, da biblioteca da Universidade de Salamanca. Costumava abri-los diariamente, a hora certa, sob vigilância de dois guardas. Verificamos em ambos o que ele já demonstrara numa lição: que o copista, por descuido, tinha saltado, como logo me apercebi, cerca de dez ou doze linhas, que Plínio escrevera sobre o cabo Finisterra para o passo em que descreve o cabo da Roca, do que resulta grande confusão e mesmo uma deturpação do próprio Plínio (RESENDE 1996 [1593], p. 75, grifos meus).

Em ambos os casos, o valor associado ao livro é dado tanto por seu conteúdo quanto por sua situação material: no primeiro caso, o conteúdo, embora altamente informativo, é de menor valor dado seu estilo rude, mas o que Ihe garante o estatuto de "achado" é a sua antiguidade; na segunda situação, as diferentes versões de um mesmo texto, criadas com um grande intervalo de tempo entre si, transformam os manuscritos em instrumentos de trabalho. A segunda passagem também revela o cuidado associado com o transporte, o empréstimo e o manuseio de manuscritos entre uma instituição - a Sé de Toledo - e outra, a Universidade de Salamanca.

Um segundo aspecto que se abre a ser estudado a partir desta última passagem é a própria variação entre um manuscrito contendo os textos clássicos e outro, os quais estavam longe de possuir versões integralmente estabilizadas. Como já vimos, era através da atenção às minúcias que o trabalho de erudição era feito. As Antiguidades da Lusitânia, novamente, possuem certo número de 
passagens que ilustram este problema. Ao discorrer a respeito de se os vetões e os vectões são ou não o mesmo povo, Resende lamenta não poder ter apreciado "este passo de Políbio [...] além dos cinco livros escritos em Grego e vertidos para Latim por Nicolau Perotto, arcebispo de Macedônia, nenhuma outra edição atual me foi dado encontrar" (RESENDE 1996 [1593], p. 83; grifo meu). Logo depois, ele deixa sua conclusão em suspenso, pois "embora seja bem evidente pelo diverso testemunho dos autores e pela diferença de grafia de uma só letra", ele não pode consultar "Estrabão, em cujos códices, que parecem brincar estranhamente com este nome, não sei se por culpa dele ou dos copistas, ora são Ovetões, depois Vuetões e logo Oveciões" (RESENDE 1996 [1593], p. 85; grifo meu). Manuscritos corrompidos e edições defeituosas dificultavam o trabalho do antiquário, de modo que a tarefa da erudição era não apenas purificar o latim escrito em seu século (RESENDE 1996 [1593], p. 57) mas também corrigir os textos então em circulação:

Compreendemos assim claramente que não estariam muito distantes [os pesuros, outro povo limítrofe aos lusos na Antiguidade] daquele lugar e ao mesmo tempo que o seu nome devia ser emendado, passando da segunda para a terceira declinação nos manuscritos de Plínio (RESENDE 1996 [1593], p. 91, grifo meu).

Os textos clássicos - as fontes literárias - não eram unívocos e podiam ser modificados pelo influxo da argumentação do próprio erudito, através da comparação com outros manuscritos ou com outras espécies de evidência, mormente as epigráficas. Na verdade, eles pouco eram textos mas sim edições, volumes, códices e manuscritos, ou seja, objetos variáveis que apontavam tanto para si mesmos quanto para o conteúdo que continham. As passagens acima também mostram que o antiquário se aproximava de suas fontes atuando como um filólogo (HERKLOTZ 2007, p. 131-132), procedendo por cotejamento com vistas à emenda dos textos antigos. Seu procedimento de trabalho, portanto, tinha maior sucesso quando havia exemplares entre os quais comparar. Nas situações onde os exemplares não existiam ou estavam indisponíveis, como na primeira hagiografia de frei Gil ou nas edições defeituosas citadas por Resende, os antiquários ou tinham de deixar suas questões em aberto ou recorrer à conjectura para conseguir estudar os textos. Estes problemas, logo veremos, se tornavam mais agudos no caso das inscrições epigráficas.

Estes exemplos mostram que a distinção entre fontes literárias e nãoliterárias não era tanto um princípio metodológico quanto uma circunstância da pesquisa (HERKLOTZ 2007, p. 136-137). Quando estavam disponíveis exemplares diferentes de um mesmo texto, diferenças materiais entre uma versão e outra eram ressaltadas. Isso também indicava o efeito de uniformização causado pela imprensa, cujas edições principes se tornavam o padrão, por mais defeituosas que fossem, para a análise dos manuscritos por eruditos do continente inteiro. Até mesmo para um antiquário trabalhando numa região menos marginal do Império romano como era a Lusitânia, por mais que as evidências "não-literárias" fossem buscadas, as fontes "literárias" eram, ao 
cabo, incontornáveis e, no fim, ambas se confundiam. Como afirma André de Resende perto do abrupto fim de suas Antiguidades da Lusitânia, ele não se propôs enumerar todas as cidades do Portugal moderno e o seu correspondente antigo, "mas tão-só aquelas que ou foram nomeadas pelos escritores antigos ou que, graças a velhas inscrições ou a um feito muito notável, tornaram em qualquer lado e por seu mérito os nomes conhecidos" (RESENDE 1996 [1593], p. 194). Ou seja, o que não estava escrito não podia ser estudado.

\section{Imprensa e epigrafia}

"O renovado interesse no mundo clássico no Quatrocentos", afirma Lucia A. Ciapponi, "trouxe uma mudança no gosto que afetou toda atividade cultural" (CIAPPONI 1979, p. 18), e isso não apenas no limitado campo da caligrafia que a autora estuda, mas sobretudo na educação, na política, na estética e, claro, no estudo histórico e antiquário. Pode-se dizer, com isso, que a era dos antiquários não representou apenas "uma revolução no método histórico", mas também uma "revolução no gosto" pela Antiguidade clássica, invertendo-se a ênfase da formulação de Arnaldo Momigliano (MOMIGLIANO 2014, p. 20). Era o interesse renovado pelo mundo clássico que tornava possível estabelecer novas espécies de evidências para estudá-lo.

Uma breve anedota contada a respeito de André de Resende pelo editor das Antiguidades da Lusitânia, o também eborense Diogo de Vasconcelos, ajuda a compreender esta situação. Segundo o editor, Resende, de retorno a Portugal, passou a se dedicar com tamanho afinco à tarefa de decorar sua residência com "antigos mármores" e "inscrições romanas" que

[...] todas as vezes que ia de viagem, muito embora partisse para lugares bem longe, tinha sempre o cuidado de levar dentro da bagagem uma enxada e outras ferramentas, para que, se the aparecessem nalgum sítio vestígios da antiguidade, os pudesse mandar escavar, pagando do seu próprio bolso e por sua iniciativa, para os dar a conhecer aos seus habitantes (RESENDE 1996 [1593], p. 55).

Ou seja, no cotidiano do antiquário, as evidências materiais eram simultaneamente meios para se obter uma imagem mais completa do passado e objetos que serviam para atender ao gosto classicizante da época. Ainda assim, se Resende apreciava esteticamente os vestígios do passado, não parece claro que ele tinha os instrumentos para abordar os aspectos mais propriamente "artísticos" e materiais destas evidências em sua atuação enquanto antiquário.

O caso das inscrições epigráficas se torna especialmente significativo, pois elas combinam de maneira única e indissociável a materialidade do objeto histórico e a legibilidade do texto antigo. Como bem sintetiza André de Resende em sua História da Antiguidade da Cidade de Évora, trata-se de "escrituras de pedra" (RESENDE 1963 [1553], p. 14), ou, noutro momento, na epístola a Bartolomeu de Quevedo, quando afirma mais explicitamente: as inscrições são "pedras falantes" (RESENDE 1988 [1567], p. 123). Estas pedras que falam se prestam a ser lidas porque "ou mantêm intacto ou morrem ao mesmo tempo que as letras nelas 
gravadas" (RESENDE 1996 [1593], p. 58). Conteúdo e suporte, nas inscrições epigráficas, são uma e mesma coisa; as declarações de Resende, no entanto, mostram que as inscrições parecem interessar mais pelo conteúdo escrito do que pelos elementos gráficos que as cercavam e, no fim, as constituíam.

Essa será uma dificuldade apenas ocasionalmente superada na história dos estudos epigráficos ao longo dos séculos XV e XVI. Como sugere William Stenhouse, os dois caminhos já estavam presentes em Poggio Bracciolini (13801459) e Ciríaco de Ancona (1391-c.1435), pioneiros no estudo das escritas talhadas em pedras. Enquanto o primeiro se ocupava do estudo dos textos e do que elas poderiam revelar de novo acerca da história antiga, o segundo, talvez pelas deficiências de seu conhecimento linguístico, tendo aprendido latim apenas em sua maturidade, se interessava mais pela estrutura física, a qual reproduzia em desenhos de variado detalhamento (STENHOUSE 2005, p. 22). No caso de Ciríaco de Ancona, mercador e diplomata que entrara em contato com as inscrições em suas muitas viagens ao Oriente, a atenção aos detalhes físicos também se explica pelo fato de que a maior parte das inscrições que copiava eram em grego, o que, dado o relativo desconhecimento do idioma, dava margens menores para a interpretação.

Ainda segundo Stenhouse, talvez o mais importante epigrafista da segunda metade do século XV tenha sido Fra Giovanni Giocondo (1433-1515). Giocondo teria sido um dos primeiros a aplicar os conhecimentos da filologia ao estudo das inscrições, organizando o corpus epigráfico em famílias de inscrições de acordo com sua origem e distinguindo entre as evidências que ele mesmo vira e, outras, que soubera por meio de terceiros, como, por exemplo, outras coleções epigráficas (STENHOUSE 2005, p. 24). Ele também se interessava pelos aspectos gráficos das inscrições, em especial pela forma das letras e pela qualidade do entalhamento, através de cuja análise ele poderia datar em que momento da história romana elas foram feitas (STENHOUSE 2005, p. 25). Essas preocupações devem ser pensadas em conjunto com sua atuação nos círculos ligados ao pintor Andrea Mantegna (c. 1431-1506); por volta da metade do século $\mathrm{XV}$, o artista florentino começara a incorporar o texto e a caligrafia das inscrições em seus trabalhos, de modo que o estudo da materialidade das inscrições também servia para reforçar a legitimidade e a ambientação clássica de seus próprios quadros (CIAPPONI 1979, p. 23). ${ }^{1}$

Apesar das iniciativas de Giovanni Giocondo, a aproximação entre artistas e eruditos continuaria apenas esporádica. Como admite o próprio Stenhouse ao reconhecer que a segunda inovação de Giocondo - o estudo das condições de feitura das inscrições e de suas características físicas - teria fortuna consideravelmente menor que seu primeiro insight, o qual aproximava o estudo

\footnotetext{
${ }^{1}$ Algo semelhante se aplica ao relacionamento entre André de Resende e Francisco de Holanda explorado, em variadas publicações, por Sylvie Deswarte-Rosa. Com profundo interesse antiquário, o retratista e tratadista Holanda, mais jovem que Resende, recebeu deste educação na composição epigráfica; ambos se aproveitavam de seus conhecimentos para forjar inscrições que eram então "descobertas", diz a autora, quando a corte estava reunida, para grande efeito (DESWARTE-ROSA 2008, p. 282-283). Que pouco deste conhecimento do como fazer as inscrições, necessário para criar falsificações bem-sucedidas, transpareça no trabalho antiquário de Resende é mostra do distanciamento que estamos propondo aqui.
} 
epigráfico das técnicas já disponíveis para a avaliação de manuscritos antigos (STENHOUSE p. 25). O surgimento da imprensa e, com ela, o desenvolvimento das técnicas da xilogravura e da gravura em metal, não mudaria este cenário (WOOD 1998, p. 85) - e isso por causa dos objetivos e métodos dos próprios antiquários. Este cenário somente sofreria mudanças significativas a partir da segunda metade do século XVI, quando antiquários, compiladores e patronos como Onofrio Panvinio, Jean Matal e Antonio Agustín passariam a levar em consideração as características físicas das inscrições para inclui-las num quadro ampiado da história romana (STENHOUSE 2005, p. 43 e ss.). Esta é uma mudança da qual, entretanto, tanto André de Resende como outros antiquários e epigrafistas portugueses não parecem ter participado (ALMAGRO 2008).

As inscrições normalmente eram reunidas em coletâneas, os chamados syllogai, que circulavam em forma manuscrita. Segundo Christopher S. Wood, uma série de motivos presidiam a decisão por mantê-los em forma manuscrita. Em primeiro lugar, a base de leitores dos syllogai era muito pequena, não justificando os custos da impressão (WOOD 1998, p. 88). Livros a respeito de temas eruditos, como se sabe, eram notoriamente difíceis de serem compostos. Comentários exigiam repensar a distribuição do texto na página; volumes que abordavam as tradições grega ou hebraica necessitavam do desenvolvimento de caracteres tipográficos próprios; obras que dependiam de material visual tinham de contar com o desenvolvimento das técnicas de gravura para recriá-las fielmente. Algumas destas iniciativas foram realizadas, já em meados do Quinhentos, com esmerado empenho, como as coleções numismáticas de Guillaume Rouillé, Promptuaire de médailles, e o Epithome du thrésor des Antiquitez, de Jacopo Strada, ambos de 1533, e os Discorsi sopra le medaglie de gli antichi, de Enea Vico, publicado em 1555 (HASKELL 1993, p. 14-16), para não mencionar, no campo da epigrafia, a pequena coletânea que reproduzia vinte e duas inscrições realizadas sob direção de Conrad Peutinger em 1505 (WOOD 1998). Os motivos para imprimir tinham mais a ver com a tentativa de alcançar um público maior, especialmente para eruditos baseados em localidades periféricas da República das Letras europeia naquele momento, do que com a busca de fidelidade na reprodução das evidências materiais (WOOD 1998, p. 84). Isso também mostra, como veremos em maior detalhe nos procedimentos de trabalho de André de Resende, que, no mundo dos antiquários, o contato pessoal e a correspondência continuaram sendo meios privilegiados para o estabelecimento das redes de contato muito tempo após a introdução da tipografia.

Um segundo motivo, por sua vez, possui relação direta com estas últimas considerações. Os syllogai eram vistos como empresas colaborativas e o próprio conceito de autor de uma coletânea de inscrições era problemático (WOOD 1998, p. 88); quando impressas, elas recebiam o nome do impressor (WOOD 2001, p. 113) ou do patrono que as encomendara (STENHOUSE 2005, p. 45-46). Um exemplo destas coletâneas manuscritas que circularam pela Europa, articulando uma ampla de rede de colaboradores mas sem chegar à imprensa, é a de Mariangelo Accursio (c. 1490-c. 1546), que no primeiro quarto do século XVI perambulou pelo continente europeu, chegando até 
Portugal, com o objetivo de anotar todas as inscrições disponíveis em sua época (DESWARTE-ROSA 2012a) - ou seja, um equivalente renascentista do Corpus Inscriptionum Latinum.

Manuscritas ou impressas, as inscrições também variavam consideravelmente de acordo com o talento - ou a falta de talento - de quem as copiava. Variações na caligrafia, que poderiam ajudar a datar as inscrições ou a quebra das linhas, elementos que auxiliavam na compreensão do uso do espaço na superfície das rochas inscritas e, por conseguinte, na ênfase e nos modos de leitura das frases nelas gravadas, dificilmente eram reproduzidas (WOOD 1998, p. 87). No ambiente altamente competitivo dos círculos eruditos do Quatrocentos e Quinhentos, as abreviações e as ligaduras presentes nas inscrições normalmente eram desdobradas (STENHOUSE 2005, p. 47); elas ofereciam, assim, aos antiquários uma oportunidade de demonstrar seu "gênio" pessoal ao transformar as alquebradas inscrições epigráficas em prístinas peças de discurso. O interesse pelas características físicas dos cipos, frisos, degraus de escadas, colunas, marcos miliários e ruínas onde as inscrições se encontravam parece surgir apenas ocasionalmente de acordo com os interesses do erudito que as estuda, e não como uma etapa da investigação necessária a sua compreensão. O fato de que eram únicas impunha a necessidade de revêlas para que pudessem ser comparadas, o que era dificultado pela própria perda de inscrições com as constantes renovações urbanas da época quanto pelo grande número de falsificações (WOOD 2001, p. 99). Por todos estes motivos, as inscrições eram estudadas sobretudo por seu seu conteúdo linguístico e, nesse contexto, a introdução da imprensa era vista como um obstáculo adicional entre a observação, a anotação e a leitura, e não como uma solução para sua fiel reprodução.

Um exemplo pode ser encontrado na epístola de André de Resende endereçada a Bartolomeu de Quevedo, que já tivemos a oportunidade de conhecer antes. A data de escrita e publicação - 1567 - demonstra que estes problemas persistiam mesmo com o correr do século. Ao discutir a respeito dos limites da província romana da Lusitânia em comparação com o território do reino de Portugal, Resende afirma:

Tenho em minha casa um enorme cipo de mármore, a que faz referência o reverendo senhor que atualmente é bispo de Osma, na sua obra Das várias resoluções. O cipo diz o seguinte (só não tive oportunidade de reproduzir, por falta de caracteres tipográficos adequados, os nexos das letras que se sobrepõem umas às outras para economizar espaço) (RESENDE 1988 [1567], p. 137).

Ao que se segue a reprodução, de página inteira, da referida inscrição. 
Figura 1 - Inscrição apresentada na carta a Bartolomeu de Quevedo, reproduzida aqui a partir da primeira edição contida no volume Carmen Endecassylabon (Lisboa, 1567)

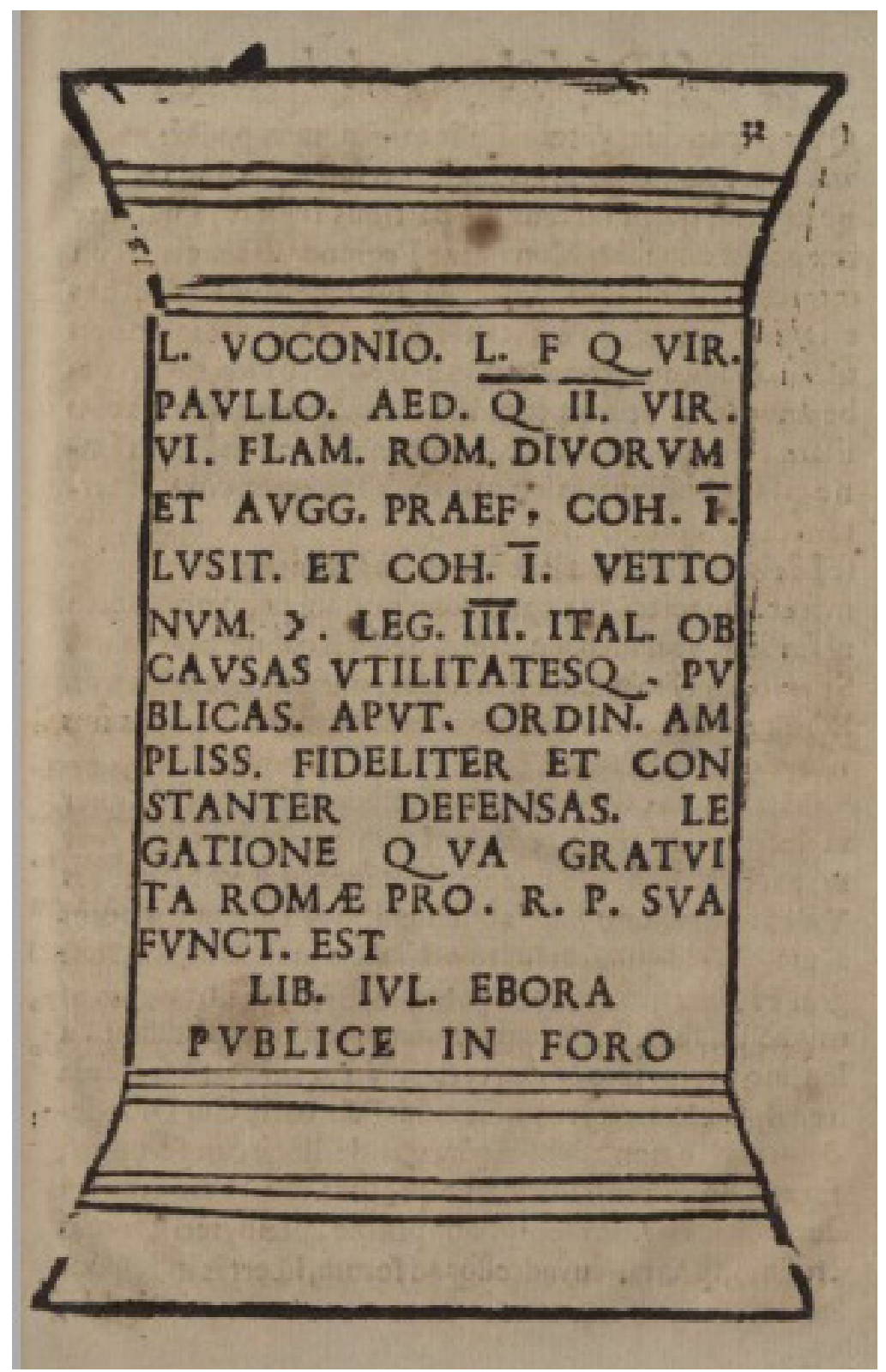

Este exemplo ainda é excepcional porque mostra a atenção de Resende à forma das letras; esta atenção, todavia, não serve para motivos de datação ou entendimento das circunstâncias em que a evidência fora constituída (STENHOUSE 2005, p. 54), e se reduz à avaliação do grau de dificuldade de sua leitura. Ela acaba por revelar o limite técnico alcançado pelas práticas mais cotidianas da imprensa em meados do Quinhentos, as quais eram normalmente incapazes de reproduzir graficamente a materialidade das inscrições. A passagem confirma, portanto, a declaração de Christopher S. Wood segundo a qual se a imprensa causou algum efeito no estudo epigráfico, foi o de ter acelerado "a divisão entre a ilustração erudita e a ilustração decorativa" (WOOD 2001, p. 105).

Observando-se outros exemplos de inscrições representadas em obras de André de Resende, percebe-se que eles são apresentados de forma bastante 
esquemática, muitas vezes trocando-se apenas o texto aplicado sobre um mesmo modelo, em outros casos retirando-se toda a referência à materialidade do objeto (tal como o desenho dos contornos) para apresentar somente as letras. A incapacidade técnica de render a unicidade de cada inscrição acabava por dissociar conteúdo e suporte - o qual era meramente descrito no texto do autor - e transformava uma evidência visual numa evidência textual. Nesse caso, a passagem preconizada por Arnaldo Momigliano do estudo das fontes textuais para as fontes materiais não era necessariamente resultado de uma decisão metodológica, mas de uma falha técnica.

Figuras 2 e 3 - Exemplos de inscrições retirados da primeira edição das Antiguidades da Lusitânia (1593)

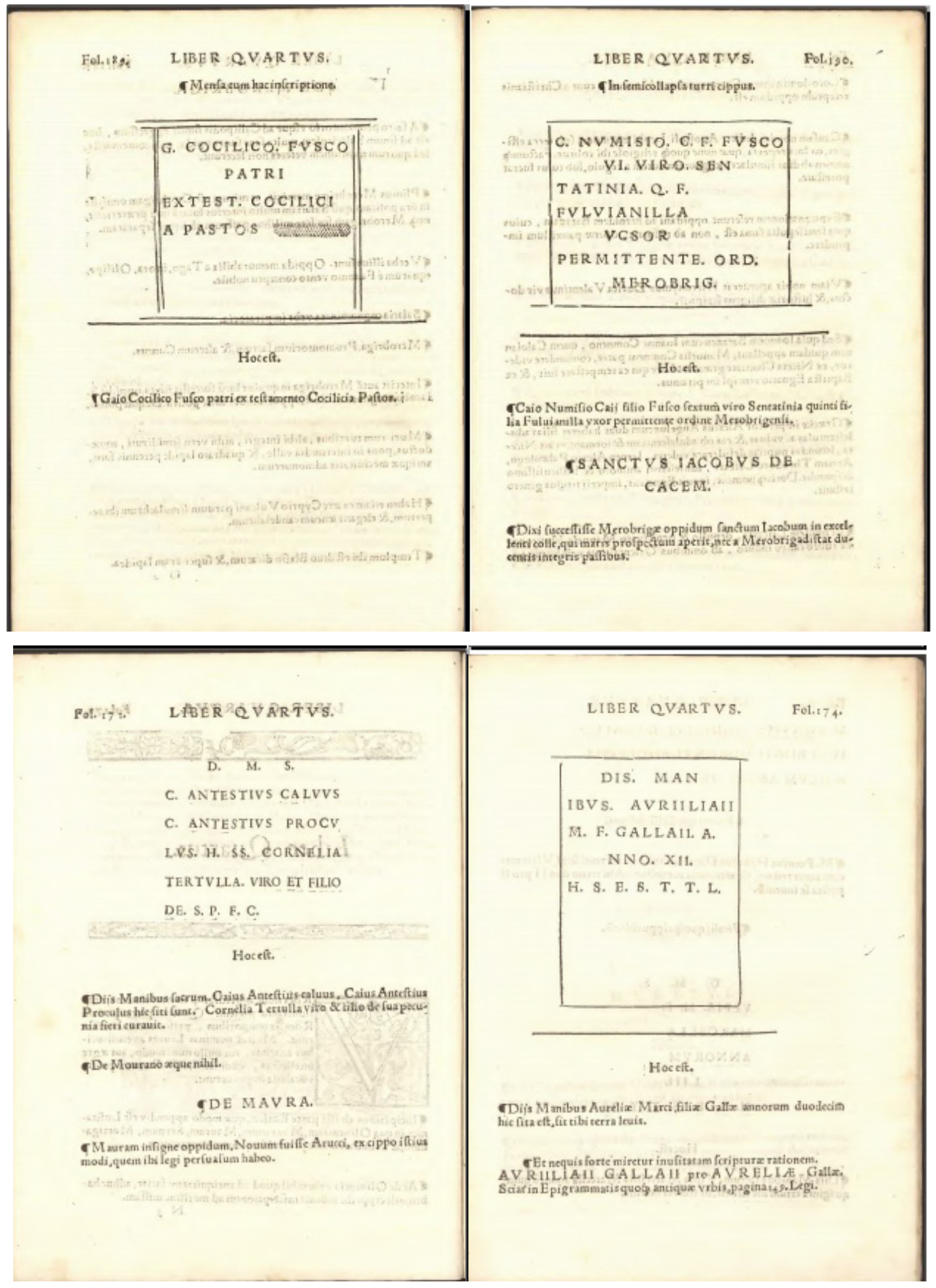


Além disso, outras séries de preocupações se somavam à representação das inscrições epigráficas. De um lado, os interesses dos editores, que, buscando reduzir os custos da impressão, escolhiam molduras simples para baratear os gastos com as provas e procuravam posicionar o maior número possível de caracteres na página de modo a aproveitar o espaço da folha (WOOD 1998, p. 99 e ss.). De outro lado, as próprias funções retóricas destes recursos gráficos, ainda que simples ou justamente porque eram simples. As quatro linhas da moldura que cercavam as inscrições reproduzidas na página e as letras, sempre grafadas em maiúsculas, eram uma convenção estilística que sinalizava a representação das inscrições e desviava a atenção de outros aspectos da materialidade das mesmas que, por não serem passíveis de reprodução, a apresentação defeituosa poderia ser tomada como um ato de má-fé. Importava mais, nesse sentido, submeterse às convenções em torno à forma de apresentação das inscrições do que dar indicações precisas acerca de sua constituição ou do local onde pudessem ser encontradas para serem verificadas por outros eruditos - e, importa lembrar, muitas inscrições nunca existiram fora das páginas, manuscritas ou impressas, das coletâneas antiquárias, de modo que o próprio caráter vago da apresentação servia para sustentar a pretensa autenticidade de evidências espúrias (WOOD 2001, p. 109).

Com isso, podemos percorrer no caminho inverso o trabalho antiquário, partindo de seu produto final - um livro ou uma coletânea, por exemplo - em direção a seus procedimentos de trabalho, onde, novamente, não houve uma simples transição do manuscrito ao impresso, mas um complexo jogo de idas e vindas entre os dois. Embora tenhamos poucos registros do método de trabalho de André de Resende, a complicada história de sua obra mais conhecida, as Antiguidades da Lusitânia, nos permite ter um vislumbre de como ele atuava.

Quando faleceu em 1573, André de Resende organizara apenas parte do texto para publicação. Suas anotações e sua biblioteca foram inventariadas logo após sua morte, todavia o trabalho no livro só foi retomado na década de 1580, sob insistência do monarca Filipe II, que designou o editor Diogo Mendes de Vasconcelos para completar a obra (RESENDE 1996 [1593], p. 61). O editor pinta um quadro um tanto quanto caótico do estado da obra quando passou a dela se ocupar. $O$ antiquário eborense deixara preparados apenas quatro dos dez livros que se propunha escrever (a obra foi editada com quatro livros mais uma parte suplementar a respeito de Évora, composta por Vasconcelos). Os cadernos de Resende, entretanto, "ficaram tão cheios de rasuras e apagados com asteriscos e obeliscos, que cheguei a suspeitar estar à mão com tarefa sem solução" (RESENDE 1996 [1593], p. 60). Além disso, Resende deixara as inscrições "totalmente dispersas e confundidas por várias folhas, num só códice" (RESENDE 1996 [1593], p. 60). Para Vasconcelos, o motivo pelo qual o antiquário tinha assim procedido talvez seja que não lhe "sobrara tempo para as transcrever e para as por em ordem, a um homem que sem parar trabalhava em todo o gênero de coisas literárias", 
ou porque, a fim de ter notícias exata das antiguidades e devido à sua extraordinária memória, só ficava satisfeito com as folhas originais, que Ihe fossem mandadas de toda a parte, embora mal copiadas e corrompidas (RESENDE 1996 [1593], p. 61, grifo meu).

Ou seja, o manuscrito tinha um papel preponderante no trabalho antiquário, não apenas no que toca aos rascunhos preparados para impressão, mas também nas anotações das evidências que encontrava e na circulação destas evidências, como atesta o caso das inscrições anotadas por Resende e também das enviadas a ele. Como destaca Angus Vine, "uma história do antiquário deve ser também uma história de seu círculo e de seus correspondentes" (VINE 2010, p. 82). Esta comunicação é que Diogo de Vasconcelos considera tão difícil de reduzir ao formato de livro, praticamente reescrevendo a obra de Resende.

Embora as referências acima situem o manuscrito quase que apenas em relação ao impresso, é possível ver como a circulação manuscrita era relevante para o antiquário. Em especial, ele coloca um problema que pode passar da esfera técnica à esfera teórica. Como um das passagens acima afirma, André de Resende dependia de muitas anotações que Ihe eram enviadas, com diferentes graus de fidelidade. Trazendo-se a discussão para o contexto em que Arnaldo Momigliano a trata, pode-se pensar na anotação desmaterializando uma evidência material para depos recriá-la sob a forma, primeiro, da anotação e, posteriormente, da edição impressa (WOOD 2001, p. 95). Sendo assim, mesmo as evidências materiais, ainda que fossem vistas à primeira mão, se estabeleciam numa relação mediada pela escrita. Como afirma, novamente, Angus Vine, "a preservação do passado se transforma numa empresa tanto literária quanto histórica" (VINE 2010, p. 83).

Tendo isso em vista, podemos considerar que os antiquários e eruditos da Idade Moderna não participavam apenas de uma cultura letrada - a República das Letras - centrada em si mesma tampouco ascendiam por seu status de autor, todas estas prefigurações de um ambiente acadêmico que somente surgirá muito posteriormente. Talvez seja necessário pensar que os antiquários e eruditos participavam também de uma cultura escrita, onde as inscrições que estudam demonstram sua atenção às escritas expostas, onde a comunicação não se dá apenas com seus pares mas também com pessoas de maior ou menor grau social que compartilham o interesse pelas evidências históricas, onde estudar o passado não significa estar apartado das preocupações - bastante materiais e pragmáticas - do mercado dos livros e do trato com editores e impressores e onde, por fim, a construção das evidências históricas estava sujeita não apenas a imperativos teóricos como também a injunções relativas à técnica e ao trato pessoal entre antiquários, eruditos, impressores e o público à sua volta.

\section{Referências bibliográficas}

ALMAGRO, Alejandra Guzmán. A Portuguese Contribution to 16th Century Roman Antiquarianism: The Case of Aquiles Estaço (1524-1581) and Roman Epigraphy. In: BERBARA, Maria; ENENKEL, Karl A. E. (eds.). Portuguese Humanism and the Republic of Letters. Leiden: Brill, 2012, p. 353-373. 
ANSELMO, Artur. Origens da imprensa em Portugal. Lisboa: Imprensa Nacional/Casa da Moeda, 1981.

BATAILLON, Marcel. Erasmo y España. Estudios sobre la historia espiritual del siglo xvi. Mexico, D.F.; Buenos Aires: Fondo de Cultura Económica, 1966.

BOUZA, Fernando. Corre manuscrito: una historia cultural del Siglo de Oro. Alvarez: Marcial Pons, 2001.

CIAPPONI, Lucia A. A Fragmentary Treatise on Epigraphic Alphabets by Fra Giocondo da Verona. Renaissance Quarterly, v. 32, n. 1, p. 18-40, 1979.

COROLEU, Alejandro. Anti-Erasmianism in Spain. In: RUMMEL, Erika (org.). Humanism and Scholasticism in the Age of Erasmus. Leiden: Brill, 2008, p. 73-92.

DESWARTE-ROSA, Sylvie. Le voyage épigraphique de Mariangelo Accursio au Portugal, printemps 1527. In: BERBARA, Maria; ENENKEL, Karl A. E. (eds.). Portuguese Humanism and the Republic of Letters. Leiden: Brill, 2012, p. 19-111.

. O ramo de ouro do saber. F. Olandius. Apoloni Dicauit. In: MORAES, Luiz (org.). A Fábrica do Antigo. Campinas: Ed. UNICAMP, 2008, p. 269-292.

EISENSTEIN, Elisabeth. A revolução da cultura impressa: os primórdios da Europa moderna. São Paulo: Ática, 1998.

GRENDLER, Paul F. Schooling in the Renaissance Italy. Literacy and Learning, 1300-1600. Baltimore: The Johns Hopkins University Press, 1989.

GRAFTON, Anthony. The Importance of Being Printed. Journal of Interdisciplinary History, v. 11, n. 2, p. 265-286, 1980.

HASKELL, Francis. History and its images: art and the interpretation of the past. New Haven: Yale University Press, 1993.

HERKLOTZ, Ingo. Momigliano's 'Ancient History and the Antiquarian': A Critical Review. In: MILLER, Peter N. (ed.). Momigliano and Antiquarianism: Foundations of the Modern Cultural Sciences. Toronto: Toronto University Press, 2007, p. 127-153.

LOPES, Marília dos Santos. From Discovery to Knowledge: Portuguese Maritime Navigation and German Humanism. In: BERBARA, Maria; ENENKEL, Karl A. E. (eds.). Portuguese Humanism and the Republic of Letters. Leiden: Brill, 2012, p. 425-445.

MATOS, Manuel Cadafaz de. André de Resende (c. 1500-1573), o homem e a obra: um contributo para a sistematização dos seus trabalhos impressos até 1551. No quinto centenário do nascimento de um humanista erasmiano. In: Algumas obras de André de Resende: 1531-1551. Lisboa: Câmara Municipal de Évora, 2000, v. 1, p. VII-XCVI.

MILLER, Peter N. "Introduction: Momigliano, Antiquarianism, and the Cultural Sciences", in MILLER, Peter N. (org.). Momigliano and Antiquarianism: 
Foundations of the Modern Cultural Sciences. Toronto: Toronto University Press, 2007, p. 3-65.

MOMIGLIANO, Arnaldo. História antiga e o antiquário. Anos 90, v. 21, n. 39, julho de 2014, p. 19-76.

MOREIRA DE SÁ, Artur. De re erasmiana: aspectos do erasmismo na cultura portuguesa do século XVI. Braga: Publicações da Faculdade de Filosofia, 1977.

MUSSER, Ricarda. Building up Networks of Knowledge: Printing and Collecting Books in the Age of Humanism in the University City of Coimbra. In: BerbARA, Maria; ENENKEL, Karl A. E. (eds.). Portuguese Humanism and the Republic of Letters. Leiden: Brill, 2012, p. 113-127.

PETTEGREE, Andrew. The Book in the Renaissance. New Haven: Yale University Press, 2010.

PHILLIPS, Mark Salber. Reconsiderations on History and Antiquarianism: Arnaldo Momigliano and the Historiography of Eighteenth-Century Britain. Journal of the History of Ideas, v. 57, n. 2, p. 297-316, 1996.

RESENDE, André de. Aegidius Scallabitanus. In: PEREIRA, Virgínia Soares. Aegidius Scallabitanus: um diálogo sobre Fr. Gil de Santarém. Lisboa: Fundação Calouste Gulbenkian, 2000, p. 277-695.

Antiguidades da Lusitânia. Introdução, tradução e comentário de R. M. Rosado Fernandes. Lisboa: Fundação Calouste Gulbenkian, 1996;

. Carta a Bartolomeu de Quevedo. Tradução, introdução e notas de Virgínia Soares Pereira. Coimbra: Instituto Nacional de Investigação Científica/Centro de Estudos Clássicos e Humanísticos da Universidade de Coimbra, 1988 [1567].

- História da Antiguidade da Cidade de Évora. In: Obras portuguesas de André de Resende. Lisboa: Livraria Sá da Costa, 1963 [1553], p. 1-69.

. Oração de sapiência (Oratio pro rostris). Tradução de Miguel Pinto de Meneses, introdução e notas de A. Moreira de Sá. Lisboa: Instituto de Alta Cultura, 1956 [1534].

STENHOUSE, William. Reading Inscriptions and Writing Ancient History: Historical Scholarship in the Late Renaissance. London: Institute of Classical Studies, 2005.

TARRÍO, Ana María Sanchez. Pedro Nunes e os humanistas do seu tempo. In: NASCIMENTO, Aires A. (org.). Pedro Nunes e Damião de Góis: dois rostos do humanismo português - atas dos colóquios no $\mathrm{V}$ centenário do nascimento. Lisboa: Guimarães, 2002, p. 59-93.

VINE, Angus. In Defiance of Time: Antiquarian Writing in Early Modern Britain. Oxford: Oxford University Press, 2010. 
WOMERSLEY, David. Against the Teleology of Technique. In: KEWES, Paulina (org.). The Uses of History in Early Modern England. San Marino: Huntington Library, 2006, p. 91-104.

WOOD, Christopher S. Early Archaeology and the Book Tradition. The Case of Peutinger's Romanae uetustatis fragmenta (1505). Journal of Medieval and Early Modern Studies, v. 28, n.1, Winter 1998, p. 83-118. . Notation of visual information in the earliest archaeological scholarship. Word \& Image, v. 17, n. 1/2, p. 94-118, 2001. 


\title{
French erudités and the construction of Merovingian history
}

\author{
Dmitri Starostin \\ starostin.dmitry@gmail.com \\ Lecturer \\ Institute of History - University of St-Petersburg \\ 5, Mendeleevskaia Liniia \\ 199034 - St-Petersburg \\ Russia \\ Elena Kuleshova \\ kuleshova27@gmail.com \\ Lecturer \\ Institute of History - University of St-Petersburg \\ 5, Mendeleevskaia Liniia \\ 199034 - St-Petersburg \\ Russia
}

\begin{abstract}
This article addresses the ways in which scholars of history who worked in France in the 16th century attempted to describe and consider early medieval history and how in the course of this process they made slight adaptations to the image of the early medieval Frankish history that corresponded to the needs of the educated community and the emerging French monarchy. Thus, the article compares how the scholars Claude Fauchet, Bernards de Girarnd Sieur Du Haillan and others looked at the process of construction of the Frankish kingdom and how they addressed the relationship between the Mediterranean core of the Late Roman Empire and the diocese of Gaul which had long attracted the attention of the Franks, who became Roman soldiers and foederati. It is suggested that the bifurcation in historical knowledge took place in the 1570s in the works of Claude Fauchet and Bernard Du Haillan, one of which may still be ascribed to the earlier group of humanists who operated within the framework created by Leonardo Bruni and Flavio Biondo, whereas Bernard Du Haillan, on the other hand, sought to overcome the ideas and terms used by them and conceived of Frankish history in different terms. He emphasized the discontinuity between the Roman Empire and the Frankish Gaul, but at the same time sought to avoid the use of the discourse of national self-identification that permeated the works of earlier humanists.
\end{abstract}

\section{Keywords}

Intellectual history; Medieval History; History of France. 
Self-representations of European nations changed significantly when the later Middle Ages gave way to new society of the early Modern period despite a significant amount of continuity between the Later Middle Ages and the 16th century. The shifts in perception and the unique character of the modern view of the past were explained by a unique "régime de historicité", which appears within each chronologically-determined cultural system and which had changed significantly in the modern period in comparison to the Middle Ages (HARTOG 1993; HARTOG 2015, p. 15-20; 107-113). One may see the early modern "regime" as different from both medieval and modern, as one of a transition period, which, nevertheless, had its own peculiarities. It was the time when in the period between the Middle Ages and the Modern age a peculiar form of organization of knowledge, based around a "Republic of letters", was born and managed to survive for a historically short period of time (GRAFTON 2011, p. 13-14). Development of history as a discipline tremendously benefited from this process, but in the wake of nascent competition for priority in Europe by emerging monarchies of the early modern age it produced significant polemics between various strains of historical thought. Early medieval history became, as we will try to show, in addition to Roman history, one of the fields in which competition and tensions ran high as scholars from different parts of Europe sought to contribute to their own country's identity by envisioning the emerging medieval world from the perspective relevant to their own country's European ambitions.

In France, which will interest us as a country which produced its own strain of Renaissance historiography, the idea that a "new history" was in the making was shared in the end of the sixteenth century by authors like Jean Bodin and La Popelenier (HUPPERT 1970, p. 9; 23-27). This feeling among the educated historians has been interpreted in a number of ways, as that implying significant social repercussions of the new attitude to history, or as an indication of the discipline's conceptual and methodological characteristics. The new social role of historiography has been shown to express itself in a number of significant ways. But the question is whether the development of early modern history writing in France, North of the Alps, was in any way similar to the path it went in Italy, and whether the "republic of letters" was perceived in the field of historical knowledge. Much as in other disciplines, the intellectual community of scholars which enjoyed a free exchange of opinions in history and a polemic free of confessional or political restraints, barely managed to survive the 1550 s when the pressures from ecclesiastical and lay structures of authority began to mount (GRAFTON 2011, p. 13-14). In Italy, where the Renaissance history writing first appeared, it split by the 17 th century into three distinct types. In Florence public utility of writing about the past had disappeared by sheer attrition and it moved from piazza to the studio, thus becoming a purely learned pursuit. In Rome its utility was refashioned and history writing became a tool of Counter- Reformation, and in Venice it transformed into a new historiography that answered crucial problems of political and social existence (BOUWSMA 1990, p. 304-309). By the mid-17th century history-writing would also change in terms of approach, as the productive synthesis between rhetorical perfection, civic values and erudite 
knowledge of the past which had been achieved by the end of the 16th century would be split into two disparate strains: history as literature and history as research (COCHRANE 1981, p. 489). This happened in the 17 th-century France as "history reverted back to pleasant annals, while erudition turned into harmless antiquarianism" (HUPPERT 1970, p. 170-182). To make the matters worse, the synthetic approach, the use of which had been achieved by the early 17th century, fell in disfavor and almost disappeared from university and Jesuit schools' curricula, as they began to value literary aspects of historical treatises over those which sought to interpret the past by using a synthesis of rhetorical approach and erudite knowledge (BOUWSMA 1964-1965, p. 310; COCHRANE 1981, p. 489; FEINGOLD 1997, p. 329). And finally the interest to the ancients faded away and became more academic as the experience of New World conquest made the Ancient World resemble the savages and thus put a barrier, in fact, an ocean between them ("entre les Anciens et nous, il finira par yavoir un ocean") (HARTOG 2005, p. 38). Thus in the relatively short period of time between the 1500 and 1650 the development of history writing went full circle as it reached its peak by 1600 , at least as viewed by its contemporaries, and then lost much of its synthetic quality by the middle of the 17th century. The modernity with its fervent interest to the present gradually took its hold (HARTOG 2015, p. 107-113).

But was there a period in history writing in the 16th century, the achievements of which were more durable and which may still be employed to support the idea of continuity of historical thinking throughout the early modern period and to find elements of concepts and method that united, rather than divided historians of the early modern and modern period? Moreover, what model is applicable to France, given the different structure of power in which the monarchy had long occupied a central place in the politics? It has been established that history writing became in France a learned exercise for layers and jurists who made it into a sign of their intellectual and even social identity and a corollary to their profession (KELLEY 1970). History thus became part of knowledge espoused by those who considered themselves belonging to "republic of letters" (GRAFTON 2011 , p. 9). Looking at the same process from the standpoint of emerging and quickly transforming early modern monarchies (LE ROY LADURIE 1987, see part III; ELLIOTT 1992). scholars noted how writing of history became a means of furthering the construction and buttressing of monarchy, as historians were "charged" with the task of describing and confirming the monarchy's success (GRELL 1998, p. 538). The problem of power balance between the Empire, held by Charles $\mathrm{V}$ and Philip II, and the kingdoms which naturally felt themselves sidelined caused history, and especially that of the late Roman Empire and of the early medieval kingdoms, to become one of the politically charged themes (GRELL 2011). Thus already in the 16th century a process had begun which in the 17 th century would cause history to become an instrument of apologetic commentaries and justification of monarchy (GRELL 2007). But development of history writing in France may warrant more attention as there had obviously been undercurrents of historical thought that disappeared from wide usage 
and as there are still many problems of interpreting the approaches taken by scholars of history.

In this study we would like to address French history writing from a perspective of its approach to the emergence of the early medieval kingdom of Franks and its assessment in terms of relationship to Roman Empire's heritage. This is especially interesting because few specialists in early medieval history ever addressed 16th-century historical treatises from a purely medievalist's standpoint as they are considered fairly outdated in terms of their academic value. However, they are important as treatises that provide a look at the concepts of past that were created in struggles for France's image in Europe. Representations of early medieval history and their transformation over the early modern period occupy a very important place in this context because for the intellectuals and their royal sponsors in Europe North of the Alps this period became key to producing a new early modern self-identification for the emerging early modern monarchy in the period of "Bourbon spring" (LE ROY LADURIE 1987, Part III). The ways in which early medieval themes were re-interpreted by French historians who led a search of the kingdom's identity in the context of new European intellectual climate is the purpose of this investigation. Historical works on the Frankish kingdom laid the foundation for this period's study and made it into a significant historical field. Scholars like Étienne Pasquier (1529-1615), Bernard de Girard Sieur Du Haillan (1535-1610), Claude Fauchet (1530-1602). were those who laid the foundation of the France's early medieval history that allowed Bodin and La 80 Popelenier to produce their synthetic and conceptual visions of history in general (PASQUIER 1560; DU HAILLAN 1570; DU HAILLAN 1576b; DU HAILLAN 1576a; FAUCHET 1579). The period of the 1560-1580 was especially productive for this kind of studies as the new intellectual climate let scholars produce works on early medieval, Frankish history which combined both rhetorical perfection and erudite content. This is the period to which we would like to pay attention in this study, since a number of interesting treatises appeared in this period which may help illustrate the key aspects of the shift towards new meaning of early Frankish history and new forms of historical investigation.

One of the ways in which modern scholars sought to capture and define this change was addressing the formal methodology of the historical inquiry. Thus it is obvious, for example, that a significant transformation took place in perceiving and writing about the past between the first attempts to approach history in light of the new sources on Classical and medieval periods, associated with the names of Leonardo Bruni, Flavio Biondo and a few others, and the approaches of scholars of the 18th century like Du Tillemont whose Roman history became a foundation for modern Classical scholarship and inspired Gibbon in his studies. The French scholar's investigation, although produced within the dominant historical paradigm of the moment and thus addressing the history of emperors and the history of church in two separate treatises, were a breakthrough in their own period because they sought in the first place to establish critical facts of Roman history regardless of the ecclesiastical affiliation of its author, to provide critical review of all available sources (LE NAIN DE 
TILLEMONT 1701; LE NAIN DE TILLEMONT 1720; BREISACH 2008, p. 194-195). Thus it was noticed that only in the third quarter of the 16th century historical studies began to turn into "investigations" and away from the formerly used adaptation of Classical, and partly rhetorical, discourse (BOUTEILLER 1945, p. 357). Many, if not all of the techniques modern historians use in their work in collecting piecemeal evidence appeared in the Renaissance (FINDLEN 2002, p. 116). In this period scholars contributed to the transformation of history writing from a chronicle with purely chronological structure to a treatise which was structured events and thus provided an interpretation (COCHRANE 1981, p. 295-315). More importantly, it was in the second half of the 16th century that scholars came to understand that history cannot be reconstructed by using just one narrative, but needs to be reconstructed and collected from all available sources (FINDLEN 2002, p. 116; GRAFTON 2007, p. 68). At the same time, the Renaissance art of history produced the basic chronological structure that we still use today, and created the notion of "Medieval" history that up to know serves as a source for investigating the construction of Europe's identity in the aftermath of the Western Empire's collapse (BRUNI 2001, p. 88; 89; FINDLEN 2002, p. 116; CONNELL 2012, p. 352). This coincided with and in some ways was the cause of rethinking of the role of early medieval Frankish kingdom for the history of Europe in general, and of its claim to be an heir of the Roman Empire. Which of these models of interpreting early modern historical treatises work for a specialist in early medieval history if he addresses the treatment of early medieval Frankish kingdom in these treatises?

To understand and better perceive the challenges which the French historians faced when writing on the creation of the Frankish kingdom one may need to examine first the idealized picture of Roman history which came to dominate early modern history writing and which greatly influenced the ways in which French scholars created their own vision of medieval history. Leonardo Bruni from Arezzo, one-time Chancellor of the Florentine republic, exemplified how historians could use the ideal constructed representations of the political and civic culture of Antique polis and rhetorical and narrative structures and strategies of the Classical authors like Thucydides in describing medieval history of Florence. His Florentine history greatly influenced Humanistic historians (IANZITI 2012, p. 7). His treatise carried almost no new factual information because it was based on the histories of this city written hitherto. Bruni used "the classical topoi to establish the coordinates of the positions of protagonists in the stream of historical events" (STRUEVER 1970, p. 138). Thus history's presentation underwent significant transformations because "the gap between theory and practice, between intellect and will was to be bridged by speech." (VICKERS 1981, p. 128; MACK 2011, p. 311-315). Rhetorical practices became a part of the discipline's official presentation, but they also led to interiorization of discourse and to production of the more personal, if not psychologizing approach to described events (PÉCORA 2001, p. 79-116; HANSEN 2012, p. 159-161). In history this acquired a peculiar strand because it meant using the rules of rhetoric and hence, reason, in an attempt to establish the author's own 
interpretation of events against succumbing to chronicle tradition. Bruni sought to give a new touch to Florence's past because he insisted that this city had been established no later than Caesar and Octavian Augustus created Roman Empire. Thus Leonardo Bruni argued for republican roots of Florentine history and set the past of this city apart from both certain tyrannical aspects in Roman history and from the medieval history of other Italian cities, at the same time trying to represent its political organization and standing as unique (CONNELL 2012, p. 352; CABRINI 2010, p. 130; IANZITI 2012, p. 117-147, 204-236). It has been argued that this argument had less to do with nascent historical criticism that with the interpretation of the scholar of Roman and medieval history and hence of present-day events in Europe (IANZITI 2007, p. 253-257). Bruni also pioneered the division of history into three periods that established a dichotomy of the Antique Mediterranean South with its civic values and polis organization and the barbarian North which caused the destruction of the Classical world and contributed to its replacement by medieval barbarian kingdoms. His division consisted of the Classical, Medieval and Modern periods and he thus put the Middle Ages on the map (BRUNI 2001, p. XVII; 88-89; CONNELL 2012, p. 351). This periodization suggests that he saw the Middle Ages as lacking in Roman imperial legitimacy. In his narrative barbarians overtook Rome and thus the cause of the Roman downfall was external rather than internal. Odovacer, who displaced the last Roman emperor, was for him, paradoxically, no other than a tyrant ("Gothi Theoderico duce invadere Italiam statuerunt iam pridem afflictam 82 variis barbarorum incursionibus et tunc Odoacri tyrannide occupatam") (BRUNI 1441 , p. 3). The attacks of Theoderic the Great and his rule, although being the same in quality as those of Odovacer, received a welcome response from Bruni although it is difficult to see the difference between the two barbarian rulers. The acceptance of Theodoric by the Roman aristocracy, his title of a patricius, his Edict that was to make him resemble Roman emperors made him a more acceptable ruler in terms of Roman tradition (BRUNI 1441, p. 4). Thus Bruni created an imagined ideal of Romanness which was different from actual, imperial Rome, and made a distinction between different barbarian rulers, seeing acceptance by some of them of Roman traditions as a sign of positive development within society of barbarians (BRUNI 1441, p. 4). His vision his was meant to emphasize the primacy of the Mediterranean and, particularly, Italian culture as an heir to the Roman Empire in the long-standing competition and conflict with the Holy Roman Empire of the Middle Ages.

This approach had an enormous effect on the writing of history in early modern Europe as proving continuity and importance of Roman heritage became one of the utmost goals of Humanists from Spain. The two best-known authors Ocampo and Ambrosio de Morales put tremendous effort into establishing the Roman foundation under the early modern Spanish monarchy. Unlike his predecessor Ocampo, Morales got rid of the traditional scheme of universal history where the history of Spain was located within the Biblical and Christian frame of reference, created by Eusebius and Orosius, and firmly placed it within the context of Roman Empire's history (OSTENFELD-SUSKE 2012, p. 440). The 
Mediterranean countries thus produced historians who followed the Humanists' approach to the maximum. This was a representation of the so-called "raison d'État chrétienne" that came to formed in the southern regions of Europe as a response to the perceived or imagined challenges (SCHAUB 2005, p. 58- 59). It is under this pressure from the Empire that relied on its Roman tradition that in the North of Europe, in France, scholars had to invent ways to integrate their country's past into the Roman myth and at the same time prove an independent path of development. While the kingdoms of the Iberian peninsula could boast a Roman past which had significantly influenced their history, France's historians had to do with a continuous history of conflicting integration with and attempts to separate from the Empire in the form of Gallic Empire, bacaudae, multiple usurpers and general disintegration of Roman authority in Gaul at the expense of local, provincial power structures (DRINKWATER 1992; VAN DAM 1992; MACGEORGE 2002).

The situation of contact and conflict between Roman generals and civil officials, on the one hand, and barbarian chieftains, on the other, early became a theme for early modern historians. In the context of Roman Gaul rulers like Childeric (d. 481/482). and Clovis (482-511). thus become key figures whose reigns attracted much attention from early modern scholars because it was them who laid the foundations of early medieval and medieval Frankish kingdom and France. Childeric, as is now known, was a barbarian chieftain who, much like Arbogast, Odoacer, Theodoric the Great and others, managed to establish both a strong position among the Franks and at the same time to be accepted by Gallo-Romans and Roman imperial elites as a person worthy of rule in a Roman province (FRYE 1992). Gregory of Tours told how Childeric was exiled by the Franks in Soissons for his lewd behaviour and had to hide at Thuringian king Basin's household. The Franks chose instead as their ruler and even «king» a Roman general Aegidius. But according to Gregory of Tours, they soon got tired of his oppressive behaviour and called back Childeric, who triumphantly returned to rule (GREGORIUS TURONENSIS 1951, 2:12). The «Soissons kingdom» under the rule of Aegidius was one the many examples of the political units created by late Roman warlords, which were the result of the synthesis of Roman and barbarian traditions within the weakening Roman Empire and after its downfall (JAMES 1988). Although as many late Antique topics, the status of these Franks is open to scrutiny, it is likely that they had something of a «foederati» status. It is quite likely that this status was a result of the special treaty which had been concluded between emperor Julian and the Franks in Gaul in 359 after the former's successful attempts to bring order to these provinces (ROUCHE 1996, p. 451).Archaeologists suggest that his tomb shows how the new trends began to appear in the Roman provinces and that his authority was more than that of a barbarian chieftain (PÉRIN 1981; PÉRIN 1987; SALAÜN 2008, p. 218). The story of Childeric's coming to power suggested an interpenetration of Romans and barbarians. The rule of Clovis (482-511), who demanded his troops to pay homage to St.Martin, St. Hilary and their respective cities of veneration Tours and Poitiers, shows how a barbarian ruler could appeal to both Gallo-Roman elites 
and Franks after the Roman Empire was gone in 476 and create a kingdom within its former borders which was built on a synthesis of Gallo-Roman provincial and Frankish barbarian traditions (BURY 1889, p. 107; WALLACE-HADRILL 1962, p. 162; GANSHOF 1966, p. 9-12; WERNER 1984, p. 286; WERNER 1988, p. 4; JAMES 1988, p. 12; DALY 1994, p. 962-964; HEINZELMANN 1994, S. 189; LEBECQ 1990; ROUCHE 1996, p. 187; MACGEORGE 2002, p. 111-137, 169176; SCHMAUDER 2003, p. 300-306; HALSALL 2010, p. 169-187; BECHER 2011; REIMITZ 2015, p. 444). Moreover, it was a story of the split between the Mediterranean and the barbarian North that took place in Gaul when this region started to turn away from the former nominal dependence on the power center in Italy, Milan and later Ravenna, and began to exhibit more interest towards independent existence as a new political landscape where the Mediterranean and the barbarian North came in close contact.

It is therefore interesting to inquire when exactly the understanding of the close interrelationship between the Empire, the diocese of Gaul and the Franks settled into historiography and the polemics it raised in the European "republic of letters". In addition to the sense of unity within this educated community (GRAFTON 2011), it began to produce factions. We argue, however, that these boundaries of these factions did not run along purely political borders and were determined less by nascent national feeling than by the traditional struggle between the scholars of the South and those of the North for the right to claim imperial legitimacy and Roman heritage. The emergence of the Frankish kingdom as the only successful legitimate heir to Rome's provinces from among various barbarian groups was exactly this topic that shows the differences in various authors' approaches to the problem of continuity between the Western Roman Empire and Gaul as its diocese and the kingdom of the Franks as both new political unit and heir to the Empire. From Gregory of Tours, whose passage spoke of Clovis acquiring both consul and augustus status, all early modern scholars knew of the Frankish claims to partaking in imperial heritage ("Igitur ab Anastasio imperatore codecillos de consolato accepit, et in basilica beati Martini tunica blattea indutus et clamide, inponens vertice diademam. Tunc ascenso equite, aurum argentumque in itinere illo, quod inter portam atrii et eclesiam civitatis est, praesentibus populis manu propria spargens, voluntate benignissima erogavit, et ab ea die tamquam consul aut augustus est vocitatus") (GREGORIUS TURONENSIS 1951, 2:38). For dating the transformations which the perception of the Franks' coming to power in the Roman province underwent one needs to examine a number of early modern treatises.

This pride of Roman heritage and offhand dismissal of barbarians, however, did not work once used in relation to the history of other European regions, mainly the kingdom of France, and in fact caused irritation among French scholars. The latter's geographical position made them incorporate into its own history, political traditions and mentality both Mediterranean, Roman and imperial traditions and those which originated in the barbarian society of the Rhine frontier. In the work of a 15th-century French scholar Robert Gaguin the history of Frankish kingdom and France reached its best- developed format 
and his compendium of medieval knowledge of the past was well-known for all those interested in the history of the Franks (GAGUIN 1504). In his treatise he followed all those sources that were available of medieval scholars, and in the case of early medieval history relied on Gregory of Tours, staying close to his text and interpretation. But he made Frankish kings sound more friendly to the Gallo-Romans than they were described by the famous early medieval historian. Interestingly, he emphasized that Childeric received fealty from the inhabitants of Angers ca. 364 ("Andegavos in fidem recepit"), while Gregory described this as an act of capure ("civitatem obtinuit") (GREGORIUS TURONENSIS 1951, 2:18; GAGUIN 1504, fol. 2). Thus the Early Middle Ages have been studied well enough in medieval and late medieval France, although with only those sources that had been available to medieval scholars before the great discoveries of the age of the erudites, and were developed into a tradition which emphasized a long- standing connection and friendship between the Franks and the Roman Empire.

Thus first attempts to look at the Frankish kingdom from a new perspective were a compromise between Bruni's republican ideal of Rome and the realities of barbarian kingdoms which only saw the Empire. Thus an Alsatian humanist Beatus Rhenanus emphasized the Germanic origin of the barbarians who settled near the boundaries of the Roman Empire and who later came within its borders. But at the same time, he made a number of interesting statements about the relationships between the Roman Empire and the barbarians that may have looked different from those that had been developed hitherto. For example, he emphasized the fact that many Roman provinces were settled by the Germanic tribes, which in his eyes meant that they were under a significant pressure from the provincial Roman population and may have adapted to the latter's traditions of power and cultural paradigms. Thus paradoxically, although a proponent of strong barbarian influence on the history of early medieval kingdoms, he was also a scholar who emphasized that in many cases the Germanic tribes went under a significant influence of the provincial traditions. The Franks for him were one of those tribes which became the most Romanized and thus to an extent lost some of their traditional Germanic freedoms. However, he further developed this dichotomy, suggesting that only by the time of the Carolingian success the Franks were able to regain their ancient freedoms. In fact, he emphasized that the Franks were much more Romanized than had been previously suggested and showed that in the terms of early modern Europe they had almost become enslaved by the Roman Empire rather than remain a free people. In the same vein, the Visigoths were a people which encountered so deep an immersion into the Mediterranean world that they in fact lost their barbarian status (BEATUS RHENANUS 2008, p. 152-154, 228). Thus one may note that in 1531 when Beatus Rhenanus wrote his interesting treatise the divide between the North and the South, between southern and northern Gaul had not yet become an important topic for scholars of history. In fact, the divide still lay along the old Roman line of the limes on Rhine and Danube, and the mentality had not yet shifted from the center-periphery way of thinking to the new North-South one. 
The concept of the cultural domination of the Roman Empire over the barbarian world and the subject role of the barbarian in history acquired a completely different perspective when viewed from the lands North of the Alps. The dichotomy of Roman and barbarian worlds and, more importantly, the feeling of their tension and conflict was much reduced even in the treatises of Italians gone North, in comparison to the more adversarial vision one may find the Leonardo Bruni's works. It was absent in the key treatise on the Frankish history written by Paolo Emilio from Verona, «De rebus gestis Francorum» (1516), which represented a new stage in the development of this topic in the new European context (EMILIO 1516; REYNOLDS 1955). Its novelty was in the fact that this vision of Frankish history was set in the new cultural and political environment which had been imbued with Humanist sensitivities and perceptions of the past. Although in this work the author from Verona used all literary skill that was available to him and his Humanist colleagues after the works of Leonardo Bruni to establish a new Renassaince standard of vision of the history of France, he never sought to use the same dichtomy of the Roman and barbarian worlds that was used by his Humanist predecessor. In fact, he was the historian who keenly emphasized that Aegidius, the Roman general who the Franks had chosen over the exiled Childeric, also had a civilian position of governor or procurator since he was able to dispense justice in addition to military expertise ("[...] Octo annos Francis iura dixit Aegidius in amicorum cohortem [...]") (EMILIO 1516, fol. $6 \mathrm{v}$ ). This meant that unlike Gregory of Tours, this early modern historian saw in this representative of Gallo-Roman elites a person who bridged the gap between the civic traditions of the late Roman Empire and the military tradition of barbarian soldiers and foederati. In a sense, he was the scholar who set a longterm tradition that is used very actively in modern historical scholarship, that of significant similarity in the means of ruling between Gallo-Roman magnates and barbarian commanders like Childeric or Clovis (WERNER 1984, p. 286; WERNER 1988, p. 4; JAMES 1988, p. 12; ROUCHE 1996, p. 187; MACGEORGE 2002, p. 111- 137, 169-176; HALSALL 2010, p. 169-187; REIMITZ 2015, p. 444). In fact, he sought to see the Franks as those who were incorporated into the Mediterranean world of the Late Roman Gaul and of Gaul after the fall of the Empire in 476. In this sense his vision was somewhat contrary to the vision that had been proposed by Leonardo Bruni because he emphasized the unity of the Roman and of the barbarian worlds instead of making stress on their tensions.

The disparaging attitude of Bruni to the barbarians reached its peak in the writing of Paolo Giovio (1483-1552). Speaking of the Galls (and one may imagine, implying the Franks, too). he obviously considered them as barbarians, as one may understand from a polemic statement of Étienne Pasquier against him: " Que Jules Cesar n'eut les Galois en opinion de Barbares, et que I'occasion de ce vint de leur ancienne police, ensemble de ce que quelques autheurs Italiens nous veulent blasonner de ce tiltre" (PASQUIER 1560, p. 6). This French historian spend a large amount of his work proving the integration of the Galls and the Franks into the Roman cultural world. Moreover, he claimed that Romans themselves saw in the germanic peoples the main threat to the Empire and 
their heirs the reason for its downfall (PASQUIER 1560, p. 29-30). He reduced the arguments about origins of peoples, and particularly the Trojan origin of the Franks, to non- historical matter by his famous citation on this as "ticklish business": "Quant a moy, je n'ose ny bonnement contreuenir a`cette opinion, ny semblablement y consentir librement: toutes-fois il me semble que de disputer de la vielle origine des nations, c'est chose fort chatouilleuse" (PASQUIER 1560, p. 37). Thus in the works of Pasquier we may see an attempt to counter the Italian scholars' disparaging remarks about the North of Europe's people. This French historian emphasized, on the other hand, how important were the Franks for the Roman Empire, to the rulers of which they consistently lent support and troops (PASQUIER 1560, p. 19). Moreover, he emphasized from the very beginning the unity of Gaul's population, in contrast to Italy's disorder ("[...] combien qu'il n'y ait aucune comparaison des partialitez et divisions d'Italie, 'a la commune union de nostre France [...]") (PASQUIER 1560, p. 6). And it was Charlemagne who picked up the imperial title and managed to put the Franks ahead of all barbarian peoples (PASQUIER 1560, p. 30). But although Pasquier's work was a first attempt of a French historian to tackle the difficult themes of the contact between Roman and barbarian civilizations, in it he did not manage to pay adequate attention to the questions of early medieval Merovingian kingdom and left both narrative history of this period and thematic analysis outside the scope of his work.

Thus the distinction between civilization and barbarian culture was less useful in France, or rather totally adversarial, because historians, who were writing on the history of the Frankish kingdom and France, had long made use of the idea of community that the Frankish kings created in addition to espousing the Roman imperial aspirations of Clovis, Pippin III, Charlemagne, Louis the Pious and some other rulers (DU HAILLAN 1570, p. 3-4). In contrast to statement of barbarism, Du Haillan hailed the dignity of the royal dynasties which, even though lacking in Roman culture in the true sense of the term, managed to master the Roman way of holding to power. In a sense, writing a history of the Frankish kingdom in the early Middle Ages required from the very beginning a careful choice of terminology which was to make due to the complex interaction of a Roman imperial structure of power, its provincial realization, local Gallo-Roman aristocrats, the friendly barbarians both within and immediately outside the Roman border who served in legions or possessed a federate or quasi-federate status. In addition, the history of the Frankish kingdom was welldeveloped in a long-standing tradition of history treatises that had received in the Middle Ages a continuous attention and reworking. Thus the questions which historians of the Frankish kingdom asked were different from those posed by Leonardo Bruni and other Italian historians. A treatise by Bernard de Girard seigneur Du Haillan on the history of the kings of France put historical studies on the new plane because it asked and sought to give an answer to the questions important for the French vision of early modern history-writing (DU HAILLAN $1576 \mathrm{~b}$ ). This work has been shown to possess a number of qualities that made it superior in terms of coverage of French medieval history to many if not all 
previous and even some subsequent works (ALLEN 1957, p. 310). Its peculiar achievements lay less in the new information, of which there was almost none, but in restructuring of the narrative of the early medieval Frankish kingdom in a way that satisfied both those who were looking for a rhetorical treatment of the historical subject and those who interested in gathering all available information on the period.

1570s were the period which, we argue, witnessed a bifurcation in the development of history writing among French scholars. This bifurcation was visible in the choice of approaches to early medieval history and to the way in which particular scholars solved for themselves the dichotomy between the Roman Empire, its tyrannical side, and the barbarians' otherness and integration. The changes took a number of forms, in the relationships to the Roman heritage and in the assessment of the first Frankish kings and their place in the history of medieval France. One may see how the attempt to write history of France by Paolo Emilio from Verona resulted in a fairly traditional pro-Roman approach, because key elements of the narrative were discussed from the standpoint of Roman history. Thus one of the Roman generals and local imperial representatives (one may say, magnates). Aegidius was envisioned by him as both military commander and a civil official, a praefectus, whose role was to judge Frankish soldiers as if they were completely Roman in status. Sticking close to the traditional sources like Gregory of Tours, Paolo Emilio stressed those events in history that made the Franks look as long-time allies of Rome and as docile friends of Roman authority as one may imagine. Although Du Haillan chose to adorn the kings as the main bearers of medieval continuity and made them look as those who helped gather the kingdom and drive away the Roman Empire and the magnates who ruled in its names in the last decades before 476, other barbarian and external groups ("Clodion, le Cheuelu, Merouee, Clouis, Charles Martel, et Charles Magne, ont gaigné piece à piece ce Royame sur les Romains, puis sur les Gots, Visigots, Bourguignons, Alans, Sarrazins et autres barbares nations, et les ont chassez de la France") (DU HAILLAN 1570, p. 4v). While the struggle against the Visigoths was a common story in histories because of the approach of Gregory of Tours to this question for the reason of the Goths Arianism, the struggle against the Romans was a point only he among his contemporaries made in his treatise. This was in a sense contrary to Pasquier, and especially to Fauchet, who sought, on the other hand, to emphasize the early kings' integration into the Mediterranean world and acceptance by them of the Roman imperial aura in whatever form it came (PASQUIER 1560, p. 37). The place of Aegidius (Gillon). changed in Claude Fauchet's treatise because in his work he was beseiged in Soissons and ever left until his death, although Paolo Emilio wrote that he ran away to the Visigoths. "Puis ayant joint ses forces à celles des Francois, apres auoir gaigné une bataille, il chassa Gilon de son Royame; et tout le reste de sa vie le contraignit demourer en la ville de Soissons, ou (comme dit Paul Emil). fuit vers les Gots, abandonné des Francois auec la mesme legiereté qu'ils l'auoient esleu: car en ce temps-là, ils estoient remarquez pour gens varibles" (FAUCHET 1579, p. 51v-52). One may take this as a sign of certain reverence towards a Roman governor who, 
in the eyes of the educated French historiographer, was also a part of Roman history. Perhaps, his running away would count as a sign of discontinuity with the Roman past, whereas the joint rule, Childeric's in Gaul in general and Aegidius in Soissons made the Frankish kingdom a true representation of the Roman power in the diocese of Gaul. Fauchet, on the other hand, continued in the vein set by Pasquier, discussing the Frankish kings as part of the larger Mediterranean world and the group which was closely connected with the Roman Empire and its traditions "Depuis, les Romains qui demeuroient en gaule vers I'Aquitaine, travaillez par les visigoths arriens, s'allierent des Francs et leur firent la guerre sous la conduite du Comte Paul" (FAUCHET 1579, p. 53).

It is, therefore, interesting to note that Du Haillan, in contrast to Gregory of Tours, suggested how Siagrius, the son of Aegidius, sought the help of the Visigoths to return to power after he was expelled himself by the returning Childeric (DU HAILLAN 1576b, p. 24). This statement is not supported by anything contained in the bishop of Tours' treatise or any information available to modern historians, and thus is a result of the free interpretation by the early modern historian. On the other hand, in the treatise of Claude Fauchet the negative role of the Visigoths and the conflict between them and the Franks was downplayed. Instead, the balance of power in Gaul came to be seen in the context of the Late Roman political situation in the Western Mediterranean. Thus unlike Bernard Du Haillan, he emphasized that both Franks and Visigoths were part of the complex power struggles between the Western and the Eastern imperial courts, between the Western imperial court and local Romanized elites, and between the Roman and local elites, on the one hand, and barbarians, on the other. For example, he thought that it were the Gallo-Roman elites in the person of Avitus (455-456). and even Byzatine emperor Marcian (450-457) (FAUCHET 1579, p. 98-100). who were behind the advances that the Visigothic king Theoderic II (453-456). managed to make. Thus for Fauchet the Visigoths, apart from becoming an agressive force, turned instead into a warrior group who acted within the context set by the local Gallo-Roman magnates and the Byzantine Empire.

The moral aspect rang a high note in the treatise of Du Haillan, where he claimed that all kings of the first "race", the Merovingians, were in their behavior were much like children, and thus period of the Frankish history could be considered childhood " Le second age qui est de ieiunesse et adolescence commance au Roy Clovis, qui fut le premier Roy Chrestien, et qui accreust le Royame de la soy Chrestiéne ... L'age de ces Rois de la race de Clovis qui se laisserent couler aux voluptez, à la neantise, et à la nonchalance, se peult veritablement comparer à la ieunesse et adolescence" (DU HAILLAN 1570, p. 1v). Fauchet made Childeric significantly change his behaviour after a vision he had from a window of his new wife Basina's palace. He claimed that having seen the tribulations which expected the kingdom if were not change his ways, Childeric turned to the good side "Childeric à la facon des Roys (oubliant ce qui estoit mauuais, se resiouit de la belle et noble lignée qui deuoit fortir de luy" (FAUCHET 1579, p. 52v). Fauchet sought to emphasize continuity between the early medieval Frankish kingdom 
and medieval France, calling Clovis the first Louis the Christian. "Louis premier Chrétien" (FAUCHET 1579, p. 53). This was obviously an attempt to draw a line of succession between the Merovingians and the Capetians, in this case Louis IX the Saint. "Louis premier Chrétien" (FAUCHET 1579, p. 53). This construction of the rhetorical narrative with a strong emphasis on moral elements (which were supposed to be perceived on a very personal, internal level). well fits the suggestion of scholars discussing the general development of the Humanities in the early modern period (PÉCORA 2001, p. 79-116; HANSEN 2012, p. 159-161).

Thus the crisis of the mid-17th century, which has been so vividly described by scholars, was already anticipated by this bifurcation in the $1560 \mathrm{~s}-1570 \mathrm{~s}$, which already led to growing difference between rhetorical presentation, constructed around psychologization of narrative, and erudite knowledge. All authors heavily used the moral approach that had developed within the dominant paradigm of the "republic of letters". Thus looking at Pasquier's, Du Haillan's and Fauchet's treatises, one may notice that they have gone different ways. Pasquier sought to the best of his ability to stay within the erudite discourse for which establishment of fact, close relationship with the Roman Empire and the Franks' Roman heritage were important. In this he followed the tradition set out by both native French scholars like Robert Gaguin and by those Italians like Paolo Emilio who chose to move to France and write its history. Du Haillan, on the other hand, sought to construct his text with reverence to and in agreement with the principles of the rhetorical genre, paying attention to the narrative with definite psychological characterizations. Thus one may notice in the latter's work a trend which has been established for other humanities (STRUEVER 1970, p. 138; IANZITI 2007, p. 253-257; HANSEN 2012, p. 159-161). Fauchet, on the other hand, while paying significant attention to a moral lesson, tended to lean back to Gaguin's and Pasquier's reverence towards the Roman past and withheld all comments about expurgation of the "others" from Gaul. In a sense, this was in interesting case of development of historical thought between the two opposites and its subsequent synthesis. Thus by the 1570 s the polemic between scholars who claimed to their kingdoms, principalities or Empires the right to call themselves heirs of the Roman Empire subsided as a discourse of power, and turned into scholarly discussions.

The changes in the perception of early medieval history and the relevance of Roman heritage and Frankish-Roman record of cooperation in the context of creating the early medieval Frankish kingdom took place in the situation of considerable political changes in Europe. The idea of European unity, that had originated in the Middle Ages under the aegis of the Papacy, was the foundation of all interaction between the Empire and the kingdoms (ANDERSON 1998). The transformation of political power which manifested itself in the emergence of "composite monarchies", carrying the traits of "legal pluralism", may have been instrumental in providing the grounds for the scholarly community, "the republic of letters", to disagree significantly on the uses of the past. The heritage of early modern history- writing, set out by Leonardo Bruni and others, produced, as we have seen, significantly different results even within the community of French scholars of history, while the differences between scholars of the 
South (Italy, the Iberian peninsula). and the North (France, Empire, England). were much more pronounced. However, even these differences allowed for the polemics in France to stay within the boundaries of academic community. The divergent views on the relationship between the kingdom of France and the Mediterranean did show up in significant disagreements about historical events and their interpretation, but these disagreements, as we have seen, never took forms which could damage the long-term interest of the French crown towards the Mediterranean.

\section{Bibliography}

ALLEN, J. W. A history of political thought in the sixteenth century. London: Methuen, 1957.

ANDERSON, M. S. The origins of the modern European state system, 1494- 1618. The modern European state system. London; New York: Longman, 1998.

BEATUS RHENANUS. Rerum Germanicarum libri tres (1531): Ausgabe, Übersetzung, Studien. MUNDT, Felix (ed.). Tübingen: Niemeyer, 2008.

BRUNI, Leonardo. De bello italico versus gothos. s. I., 1441.

. History of the Florentine people. HANKINS, James (ed.). Cambridge: Harvard University Press, 2001.

DU HAILLAN, Bernard de Girard. De I'estat et succez des affaires de France: oeuure contenant les choses plus singulieres \& plus remarquables, aduenuës durant les regnes des rois de France, depuis Pharamo[n]d premier roy des Francs, Francons, ou Fra[n]çoys, iusques au roy Loys vnziesme: ensemble vne sommaire histoire des seigneurs, comtes, \& ducs d'Aniou. Paris: I'Huillier, 1570.

. L'Histoire de France. Paris: L'Huillier, 1576.

. L'histoire générale des rois de France jusqu'à Charles VII inclusivement. Paris: L'Huillier, 1576.

BECHER, Matthias. Chlodwig I: der Aufstieg der Merowinger und das Ende der antiken Welt. München: Beck, 2011.

BOUTEILLER, P. Un historien du XVI siecle: Etienne Pasquier. Bibliothèque d'Humanisme et Renaissance, v. 6, p. 357-392, 1945.

BOUWSMA, W. J. Three types of historiography in post-renaissance Italy. History and Theory, v. 4, p. 303-314, 1964-1965.

BOUWSMA, William J. A Usable Past: Essays in European Cultural History. Berkeley: The University of California Press, 1990.

BREISACH, E. Historiography: Ancient, Medieval, and Modern, Third Edition. Chicago: University of Chicago Press, 2008. 
BURY, John Bagnell. A history of the later Roman Empire from Arcadius to Irene (395 A.D. to 800 A.D.). London: Macmillan, 1889. v. 1.

CABRINI, Anna Maria. Macchiavelli's Florentine histories. In: NAJEMY, John M. (ed.). The Cambridge companion to Machiavelli. Cambridge: Cambridge University Press, 2010, p. 128-143.

COCHRANE, Eric W. Historians and historiography in the Italian Renaissance. Chicago: University of Chicago Press, 1981.

CONNELL, William J. Italian Renaissance Historical Narrative. In: RABASA, José et al. (eds.). The Oxford History of Historical Writing. 1400-1800. Oxford: Oxford University Press, 2012. v. 3, p. 347-363.

DALY, W. M. Clovis: how barbaric, how pagan? Speculum, v. 69, p. 919-664, 1994.

DRINKWATER, J. F. The Bacaudae of fifth-century Gaul. In: DRINKWATER, J. F.; ELTON, H. (eds.). Fifth-century Gaul: a crisis of identity? Cambridge: Cambridge University Press, 1992, p. 208-217.

ELliOT, J. H. A Europe of composite monarchies. Past \& Present, v. 137, p. 48-71, 1992.

EMILIO, Paolo. De rebus gestibus francorum. Paris: Lodocus Badicus, 1516.

FAUCHET, Claude. Recueil des antiquitez gauloises et francoises. Paris: Chez Iacques du Puys, 1579.

FEINGOLD, Mordechai. The humanities. In: TYACKE, Nicholas (ed.). The history of the University of Oxford: Seventeenth-century Oxford. Oxford: Oxford University Press, 1997. v. 4, p. 211-358.

FINDLEN, Paula. Historical Thought in the Renaissance. In: KRAMER, Lloyd; MAZA, Sarah (eds.). A Companion to Western Historical Thought. Malden: Blackwell, 2002, p. 99-122.

FRYE, David. Aegidius, Childeric, Odovacer and Paul. Nottingham Medieval Studies, v. 36, p. 1-14, 1992.

GAGUIN, Robert. Compendium Roberti Gaguini super Francorum gestis: ab ipso recognitum et auctum. Paris: Petit, 1504.

GANSHOF, F. Een historicus uit de VI-e eeuw: Gregorius van Tours. In: Medelingen van de Koniklijke Vlaamse Academie voor Wetenschappen, Letteren en Schone Kusten van Belgie, Klasse der Letteren, Bd. 28, Heft 5, 1966.

GRAFTON, Anthony. A sketch map of a lost continent: the republic of letters. In:

World made by words: scholarship and community in the early modern West. Cambridge: Harvard University Press, 2011, p. 9-34.

GRAFTON, Antony. What was history? The Art of History in Early Modern Europe. Cambridge: Cambridge University Press, 2007. 
GREGORIUS TURONENSIS. Libri Historiarum X. In: KRUSCH, Bruno; LEVISON, Wilhelm (eds.). MGH Scriptores Rerum Merovingicarum. Bd. 1.1: Gregorii episcopi Tvronensis Libri Historiarum X. 2. Aufl. Hannover, 1951.

GRELL, Chantal. La monarchie francaise et I'histoire en France au XVII siecle. Etat des recherches en France. In: GRELL, Chantal; PARAVICINI, Werner; VOSS, Jurgen (eds.). Les princes et I'histoire du XIV au XVIII siècle (Paris-Versailles, 13-16 mars 1996). Bonn: Bouvier, 1998, p. 535-554.

. L'histoire au service d'ambitions hégémoniques. La monarchie francaise et I'instrumentalisation du passé au XVIIe siècle. In: GRELL, Chantal; PELLISTRANDI, Benoit (eds.). Les cours d'Espagne et de France au XVIIe siècle. . Madrid: Casa de Velázquez, 2007, p. 263-308.

Références historiques et modéles politiques: images du pouvoir impérial en Europe XVIé-XVIIIé siècles. Revista de historiographía, v. 14 , n. 8, p. 4-11, 2011.

HALSALL, Guy. Cemeteries and society in Merovingian Gaul: selected studies in history and archaeology, 1992-2009. Leiden: Brill, 2010 (Brill's series on the early Middle Ages, v. 18).

HANSEN, João Adolfo. Instituicão retórica, técnica retórica, discurso. Matraga, v. 20, n. $33,2012$.

HARTOG, Francois. Anciens, modernes, sauvages. Paris: Galaade, 2005.

Regimes of historicity: presentism and experiences of time. Trans.

by Saskia BROWN. European perspectives: a series in social thought and cultural criticism. New York: Columbia University Press, 2015.

HARTOG, Francois and Gérard LENCLUD. Régimes d'historicité. In: DUTU, Alexandru; DODILLE, Nobert (eds.). L'État des lieux des sciences sociales. . Paris: Éditions L'Harmattan, 1993, p. 18-38.

HEINZELMANN, Martin. Gregor von Tours (538-594). «Zehn Bücher Geschichte»: Historiographie und Gesellschaftskonzept in 6 Jahrhundert. Darmstadt: Wissenschaftliche Buchgesellschaft, 1994.

HUPPERT, George. The idea of perfect history: historical erudition and historical philosophy in Renaissance France. Urbana: University of Illinois Press, 1970.

IANZITI, Gary. Challenging chronicles: Leonardo Bruni's History of the Florentine people. In: DALE, S.; LEWIN, A. W.; OSHEIM, D. J. (eds.). Chronicling History: Chroniclers and Historians in Medieval and Renaissance. University Park: Pennsylvania State University Press, 2007, p. 249-272.

. Writing history in Renaissance Italy: Leonardo Bruni and the uses of the past. Cambridge: Harvard University Press, 2012.

JAMES, E. Childéric, Syagrius et la disparition du royaume de Soissons. Revue archéologique de Picardie, v. 3, n. 4, p. 9-12, 1988. 
KELLEY, Donald R. Foundations of modern historical scholarship: language, law, and history in the French Renaissance. New York: Columbia University Press, 1970.

LE ROY LADURIE, Emmanuel. L'État royal de Louis XI à Henri IV, 14601610. Paris: Hachette, 1987.

LEBECQ, Stéphane. Les origines franques: Ve-IXe siècle. Nouvelle histoire de la France médiévale 1. Paris: Seuil, 1990.

MACGEORGE, Penny. Late Roman warlords. New York: Oxford University Press, 2002.

LE NAIN DE TILLEMONT, Louis-Sébastien. Histoire des empereurs et des autres princes qui ont regné durant les six premiers siecles de I'Eglise: de leurs guerres contre les juifs, des ecrivains profanes \& des personnes les plus illustres de leur temps: justifiée par les citations des auteurs originaux: avec des notes pour eclaircir les principales difficultez de l'histoire. Paris: Chez Charles Robustel ..., 1720.

LE NAIN DE TILLEMONT, Louis-Sébastien. Mémoires pour servir à I'histoire ecclésiastique des six premiers siècles, justifiez par les citations des auteurs originaux: avec une chronologie, ou l'on fait un abrégé de I'histoire ecclésiastique; \& avec des notes pour éclaircir les difficultez des faits \& de la chronologie. Paris: Charles Robustel, 1701.

94 PASQUIER, Étienne. Des recherches de la France. Paris: Jean Longis et Robert le Mâgnier, 1560.

MACK, Peter. A History of Renaissance Rhetoric: 1380-1620. Oxford: Oxford University Press, 2011.

OSTENFELD-SUSKE, Kira von. Writing official history in Spain: History and politics, c. 1474-1600. In: RABASA, José et al. (eds.). The Oxford History of Historical Writing. 1400-1800. Oxford: Oxford University Press, 2012. v. 3, p. 428-448.

PÉCORA, Alcir. Máquina de generos. Saõ Paulo: EdUSP, 2001.

PÉRIN, Patrick. À propos des publications récentes concernant le peuplement en Gaule à l'époque mérovingienne: la question francque. Archéologie Médiévale, v. 11, p. 125-145, 1981.

PÉRIN, Patrick;FEFFER, L.-C. Les Francs: Á la conquête de la Gaule. Paris: Armand Colin, 1987. t. 1.

REIMITZ, H. History, Frankish Identity and the Framing of Western Ethnicity, 550-850. Cambridge: Cambridge University Press, 2015 (Cambridge Studies in Medieval Life and Thought: Fourth Series).

REYNOLDS, Beatrice R. Latin Historiography: A Survey, 1400-1600. Studies in the Renaissance, v. 2, p. 7-66, 1955. 
ROUCHE, M. Clovis: suivi de vingt et un documents traduits et commentés. Paris: Fayard, 1996.

SALAÜN, G., A. MCGREGOR et P. PÉRIN. Empreintes inédites de l'anneau sigillaire de Childéric Ier: état des connaissances. Antiquités Nationales, 39, p. 217-224, 2008.

SCHAUB, J. La notion d'État Moderne est-elle utile? Cahiers du Monde Russe, v. 46, n. 1-2, p. 51-64, 2005.

SCHMAUDER, M. The relationship between Frankish gens and regnum: a proposal based on archaeological evidence. In: GOETZ, H.-W.; JARNUT, J.; POHL, W. (eds.). Regna and gentes: The relationship between Late Antique and early medieval peoples and kingdoms in the transformation of the Roman world. Leiden: Brill, 2003, p. 271-306 (The Transformation of the Roman World, 13).

STRUEVER, Nancy S. The language of history in the Renaissance: rhetoric and historical consciousness in Florentine humanism. Princeton: Princeton University Press, 1970.

VAN DAM, Raymond. The Pirenne thesis and fifth-century Gaul. In: Fifthcentury Gaul: A crisis of identity? DRINKWATER, J. F.; ELTON, H. (eds.). Cambridge: Cambridge University Press, 1992, p. 321-34.

VICKERS, Brian. Rhetorical and anti-Rhetorical tropes: on writing the history of elocutio. In: SCHAFFER, E. S. (ed.). Comparative criticism: a yearbook. . Cambridge: Cambridge University Press, 1981. v. 3, p. 105-132.

WALLACE-HADRILL, J. M. The long-haired kings and other studies in Frankish history. New York: Barnes \& Noble, 1962.

WERNER, Karl Ferdinand. De Childéric à Clovis: antécédents et conséquences de la bataille de Soissons en 486. Revue archéologique de Picardie, $v$. 3-4, n. 1, p. 3-7, 1988.

. Les Origines. Histoire de France 1. Paris: Librairie Arthème Fayard, 1984. 


\title{
Desde la justicia al abordaje historiográfico: los expedientes judiciales-criminales decimonónicos del Archivo Nacional Histórico*
}

\author{
From justice to historiographical approach: nineteenth-century criminal \\ court records of the Chilean Historical National Archive
}

\author{
Víctor Mauricio Brangier Peñailillo \\ vmbrangi@gmail.com \\ Investigador y Académico \\ Centro de Estudios Históricos, Universidad Bernardo O 'Higgins \\ Calle Fábrica 1990, Boulevard Universidad Bernardo O 'Higgins, segundo piso \\ Comuna de Santiago - Santiago \\ Chile \\ Germán Adolfo Morong Reyes \\ gmorongreyes@yahoo.es \\ Investigador y Académico \\ Centro de Estudios Históricos, Universidad Bernardo O 'Higgins \\ Calle Fábrica 1990, Boulevard Universidad Bernardo O 'Higgins, segundo piso \\ Comuna de Santiago - Santiago \\ Chile
}

\section{Resumen}

El artículo examina las formas en que la historiografía chilena de las tres últimas décadas ha abordado el valor testimonial presente en los expedientes judiciales criminales, elaborados en el siglo XIX y almacenados en el Archivo Nacional Histórico. El estudio tiene como objetivos analizar las dinámicas históricas que convergieron en la fabricación del documento, en la estructuración de un material fragmentario y mediado, deduciendo por tanto, los desafíos en su utilización como fuente primaria. Luego, se pretende evaluar la pertinencia de metodologías centradas en aquellas condiciones de posibilidad, rescatando el potencial heurístico de "lecturas a contrapelo" y de enfoques "culturalistas" que permitan enfrentar el fenómeno de la mediación escritural entre testimonio y expediente. El diagnóstico sobre el grado de asimilación que ha tenido la historiografía nacional respecto de estos enfoques permite concluir la serie de tareas pendientes en la problematización y hermenéutica de una documentación de uso creciente.

\section{Palabras claves}

Archivo; Historiografía; Enfoque cultural.

\begin{abstract}
This article examines the ways in which Chilean historiography has addressed, in the last three decades, the issue of evidential value in the judicial criminal records made in the 19th century and stored in the National Historical Archive. The study aims to analyze the historical dynamics that converged in the manufacture of documents, in structuring a fragmentary and mediated material, thus deducing the challenges of using them as a primary source. Therefore, it provides an assessment of the relevance of methodologies focused on those conditions of possibility, rescuing the heuristic potential of "reading against the grain" and "culturalist" approaches able to address the phenomenon of scriptural mediation between witness and record. The diagnosis of the assimilation that national historiography has had on these approaches allows us to conclude the number of outstanding tasks on the problematization and hermeneutics over this documentation of increased use.
\end{abstract}

\section{Keywords}

Archive; Historiography; Cultural approach.

Recibido el: 11/2/2016

Aceptado el: 27/7/2016

\footnotetext{
* El estudio es parte integrante de una tesis doctoral inédita, relativa a las "culturas jurídico-judiciales" y a los "usos sociales" presentes en la justicia criminal de la zona centro sur de Chile, entre 1824 y 1875 . El contenido del artículo conformó el análisis introductorio sobre la materia prima central de la obra: un cuerpo de 411 expedientes judiciales por conflictos interpersonales, incoados por iniciativa de parte y donde se disputaban intereses de alto valor para los litigantes, como la vida, la honra, la propiedad agro-ganadera y la paz en el vecindario. El estudio doctoral contó con el patrocinio de la Beca para Estudios de Doctorado en Chile, a cargo de la Comisión Nacional de Investigación Científica y Tecnológica (CONICET) entre los años 2010 y 2014.
} 
Durante las últimas tres décadas, la historiografía en Chile ha ido utilizando con mayor frecuencia e intensidad los expedientes judiciales como materia prima. Este proceso ha sido abonado por las corrientes de la Historia Social occidental que, desde la segunda mitad del siglo XX "re-descubrieron" este material abundante en los archivos para alimentar los lineamientos centrales de una History from below. El enfoque ganó terreno rápidamente en América Latina y Chile no fue la excepción, como se detallará a lo largo de estas páginas. Desde fines de la década de 1980, y tras el cese de la dictadura cívico-militar, los estudios históricos se volcaron fundamentalmente hacia la "Historia social del bajo pueblo". Desde entonces, se produjo una orientación de las ciencias sociales y humanidades nacionales a nutrir una memoria social y de ese modo, superar los efectos amnésicos de la política de estado autoritario, concentrada en el olvido de proyectos políticos populares en el pasado. También ha contribuido a esta valoración del documento judicial, la existencia de un material generoso en el Archivo Nacional Histórico de Santiago [en adelante ANH], con una catalogación certera y de permanente incremento en la cobertura de piezas y legajos para facilitar su consulta pública.

Desde 1930, el ANH almacena expedientes judiciales inéditos, con la promulgación en noviembre del año anterior de la ley que dio a luz a la Dirección General de Bibliotecas, Archivos y Museos. El artículo $14^{\circ}$ de esta normativa explicaba que al ANH debían ingresar anualmente "los libros copiadores de sentencia de los Tribunales de Justicia y los expedientes judiciales que hayan cumplido ochenta años de antigüedad". De todos modos, la constitución de los expedientes judiciales como material de archivo, había comenzado antes, pues por ley de 15 de octubre de 1875 se dio nacimiento a los archivos judiciales de Santiago y de Valparaíso (ANH 2009, p. 14). El ANH, por tanto, se constituye en la actualidad en el principal repositorio nacional de expedientes judiciales confeccionados antes de 1900. Los contiene

en los archivos pertenecientes a cada juzgado de Letras del siglo XIX. Estos fondos están presentados por un catálogo que divide el material en causas civiles y criminales. Además, los ordena cronológicamente y de acuerdo a la materia jurídica que dio origen al juicio, según figura transcrito en la carátula de cada unidad.

El uso sistemático de esta documentación obliga a hacer un alto en el camino para reflexionar sobre los desafíos metodológicos que presenta, los enfoques utilizados para enfrentar sus testimonios y las oportunidades que ofrece la misma fuente para capitalizar su especificidad entre las otras categorías de fuentes primarias. La historiografía nacional ha puesto atención particular en aquellos expedientes que, a primera vista, permitirían acceder a las voces de actores sociales silenciados por los relatos historiográficos tradicionales y por documentación más oficial. La profusión de trabajos monográficos se ha centrado en declaraciones de inculpados, de testigos, en los autos de querellas y denuncias presentes en sumarios. Por tanto, han sido los expedientes nacidos de juicios criminales los que han capturado con mayor efectividad los esfuerzos investigativos. Han recibido un tratamiento mayoritario debido a que satisfarían 
las expectativas de la historia social del bajo pueblo por dar cuenta de historias de lucha y gestión social ante los embates del poder y sus aparatos policiales y de criminalización social. En este sentido, los estudios se han concentrado en el proceso histórico de incremento en la voluntad de intervención estatal experimentado entre las reformas borbónicas del siglo XVIII y la construcción de estado independiente desde la década de 1830, con supresión de las soberanías locales y las culturas populares. ${ }^{1}$

Tomando en consideración este escenario, en estas páginas se ha planteado como objetivo el análisis de los desafíos que plantean hacia la historiografía nacional, los testimonios inscritos en los expedientes judiciales-criminales tramitados en el siglo XIX y almacenados en el ANH. Este propósito se ha diseñado, considerando que la documentación fue fruto de una práctica judicial socialmente localizada y mediada por un ejercicio escritural especializado en la traducción de los testimonios de litigantes y de testigos. Complementariamente, el artículo se propone examinar la utilidad de metodologías aplicadas en investigaciones sobre material similar en historiografías de otras latitudes y que han problematizado el valor informativo de los testimonios de los expedientes. De ese modo, y como tercer objetivo, se apunta a diagnosticar el impacto que han tenido estas metodologías en los abordajes sobre esta documentación en Chile.

\section{Expedientes judiciales de archivo: esquirlas de justicia, de conflictos y de mediaciones}

En la administración de justicia criminal del siglo XIX, la práctica de los juzgados generaba un registro escritural heterogéneo, discontinuo y muchas veces inconcluso. La serie de variables que influían en la fabricación de la documentación dio como resultado la existencia de un cuerpo documental diverso en extremo que atestigua el grado de especificidad presente en cada situación judicial a la hora de poner por escrito las fases de las causas. Cada escalafón del organigrama de autoridades con potestad de juzgar podía generar documentos. Así lo hacían los inspectores, jueces instalados en las bases de la pirámide y los subdelegados, quienes, por lo general, recibían las querellas y denuncias y efectuaban la investigación sumaria poniendo por escrito sus resultados. Los mismos alcaldes o regidores de municipio, actuando como jueces "legos" de primera instancia, reproducían el ejercicio cuando las partes concurrían a sus despachos o la gravedad de los hechos les conminaba a actuar por iniciativa propia o "de oficio".2 La situación escritural se complejizaba cuando estos magistrados recibían los sumarios de aquellos jueces subalternos

\footnotetext{
${ }^{1}$ El listado de esta discusión historiográfica es extenso, pero sirva de muestra los trabajos chilenos presentes en la obra colectiva editada por Ernesto Boholavsky y Milton Godoy (2010).

2 El Reglamento de Administración de Justicia promulgado en 1824 sirvió como marco normativo provisorio para la organización de juzgados, tribunales y de atribuciones de los jueces hasta 1875, cuando salió a la luz la ley orgánica al respecto. El Reglamento estipulaba que en las ocho provincias existentes en el territorio nacional, debía operar un juez de Letras en cada Departamento (las unidades administrativas en que se dividían las provincias). Pero señalaba que en caso que se careciera de jueces de este tipo, le subrogaría "indefinidamente" el alcalde de la villa cabecera departamental. Por su parte, la justicia de menor y de mínima cuantía, en las subdelegaciones y distritos, estarían a cargo respectivamente de los subdelegados e inspectores, autoridades gubernativas y policiales dependientes del Gobernador departamental (ANGUITA 1913 , p. 152-163).
} 
y debían continuar la causa, agregando, corrigiendo o devolviendo escritos mal tramitados. En muchas ocasiones, estos jueces actuaban en forma verbal, llegando a acuerdos con las partes de los que no quedaba evidencia más que el carácter inconcluso de la tramitación que finalizaba en un punto intermedio del juicio. De ese modo, y como lo requería el Reglamento de Administración de Justicia de 1824, cada uno de estos jueces locales debía tener un archivo propio ("un libro a cargo de su respectivo escribano") donde conservar estos trazos marginales de sus prácticas judiciales (ANGUITA 1913, p. 152).

Las visitas judiciales, correspondiente a fiscalizaciones periódicas y en terreno, de jueces de Letras hacia estos jueces "legos", se concentraron en estos archivos precarios y escasos. Tras la revisión de este material, surgieron las principales críticas de la esfera letrada, que subrayó la no conclusión de las causas y se escandalizó por la paralización de juicios que envolvían crímenes graves. Una situación similar deja entrever la serie de reparos que los ministros de las Cortes de Apelaciones hicieron llegar a los jueces de Letras. Los reproches descendían tras la revisión de los informes trimestrales que estos elevaban a tales tribunales dando cuenta del estado en que se encontraban las tramitaciones de las causas dentro de sus órbitas de competencia (BRANGIER 2012, p. 124-151).

La documentación que resguarda el $A N H$, refleja entonces una parte ínfima de la actividad judicial intensa del periodo. Se trata, al fin, de los expedientes que alcanzaron a derivar aquellos jueces "legos" hacia los juzgados de Letras y de los que estos produjeron por iniciativa propia. Pero a su vez, el ANH recibió sólo los registros de juicios que pudieron rescatarse de los archivos de los jueces letrados, los que no gozaban de las condiciones ideales de seguridad para evitar extravíos, hurtos y deterioro por las condiciones laborales y ambientales adversas (PALMA 2014, p. 20). Al fin, el ANH guarda retazos de la judicialización del proceso: no todo el litigio se escribió. Y de lo que se escribió, no todo se conserva.

Por otro lado, estos expedientes judiciales en materia criminal se vinculaban a estelas de conflictos interpersonales que desbordaban con creces las fronteras del juzgado. El juicio en sí se asociaba a esquirlas de discursos, de acuerdos y de pacificaciones previas y simultáneas. Fragmentos de emociones, razonamientos e intereses. Esta condición segmentada del documento se debía, en gran medida, a que la judicialización figuraba como el recorte de un conflicto más largo que tuvo lugar fuera del juzgado. Precedido, acompañado y sucedido por el plexo de las tensiones sociales, el acto de asistir ante la autoridad con potestad judicial apuntaba a la reformulación de la trama compleja que sostenía al conflicto interpersonal (UNDURRAGA 2015, p. 1-2).

La incardinación de la potestad de juzgar que portaban las autoridades gubernativas locales, en el seno de las relaciones sociales, satisfacía las expectativas sobre la función de la justicia, desde el periodo de construcción de estado independiente, heredadas de la cultura jurídica y política de la monarquía ibérica y sus posesiones de ultramar. Como ha precisado la historia crítica del derecho, las metrópolis de España y Portugal reinaron sobre suelo americano a partir de la delegación de la potestad de juzgar en la gama de funcionarios que gobernaban en su nombre, quienes debían, sobre todo, mantener la paz social 
en comunidades internamente desiguales y con corporaciones celosas de sus fueros y derechos. De ese modo, la justicia se concebía con un fin "redistributivo", manteniendo el orden social establecido, preservando a cada cual en su derecho específico y dándole a cada quien lo que "le correspondiese" (HESPANHA 1993, p. 210; GARRIGA 2004, p. 13-44; AGÜERO 2008, p. 130; BARRIERA 2010, p. 28; DE ARAUJO 2015). Tras las batallas de independencia en Chile, se sucedieron discursos tendientes a resguardar una férrea separación de los poderes del estado, sin embargo, en ningún caso se les arrebató la potestad de juzgar a las autoridades gubernativas, policiales y edilicias locales. La necesidad de mantener "la tranquilidad del vecindario" y el "orden público", junto con el interés escaso de los abogados por fungir como jueces de Letras territoriales (DE RAMÓN 1989, p. 1-59), llevó a las dirigencias nacionales a confiar la función judicial en estos "jueces legos" hasta bien entrado el siglo XIX. ${ }^{3}$

La convicción respecto a que la justicia hispanoamericana debía insertarse en medio del curso del conflicto social para mantener la paz y la "vida en policía" (MARCONI; BARRIERA 2015, p. 148), sumado a la pertenencia de los jueces "legos" al entorno social y cultural en que se desenvolvían los litigantes, generó una práctica judicial cotidiana sin límites precisos con otras esferas sociales de resolución de conflictos, como ha ido demostrándose paulatinamente en la historiografía chilena (SALINAS 2000; ROJAS 2008; MORENO 2015; CELIS 2015). Tal como se sabe para el caso de España desde inicios de la Modernidad, de los tránsitos experimentados por los conflictos sociales y sus respectivos 100 acuerdos, negociaciones y (re)conciliaciones, desde los escenarios informales hacia los juzgados, (KAGAN 1991, p. 41; MANTECÓN 2015), hoy se conoce un poco más respecto a la complejidad de los conflictos sociales interpersonales en Chile en el siglo XIX y el espacio marginal (aunque a veces determinante) que ocupaba la judicialización dentro del conjunto. Por ello, el juicio y los expedientes que de ahí derivaron, se conciben como estelas ínfimas de una red densa de tensiones que conformaban al conflicto y que escapaban del radio judicial, de sus prácticas de escritura y del expediente. Al fin, para sintetizar las dos aristas de la fragmentación que refleja el expediente judicial en relación a los conflictos sociales que pretendía traducir, es posible asentar que el juicio reflejaría un recorte de la realidad y el expediente un recorte del juicio.

Por último, debe considerarse un tercer ángulo respecto a la naturaleza fragmentaria del documento y se vincula al proceso de su fabricación: las fuentes judiciales fueron elaboradas tras un ejercicio insoslayable de mediación. Entre la voz de los sujetos sociales y el resultado escrito de las tramitaciones se encontraba el arte cotidiano de agentes especializados en la escritura judicial. El testimonio de los litigantes, de los testigos y de los reos, por lo general no quedó plasmado directamente en el papel. Hubo un ejercicio de transcripción y de

\footnotetext{
3 El reemplazo de una esfera "lega" por una justicia letrada, fue un proceso institucionalmente muy lento a lo largo de la centuria. Recién en 1888 se dictó la normativa -que no se alcanzaría a cumplir del todo a fines del siglo XIX- que exigía un juez de Letras en cada Departamento que contara con más de 30.000 habitantes (STABILI 2000, p. 238). Además, sólo la ley orgánica de tribunales de 1875 estipuló la separación de funciones gubernativas y judiciales para los cargos de subdelegados e inspectores, creando, paralelos a estos funcionarios, los jueces de subdelegación y de distrito (Estado de Chile 1875, p. 16 y ss.).
} 
traducción por parte de escribanos, representantes especializados, defensores, curadores y hasta del mismo juez. Los historiadores franceses Arlette Farge y Jacques Revel, concibieron esta mediación escritural, respectivamente, como una "práctica específica de poder", que desnudaría las "relaciones de fuerza" vigentes en cada juicio (GALLUCI 2009, p. 3).

A fin de cuentas, los expedientes judiciales criminales del siglo XIX chileno, portan en su integridad una triple fragmentación. Su dispersión constitutiva es el resultado de prácticas discontinuas de escritura judicial, de la inserción del juicio en conflictos sociales complejos y de un doble proceso de mediación: de tipificación técnico-jurídica de las pugnas desarrolladas en la arena social y de traducción de las voces de sus actores a través de la escucha y la escritura de los agentes de los juzgados. La fuente judicial se ofrece en el archivo, a primera vista, como un conjunto mal cosido de retazos que escasamente pueden dar cuenta de las experiencias vividas en los juzgados y sus fronteras sociales. La historiografía en Chile que ha trabajado con este material, ha debido asumir el desafío de cuestionar su valor informativo per se $y$ se ha visto en la obligación de forzar fronteras metodológicas, hurgar en las condiciones de posibilidad del documento y cautelar las conclusiones que se puedan ir levantando al respecto.

\section{El investigador frente al expediente}

En términos generales, los primeros usos historiográficos que se hicieron de la fuente judicial, no cuestionaron el potencial informativo que ofrecía, volcándose con confianza a la búsqueda de los fenómenos sociales y culturales que sus fojas corroídas habrían permitido reconstruir. Pueden considerarse, sobre todo, los trabajos de Edward P. Thompson. El historiador argentino Darío Barriera (2013, p. 359) ha expuesto los lineamientos de esta discusión y las respectivas referencias bibliográficas ligadas al "redescubrimiento de las fuentes judiciales". En esta línea coincide también la primera micro-historia italiana, de la mano de Carlo Ginzburg y de Giovanni Levi, quienes confiaron en la capacidad de las fuentes judiciales de transmitir prístinamente los fenómenos culturales y la dinámica de las redes sociales (GALLUCI 2009, p. 14).

Con los influjos post-estructuralistas, el impulso del "giro lingüístico" y la asunción de las premisas de la "deconstrucción" que adoptaron las humanidades y las ciencias sociales desde fines de la década de 1960 (AGUIRRE 2006, p. 89 y ss.) las investigaciones debieron reconsiderar el valor informativo directo de las fuentes judiciales, como así mismo, el quehacer historiográfico en su integridad. Desde entonces, la pregunta por la veracidad de los testimonios que conformaban la hebra fina de los expedientes, se tornó en una parada obligatoria antes del abordaje de su contenido (BURKE 1978). En este sentido, jugaron un papel relevante los trabajos de las historiadoras Arlette Farge (1991) y Natalie Zemon Davis (1987), quienes realizaron un ejercicio heurístico sobre las narrativas presentes en los testimonios y en las construcciones de discursos judiciales verosímiles, como enfoque necesario antes de desechar este material por carecer de verosimilitud. Las formas comunes y reiterativas de tejer los enunciados con tal de persuadir al interlocutor en el juzgado, decían bastante 
sobre los imaginarios y los valores que se consideraban socialmente legítimos en el pasado. Las narrativas de los litigantes e inculpados, se deslizaban desde la forma del documento hacia su contenido.

La historiografía latinoamericana y latinoamericanista que comenzó trabajando con los expedientes, tampoco cuestionó mayormente este tipo de barreras informativas. De acuerdo a la discusión bibliográfica que propuso Tamar Herzog (1995, p. 318), en esta línea podrían inscribirse, por ejemplo, los trabajos de Michael Scardaville, sobre la criminalidad urbana en México tardo colonial, de Susan Socolow, acerca de la criminalidad femenina en Buenos Aires a fines del siglo XVIII y de Francois Giraud, respecto a las modalidades de la violencia social en México en el mismo periodo.

En Chile ocurrió otro tanto. Desde sus orígenes, la historiografía nacional había esperado el transcurrir de un lento proceso de ordenamiento archivístico entre fines del siglo XIX y el primer cuarto del siglo XX. Por ello, la literatura se había concentrado en el acontecimiento emanado de la dispersa documentación oficial disponible (ENCINA 1949). La discusión estaba condicionada a orientarse hacia las gestas militares heroicas, a los prohombres de la construcción del Estado republicano y a las familias asociadas a estas figuras. La ausencia de las grandes mayorías en el relato historiográfico sólo fue suplida por la emergencia de la historiografía marxista desde mediados del siglo XX (GREZ 2005), aunque los sectores sociales que merecieron la atención sólo fueron aquellos inscritos en el devenir de la proletarización progresiva. Sólo las figuras de Mario Góngora desde la medianía del siglo XX y de Álvaro Jara, Rolando Mellafe y Gabriel Salazar, desde entonces hasta la década de 1980, contribuyeron, junto a otros y otras, a problematizar históricamente la existencia de sectores sociales de los que no se sabía nada hasta el momento, como los inquilinos, vagabundos, afrodescendientes, labradores y peones.

Por lo anterior, la historiografía nacional de las últimas décadas ha interpretado la disponibilidad de la fuente judicial como una veta inexplorada para recuperar las vidas y conciencias de vastos sectores de la población marginados de la producción académica. El entusiasmo nacido de la convicción de estar frente a un material sub-utilizado por el oficio y de la prisa por acceder a sus hallazgos, opacó los cuestionamientos críticos que ameritaba este tipo de insumos. Algunos estudios que se levantaron y lo siguen haciendo desde las fuentes judiciales y que no han enfrentado las preguntas respecto a su naturaleza fragmentaria y mediada, han sido los de Jaime Valenzuela (1991), Holdenis Casanova (1994), Rolando Mellafe (1994), Eduardo Cavieres (1998), René Salinas M. (1998; 2000) Claudia Arancibia, Tomás Cornejo y Carolina González (2003), Leonardo León (2005), Mauricio Rojas (2008), Verónica Undurraga (2012) Ivette Lozoya (2014), entre los que han tenido mayor influencia.

Así entonces, la historiografía en Chile que ha apoyado sus investigaciones sobre estos expedientes, parece presa en los vericuetos de un nudo gordiano. En los casos en que se ha visualizado la utilidad de los testimonios presentes en sus fojas, se han soslayado las preguntas elementales respecto a las condiciones de posibilidad de tales enunciados y a las distancias entre hechos y versiones de 
hechos. Por el contrario, el sometimiento de los discursos judiciales a una crítica de-constructiva tiende a arrastrar la investigación hacia un pesimismo heurístico, concluyendo la inutilidad del documento para decir algo certero sobre el pasado. Todo indica que una salida productiva al respecto viene construyéndose desde la posibilidad de ejercer una "lectura a contrapelo" sobre el archivo.

La aplicación del método asociado a una "lectura a contrapelo" de la documentación de archivo, entrega las herramientas para trascender la información explícita, comprender las condiciones de producción que le dieron vida material y, sobre todo, develar las correlaciones de fuerza que generaron la mediación escritural. Una serie de autores han propuesto el método de la "lectura a contrapelo" de los documentos, como ejercicio de búsqueda de las relaciones de poder que sostuvieron su construcción. El pionero en este sentido y que acuñó el término fue Walter Benjamin (AGUIRRE 2015, p. 41 y ss.) Este ejercicio crítico sobre las condiciones de producción de cualquier constructo cultural (entendidos por tanto como "textos" que podían someterse a la crítica sobre las dinámicas de su generación), recibió nuevos aires tras las propuestas etnográficas de Cliford Geertz, en la década de 1970 (TERRADAS i SABORIT 2001, p. 188). Particularmente para el caso de propuestas de "lectura a contrapelo" en las fuentes judiciales, sirvieron los subsidios post-marxistas y post-coloniales que el Grupo de Estudios Subalternos le brindó a la "Historia desde abajo", desde mediados de la década de 1980, escudriñando la serie de estratos de dominación y hegemonía que operaron en la construcción de la fuente y en la invisibilización de la "voluntad del sujeto" (GUHA 1988, p. 45-86; 1998, p. 39-40).

La aproximación a los testimonios en los expedientes de archivo, no radicaría en un ejercicio de extracción directa del contenido de sus relatos, sino, en cambio, del análisis respecto a la trama compleja de fabricación documental. Desde entonces, el proceso de construcción de la fuente debía ser entendido como producto de relaciones desiguales de fuerza, donde el sujeto histórico, pese a encontrarse en situación de desventaja, pudo maniobrar y deslizar su voluntad por los intersticios del poder. Las relaciones de fuerza que antecedieron y sostuvieron el proceso de escritura oficial en el pasado, habrían permitido todo un "arte de la resistencia" de estos actores sociales (SCOTT 2000). La historiografía latinoamericana y latinoamericanista se apoyó en estos marcos teoréticos para enfrentar el estudio de la "construcción negociada" del poder y para el análisis de las "culturas políticas" de la plebe. Hasta hoy, son de referencia obligada los trabajos de Eric Van Young, Gilbert Joseph, Daniel Nugent, Florencia Mallon, Luis Miguel Glave, Ricardo Salvatore, entre otros, discusión que sintetizó con acierto Raúl O. Fradkin (2008, p. 27, 29 y 56). También resultan pertinentes los aportes de Inés Ortiz Yam (2005) y de Di Meglio (2008). ${ }^{4}$

Tras la consideración de estos antecedentes, en la historiografía chilena comenzaron a surgir estudios que tenían como centro la problematización del

\footnotetext{
${ }^{4}$ De modo más directo, la "historia de la justicia" en la región venía centrando su atención en los "usos sociales" que los sujetos en situación de dominación -indios, "castas", afrodescendientes, mujeres, pobres urbanos, etc.- hicieron de la disponibilidad judicial en busca de mantener o mejorar sus posiciones (STERN 1982; BORAH 1985; REIS 1986; AGUIRRE 1993; DÍAZ 2000; OWENSBY 2011).
} 
documento judicial con tal de visualizar los perfiles de "conciencias subalternas". La hermenéutica sobre las narrativas de los testimonios y los ejercicios de "lecturas a contrapelo", permitieron la emergencia de monografías que se enfocaban crecientemente en las estructuras de discursos persuasivos de los litigantes e inculpados, como tácticas integrantes de un "saber hacer" en situación judicial (TUOZZO 1996; ROJAS 1999; FERNÁNDEZ 2007; BRANGIER 2012b). Esta presunción metodológica llevó a centrar el análisis en los elementos axiológicos que conformaban tales versiones argumentadas y a estudiar los intereses que constituían su norte (CORNEJO 2007).

El salto desde el foco en las estructuras narrativas y en las tácticas persuasivas, hacia una "lectura a contrapelo" que desmonte las etapas y tensiones sociales incrustadas en la fabricación del documento, resulta aún una tarea pendiente. Los trabajos de las historiadoras María Eugenia Albornoz (2006; 2011; 2012) y Aude Argouse $(2013 ;$ 2014), han permitido pensar la documentación judicial expedientes judiciales coloniales y los cuadernos de escribanos- como constructos generados a raíz de situaciones específicas de poder, de encuentros dialógicos y con una función política performativa de la realidad.

La doble fragmentariedad constitutiva de los juicios criminales iniciados de parte, presentes en los repositorios del $\mathrm{ANH}$, obligan a esquivar la tentación de reconocer su contenido como versiones diáfanas de realidades externas al juicio. En cambio, la deconstrucción de su proceso tenso de fabricación, como estrategia metodológica, entrega pistas sobre los juegos tensos en que se sostuvieron las sociedades en el pasado y respecto a las oportunidades sociales de participar en el proceso de escritura judicial, y por tanto, de erección de la misma institucionalidad judicial. Particularmente para los estudios centrados en el siglo XIX, el enfoque permite atisbar los modos en que los sujetos sociales supieron participar del sendero frágil y reversible que llevó a la construcción de Estado, como además, en el delineamiento de un poder judicial corporizado y localizado en su entorno más inmediato. ${ }^{5}$

Por otro lado, queda pendiente la tarea por abordar los expedientes, considerando el gesto de mediación que les resultó inherente y del que no pudieron escapar, pues implicaba la condición misma de su existencia material. En este sentido, la apertura hacia los enfoques culturalistas que asumió la historiografía latinoamericana desde la década de 1990 (MALERBA 2010, p. 93) ha abonado el terreno para recoger la perspectiva socialmente negociada de la noción de "cultura" que ha predominado desde entonces. La "nueva" Historia Cultural ha comprendido a la cultura como conjunto de significados, como repositorio simbólico común y aprovechable por los distintos estratos sociales. Bajo este prisma, autores como Hayden White (1974) o Peter Burke (1978)

\footnotetext{
${ }^{5}$ Los avances que podrían adelantarse bajo esta óptica, contribuirían a la erosión del antiguo lugar común de los estudios sobre el siglo XIX, respecto a la eficiencia en la construcción y consolidación prematura de un estado nacional. Pese a la crítica levantada a esta perspectiva (SALAZAR 2005), los estudios no han abordado al Estado como objeto de estudio y por tanto, como puntualizó el antropólogo e historiador argentino Germán Soprano (2010) se sabe muy poco sobre las fragilidades y porosidades de las instituciones oficiales -como la justicia- toda vez que las investigaciones en Chile, centradas en el mundo social, han dado por sentado su capacidad de intervenir la sociedad.
} 
tempranamente cuestionaron la distinción de una "alta" y una "baja" cultura. El modelo, por cierto, no excluye en absoluto la centralidad del conflicto y la lucha social entre los sujetos que hicieron uso de este conjunto de significados y símbolos. Por el contrario, el enfoque enriqueció la teoría del conflicto y de la construcción de hegemonía, al brindar pistas respecto al modo en que los actores escrutan los elementos del campo cultural que le pueden ser de más provecho, para posicionarse de mejor modo en el plexo de las tensiones sociales. Como propuso el historiador británico Edward Thompson (1995, p. 102), uno de los primeros exploradores en esta perspectiva, "la contienda simbólica adquiere su sentido sólo dentro de un equilibrio determinado de relaciones sociales".

Los influjos de esta "Nueva" Historia Cultural y de su aclimatación a las historiografías latinoamericanas, han dado pie para una re-lectura de la mediación escritural constitutiva del expediente. El guante está arrojado para que las investigaciones examinen la documentación de este tipo como artefactos culturales, como producto de las interacciones entre sujetos en contienda y en posición desigual, aunque compartiendo unos mismos lenguajes y códigos que, posteriormente fueron apropiados en pos de sus propias expectativas e intereses. En este sentido, no conviene descartar el valor informativo de los testimonios de los litigantes o imputados sólo porque fueron transcritos por agentes de los juzgados o pasaron por el tamiz de sus "escuchas" tergiversadoras. El escrutinio de la transversalidad social de los lenguajes desplegados en los estrados, suaviza la violencia con la que se pensaba el ejercicio de la escritura del expediente y permite, en cambio, examinar los valores, representaciones e imaginarios que compartían los justiciables con los agentes de la escritura judicial. Los códigos axiológicos, lenguajes y legitimidades socialmente compartidos y apropiados en la justicia criminal del Chile del siglo XIX instan a analizar la traducción del escribano, como una práctica inserta en estos imaginarios sociales de los que también formaban parte los sujetos deponentes.

La historiografía en Chile no ha echado mano del enfoque de los lenguajes comunes para enfrentar la condición mediada de los testimonios judiciales. Pese a que a mediados del siglo XX, el historiador Mario Góngora (1951) había sentado las bases para una lectura de la construcción de todo documento oficial, bajo el prisma de las "convicciones jurídicas" socialmente compartidas, el legado no fue recogido sistemáticamente. De todos modos, en los últimos 20 años ha habido una incorporación de enfoques culturalistas de orientación deconstructiva que ha permeado al campo historiográfico nacional y particularmente a los estudios centrados en las fuentes judiciales. Uno de los factores que explican este giro ha sido la fundación y desarrollo de centros de estudios culturales alojados en el seno de los principales nichos académicos de investigación humanística del país. ${ }^{6}$ El proceso debe ser complementado con el impulso que la historiografía latinoamericana sobre la justicia ha irrogado sobre los círculos nacionales de

\footnotetext{
${ }_{6}$ Cabe destacar el Centro de Estudios Culturales Latinoamericanos y el Centro de Estudios de Género y Cultura de América Latina, ambos de la Facultad de Filosofía y Humanidades de la Universidad de Chile, cuyo desarrollo ha estado en curso desde la década de 1990. En esta línea, también ha jugado un papel importante el Instituto de Estudios Avanzados de la Universidad de Santiago de Chile, desde la misma década.
} 
discusión. El influjo motivó un interés que ha llevado al despliegue creciente de la investigación al respecto y al nacimiento, el año 2011, del Grupo de Estudios Historia y Justicia y el año 2013, de la Revista Historia y Justicia, gestionada por el mismo colectivo.

Precisamente en el seno del Grupo de Estudios Historia y Justicia se ha aventurado un diálogo interdisciplinario que ha permitido lecturas deconstructivas sobre la fuente judicial. ${ }^{7}$ El producto de la discusión ha sido la emergencia de trabajos que han escrutado los lenguajes comunes presentes en la documentación. Por ejemplo, destacan los de Carolina González (2012; 2012b) que han puesto el acento en los agentes de los juzgados coloniales encargados de vehiculizar socialmente todo un campo de "saber hacer" en justicia. También han jugado un papel significativo los avances de María Eugenia Albornoz (2007; 2014), respecto a los mismos saberes desplegados por sujetos - principalmente mujeres- en situaciones de injuria y reconocidos por los jueces. Víctor Brangier, últimamente, en co-autoría con Darío Barriera (2015), ha escarbado en la manifestación judicial de estos lenguajes comunes compartidos tensamente por los justiciables, los jueces y los agentes encargados de la escritura de los testimonios. Sin embargo, se trata de esfuerzos en desarrollo que requieren la puesta en común de problemas, registros y experiencias de archivo. El desafío de la mediación escritural representa todavía un tópico que debe situarse en el centro de la discusión de aquel trabajo historiográfico que construye sus indagaciones desde los expedientes judiciales del ANH.

\section{Consideraciones finales}

Tras el escrutinio de los factores que confluyeron en la escritura de los expedientes judiciales criminales en el siglo XIX en Chile, ha podido asentarse su doble carácter fragmentario (como retazos de juicios, los que a su vez reflejaron estelas de conflictos sociales) y la necesaria mediación escritural existente entre voz testimonial y documento. El examen ha permitido evaluar el modo en que la historiografía chilena, que ha venido trabajando con intensidad sobre este material durante las últimas décadas, ha problematizado estas aristas y ha apropiado metodologías surgidas en otras latitudes tendientes a constituir a la fuente judicial como objeto de estudio. El artículo ha dado pistas para proyectar el horizonte de desafíos hermenéuticos por abordar, antes de continuar con un ejercicio de archivo acrítico respecto al testimonio en situación de justicia. En este sentido, el análisis de enfoques que apunten a transitar al revés las fases históricas que convergieron para posibilitar la existencia material del expediente, la indagación sobre las tensiones sociales y políticas que insuflaron vida al conflicto social, al juicio y a la escritura de los testimonios, en una palabra, las "lecturas a contrapelo" sobre esta materia prima, permitirían abrir nuevas preguntas que sitúen en el centro de la cuestión al archivo judicial. El abordaje documental desde estas claves propiciará el desplazamiento del expediente 
desde su condición de fuente primaria a objeto de estudio, en el diseño de investigación. De modo análogo, la lectura de los lenguajes, las legitimidades y las retóricas persuasivas de los justiciables, por un lado $y$, por otro, las escuchas y escrituras de escribanos y jueces, desde un prisma "culturalista", permitiría situar la atención en los lenguajes y códigos socialmente compartidos y tensamente apropiados, como condición de posibilidad del conflicto, del juicio y del expediente. En este sentido, la escritura del documento ya no se concibe como un obstáculo para acceder a las conciencias y voces genuinas de los deponentes, sino como una ventana para comprender las interacciones de esas conciencias dentro de un campo cultural en permanente desgarro por los distintos intereses en juego.

\section{Referencias bibliográficas}

AGÜERO, Alejandro. Castigar y perdonar cuando conviene a la república:

La justicia penal de Córdoba del Tucumán, siglos XVII y XVIII. Madrid: Centro de Estudios Políticos y Constitucionales, 2008.

AGUIRRE, Carlos. Agentes de su propia libertad: Los esclavos de Lima y la desintegración de la esclavitud, 1821-1854. Lima: Pontificia Universidad Católica del Perú, 1993.

AGUIRRE, Carlos. La escuela de los Annales: Ayer, Hoy, Mañana. Rosario: Prohistoria, 2006.

Retratos para la Historia: Ensayos de biografía intelectual sobre pensadores del siglo XX. Rosario: Prohistoria; Universidad Nacional de Rosario, 2015.

ALBORNOZ, María E. Seguir un delito a lo largo de los siglos: interrogaciones al cuerpo documental de pleitos por injuria en Chile. Revista de Historia Social y de las Mentalidades, v. 10, n. 2, p. 195-225, 2006.

El mandato de 'silencio perpetuo'. Existencia, escritura y olvido de conflictos cotidianos (Chile, 1720-1840). In: CORNEJO, T.; GONZÁLEZ C. (eds.). Justicia, poder y sociedad en Chile: recorridos históricos. Santiago: Universidad Diego Portales, 2007, p. 17-55.

.El Archivo Secreto de la Real Audiencia de Chile (1780-1809): ¿Proteger la memoria de la injuria o censurar prácticas díscolas de poder local? In: BERNABEÚ, S.; LANGUE, F. (coords.). Fronteras y sensibilidades en las Américas. Madrid: Doce Calles, 2011, p. 99-124.

. La temporalidad, las ausencias presentes y los motivos. Conflictos, justicias y género en una villa recién fundada: San Felipe, Chile, 1747. Nuevo Mundo Mundos Nuevos, n. 12, 2012.

- Casos de corte y privilegios de pobreza: lenguajes jurídicos coloniales y republicanos para el rescate de derechos especiales en el momento de litigar por injurias. Chile, 1700-1874. Signos Históricos, n. 32, p. 58-85, 2014. 
ANGUITA, Ricardo. Leyes promulgadas en Chile desde 1810 hasta el $1^{\circ}$ de junio de 1913. Santiago: Imprenta Litografía y Encuadernación Barcelona, 1913. t. 1.

ARANCIBIA, C. ; CORNEJO, T. ; GONZÁLEZ C. Pena de muerte en Chile Colonial: Cinco casos de homicidio de la Real Audiencia, estudio preliminar y transcripción. Santiago: Universidad de Chile; Centro de Investigaciones Diego Barros Arana; RIL, 2003.

ARCHIVO NACIONAL HISTÓRICO. Guía de Fondos del Archivo Nacional Histórico: Instituciones coloniales y republicanas. Santiago: Dirección de Bibliotecas, Archivos y Museos; Centro de Investigación Diego Barros Arana, 2009.

ARGOUSE, Aude. De los momentos del delito al monumento archivístico: el expediente criminal del oidor león. Santiago de Chile, 1673-1675. Historia y Justicia, n. 1, p. 1-27, 2013.

- Testimonios voluntarios e involuntarios de la vida cotidiana y de la justicia en Valparaíso. Los primeros registros de escritura pública, entre cuadernos y pruebas. In: CORREA, María J. (coord.). Justicia y vida cotidiana en Valparaíso: Siglos XVII-XX. Santiago: Acto, 2014, p. 5994.

BARRIERA, Darío. El equipamiento político del territorio. Del Pago de los Arroyos a la ciudad de Rosario (1725-1852). In: BARRIERA, D. (dir.). Instituciones, Gobierno y Territorio: Rosario, de la Capilla al Municipio (1725-1930). Rosario: ISHIR; CONICET, 2010, p. 17-63.

- Abrir puertas a la tierra: Microanálisis de la construcción de un espacio político. Santa Fe, 1573-1640. Santa Fe: Ministerio de Innovación y Cultura de la Provincia de Santa Fe; Museo Histórico Provincial "Brigadier Estanislao López", 2013.

BOHOSLAVSKY, E.; GODOY, M. (eds.).Construcción estatal, orden oligárquico

y respuestas sociales: Argentina y Chile, 1840-1930. Buenos Aires: Prometeo; Universidad Nacional del General Sarmiento, 2010.

BORAH, Woodrow. El Juzgado General de Indios en la Nueva España. México: Fondo de Cultura Económica, 1985.

BRANGIER, Víctor. 'En la más bastante forma que haya lugar en derecho ante vuestra merced comparezco...'. Entre el 'sujeto social' y el 'subalterno judicial': en torno al valor heurístico de las fuentes judiciales. Análisis de un expediente modelo. Chile, inicios del siglo XIX. Tradición y Saber, $n$. 9, p. 195-223, 2012a.

- Transacciones entre ley y prácticas judiciales locales, en tiempos de codificación. El caso de la Visita Judicial Nacional. Chile, 1848-1849. SudHistoria, n. 5, p. 124-151, 2012b. 
; BARRIERA, Darío. Lenguajes comunes en 'justicias de jueces'. Tratamientos historiográficos y fondos judiciales en Chile y Argentina. Revista de Humanidades, n. 32, p. 227-258, 2015.

BURKE, Peter. Popular Culture in Early Modern Europe. Nueva York: New York University Press, 1978.

CASANOVA, Holdenis. Diablos, brujos y espíritus maléficos: Chillán, un proceso judicial del siglo XVIII. Temuco: Universidad de La Frontera, 1994.

CAVIERES, Eduardo. Faltando a la fe y burlando a la ley. Bígamos y adúlteros en el Chile tradicional. Contribuciones Científicas y Tecnológicas, $n$. 118, p. 137-151, 1998.

CELIS, Nicolás. 'Lo que se hablaba de él y la escandalosa vida que estaba dando al público'. Aproximación a la noción de escándalo a partir de las huellas del rumor en las prácticas de conciliación informal. el caso de don José Tadeo Alquizar por vivir escandalosamente con una mulata. Santiago de Chile 1795. Revista de Historia Social y de las Mentalidades, v. 19, n. 2, p. 105-126, 2015.

CORNEJO, Tomás. Testimonios y testigos: el problema de la fuente. In: CORNEJO, T.; GONZÁLEZ, C. (eds.). Justicia, poder y sociedad en Chile: recorridos históricos. Santiago: Universidad Diego Portales, 2007, p. 241-266.

DAVIS, Natalie Z. Fiction in the Archives: Pardon Tales and their Tellers in Sixteenth-century France. Stanford: Stanford University Press, 1987.

DE ARAUJO, Álvaro. O Código Intentado: lei e justiça na 'economia da imposição' Portugal, finais do século XVIII e início do século XIX. In: BARRAL, M. E.; SILVEIRA, M. (coords.). Historia, poder e instituciones: Diálogo entre Brasil y Argentina.Rosario: Prohistora; Universidad Nacional de Rosario, 2015, p. 126-142.

DE RAMÓN, Armando. La justicia chilena entre 1875 y 1924. Cuadernos de Análisis Jurídico, v. 12, p. 1-59, 1989.

DIAZ, María E. The Virgin, The King, and the royal slaves of El Cobre: Negotiating freedom in colonial Cuba, 1670-1780. Stanford: Stanford University Press, 2000.

DI MEGLIO, Gabriel. Las palabras de Manul. La plebe porteña y la política en los años revolucionarios. In: FRADKIN, R. (ed.). ¿Y el pueblo dónde está? Contribuciones para una historia popular de la revolución de independencia en el Río de la Plata. Buenos Aires: Prometeo, 2008, p. 67-105.

ENCINA, Francisco. Breve bosquejo de la literatura histórica chilena. Atenea, n. 291, p. 27-68, 1949.

ESTADO DE CHILE. Lei de Organizacion i Atribuciones de los Tribunales.

Santiago: Imprenta de la República, 1875. 
FARGE, Arlette. La atracción del archivo. Valencia: Ediciones Alfons El Magnánim; Institució Valenciana D’ Estudis i Investigació, 1991.

FERNÁNDEZ, Marcos. Sangre por sangre: la retórica judicial y la veracidad documental como problema heurístico en las solicitudes de indulto. In: CORNEJO, T. ; GONZÁLEZ C. (eds.). Justicia, poder y sociedad en Chile: recorridos históricos. Santiago: Universidad Diego Portales, 2007, p. 195-223.

FRADKIN, Raúl. Cultura política y acción colectiva en Buenos Aires (18061829): un ejercicio de exploración. In: FRADKIN, R. (ed.). ¿Y el pueblo dónde está? Contribuciones para una historia popular de la revolución de independencia en el Río de la Plata. Buenos Aires: Prometeo, 2008, p. 27-65.

GALLUCI, Lisandro. Las fuentes judiciales y el estudio de los sectores subalternos: Desafíos y posibilidades de su relación en la investigación historiográfica. Ponencia. Segundas Jornadas Nacionales de Historia Social. Córdoba, Argentina, 2009. Disponible en: ww.refa.org.ar/file. php?name=FILE_ediciones1369674443.pdf. Consultado el: 18 ene. 2015.

GARRIGA, Carlos. Orden jurídico y poder político en el Antiguo Régimen. Istor, v. IV, n. 16, p. 13-44, 2004.

GREZ, Sergio. Escribir la historia de los sectores populares ¿con o sin la política incluida? A propósito de dos miradas a la historia social (Chile, siglo XIX). Política, n. 44, p. 17-31, 2005.

GÓNGORA, Mario. El Estado en el Derecho Indiano: Época de Fundación (1492-1570). Santiago: Universitaria, 1951.

GONZÁLEZ, Carolina. El abogado y el procurador de pobres: la representación de esclavos y esclavas a fines de la Colonia y principios de la República. SudHistoria, n. 5, p. 81-98, 2012.

- Las posibilidades del registro judicial para rastrear la recepción de saberes sobre justicia y gobierno. Nuevo Mundo Mundos Nuevos, 2012. Disponible en: http://nuevomundo.revues.org/62418. Consultado el: 29 nov. 2013 b.

GUHA, Ranajit. The Prose of Counter Insurgency. In: GUHA, R.; SPIVAK, G. (eds.) Selected Subaltern Studies. Oxford; New York: Oxford University Press, 1988, 45-86.

.Chandra's Death. In: GUHA, R. (ed.). A Subaltern Studies Reader: 1986-1995. Minneapolis; London: University of Minnesota Press, 1998, p. 34-62.

HERZOG, Tamar. La administración como un fenómeno social: la justicia penal de la ciudad de Quito (1650-1750). Madrid: Centro de Estudios Constitucionales, 1995. 
HESPANHA, Antonio M. De Iustitia a Disciplina. In: La Gracia del Derecho: Economía de la Cultura en la Edad Moderna. Madrid: Centro de Estudios Constitucionales, 1993, p. 203-273.

KAGAN, Richard. Pleitos y pleiteantes en Castilla: 1500-1700. Salamanca: Junta de Castilla y León; Consejería de Cultura y Turismo, 1991.

LEÓN, Leonardo. La Violencia Mestiza y el mito de la Pacificación: 18801900. Santiago: Universidad Arcis, 2005.

LOZOYA, Ivette. Delincuentes, bandoleros y montoneros: Violencia social en el espacio rural chileno (1850-1870). Santiago: LOM, 2014.

MALERBA, Jurandir. La historia en América Latina: Ensayo de crítica historiográfica. Rosario: Prohistoria, 2010.

MANTECÓN, Tomás. Usos de la justicia y arbitraje de los conflictos en el antiguo régimen: experiencias en la monarquía hispánica. Revista de Historia Social y de las Mentalidades, v. 19, n. 2, p. 209-235, 2015.

MELLAFE, Rolando. Interpretación histórico-metodológica de la delincuencia en Chile del siglo XXI. Contribuciones Científicas y Tecnológicas, n.118, p. 21-26, 1994.

MORENO, Daniel. 'Un devorador de su propia especie'. Violencia, justicia y cultura popular en santa rosa de los andes: las formas de la autoridad a los ojos de un peón de oficio matador, Chile 1805. Revista de Historia Social y de las Mentalidades, v. 19, n. 2, p. 127-158, 2015.

MORICONI, M.; BARRIERA, D. Las justicias en Santa Fe del Río de la Plata durante el periodo colonial (ss. XVI-XVIII). In: BARRAL, María E.; SILVEIRA, M. (coords.). Historia, poder e instituciones: Diálogo entre Brasil y Argentina.Rosario: Prohistora; Universidad Nacional de Rosario, 2015, p. 143-165.

ORTIZ, Inés. El Descontento de los Pueblos Yucatecos a Finales del Siglo XX. Una Aproximación a la Percepción de los Milperos Durante el Proceso Privatizador. In: FALCÓN R. (coord.). Culturas de pobreza y resistencia: Estudios de marginados, proscritos y descontentos México, 1804-1910. México: El Colegio de México; Universidad Autónoma de Querétaro, 2005, p. 285-305.

OWENSBY, Brian. Pacto entre rey lejano y súbditos indígenas. Justicia, legalidad y política en Nueva España, siglo XVII. Historia Mexicana, v. 1, n. LXI, p. 59-106, 2011.

REIS, Joao J. Rebeliao escrava no Brasil: historia do levante dos Males (1835). San Pablo: Brasiliense, 1986.

ROJAS. María T. Agresión de hombre, defensa de mujer: Una aproximación a la violencia conyugal y la justicia en el mundo popular. Zona central de Chile 1760-1830. Revista de Historia Social y de las Mentalidades, v. 2, n. 3, p. 89-16, 1999. 
ROJAS, Mauricio. Las Voces de la Justicia: Delito y sociedad en Concepción (1820-1875). Atentados sexuales, pendencias, bigamia, amancebamiento e injurias. Santiago: DIBAM; Centro de Investigaciones Diego Barros Arana, 2008.

SALAZAR, Gabriel. Construcción de Estado en Chile (1800-1837): Democracia de "los "pueblos. Militarismo ciudadano. Golpismo oligárquico. Santiago: Sudamericana, 2005.

SALINAS, René. Espacio doméstico, solidaridades y redes de sociabilidad aldeana en Chile tradicional, 1750-1880. Contribuciones Científicas y Tecnológicas, n. 118, p. 1-19, 1998.

. Violencias sexuales e interpersonales en Chile tradicional. Revista de Historia y de las Mentalidades, n. 4, p 13-49, 2000.

SCOTT, James. Los dominados y el arte de la resistencia: Discursos ocultos. México D.F.: Era, 2000.

SOPRANO, Germán. Estados nacionales, regiones y fronteras en la producción de una historia social del orden estatal en América Latina. In: BOHOSLAVSKY, E.; GODOY, M. (eds.). Construcción estatal, orden oligárquico y respuestas sociales: Argentina y Chile, 1840-1930. Buenos Aires: Prometeo; Universidad Nacional del General Sarmiento, 2010, p. 323332.

112 StABili, María R. Jueces y justicia en el Chile liberal. In: CARMAGNANI, M. (coord.). Constitucionalismo y orden liberal: América Latina, 18501920. Turín: Otto Editore, 2000, p. 227-258.

STERN, Steve. Perú's Indian Peoples and the Challenge of Spanish Conquest: Huamanga to 1640. Madison: University of Wisconsin Press, 1982.

TERRADAS I SABORIT, Ignasi. La Historia de las Estructuras y la Historia de la Vida. Reflexiones sobre las Formas de Relacionar la Historia Local y la Historia General. In: FERNÁNDEZ, S. ; DALLA CORTE, G. (comps.). Lugares para la historia: Espacio, historia regional e historia local en los estudios contemporáneos. Rosario: Universidad Nacional de Rosario Editora, 2001, p. 179-308.

THOMPSON, Edward. Costumbres en Común. Barcelona: Crítica, 1995.

TUOZZO, María C. Apuntes metodológicos: el problema de la verosimilitud en el estudio de los sumarios criminales. Actas Americanas, n.4, p. 5-17, 1996.

UNDURRAGA, Verónica. Los rostros del honor: Normas culturales y estrategias de promoción social en Chile colonial, siglo XVIII. Santiago: Editorial Universitaria; DIBAM; Centro de Investigaciones Diego Barros Arana, 2012. 
Presentación Dossier Formas de conciliación y mecanismos informales de resolución de conflictos en Chile siglos XVII a XIX. Revista de Historia Social y de las Mentalidades, v. 19, n. 2, p. 1-2, 2015.

VALENZUELA, Jaime. Bandidaje Rural en Chile Central: Curicó 1850-1900. Santiago: DIBAM, 1991.

WHITE, Hayden. Structuralism and Popular Culture. Journal of Popular Culture, n. 7, p. 759-775, 1974. 


\title{
Miradas historiográficas sobre los obispos. Abordajes de un sujeto histórico complejo a través de la historiografía argentina en el periodo colonial y temprano-independiente
}

\author{
Historiographical points of view the bishops. Approaches to a complex \\ historical subject through Argentinian historiography in colonial and \\ early independent times
}

\author{
María Laura Mazzoni \\ mazzonilaura@gmail.com \\ Doctora en Historia \\ Instituto de Historia Argentina y Americana "Dr. E. Ravignani" \\ Millán, 1136 \\ Mar del Plata - Provincia de Buenos Aires \\ Argentina
}

\section{Resumen}

La historia social de la iglesia en Argentina se ha desarrollado con mucho ímpetu a partir de la década de 1990, de la mano de la ampliación y proliferación de la producción historiográfica académica en el país. Este trabajo se propone, en primer término, dar cuenta de ese recorrido centrándose en la historia de la jerarquía eclesiástica y atendiendo a las nuevas preguntas, y los cambios temáticos y analíticos de los especialistas de este campo. En segundo lugar, y a modo de ejemplo de lo antedicho, este texto tiene por objetivo puntualizar la distancia que marca la historiografía actual sobre el gobierno episcopal en diócesis de antigua colonización, como la de Córdoba del Tucumán, con respecto a diócesis "de frontera" en el espacio rioplatense a fines del siglo XVIII y principios del XIX.

\section{Palabras claves}

Historia social; Historiografía argentina; Siglo XIX.

\begin{abstract}
Church social history in Argentina has developed vigorously since the 1990s along with the expansion of the academic historiographical production in the country. This article proposes, in the first place, to examine these studies focusing on the history of ecclesiastical hierarchy and taking into account new questions, subjects and analytical changes in this field. In the second place, and as an example of these innovations, this paper aims to specify the distance held by current historiography about the episcopal government in ancient colonized dioceses, like Córdoba del Tucumán, in relation to "border churches" in the Río de la Plata region between the last decades of the $18^{\text {th }}$ century and the first half of the $19^{\text {th }}$ century.
\end{abstract}

Keywords

Social history; Historiography of Argentina; $19^{\text {th }}$ century.

Recibido el: 28/7/2016

Aceptado el: 5/8/2016 
La ampliación y proliferación de la producción historiográfica académica en la Argentina acompañó los caminos de la apertura democrática. El retorno de numerosos investigadores al país, un contacto más asiduo con centros de investigación prestigiosos, y la multiplicación de reuniones científicas de historiadores dieron como resultado una mayor profesionalización de la disciplina, y la aparición de nuevos temas y horizontes historiográficos.

La historia social de la iglesia en Argentina se ha desarrollado con mucho ímpetu a partir de la década de 1990, con la incorporación de historiadores que en muchos casos se nutrieron y formaron en centros de investigación europeos que ya abordaban cuestiones eclesiásticas desde la historia social, política y económica, tanto para el periodo colonial como para los siglos XIX y XX. En este sentido, la historia colonial, y la de los primeros años independientes se nutrió, a partir de entonces, de nuevas preguntas y problemas históricos sobre temas y documentos, que completaron y complementaron aquellos nudos problemáticos que habían sido objeto de una importante renovación desde la historia política. Es decir, la cuestión de las reformas borbónicas, la retroversión de la soberanía a partir de la independencia, la participación de diferentes actores en el proceso revolucionario, o el papel de la mujer en el periodo colonial y decimonónico, por nombrar solo algunos problemas históricos, fueron atendidos ahora desde la historia de la iglesia. Esto se vio plasmado en un importante número de tesis doctorales y libros que materializaron este derrotero (AYROLO 2007; BARRAL 2007; DI STEFANO 2004; FOGELMAN 2000; FRASCHINA 2010; GALLO; CALVO y DI STEFANO 2002; LIDA 2006; PEIRE 2000).

Este trabajo se propone, en primer término, dar cuenta de las líneas generales de investigación que abordaron el estudio de los obispos como actores claves del periodo, y del episcopado y la diócesis como institución para el periodo colonial y temprano independiente. En segundo lugar, el trabajo se propone cuestionar algunas generalizaciones que se han hecho sobre el gobierno y el accionar de los obispos en los diferentes obispados del territorio del ex Virreinato del Río de la Plata. Basándonos en las diferencias existentes entre una "iglesia de frontera" como la porteña, y obispados en espacios de antigua colonización, como el tucumano, marcaremos un contrapunto con estas visiones.

Nos centraremos en la diócesis de Córdoba del Tucumán. Este espacio tiene una historia de antigua colonización en el área tucumana. Creada en 1570, la Diócesis del Tucumán cuya sede primera había sido Santiago del Estero, trasladó en 1699 su sede diocesana a Córdoba. Córdoba pasó a ser entonces cabeza del obispado. La ciudad albergaba la catedral, y poseía una casa de altos estudios que otorgaba títulos universitarios por concesión pontificia y real, fundada a principios del siglo XVII por la Compañía de Jesús, única institución que otorgaba títulos de grado en la región. Por otra parte, Córdoba tenía dos colegios convictorios y cuatro conventos que marcaban la presencia de las órdenes religiosas: jesuitas, franciscanos, dominicos y mercedarios. Existían, además, dos conventos de monjas, el de las teresas y el de las catalinas. Se trata de un espacio jurisdiccional muy importante, dotado de una estructura eclesiástica antigua, y que por otra parte, albergaba la sede de la Gobernación 
Intendencia de Córdoba desde 1783. En 1806 la Diócesis del Tucumán fue desmembrada y se crearon dos obispados nuevos. El de Salta, y el de Córdoba que contenía a las jurisdicciones de Córdoba y La Rioja y a la que se sumaron las tres jurisdicciones cuyanas (San Juan, San Luis y Mendoza), que antes habían pertenecido a la Diócesis de Santiago de Chile.

\section{Los obispos en el centro del análisis de la historia de la Iglesia en Argentina}

Si bien la historia eclesiástica en Argentina se consolidó como un campo en sí mismo gracias a las contribuciones de la historia social, política y cultural (AYROLO 2007; BARRAL 2007; DI STEFANO 2004; DI STEFANO; ZANATTA 2000; PEIRE 2000), los estudios desde el ámbito confesional (por citar solo algunos ejemplos: BRUNO 1970; TONDA 2009) o aquellos centrados en la historia eclesiástica desde una mirada más institucional (DELLAFERRERA 1999; LEVAGGI 2003; MAEDER 2003; MARTÍNEZ DE SÁNCHEZ 2006; PEÑA 1994) fueron imprescindibles para dicho proceso, ya que brindaron un corpus bibliográfico que abrió las puertas a nuevas fuentes -eclesiásticas- y preguntas que se tomaron como punto de partida. Por ello, el estudio de las administraciones diocesanas precisaron y precisan de la consulta a estas obras pioneras.

La Historia de la Iglesia en Argentina, de Cayetano Bruno, conforma un trabajo monumental que, entre otros temas, aborda la cuestión de la gestión eclesiástica de los obispos (BRUNO 1970). ${ }^{1}$ La amplia variedad de archivos consultados por Bruno es una valiosa guía para comenzar cualquier investigación

116 relacionada con la iglesia en el espacio rioplatense. El autor no sólo atendió al origen, formación y trayectoria de los obispos de las diócesis existentes desde la creación de la primera mitra en el territorio en 1570, sino que también prestó atención a su actuación política. Su análisis se centra en una mirada institucional, a través de la cual subyace una puja constante entre el poder civil y el religioso en detrimento de este último. Veamos un pasaje de la Historia de la Iglesia en Argentina, que ilustra la adjetivación propia del discurso de los estudios confesionales cuya carga valorativa - positiva- hacia los eclesiásticos es propia de una reconstrucción biográfica arquetípica (ROMERO 2008). Estos textos intentan mostrar a través de las vidas de los prelados, un ideal, un modelo, portaestandarte de los valores de la fe católica:

¿Tenía algún fundamento esta reiterada acusación denigrativa del buen nombre de los referidos clérigos y del Obispo? Ninguno. Lo verá el lector. Y da grima comprobar que casi siempre este cargo fuese pantalla de ocultos manejos, y que se tildase con él generalmente a las personas más sensatas y virtuosas de la sociedad de entonces (BRUNO 1970, v. VIII, p. 250).

En el mismo registro podemos mencionar El Obispo Orellana y la Revolución, de Américo Tonda (TONDA 2009), fuente de consulta obligatoria para el estudio de este prelado en particular y del proceso revolucionario que se inicia a pocos

\footnotetext{
${ }^{1}$ La obra de Cayetano Bruno Historia de la Iglesia en Argentina consiste en 12 tomos que fueron publicados entre 1966 y 1981. La fecha de 1970 corresponde a los tomos VIII, IX y X que concentran el análisis del periodo tardocolonial y temprano-independiente.
} 
años de su arribo a Córdoba. En este caso, Tonda destaca la figura de quien fue el último obispo español en llegar al Río de la Plata y el primero de la diócesis cordobesa creada en 1806. Retoma sus atributos y sus particularidades y a partir de allí analiza su actuación frente al proceso de independencia. Su relato imprime una mirada condenatoria al proceso revolucionario, y la gestión diocesana es observada como una carrera de obstáculos frente a las trabas impuestas a Orellana por el nuevo gobierno.

Por supuesto que en esta literatura histórica los méritos religiosos son resaltados por encima de la actuación política de los sacerdotes o prelados, en sintonía con un clima de época de la décadas de 1970 y 1980, cuando la participación política de los sacerdotes no gozaba ya de consenso dentro de la iglesia católica. Así, Nelson Dellaferrera ha descrito al provisor del obispado de Córdoba, Gregorio Funes -destacado sacerdote de la década de 1810 que estuvo cerca de lograr la mitra cordobesa- rescatando los rasgos de su actuación sacerdotal pese a haberse involucrado en las lides de la política. Funes era, según Dellaferrera, "un juez recto, probo, perspicaz e inteligente, y esto por encima de su actuación política". Y de Benito Lascano, vicario apostólico y luego obispo auxiliar de Córdoba, destacaba "la fuerza y la reciedumbre [...], aunque no siempre fue capaz de mantenerse fuera de la lucha política de su tiempo [...]" (DELLAFERRERA 1996, p. 118).

Esta mirada condescendiente con los actores eclesiásticos fue superada, en un principio, por la proliferación de estudios sobre el episcopado en las monarquías ibéricas para el caso español, novohispano y portugués, con mayor profundidad que para el espacio rioplatense. José Manuel Cuenca Toribio ha rastreado y estudiado al episcopado español desde fines del Antiguo Régimen hasta mediados del siglo XX. Para el periodo antiguoregimental, el autor resaltó el peso de la política y los intereses personales en los nombramientos de obispos del periodo (CUENCA TORIBIO 1976). Trabajos como el de Barrio Gozalo sobre los obispos españoles a lo largo del siglo XVI al XIX muestran un perfil sociológico del episcopado en la península mediante el método prosopográfico (BARRIO GOZALO 2000). Estas investigaciones presentan aspectos como el origen o la formación de los candidatos al episcopado español. Otro ejemplo lo constituye el trabajo que realizaron Castañeda y Marchena para los obispos de Indias desde 1500 a 1850, una especie de diccionario biográfico donde incluyeron datos de la trayectoria de los prelados en la estructura eclesiástica (CASTAÑEDA DELGADO; MARCHENA FERNÁNDEZ 1992). En los últimos años, Andoni Artola ha analizado el acceso al episcopado en la España moderna aplicando el estudio de redes a este tema. El autor destaca en sus escritos la importancia de las dinámicas relacionales internas del alto clero para el acceso a una mitra. Los canales institucionales de selección de candidatos para mitras fueron suprimidos hasta pasar a ser, en 1793, prácticamente una decisión personal del monarca o de su principal ministro, y esto fue utilizado como un mecanismo arbitrario para premiar a obispos cercanos al monarca. Sus estudios demuestran cómo la selección de los obispos peninsulares y americanos estuvo regida por una tendencia episcopalista dentro de la jerarquía eclesiástica (ARTOLA RENEDO 2013; 2014). 
En el caso de Portugal, José Pedro Paiva ha discutido la idea de que el regalismo pombalino arremetió contra la voluntad de la jerarquía eclesiástica portuguesa. Por el contrario, sostiene el historiador, la embestida regalista fue consumada con el apoyo de un clero que compartió estas doctrinas y que en el plano práctico se encargó de viabilizarlo e instaurarlo (PAIVA 2006).

En otros espacios, la actuación de los obispos en contextos de reforma o revolución ha sido estudiada atendiendo a su trayectoria y formación, sus vinculaciones sociales y políticas, y su labor pastoral (FERNÁNDEZ MELLÉN 2014; HERNÁNDEZ GARCÍA 2008). En lo que se refiere a las guerras de independencia americanas, el episcopado ha sido estudiado como un actor clave de la oposición a estos procesos políticos emancipatorios. En general, la jerarquía eclesiástica fue analizada teniendo en cuenta su mayoritaria adhesión a la causa realista (AMORES CARREDANO 2009).

En Nueva España, donde las instituciones eclesiásticas tenían un peso social y político, pero sobre todo económico, mucho más palpable, Leticia Puente ha observado que los prelados, en tanto hombres políticos, hicieron uso de estrategias comunes a todos los grupos de poder del período analizado. No hay que desdeñar "el importante papel desempeñado por las redes privadas de lealtad personal que se tejían en consejos, audiencias y cancillerías" en pos de la obtención de una mitra (PÉREZ PUENTE 2012, p. 162). En este sentido, la tarea reformadora de los obispos regalistas en el siglo XVIII ha sido vista como un incremento significativo de la supervisión de prácticas por parte de los funcionarios reales

118 (CONNAUGHTON 2008, p. 191). Los obispos fueron considerados ejes mayores de la transformación (CONNAUGHTON 2008, p. 193).

Los aportes desde la historia social y cultural han permitido prestar atención a la institución eclesiástica como un espacio de poder y sociabilidad atravesado por las relaciones personales, la política, la economía y hasta la guerra, y a los obispos y clérigos, como hombres políticos (SALVADOR AGUIRRE 2010).

La jerarquía eclesiástica no ha sido estudiada en forma tan exhaustiva como el clero en general, tanto secular como regular, en la historiografía argentina. Algunos estudios han atendido a la formación del clero, su extracción social, su participación en política (AYROLO 2000, 2001, 2001, 2006, 2007, 2011; AYROLO; BARRAL 2011; AYROLO; CARETTA 2003, 2009; BARRAL 2007, 2009; DI STEFANO 1997, 2000, 2000, 2004, 2013; PEIRE 2000; TROISI-MELEAN 2008; TROISI MELEAN 2006), y su vínculo con la feligresía (AYROLO 2006; AYROLO; CARETTA 2003; MALLO 1995, 2000; PELAGATTI 2008). En definitiva, se ha subrayado el papel central del clero dentro de la sociedad, en el ámbito urbano, y también en el rural, donde sus miembros actuaron como jueces (BARRAL 2003), maestros (BARRAL 2007) y mediadores (BARRAL 2009; BARRAL; DI STEFANO 2008).

El clero secular ha sido, por su parte, objeto de una revisión profunda a partir de la renovación historiográfica señalada. Roberto Di Stefano ha estudiado el clero secular de Buenos Aires y advirtió que este estamento religioso fue el mayor beneficiado por la expulsión de la Compañía de Jesús de la monarquía hispánica, a raíz de la cual fue adquiriendo un creciente prestigio y poder (DI STEFANO 2004, p. 97). Valentina Ayrolo señaló que la participación del clero 
secular en la construcción de la nueva entidad política durante las autonomías provinciales en la década de 1820 encontró a los clérigos "proporcionando los fundamentos teóricos al nuevo sistema, colaborando en su legislación y resolviendo problemas de gobierno, como también legitimando lo actuado por sus pares civiles" (AYROLO 2007, p. 172).

Particularmente en el caso de los obispos, la historiografía reciente ha destacado su función en tanto mediador entre los fieles y la corona, y el intento de la monarquía española de convertir al obispo en el siglo XVIII, en funcionario al servicio del Rey (AYROLO 2007; BARRAL 2007; CONNAUGHTON 2008; DI STEFANO 1999; MAZZONI 2013, 2013, 2015; TAYLOR 1999; URQUIZA 1993).

Desde la historia social y cultural, la historiografía argentina ha reflexionado sobre las instituciones religiosas y sus actores. Peire ha estudiado las instituciones eclesiásticas y el imaginario cultural desde la expulsión jesuita hasta el periodo revolucionario en el Río de la Plata, y ha subrayado que "la sociedad tardocolonial era incapaz de disolver el núcleo y la estructura específicamente clerical, y más en concreto el clero, que formaba en el imaginario colonial, aquella parte de la sociedad a la que el resto miraba como un 'espejo' donde creía debía verse reflejado el ideal de persona y sociedad" (PEIRE 2000, p. 192). En El Taller de los Espejos, el autor demuestra la importancia de las órdenes regulares en el periodo temprano colonial en la evangelización que acompañó el proceso de conquista, y en el ámbito de la educación. En los siglos XVI y XVII, las órdenes regulares tenían una mayor presencia en América, y ocupaban espacios de poder que el clero secular intentaba disputarles. Esto se expresó, por ejemplo, en el origen de los obispos durante este período. Según el autor, en el siglo XVI, de 171 obispos de América, "108 fueron religiosos y sólo 63 seculares" (PEIRE 2000 , p. 64). Entre los motivos por los cuales la corona prefería presentar prelados regulares, el Consejo de Indias esgrimía la labor evangelizadora, el buen tratamiento que proferían a los indígenas, la humildad y el desapego hacia los bienes materiales que mostraban los religiosos (PEIRE 2000, p. 65). En el período tardocolonial, los criterios de selección de candidatos para una mitra habían cambiado y el clero secular primaba entre los candidatos a ocupar mitras americanas (MAZZONI 2013).

En relación con la jerarquía eclesiástica, Di Stefano sostiene que el progresivo dominio del clero secular generó tensiones con las intenciones de la metrópoli de conservar su prerrogativa y soberanía sobre la administración diocesana. Los seculares de Buenos Aires, acostumbrados a autogobernarse por los prolongados periodos de vacancia, ganaban cada vez más autonomía y esto chocaba contra los intereses de la corona. "La mayor parte de los clérigos servía beneficios que no eran de colación episcopal, sino de patronato laico, o se desempeñaba en puestos de la administración colonial ajenos a la órbita del obispo" (DI STEFANO 2004, p. 39). Estos datos le permiten al autor sostener que en la diócesis porteña los obispos no tenían una presencia fuerte, y las tensiones con el clero local acentuaban esa debilidad (DI STEFANO 1999; 2013).

La actuación de los obispos del ex virreinato del Río de la Plata en torno al ejercicio del patronato luego de la Revolución ha sido revisada también 
por la historiografía argentina y americana en general (AYROLO 1996; ENRÍQUEZ 2008; LIDA 2004; MARTÍNEZ 2013). Ayrolo muestra cómo el poder revolucionario tuvo que hacer frente no sólo al contexto de guerra, sino a la oposición de los prelados a reconocer al nuevo poder soberano (AYROLO 1996). Y en este mismo camino, Martínez analiza la trayectoria de los obispos que ocupaban las mitras de Salta, Córdoba y Buenos Aires y los diferentes comportamientos seguidos por los prelados en ese contexto (MARTÍNEZ 2013, especialmente cap. 2).

Los trabajos sobre prelados en Córdoba en el periodo tardocolonial y temprano independiente se han centrado en la formación y actuación de los últimos obispos coloniales y durante la década revolucionaria (BARRAL; DI STEFANO 1999; MAZZONI 2013; SÁNCHEZ PÉREZ 2014; TONDA 1973, 1973, 2009), y en su vinculación con la política local (AYROLO; MAZZONI 2013; MAZZONI; GÓMEZ 2015). En el caso del obispado de Córdoba del Tucumán, "la administración eclesiástica que llevaron a cabo los obispos moldeó la identidad -católica- de la feligresía cordobesa. La impronta diocesana formó parte de la construcción de un imaginario colectivo, en el que el sustrato religioso católico romano constituyó uno de los componentes fundamentales que caracterizaron al espacio y a sus habitantes, y los legitimaron. Esto fue posible mediante el trabajo realizado por obispos y clero en el sostenimiento de instituciones y valores fundamentales para la feligresía" (MAZZONI 2013, p. 304).

Conocemos aún muy poco sobre la relación entre las instituciones diocesanas

120 en el espacio rioplatense y las instancias de gobierno superiores. No hay, una historia del episcopado americano, y mucho menos de los obispados sufragáneos de la Arquidiócesis de Charcas de la que dependía Córdoba, en el periodo estudiado, que nos permita tener una visión de conjunto sobre los prelados que estudiamos. En ese sentido, la relación entre las diócesis y su sede arzobispal es en gran medida un terreno aun por explorar. En el caso de los gobiernos diocesanos, hemos estudiado los lazos existentes entre la arquidiócesis y su sufragánea de Córdoba a través de la trayectoria de los obispos tardocoloniales. En el siglo XVIII, el camino entre una diócesis altoperuana o el arzobispado charqueño y la mitra cordobesa era un derrotero natural y asiduo. Muchos obispos cordobeses obtenían, en premio a su labor, un ascenso a diócesis con mayores rentas en el espacio altoperuano de la misma provincia eclesiástica, o su coronación como arzobispo de Charcas, como en el caso de San Alberto en 1783 (MAZZONI 2013, cap. 1). Pero aun ignoramos en gran medida la relación entre los obispos rioplatenses y su arzobispo, y los mecanismos de control e instancias de gobierno de la arquidiócesis.

Tampoco se han investigado en profundidad los nexos entre las instituciones diocesanas y las órdenes regulares. Arena de negociación, conflicto e interacción continua, los cruces entre el clero secular y el clero regular a nivel institucional no han sido ampliamente explorados. Sí se han abordado, en este sentido, los conflictos que suscitaron estas interacciones, ya fueran en el ámbito universitario o en coyunturas críticas como la expulsión de los jesuitas de la monarquía española o la revolución de Mayo (BENITO MOYA 2011; LIDA 2006; LORANDI 
2008; TONDA 1973). Sin embargo, todavía es necesaria una revisión sobre esta fértil relación en el periodo colonial (MAZZONI 2016).

Por último, el vínculo entre las diócesis rioplatenses y la Santa Sede también exige nuevos análisis. Se ha estudiado con profundidad el ejercicio del Patronato, sobre todo luego de la ruptura de los lazos monárquicos (AYROLO 1996; MARTÍNEZ 2011, 2013), pero poco se conoce a cerca de la existencia de lazos entre el Papado y los gobiernos diocesanos que corrieran por caminos ajenos a la mediación real, como sí ha sido estudiado y demostrado para otras diócesis americanas (ALBANI 2008, 2012).

\section{La jerarquía eclesiástica en iglesias de antigua colonización}

Como vimos, el desarrollo de la historia social y de la historia de la iglesia en Argentina ha enriquecido el conocimiento que se tenía sobre las sociedades tardocoloniales y decimonónicas. En el caso del espacio cordobés, nuestro estudio se ha centrado en la gestión eclesiástica de los últimos obispos coloniales del más antiguo de los tres obispados del territorio que existían en 1806 -el de Córdoba del Tucumán fundado en 1570- (MAZZONI 2013). Analizamos la trayectoria, formación, las devociones que propiciaron y las prácticas religiosas que concibieron teniendo en cuenta el contexto político en el cual gobernaron la diócesis. Nuestra investigación también abarcó la vinculación del accionar de los prelados con la conformación de una identidad regional, que se erigió, a principios del siglo XIX, en estandarte de la religión católica de las Provincias Unidas del Río de la Plata frente a las reformas liberales en las que se embarcaron provincias como Buenos Aires, San Juan y Mendoza en la década de 1820.

Las conclusiones para el caso cordobés difieren de lo que se ha observado en el caso de la diócesis de Buenos Aires (DI STEFANO 1999; 2004; 2013; DI STEFANO; MARTÍNEZ 2011; LIDA 2004). Para el caso porteño, Di Stefano ha sostenido que las administraciones diocesanas a lo largo del siglo XVIII y la primera mitad del siglo XIX no tuvieron un peso significativo en el gobierno episcopal. Así, sostiene que "el gobierno natural de la Iglesia, sobre todo en el Río de la Plata, donde la presencia episcopal es tan irregular y las vacantes tan prolongadas, reside en el cabildo eclesiástico en representación del clero secular. Los obispos pasan [...]" (DI STEFANO 1999, p. 80).

La administración diocesana en el espacio cordobés da cuenta de una situación muy diferente. Las apreciaciones de la diócesis rioplatense se alejan de lo que acontecía en otras vecinas, como la de Córdoba, evidenciando a la diócesis porteña como una excepción, más que la norma. Valentina Ayrolo ha advertido ya sobre las diferencias entre la región del Tucumán y la rioplatense (AYROLO 2003; 2007). Sus estudios han demostrado el peso de la iglesia en el Tucumán, "no sólo porque fue la ordenadora del espacio social sino además porque actuó como mediadora, fuente de legitimidad, esencia misma del 'ser cordobés'" (AYROLO 2003, p. 179). Allí, el clero secular, y el regular gozaban de una escasa autonomía por sobre la jerarquía eclesiástica. En esto acordamos con Oscar Mazín quien destacó las diferencias estructurales que en el siglo XVII separaban a las diócesis novohispanas de las de las Indias meridionales, y señaló 
que las diócesis del espacio peruano se regían con una mayor centralización (MAZÍN GÓMEZ 2015).

La diócesis de Córdoba compartía una relación de larga data con las diócesis altoperuanas, y guardaba características que la semejaban a obispados con un historial y una experiencia en la administración diocesana muy antiguas; era, en suma, una "iglesia de vieja colonización" (AYROLO 2003, p. 184), que se distinguía de una "Iglesia de frontera" como se ha dado en llamar a las instituciones eclesiásticas coloniales porteñas (DI STEFANO 1997, p. 46). La diócesis del Río de la Plata, en tanto iglesia de frontera se alejaba de obispados de tradición, a veces milenaria, como las europeas, y "se encontraba periódicamente frente a la necesidad de crear nuevas estructuras pastorales y obligada por lo tanto a encontrar el personal dispuesto a hacerse cargo de ellas" (DI STEFANO 1997, p. 46).

En este sentido, el circuito de "pertenencia" del espacio cordobés, era aquel del Alto Perú, de la arquidiócesis de Charcas. Entre estos espacios había una tradición compartida que incluía el comercio, y la circulación de hombres. Los clérigos los transitaban portando experiencias y una identidad compartida. $Y$ lo más importante, la jerarquía eclesiástica era común en estas jurisdicciones eclesiásticas. Clérigos altoperuanos fueron premiados con la mitra cordobesa (como en el caso de Ángel Mariano Moscoso en 1789), y más frecuentemente los prelados cordobeses eran promocionados a diócesis con mayores rentas en el espacio altoperuano como una especie de compensación por las penurias pasadas en el obispado tucumano (este es el caso de Abad Illana, y el de Joseph Antonio de San Alberto por poner solo algunos ejemplos del período tardocolonial).

La jerarquía eclesiástica en espacios de antigua colonización formaba parte de la elite letrada de la comunidad, detentaba una posición de poder en tanto máximo exponente del clero diocesano y, en el período analizado, tuvo un activo papel en la defensa de la causa realista en las nuevas repúblicas que se constituían. Sin embargo, muchos pudieron mantenerse en sus puestos de jerarquía sin mostrar una adhesión sincera a la revolución. Tal es el caso de José Sebastián de Goyeneche, obispo de Arequipa desde 1817 a 1859. Goyeneche pertenecía a un linaje arequipeño con gran ascendente en la región. Y pese a su apoyo al bando realista, supo mantenerse en la mitra gracias a su gran habilidad para evitar un enfrentamiento directo con las autoridades revolucionarias. En 1859 incluso obtuvo el cargo de arzobispo de Lima (ROJAS INGUNZA 2007). También Pedro Gutiérrez de Cos, obispo de Huamanga, es considerado como uno de los representantes del "conservadurismo" en su defensa de las ideas monárquicas en el virreinato peruano (HERNÁNDEZ GARCÍA 2008). Gutiérrez de Cos tuvo que huir de su mitra en Huamanga hacia territorio aun controlado por la corona española. Su exilio y el apoyo a la causa realista le valió el nombramiento como gobernador eclesiástico de la mitra de La Habana y, poco después, con la sede de Puerto Rico. La misma postura fue compartida por Diego Antonio Navarro Martín Villodres, obispo de la diócesis de Concepción del Reino de Chile entre 1806 y 1816, y por Nicolás Videla del Pino. Navarro tuvo un destacado papel al frente del bando realista en Concepción, incluso reclutando tropa, mientras que 
Videla del Pino fue desterrado en 1812 por el General Manuel Belgrano por su comunicación con las tropas realistas del Alto Perú (AYROLO; CARETTA 2003; ENRÍQUEZ AGRAZAR 2005).

Los obispos de la diócesis cordobesa entre el fin del periodo colonial y el primer tercio del siglo XIX fueron muy activos en hacer visitas a toda la diócesis, para conocer a su feligresía, pero también para mostrar una presencia y autoridad real y para controlar al clero y a los fieles (MAZZONI 2015). Entre los años 1778 y 1836 se realizaron 66 visitas diocesanas en el obispado de Córdoba del Tucumán: San Alberto, 15; Moscoso, 39; Orellana, 11, y dos, durante el provisoriato de Lascano en 1827. Un ejemplo paradigmático son las numerosas visitas practicadas personalmente por el obispo Ángel Mariano Moscoso supervisando los curatos de la campaña donde se preocupó de reforzar la presencia de la Iglesia. En 1813, como resultado de la visita de Rodrigo de Orellana a la diócesis, el obispo escribía un informe donde mostraba con gran realismo la situación diocesana; aprovechó la oportunidad para realizar algunos reclamos al gobierno, con miras a lograr las mejoras que había ideado (AYROLO 2010).

Para el caso de Córdoba, en los años en los que el gobierno diocesano se encontraba en manos de un obispo, su conocimiento y experiencia eran la fuente principal de consulta para la resolución de cuestiones administrativas y para el correcto funcionamiento de la Audiencia episcopal. Sobre todo, desde mediados del siglo XVIII cuando la ausencia en la jurisdicción eclesiástica de concilios y sínodos implicó una mayor intervención y una vigorosa actividad legislativa por parte del episcopado (MAZZONI 2015). Ejemplo de esto fueron los consejos que se les solicitaban a los prelados sobre el ceremonial. Pero sobre todo, esta noción del obispo como fuente de legitimidad y, por ende, de consulta obligatoria puede verse en la constante relación de negociación entre el cabildo y el prelado. A modo de ejemplo, citamos el caso de la elección, por parte del cabildo, de Gregorio Funes como provisor de la diócesis en 1804 a la muerte del obispo Moscoso. Luego de las gestiones infructuosas que Funes llevó adelante para lograr la mitra cordobesa, decidió continuar peleando su lugar de provisor. Fue en 1804 cuando la elección realizada tuvo que ser ratificada -a pedido del cabildo y de Funes- por el obispo electo, Rodrigo Antonio de Orellana, quien aun estando en la Península fue consultado por el cabildo sobre la legitimidad de la elección. Por ello, sostenemos que si bien el capítulo catedral de Córdoba también representaba al clero local, gobernar con legitimidad fue, en el espacio cordobés al menos, muy importante y lo seguiría siendo a lo largo del período estudiado. Aun si en muchos momentos la situación interna de la Iglesia diocesana cordobesa fue conflictiva y difícil, nunca llegó al punto de romper con su obispo.

Conviene recordar que mientras Orellana se encontraba preso por las autoridades revolucionarias, el prelado seguía conectado con su diócesis, como lo prueban sus cartas a las carmelitas de Córdoba (TONDA 1973). Además, Orellana era consultado para la resolución de asuntos de administración eclesiástica, como lo hizo la Asamblea del año XIII (AYROLO 2013), e intervenía en el gobierno diocesano, como en la elección como provisor de Benito Lascano 
en $1816 .{ }^{2}$ Pero esto ocurre también en la Diócesis de Salta, donde el cabildo eclesiástico continuó consultando aun en su destierro al obispo Nicolás Videla del Pino, expulsado de su diócesis por el general Belgrano por sus vínculos con el bando realista (AYROLO; CARETTA 2003).

En Córdoba, la noticia del nombramiento de un obispo era recibida gratamente por el clero secular, ya que esto significaba la posibilidad de que los aspirantes a ordenarse consiguieran sus órdenes mayores (AYROLO 2001; AYROLO; CARETTA 2009). De hecho, "entre 1786 y 1792 no hay ordenaciones en la diócesis por no haber obispos" (AYROLO; CARETTA 2009, p. 91). Gabriela Caretta y Valentina Ayrolo han registrado 330 ordenados entre 1780 y 1804 por los obispos del Tucumán, mostrando que "en los años inmediatos a la llegada de un nuevo obispo puede observarse un pico en el número de ordenados que se estabiliza en los años posteriores, lo que indica que muchos esperaban la llegada del pastor para ordenarse" (AYROLO; CARETTA 2009, p. 92). Y demuestran que:

Si consideramos los obispados de San Alberto y Ángel Mariano Moscoso observamos que en los dos casos se da una mediana anual que ronda los 11 clérigos ordenados. Durante el gobierno de San Alberto (1780-1785) se ordenaron 56 clérigos. Durante la administración de Ángel Mariano Moscoso (1793-1804) se ordenaron 130 individuos. [...] En principio podemos afirmar que no hay una caída del número de ordenados y que tampoco, por lo analizado hasta el momento, los clérigos esperaran la sede vacante para ordenarse en otras diócesis [...] (AYROLO; CARETTA 2009, p. 93).

En definitiva, aunque algunos estudios de historia eclesiástica en Argentina han observado en el ámbito rioplatense la debilidad de la figura episcopal en beneficio del clero secular, agravado por las prolongadas vacancias diocesanas, esto no fue así en el caso de Córdoba. En el primer obispado de la región, y uno de los tres existentes al momento del estallido revolucionario, los obispos fueron ejes de la administración diocesana y fuente de legitimidad (MAZZONI 2013). Por ello podemos afirmar que la tarea pastoral diocesana fue importante en el proceso de construcción del espacio eclesiástico-político o político-institucional del obispado cordobés y que la influencia y participación de los obispos en cuestiones eclesiásticas y políticas en el ámbito local tuvo una mayor capacidad de gestión que en otros espacios, como el porteño (AYROLO 2008; MAZZONI 2013).

\section{Consideraciones finales}

A lo largo de este trabajo marcamos las líneas de investigación abiertas a partir de la expansión de la historiografía académica en Argentina en la década de 1990 en torno a una historia centrada en el episcopado entre el periodo tardocolonial y temprano independiente. La historia de la iglesia en nuestro país se desarrolló al calor del diálogo con la historia social, política, cultural y económica

\footnotetext{
2 En 1816, estando Orellana preso en su segundo cautiverio, Benito Lascano fue elegido por el cabildo como provisor de la diócesis. Sin embargo, el obispo Orellana se negó a legitimarlo y redactó un escrito titulado "Justa Defensa", denunciando las disposiciones ilegítimas que el cabildo estaba llevando a cabo en su ausencia. En este caso, Lascano apeló al Congreso para legitimar su nombramiento, y los representantes le aconsejaron dirigirse a Santa Fe a conseguir personalmente la confirmación del obispo en su cargo (AYROLO; MAZZONI 2013).
} 
que contribuyó con innovadoras preguntas al estudio de una institución clave para entender el periodo colonial y la primera mitad del siglo XIX.

Nos focalizamos en el debate en torno a la administración diocesana en las diferentes diócesis rioplatenses. En este sentido, analizamos cómo el gobierno de los obispos, la forma en la que ejercían su autoridad, guardaba en Córdoba relación con lo que ocurría en diócesis de antigua colonización como las del espacio peruano, y poseían una cuota de autoridad mayor que en iglesias "de frontera" como la de Buenos Aires. Como vimos, esta diferenciación se correlaciona con las disímiles trayectorias de ambos espacios. Mientras la diócesis porteña ha sido calificada como una "iglesia de frontera" (DI STEFANO 1997; 2004), la de Córdoba se erigió en un territorio de antigua colonización con un derrotero común a diócesis con una vieja tradición e historia, y con lazos más estrechos con la estructura diocesana indiana, como las altoperuanas (AYROLO 2003; MAZZONI 2013).

En este sentido, la administración diocesana en el obispado de Córdoba del Tucumán, el más antiguo del territorio rioplatense, pone en evidencia el predominio del obispo en el ejercicio del poder en su jurisdicción eclesiástica. La potestad ejercida por los prelados en este espacio constituyó uno de los puntos centrales de la pervivencia de una unidad político-religiosa en el espacio cordobés durante la primera mitad del siglo XIX.

\section{Referencias bibliográficas}

ALBANI, Benedetta. The apostolic see and the world: challenges and risks facing global history. Rechtsgeschichte-Legal History, v. 20, p. 330-331, 2012.

- El matrimonio entre Roma y la Nueva España, historia y fuentes documentales (siglos XVI-XVII). En: BIEÑKO DE PERALTA, Doris y BRAVO RUBIO, Berenise. De sendas, brechas y atajos: contexto y crítica de las fuentes eclesiásticas, siglos XVI-XVIII. México: Secretaría de Educación Pública, 2008, p. 167-184.

AMORES CARREDANO, Juan Bosco. En defensa del rey, de la patria y de la verdadera religión: el clero en el proceso de independencia de Hispanoamérica. En: AMORES CARREDANO, Juan Bosco. Las independencias iberoamericanas ¿Un proceso imaginado? Bilbao: Universidad del País Vasco, 2009, p. 209-234.

ARTOLA RENEDO, Andoni. De Madrid a Roma. La fidelidad del episcopado en España (1760-1833). España: Ediciones Trea, 2013.

El acceso al episcopado en la monarquía hispánica (1789- 1800). En: Los tiempos de Espada: Vitoria y La Habana en la era de las revoluciones atlánticas. Bilbao, España: Servicio de Publicaciones de la Universidad del País Vasco, 2014, p. 23-54.

AYROLO, Valentina. Congrua sustentación de los párrocos cordobeses. Aranceles eclesiásticos en la Córdoba del ochocientos. Cuadernos de Historia, p. 39-66, 2001. 
. Cura de almas. Aproximación al clero secular de la diócesis de Córdoba del Tucumán, en la primera mitad del siglo XIX. Anuario IEHS, v. 16, p. 421-443, 2001.

. Estudios sobre clero iberoamericano, entre la independencia y el Estado-Nación. Salta: CEPIHA, 2006.

- Funcionarios de Dios y de la República. Clero y política en las autonomías provinciales. Buenos Aires: Biblos, 2007.

- La carrera política del clero. Aproximación al perfil político-clerical de algunos hombres del siglo XIX. El caso de los de Córdoba. PolHis, v. 7, p. 100-114, 2011.

. La estela de la Ley de Obispados de 1813 en la administración diocesana. Anuario del Instituto de Historia Argentina, v. 13, p. 1-15, 2013.

- La Provincia-diócesis de Córdoba. Religión y política en la autonomía provincial 1820-1852. En: CARETTA, Gabriela; ZACCA, Isabel. Para una historia de la iglesia. Itinerarios y estudios de caso. Salta: CEPIHA/ UNSa, 2008, p. 37-45.

- Los deberes del Obispo Orellana. Entre la pastoral y la patria, 1810-

1817. En: Catolicismo y política en Córdoba, siglos XIX y XX. Córdoba: Ferreyra Editor, 2010, p. 21-42.

- Representaciones sociales de los eclesiásticos cordobeses de principios del siglo XIX. Andes, v. 11, p. 161-175, 2000.

. Una Iglesia del interior de las Provincias Unidas: Córdoba en la primera 126 mitad del siglo XIX. Jahrbuch für Geschichte Lateinamerikas, v. 40, p. 179-201, 2003.

. Una nueva lectura de los informes de la misión Muzi: la Santa Sede y la iglesia de las Provincias Unidas. Boletín del Instituto Ravignani, v. 14, p. 31-60, 1996.

; BARRAL, María Elena. El clero rural, sus formas de intervención social y su politización (las Diócesis de Buenos Aires y Córdoba en la primera mitad del siglo XIX). Anuario de Estudios Americanos, v. 69, p. 139167, 2011.

; CARETTA, Gabriela. Clérigos seculares del Tucumán entre la colonia y la independencia (1776-1810). En: AGUIRRE, Rodolfo; ENRÍQUEZ, Lucrecia. La iglesia Hispanoamericana de la colonia a la república. México: Editorial Plaza y Valdés-Ediciones Universidad Católica, 2009, p. 45-70.

- Oficiar y gobernar. Apuntes sobre la participación política del clero secular de Salta y Córdoba en la pos-revolución. Andes, v. 14, p. 105-130, 2003.

; MAZZONI, María Laura. De familiar a Obispo de Córdoba. La trayectoria política de Benito Lascano como ejemplo de ascenso en la carrera eclesiástica, 1800-1836. Anuario de la Escuela de Historia Virtual, v. 4, p. 35-56, 2013.

BARRAL, María Elena. De mediadores componedores a intermediarios banderizos: el clero rural de Buenos Aires y la "paz común" en las primeras décadas del siglo XIX. Anuario IEHS, v. 23, p. 151-174, 2009. 
. De sotanas por la pampa. Religión y sociedad en el Buenos Aires rural tardocolonial. Buenos Aires: Prometeo, 2007.

. Disciplina y civilidad en el mundo rural de Buenos Aires a fines de la Colonia. Jahrbuch für Geschichte Lateinamerikas, v. 44, p. 135-155, 2007.

. "Fuera y dentro del confesionario". Los párrocos rurales de Buenos Aires como jueces eclesiásticos a fines del período colonial. Quinto Sol, v. 7, p. 11-36, 2003.

; DI STEFANO, Roberto. Las «misiones interiores» en la campaña de Buenos Aires entre dos siglos: de los Borbones a Rosas. Hispania Sacra, 60, 122, p. 635-658, 2008.

BARRIO GOZALO, Maximiliano. La jerarquía eclesiástica en la España moderna:

Sociología de una élite de poder (1556-1834). Cuadernos de historia moderna, v. 25, p. 17-60, 2000.

BENITO MOYA, Silvano. La Universidad de Córdoba en tiempos de reformas

(1701-1810). Córdoba: Centro de Estudios Históricos "Prof. Carlos S. A. Segreti", 2011.

BRUNO, Cayetano. Historia de la Iglesia en la Argentina. Buenos Aires: Don Bosco, 1970.

CASTAÑEDA DELGADO, Paulino y MARCHENA FERNÁNDEZ, Juan. La jerarquía de la Iglesia en Indias: el episcopado americano, 1500-1850. España: Fundación MAPFRE, 1992.

CONNAUGHTON, Brian. El cura párroco al arribo del siglo XIX: el interlocutor interpelado. En: MAYER, Alicia. Religión y vida cotidiana. El historiador frente a la historia. México: UNAM, 2008, p. 189-214.

CUENCA TORIBIO, José Manuel. Iglesia y Estado a fines del Antiguo Régimen: la elección del episcopado hispano-americano. Anuario de estudios americanos, v. 33, p. 105-143, 1976.

DELLAFERRERA, Nelson. La iglesia diocesana: las instituciones. En: Nueva Historia de la Nación Argentina. Buenos Aires: Academia Nacional de la Historia-Planeta, 1999, p. 385-416. . Los provisores de Córdoba. Cuadernos de Historia, v. 6, p. 69-119, 1996.

DI STEFANO, Roberto. Abundancia de clérigos, escasez de párrocos: las contradicciones del reclutamiento del clero secular en el Río de la Plata (1770-1840). Boletín del Instituto Ravignani, v. 16/17, p. 33-59, 1997.

. El púlpito y la plaza. Clero, sociedad y política de la monarquía católica a la república rosista. Buenos Aires: Siglo XXI, 2004.

. Entre Dios y el César: el clero secular rioplatense de las reformas borbónicas a la Revolución de Independencia. Latin American Research Review, v. 35. n. 2, p. 130-159, 2000.

- Lay Patronage and the Development of Ecclesiastical Property in Spanish America: The Case of Buenos Aires, 1700-1900. The Hispanic American Historical Review, v. 93, n. 1, p. 67-98, 2013. 
. Pastores de rústicos rebaños. Cura de almas y mundo rural en la cultura ilustrada rioplatense. Boletín del Instituto Ravignani, v. 22, p. 7-32, 2000.

. Poder episcopal y poder capitular en lucha: el conflicto entre el obispo Malvar y Pinto y el cabildo eclesiástico de Buenos Aires por la cuestión de la liturgia. Memoria Americana, v. 8, p. 67-82, 1999.

; MARTÍNEZ, Ignacio. Frailes de gorro frigio. La experiencia de la Comisaría General de Regulares en el Río de la Plata (1813-1816). En: Los dominicos insurgentes y realistas, de México al Río de la Plata. Querétaro: Instituto Dominicano de Investigaciones Históricas Miguel Ángel Porrúa, 2011, p. 147-181.

; ZANATTA, Loris. Historia de la Iglesia Argentina. Desde la conquista hasta fines del Siglo XX. Buenos Aires: Sudamericana, 2000.

ENRÍQUEZ AGRAZAR, Lucrecia. Trayectoria política de un obispo español en la revolución americana: Diego Antonio Navarro Martín Villodres, obispo de Concepción (1806-1816). Anuario de Historia de la Iglesia en Chile, v. 23, p. 39-57, 2005.

ENRÍQUEZ, Lucrecia. El Patronato en Chile de Carrera a O'Higgins (1812-1824).

Hispania Sacra, 60, 122, p. 507-529, 2008.

FERNÁNDEZ MELLÉN, Consolación. Iglesia y poder en La Habana: Juan José Díaz de Espada, un obispo ilustrado (1800-1832). Bilbao, España: Universidad del País Vasco; Servicio Editorial, 2014.

FOGELMAN, Patricia. Una cofradía mariana urbana y otra rural en Buenos Aires a fines del periodo colonial. Andes, v. 11, p. 179-207, 2000.

FRASCHINA, Alicia. Mujeres consagradas en el Buenos Aires colonial. Buenos Aires: Eudeba, 2010.

GALLO, Klaus; CALVO, Nancy y DI STEFANO, Roberto. Los curas de la revolución. Buenos Aires: Emecé, 2002.

HERNÁNDEZ GARCÍA, Elizabeth. Una columna fortísima del altar y del trono: Pedro Gutiérrez de Cos, obispo de Huamanga y de Puerto Rico (17501833). Hispania sacra, v. 60, n. 122, p. 531-555, 2008.

LEVAGGI, Abelardo. La Iglesia y sus relaciones con el Estado. En: Nueva historia

de la Nación Argentina, V (1810-1914). Buenos Aires: Academia Nacional de la Historia (Argentina), 2003, p. 313-344.

LIDA, Miranda. Dos ciudades y un dean. Biografia de Gregorio Funes, 17491829. Buenos Aires: Eudeba, 2006.

- Fragmentación política y fragmentación eclesiástica. La revolución de independencia y las iglesias rioplatenses (1810-1830). Revista de Indias, v. LXIV, n. 231, p. 383-404, 2004.

LORANDI, Ana María. Poder Central, Poder Local: Funcionarios Borbónicos en el Tucumán Colonial: Un Estudio de Antropología Política. Buenos Aires: Prometeo Libros Editorial, 2008.

MAEDER, Ernesto J. A. La vida de la iglesia. En: Nueva Historia de la Nacion Argentina. Buenos Aires: Academia Nacional de la Historia, 2003, p. 277-312. 
MALLO, Silvia. Iglesia, valores cristianos y comportamientos: el Río de la Plata a fines del período colonial. Trabajos y comunicaciones, v. 26/27, p. 93-113, 2000.

Sacerdotes y feligreses en el Río de la Plata. La transición del Siglo XVIII al XIX. Estudios e Investigaciones, v. 22, p. 19-35, 1995.

MARTÍNEZ DE SÁNCHEZ, Ana María. Cofradías y obras pías en Córdoba del Tucumán. Córdoba: EDUCC, 2006.

MARTÍNEZ, Ignacio. El 'obispo universal' y sus tenientes. Ingreso de la autoridad papal a las iglesias rioplatenses. 1820-1853. En: Signos en el tiempo,

Rastros en la tierra. Luján: Universidad de Luján, 2011, p. 17-38.

Una Nación para la Iglesia argentina. Construcción del Estado y jurisdicciones eclesiásticas en el siglo XIX. Buenos Aires: Academia Nacional de la Historia, 2013.

MAZÍN GÓMEZ, Óscar. Los espacios agropecuarios como fronteras de la Monarquía Indiana en 1650. Prohistoria, v. 24, p. 21-40, 2015.

MAZZONI, María Laura. El clero regular y el gobierno diocesano en el obispado de Córdoba del Tucumán en la tardocolonia. Aproximación historiográfica a un vínculo difuso. Anuario IEHS, v. 31, n. 1, p. 119-133, 2016.

. La administración diocesana en Córdoba del Tucumán en el periodo tardocolonial en el marco de la legislación eclesiástica de Lima y Charcas. En: ALBANI, Benedetta ; DANWERTH, Otto y DUVE, Thomas. Normatividades e instituciones eclesiásticas en Iberoamérica: Perú, siglos XVI-XIX. Frankfurt, Alemania: Max-Planck-Institut für europäische Rechtsgeschichte, 2015, p. en prensa.

- La gestión diocesana como instrumento de equipamiento eclesiástico del territorio. La administración diocesana de Ángel Mariano Moscoso, diócesis del Tucumán (1788-1804). Folia Histórica del Nordeste, 2015 [en prensa].

Mandato divino y poder terrenal. La administración diocesana en el Obispado de Córdoba, 1778-1836. Tesis doctoral. Universidad Nacional del Centro de la Provincia de Buenos Aires, Tandil, 2013.

- Servidor del trono y del altar. Aproximaciones sobre el reformismo borbónico en América a través del gobierno diocesano del obispo San Alberto, Diócesis del Tucumán (1778-1783). En: SERRANO, Eliseo. De la tierra al cielo. Líneas recientes de investigación en Historia Moderna. Zaragoza: Institución "Fernando el católico" (C.S.I.C.), 2013, p. 309-328. ; GÓMEZ, Fernando. Clero y política en La Rioja en los años veinte del siglo XIX. El Teniente de cura Melchor León de la Barra, de revolucionario a 'reo de alto crimen'. Almanack, v. 9, p. 103-114, 2015.

PAIVA, José Pedro. Os bispos de Portugal e do império 1495-1777. Coimbra: Imprensa da Universidade de Coimbra, 2006.

PEIRE, Jaime. El taller de los espejos. Iglesia e imaginario 1767-1815. Buenos Aires: Claridad, 2000.

PELAGATTI, Oriana. Los capellanes de la guerra. La militarización del clero en el frente oeste de la revolución rioplatense. En: BRAGONI, Beatriz y MATA, 
Sara. Entre la Colonia y la República: Insurgencias, rebeliones y cultura política en América del Sur. Buenos Aires: Prometeo, 2008, p. 193-216.

PEÑA, Gabriela. La integración de los indios en la iglesia cordobesa. Siglos XVI y XVII. Investigaciones y Ensayos, v. 44, p. 365-380, 1994.

PÉREZ PUENTE, Leticia. El obispo. Político de institución divina. En: MARTÍNEZ LOPEZ-CANO, Pilar. La Iglesia en Nueva España. Problemas y perspectivas de Investigación. México: UNAM-Publicaciones digitales del IIH, 2012, p. 151-184.

ROJAS INGUNZA, Ernesto. El báculo y la espada: el obispo Goyeneche y la iglesia ante la iniciación de la República, Perú 1825-1841. Lima: Instituto Riva Agüero, 2007.

ROMERO, José Luis. La biografía como tipo historiográfico. En: La vida histórica. Buenos Aires: Siglo XXI, 2008, p. 104-117.

SALVADOR AGUIRRE, Rodolfo. Historia social de la Iglesia y la religiosidad novohispanas. Tendencias historiográficas. Fronteras de la Historia, v. 15, 1, p. 135-156, 2010.

SÁNCHEZ PÉREZ, Emiliano. El obispo Nicolás Videla y el General Belgrano. 18121819. Hispania Sacra, v. 66, n. 133, p. 133-177, 2014.

TAYLOR, William. Ministros de lo sagrado. Sacerdotes y feligreses en el México del siglo XVIII. México: El colegio de México y El colegio de Michoacán, 1999.

TONDA, Américo. El Obispo Orellana y la Revolución. Buenos Aires: Academia Nacional de la Historia, 2009.

El Obispo Orellana. Sus cartas a las carmelitas de Córdoba. Rosario: Pontificia Universidad Católica Argentina-Facultad de Humanidades de Rosario, 1973.

Ocampo, Orellana y los Betlemitas de Córdoba. Investigaciones y Ensayos, v. 13, p. 493-518, 1973.

TROISI-MELEAN, Jorge. Redes, Reforma y Revolución: Dos franciscanos rioplatenses sobreviviendo al siglo XIX (1800-1830). Hispania Sacra, v. 60, n. 122, p. 467-484, 2008.

. Los franciscanos de la provincia de Asunción en la transición del periodo colonial al independiente (1780-1820). En: AYROLO, Valentina. Estudios sobre clero iberoamericano, entre la Independencia y el EstadoNación. Salta: CEPIHA, 2006, p. 115-132.

URQUIZA, Fernando. Etiquetas y conflictos: el obispo, el virrey y el cabildo en el Río de la Plata en la segunda mitad del siglo XVIII. Anuario de Estudios Americanos, v. L, n. 1, p. 55-100, 1993. 


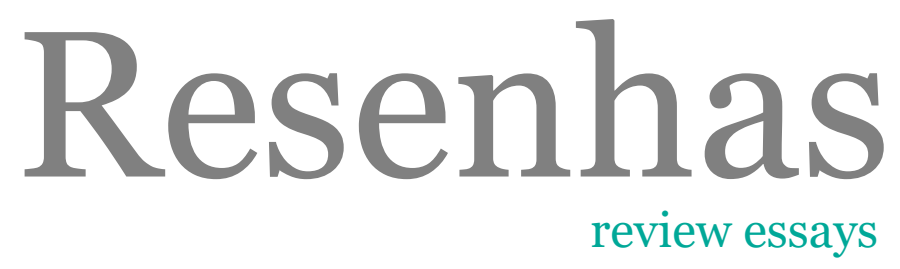




\section{$O$ (des) encontro entre História e memória}

The (dis) agreement between History and memory

CATROGA, Fernando. Memória, História e Historiografia. Rio de Janeiro: Editora FGV, 2015. 100p.

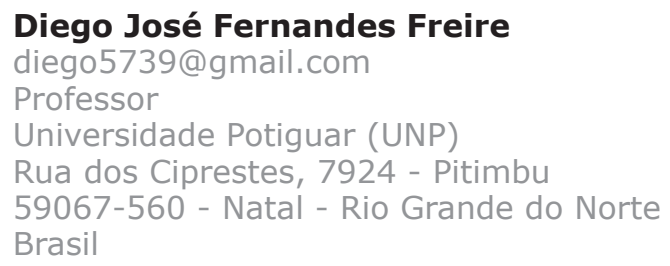

Diego José Fernandes Freire

diego5739@gmail.com

Professor

Universidade Potiguar (UNP)

Rua dos Ciprestes, 7924 - Pitimbu

59067-560 - Natal - Rio Grande do Norte

Brasil

Palavras-chave

História; Memória; Historiografia.

Keywords

History; Memory; Historiography. 
De acordo com a mitologia grega, a musa da história - Clio - teria se originado a partir da união entre Zeus e Mnemosine, deusa da memória que também deu lugar no monte Hélicon a várias outras musas gregas. Filha da memória, a história na cultura grega permaneceu durante muito tempo ligada a lembrança dos feitos humanos. Espécie de memória dos povos, a história no mundo grego guardava seus laços sanguíneos com Mnemosine e, assim, combatia o esquecimento preservando as realizações humanas. Porém, ao longo do tempo, os historiadores foram cortando o parentesco entre história e memória. Na modernidade, sobretudo no século XIX, momento em que ocorreu a institucionalização de vários saberes nas universidades, o passado mitológico da história é renegado: história não é memória, ou seja, memorialista não é historiador, bradam os metódicos franceses. Assim, a história se tornou filha ingrata da memória.

No momento em que a história almeja uma cientificidade e singularidade, acentua-se a diferenciação entre história e memória. A primeira seria fruto de um trabalho metódico, conceitual, investigativo, reflexivo, pautada em métodos ditos científicos; já a memória seria uma atividade espontânea, préreflexiva, contínua, quase natural e inerente aos indivíduos. Se a memória carregaria indelevelmente a afetividade dos sujeitos, a história traria consigo a imparcialidade, a objetividade dos fatos; uma se aproximaria do passado para revivê-lo, ao passo que a outra se distanciaria para analisa-lo. Em nome da Ciência, ergueu-se um muro para separar história e memória.

Posteriormente ao processo de disciplinarização da história, a memória continuou afastada deste saber. Os intelectuais representativos das ciências Humanas da primeira metade do século XX, como Marc Bloch, Lucien Febvre, Francois Simiand, Henri Bergson e Maurice Halbwachs, a despeito de um complexo e aprimorado debate sobre história e memória, continuaram opondo no essencial esses dois termos. Muitos historiadores da segunda metade do século passado, apesar de terem relativizado a cientificidade da história, continuaram seus antecessores na distinção entre história e memória. Embora neste momento Clio e Mnemosine tenham ensaiado um flerte familiar, espécie de flashback, a tônica continuou sendo a separação. Dois nomes de peso da historiografia francesa dão bem o tom desta distinção: Jacques Le Goff e Pierre Nora. Este último, aliás, afirmou: "memória, história: longe de sinônimos, tomamos consciência de que tudo as opõe" (NORA 1993, p. 10). ${ }^{1}$

Do exposto até agora, podemos concluir algo importante: existe uma história de longa duração da diferenciação entre história e memória, de modo que tal história é bem mais complexa do que o que aqui se apontou grosseiramente. ${ }^{2} \mathrm{O}$ livro que visamos apresentar neste texto não conta esta história, mas fornece valiosos elementos para a questionarmos. Memória, História e Historiografia, como o título sugere, procura fazer uma articulação entre as três categoriais,

\footnotetext{
${ }^{1}$ Sobre a distinção entre história e memória feita por Jacques Le Goff e com a qual certamente outros annalistas concordam ver: Le Goff (2013).

2 Para uma reconstrução resumida da oposição entre história e memória partindo do establishment francês ver: Dosse (2004, p. 169-193).
} 
mostrando suas semelhanças e diferenças. Como as diferenças são relativamente conhecidas e sustentadas pelos historiadores e teóricos das Ciências Humanas, Fernando Catroga empenha-se mais nas semelhanças que enlaçam os três termos do título do seu livro. Noções como lembrança, esquecimento, representificação e identidade aparecem em todo o livro, realizando finas e sofisticadas costuras no tecido textual da obra.

Como articular Memória, História e Historiografia? Que relações podese estabelecer entre memória e historiografia? Seria mesmo a história dos historiadores uma contra memória dos povos e dos grupos sociais? A representação do passado na memória possuiria semelhanças com a construção pretérita da historiografia? Questões como essas parecem ter ecoado na mente de Fernando Catroga, motivando-o para a escrita do livro.

Seu autor, Fernando José de Almeida Catroga, vem nos últimos anos marcando presença na historiografia brasileira. A despeito dos tradicionais diálogos entre esta historiografia e a lusitana, Fernando Catroga começou a aparecer mais efetivamente para o público brasileiro a partir dos anos 2000, quando em 2001 recebeu uma condecoração da Universidade de São Paulo por seus trabalhos sobre Portugal, os quais favoreceram a ampliação dos estudos e das iniciativas luso-brasileiras. De lá para cá, tem aqui comparecido em revistas acadêmicas e em livros, fornecendo entrevistas e tendo seus livros publicados por iniciativas brasileiras (CATROGA 2009, p. 469-487; 2005; 2009).

Fernando Catroga, professor catedrático da faculdade de letras da tradicional Universidade de Coimbra, dedica-se desde os anos 1980 ao campo da história das ideias, a partir de uma confluência com os estudos políticos e com a área de teoria da história. Temas como republicanismo, secularização da história, descristianização, positivismo, fim da história, recortados entre os séculos XVIII-XX, ocupam fortemente sua agenda de pesquisa. ${ }^{3}$

Seu livro mais recentemente publicado aqui no Brasil foi fruto da iniciativa da Editora FGV, a partir da série História da coleção de livros de bolso, coordenada pelos historiadores Marieta de Morais Ferreira e Renato Franco. Nas palavras dos editores, tal coleção é voltada para a

Produção de obras de síntese sobre os mais diversos temas das ciências humanas e sociais. Destina-se a estudantes, professores e profissionais interessados em conhecer de maneira rápida e eficaz, por meio de textos claros e acessíveis, os assuntos tratados em cada volume. Escrita por especialistas da área, a coleção FGV de Bolso reúne clareza e competência num pequeno livro (CATROGA 2015, p. 1).

É importante apontar ainda que a iniciativa de Marieta de Morais Ferreira e Renato Franco tem contribuído para a divulgação didática de questões importantes relacionadas a teoria da história e a história da historiografia, como bem atesta os livros de Jurandir Malerba (2009), Jose Carlos Reis (2010) e Luis Fernando Cerri (2011) publicados na série ora em apreço. Nesse sentido, a

\footnotetext{
${ }^{3}$ Sobre o perfil intelectual do autor, ver: http://www.uc.pt/chsc/investigadores/fjac1. Acesso em: 03 jan. 2016.
} 
Editora FGV vem contribuindo para a publicização crescente da reflexão teórica e historiográfica que vem marcando nosso momento atual. Em uma época de estudos historiográficos bastante pontuais e especializados, uma síntese escrita por alguém que conhece bem o campo no qual atua é sempre bem vinda.

Porém, ainda sobre a coleção na qual o livro Memória, História e Historiografia foi publicado, cabe uma crítica. Conforme evidenciamos na citação a seguir, a clareza e a agilidade de entendimento, objetivos caros à coleção, deixam, todavia, um pouco a desejar no livro de Fernando Catroga, tanto por questões de sua escrita, com parágrafos longos e termos rebuscados e intimamente ligados ao establishment intelectual português, como também por elementos de edição textual. Aqui, identificamos um problema que poderia ser contornado: excesso de citações em francês (contamos 20 no total, sendo muitas delas longas). Se o objetivo dos editores com a coleção é "promover uma abordagem simples e direta, acessível", por que não traduzir as citações em estrangeiro para o português, nem que fosse em rodapé? Em uma obra didática comprometida com a divulgação rápida do tema, citações em outra língua não traduzidas para o português soam como algo fora de contexto, mero preciosismo.

Deixando um pouco as questões externas de lado, o livro de Fernando Catroga divide-se em três capítulos, além de umas "palavras prévias". O capítulo inicial "recordação e esquecimento", montado a partir dos dois pares que constituem inevitavelmente a memória, traz o conceito do autor sobre o primeiro termo do título do seu livro. Nesse passo Catroga dialoga com os principais autores das Ciências Humanas que realizaram reflexões escritas sobre a memória: Henri Bergson, Maurice Halbwachs, Friedrich Nietzsche, Paul Ricoeur, Walter Benjamin, Tzvetan Todorov, Marc Augé entre outros comparecem no texto, tecendo um diálogo que mostra bem a intertextualidade do autor.

$\mathrm{Na}$ sua discussão sobre memória, Fernando Catroga parte da ideia de Umberto Eco de que "o homem é um animal histórico", isto é, os indivíduos necessitam da temporalidade para os mais diferenciados fins, sendo o tempo um elemento essencial da condição humana, tempo esse que teria como uma das formas de apreensão a memória. E isso não implica em uma naturalização da memória, dado que esta, para o autor, não é uma mera faculdade natural, ou

Um armazém inerte, onde, por ocasional e arbitrária acumulação, se recolhem os acontecimentos vividos por cada indivíduo, tal como acontece com as coisas amontoadas no sótão da casa dos avós. Bem pelo contrário. Ela é retenção afetiva e quente dos traços inscritos na tensão tridimensional do tempo - passado-presente-futuro - que permanentemente a tece (CATROGA 2015, p. 16-17).

Como se vê, o autor das palavras acima rejeita os essencialismos e as imagens clássicas sobre a memória. Não estamos aqui muito longe da ideia ricoeuriana de trabalho de memória (RICOUER 2007, p. 99-105). Esta é uma atividade, uma ação mesmo realizada pelos sujeitos e, como tal, está sujeita a todos os fatores que interferem em um trabalho qualquer: sociedade, tempo, técnicas, subjetividade etc. Sendo assim, o capítulo de abertura de Memória, 
História e Historiografia estabelece as bases teóricas sobre as quais a discussão posterior irá se desenrolar. Antes, porém, Catroga faz um rápido capítulo de transição, o qual se dedica a pontuar a noção de história do autor.

O capítulo 2, denominado "A historiografia como arsmemoriae", o menor do livro (apenas dez páginas), apresenta brevemente uma discussão conceitual sobre a historiografia, pontilhando seu nascimento e suas principais atribuições no mundo antigo greco-romano. Dialogando com Reinhart Koselleck e principalmente com François Hartog, Catroga traz à tona a historicidade antiga da história, investigando os vários significados da palavra "história" tal qual usada por Heródoto. Ao final, tem-se a seguinte conclusão:

\begin{abstract}
A historiografia nascente contava o que tinha acontecido com o fito de lembrar, à luz dos ritmos cíclicos, ou da repetição do que é característico da natureza humana, o que poderá vir a acontecer. [...] Para isso, e tal qual outras formas de bloquear o esquecimento, a historiografia era também garantia de transmissibilidade. O que dá sentido ao facto de ela ter sido qualificada como um verdadeiro testemunho contra a condenação ao Letes, isto é, como um discurso tanto memorial como alegórico ("/ux veritatis" e "vitamemoriae") (CATROGA 2015, p. 51).
\end{abstract}

A citação acima é a "deixa" do autor para começar a parte mais substancial do seu livro, contida no último capítulo, intitulado "A representificação do ausente". Após definir seu entendimento acerca das noções de memória e história, Catroga parte para o objetivo primordial de seu texto. O título do capítulo 3 fornece 136 um valioso rastro do seu pensamento: memória e historiografia não seriam tipos de "representificação do ausente"? Caçar o Outro, acertando-se com uma alteridade, não seriam objetivos comuns tanto da empresa memorialística como do empreendimento historiográfico? Memória e história não seriam grandes sínteses do passado? Para o autor, o fato de memória e história realizarem de forma diferente suas empreitadas não anularia as semelhanças entre ambas. É importante apontarmos que ele não caiu no reducionismo ingênuo de igualar história e memória. Trata-se, apenas, de não tornar as diferenças como que cinzas a apagar todas as aproximações entre os polos tradicionalmente apartados.

Segundo Fernando Catroga, quando o debate é história e memória, a discussão de boa parte dos historiadores caminha no sentido de uma radical diferenciação. É o que confirma também Beatriz Sarlo, escritora argentina formada em literatura: "o passado é sempre conflituoso. A ele se referem, em concorrência, a memória e a história, porque nem sempre a história acredita na memória, e a memória desconfia de uma reconstituição que não coloque em seu centro os direitos da lembrança" (SARLO 2007, p. 9). Disputando o passado com a memória, os historiadores tendem a opô-la a História, até mesmo no caso da História Oral, quando se defende a ideia de que os depoimentos, para virarem história, precisam ser criticados e analisados como qualquer outro documento, operação essa que, segundo alguns, violaria a reminiscência ${ }^{4}$. Para o analista

\footnotetext{
${ }^{4}$ Esta é a posição, por exemplo, de Durval Muniz de Albuquerque Junior, historiador brasileiro que na década de 1990 polemizou com a história oral, cravando radicalmente e energicamente a distinção entre história e memória (JUNIOR 2007, p. 199-211).
} 
do discurso historiográfico, faz-nos pensar o autor, tal separação precisa ser melhor pensada e avaliada:

Só um cientismo ingénuo pode aceitar a existência de uma radical separação entre a retrospectiva da memória e a retrospectiva historiográfica, tanto mais que ambas não são exclusivamente criadas pela imaginação e, ainda que por vias diferentes, aspiram ao verossímil, seja por fidelidade ou por veridição. [...] Pensando bem, as características apresentadas como típicas da memória (seleção, finalismo, presentismo, verossimilhança, representação) encontram-se, igualmente, no trabalho historiográfico, sobretudo porque, hoje, este não se restringe à busca de explicações por casualidade mecânica, elevada a deus exmachina da visão linear, acumulativa, homogénea e universalista. Afinal, a historiografia contemporânea, como saber mediato e mediado, também opera com a ideia de não continuidade do tempo e não reconhece a existência de um vazio entre o sujeito-historiador e o seu objeto (CATROGA 2015, p. 53-54).

A postura do artífice das palavras acima, além de relativizar a tradicional distinção entre história e memória, contribuiu também para pensarmos a própria história da historiografia. Se existem laços entre memória e história, se muitas vezes a segunda encontra a primeira, revestindo-se dela, a história da historiografia pode muito bem fazer o discurso da memória, e isso sem negar sua pretensão científica e seu métier institucional. Estamos longe aqui da visão segundo a qual "a história só começa no ponto onde termina a tradição, no instante em que se apaga ou se decompõe a memória social" (HALBWACHS 1990 , p. 38). História e memória podem imbricar-se, interelacionam-se, e a história da historiografia, especialmente, pode representar um terreno fértil para observar e analisar essas conexões. Na arena da historiografia, a memória pode deixar de ser adversária e virar aliada, rumo a entronização de certos enunciados.

É o próprio Catroga quem admite e discute essa possibilidade, enriquecendo ainda mais os propósitos de Memória, História e Historiografia

Também a historiografia - que nasceu sob o signo da memória - , apesar de querer falar em nome da razão, se edifica, voluntariamente ou involuntariamente, sobre silêncios e recalcamentos, como a história da história tem sobejamente demonstrado. Esta inevitabilidade aconselha a ser-se cauteloso em relação ao "discurso manifesto" dos seus textos, vigilância que deve ser redobrada quando a própria recordação é elevada a documento, isto é, ao nível arquivístico necessário para se dar objetividade ao trabalho de explicação/compreensão para onde deve subir a interpretação historiográfica (CARTOGRA 2015, p. 68).

Ao nosso ver, a principal contribuição do livro reside nessa possibilidade de pensar a história da historiografia como uma "prática de recordação disciplinar". Na ótica do autor, tal característica não anularia as outras dimensões da história da história, assim como não eliminaria outros tipos de análise. O campo da história da historiografia revela-se com uma seara rica em abordagens, de modo que o interesse de Fernando Catroga não é fechar as possibilidades a único tipo de tratamento. Ele apenas chama a atenção para uma faceta 
importante: "a escrita da história como um rito acadêmico de recordação" (CATROGA 2015, p. 56).

Diante dessa articulação entre memória, história e historiografia, como ficaria a questão da cientificidade de Clio? Ao trajar-se de memória a historiografia perderia sua áurea científica, já que este elemento é um traço fundamental para a distinção entre história e memória? O autor não aborda diretamente essas questões, já que, talvez, elas demandassem um outro capítulo ou até mesmo um outro livro. O fato é que Fernando Catroga, fazendo um texto breve porém denso e sofisticado, preferiu ficar na estrita discussão sobre os termos do título do seu livro, opção que tem seus méritos e deméritos, mas que o permitiu complexificar bastante o debate.

Por fim, cabe apontar que a discussão de Fernando Catroga lembra bastante as elucubrações de Manoel Luiz Salgado Guimarães, quando este dimensionava para a questão da "memória disciplinar" que muitas vezes a história da historiografia vinha a cimentar, a fim de legitimar suas práticas e conquistar seus postos de poder (GUIMARAES 2004). A historiografia, e mais ainda a história da historiografia, não está livre da memória, não está isenta dos mitos de origem e das invenções de tradições. Quem fará a política da memória historiográfica? Eis o questionamento que Memória, História e Historiografia nos incita.

Em tempos de institucionalização do campo, quando uma certa versão triunfa, no momento em que narrativas são criadas para serem aceitas e outras tantas para serem afastadas, é preciso suspeitar da história e dos historiadores.

138 Sendo assim, em tom de alerta, e mais uma vez aproximando história e memória, ficam as perguntas do historiador português: "Quem recorda o quê? E por quê? Que versão do passado se registra e se preserva? O que é que ficou esquecido?" (CATROGA 2015, p. 76).

\section{Referências bibliográficas}

CATROGA, Fernando. Entrevista concedida a Marieta de Morais Ferreira. Revista Brasileira de História (RBH), v. 29, n. 58, p. 469-487, 2009.

. Memória, História e Historiografia. Rio de Janeiro: Editora FGV, 2015.

. A história do mundo como tribunal do mundo. Saeculum - Revista de História, n. 21, 2009.

. Nação. Mito e Rito. Fortaleza: Museu do Ceará, 2005.

CERRI, Luis Fernando. Ensino de história e consciência histórica: implicações didáticas para uma questão contemporânea. Rio de Janeiro: Editora FGV, 2011.

DOSSE, François. A oposição História/Memória. In: DOSSE, François. História e ciências sociais. Bauru, São Paulo: Edusc, 2004, p. 169-193.

GUIMARÃES, Manoel Luiz Salgado. A cultura histórica oitocentista: a constituição de uma memória disciplinar. In: PESAVENTO, Sandra J. (org.). História 
cultural: experiências de pesquisa. Porto Alegre: Editora Universidade; UFRGS, 2003, p. 9-24.

HALBWACHS, Maurice. A memória coletiva. São Paulo: Vértice e Revista dos Tribunais, 1990.

JUNIOR, Durval Muniz de Albuquerque. Violar memórias e gestar a História: abordagem a uma problemática fecunda que torna a tarefa do historiador um parto difícil. In: ALBUQUERQUE JUNIOR, Durval Muniz de. História, a arte de inventar o passado. Bauru: Edusp, 2007, p. 199-211.

LE GOFF, Jacques. História e memória. São Paulo: Editora da Unicamp, 2013.

MALERBA, Jurandir. A história na América Latina: ensaio de crítica historiográfica. Rio de Janeiro: Editora FGV, 2009.

NORA, Pierre. Entre a história e a memória: a problemática dos lugares de memória. Revista Projeto História. Num. 10, São Paulo: Educ/PUC-SP, 1993.

REIS, Carlos Reis. O desafio historiográfico. Rio de Janeiro: Editora FGV, 2010.

RICOEUR, Paul. A memória, a história, o esquecimento. Campinas: Editora da Unicamp, 2007.

SARLO, Beatriz. Tempo passado: cultura da memória e guinada subjetiva. São Paulo: Companhia das letras; Belo Horizonte: Editora UFGM, 2007. 


\section{O tempo das expectativas decrescentes, ou os efeitos políticos do presentismo}

The time of decreasing expectations, or the political effects of presentism

ARANTES. Paulo E. O novo tempo do mundo: e outros estudos sobre a era da emergência. São Paulo: Boitempo, 2014. 464p.

\section{Guiherme Bianchi}

guilhermebianchix@gmail.com

Doutorando em História

Universidade Federal de Ouro Preto

Rua Bicame, 40A - Passagem de Mariana

35420-000 - Mariana - Minas Gerais

Brasil

Palavras-chave

Tempo; Política; Presentismo.

Keywords

Time; Politics; Presentism. 
Não se trata de uma grande novidade a anunciação da modernidade pósGuerra Fria como um tempo no qual a urgência se estabelece como fundamento central de projetos políticos ou de compreensões temporais. É possível encontrar tal diagnóstico nas obras de autores com pressupostos teóricos dos mais diferentes, como Giorgio Agamben, Naomi Klein, Roberto Esposito ou Robert Kurz, apenas para citar alguns. A pergunta que vem imediatamente para o leitor familiarizado com tais perspectivas (ou mesmo com diagnósticos mais antigos que já apresentavam tal horizonte compreensivo, como em Walter Benjamin ou Carl Schmitt) parece ser: afinal, em que sentido a proposição de Paulo Arantes em $O$ novo tempo do mundo, acerca do contemporâneo como uma "era de expectativas decrescentes", apresenta algo de novo em relação aos diagnósticos mais sedimentados pela crítica?

O livro em questão se trata da junção de dois materiais inéditos do autor (o capítulo inicial e o capítulo final) com artigos publicados ao longo dos últimos 10 anos. Daí a variedade de temas que circundam a reflexão de Paulo Arantes, variedade essa que não deixa se confundir como mero rol de exemplificações de uma tese central. Cada tema e subtema do livro, como veremos, possuem tanto a capacidade de prover força ao argumento apresentado, como também de representar em si possibilidades críticas que intensifiquem ou sobreponham o próprio núcleo de tal argumento. O que vemos ao longo do livro é uma espécie de exercício dialético negativo fiel à lição de Adorno, para quem a filosofia consistia "no esforço do conceito em curar as feridas que, necessariamente, inflige o próprio conceito" (ADORNO 1983, p. 43).

Professor aposentado do Departamento de Filosofia da Universidade de São Paulo, Paulo Arantes é reconhecido pela fertilidade de escritos capazes de conjugar história da filosofia, como em seus livros Hegel: a Ordem do Tempo (1981) e Ressentimento da Dialética (1996), com questões candentes da vida nacional, inflexão melhor observada em seus livros Um departamento francês de ultramar (1994) e O Fio da Meada (1996). Seu amigo (e feroz crítico) Ruy Fausto (2014, p. 92) chega a definir essa inflexão como ponto de mutação nas compressões filosóficas de Arantes mais à esquerda: "Excelente professor, homem de esquerda como muito de seus pares, a partir daquela quadra enveredou por um caminho original". O caminho original do qual fala Ruy Fausto seria o trajeto entre uma filosofia crítica para uma atitude "antifilosófica" ou "niilista", "indo parar lá onde estava o Marx da Ideologia Alemã".

Publicado em abril de 2014 pela Editora Boitempo na coleção organizada pelo próprio Arantes ("Coleção Estado de Sítio"), o livro surge como realização conceitual de uma percepção aguda em relação ao passado recente e ao presente global. Para o autor, nossa experiência contemporânea está cada vez mais baseada no decréscimo das expectativas de futuros qualitativamente diferentes. O paradigma securitário de um mundo completamente entregue à lógica da urgência só teria significado até agora políticas reprodutivas de um projeto de mundo tal como dado pela lógica da acumulação. Essa dinâmica temporal do capitalismo (já que a economia política detém ainda centralidade explicativa para Arantes) é orientada para o futuro, mas um futuro que nada apresenta 
de novo, que apenas reforça a necessidade do presente: "[...] essa forma de dominação através da dinâmica temporal que vem a ser o capitalismo tende paradoxalmente a se tornar cada vez mais presentista" (ARANTES 2014, p. 72).

O presentismo do qual fala Paulo Arantes detém particularidades em relação ao entendimento dado pelo historiador francês François Hartog, e tal diferenciação talvez seja fundamental para compreender o que há de original no seu argumento. Se tanto em Hartog como em Arantes a ideia de presentismo aparece como a absolutização do presente como categoria dominante de orientação histórica (e Arantes toma ciência dessa similitude, cf. ARANTES 2014, p. 167-171), a distância entre as percepções dos dois autores parece ser mais significativa que suas potenciais semelhanças. O fato é que, se Arantes articula em seu livro a percepção de um horizonte temporal do sistemamundo, as diferenciações territoriais e espaciais são centrais na construção de seu argumento. A preocupação da realidade brasileira interessa de modo fundamental ao autor. A progressiva demanda de desenvolvimentismo e de fortalecimento de dinâmicas direcionais ao futuro (projetos que só podem ser garantidos inteiramente pela reafirmação da ordem e da exceção) ${ }^{1}$ não podem senão demonstrar que o paradigma direcional sobrevive, ainda que só possa ser garantido pela repetição incessante das condições materiais do presente. Mais do que uma ferramenta heurística de compreensão histórica (tal como intencionada por Hartog), o presentismo de qual fala Arantes é, na verdade, uma evidência da experiência histórica do presente e, portanto, detém tanto um 142 potencial analítico como prático.

Com um extensivo capítulo inicial dedicado à demonstração da configuração conceitual do "novo tempo do mundo", Arantes dedica-se a apresentar para seus leitores a hipótese koselleckiana de redefinição do tempo moderno articulado entre as chaves "espaço de experiência" ou "horizonte de expectativa". Hipótese já conhecida entre historiadores, Arantes parece esmiuçá-la para um público que não a conhece tão profundamente. A retomada do arsenal analítico de Reinhart Koselleck tem o mérito de não reduzi-lo a simples sistema explicativo encerrado em si mesmo, pois é verdade que poderia ser questionado o perigo epistêmico inscrito na utilização gratuita das categorias do autor alemão como garantia política ou ética de certa coloração de valor do tempo histórico recente; creio, porém, não ser o caso, como fica claro quando o autor inclui, a partir de um comentário do historiador norteamericano Stephen Kern, uma diferenciação entre duas formas distintas de se relacionar com o futuro imediato. Além da chave koselleckiana "expectativa", o autor sugere a inclusão de uma outra, "atividade": enquanto a primeira se caracterizaria por um futuro que vem de encontro ao sujeito, "contrapondose a um ambiente a princípio hostil e todo-poderoso", a ideia de "atividade" pressuporia um sujeito que se lança ao futuro, de modo a obter algum possível controle sobre os acontecimentos (ARANTES 2014, p. 86). 
Mais que um complemento ao fundamento heurístico de Koselleck, o que tal inclusão significa é uma complexificação possível decorrente da formulação original do pensador alemão. É que Arantes nota, ao longo do primeiro capítulo, que a novidade apresentada pela chave analítica da "atividade" vem a ser a própria ideia do sujeito liberal em colonizar o futuro entreaberto pelas seguranças materiais garantidas pelo presente (segurança de propriedade, segurança bélica ou segurança contra "os inimigos"). A "expectativa" serviria mais para compreender a lógica de ação do sujeito de tipo hobbesiano, dotado de medo que acompanha a imaginação do futuro possível, onde esse futuro aparece como "fonte perene de insegurança". O indivíduo moderno seria sempre resultado de combinação dessas duas orientações em relação ao futuro.

Afirmando a centralidade da Guerra Fria como "último horizonte de expectativa dos tempos modernos" (ARANTES 2014, p. 91), o capítulo se encerra com a sugestão de que instaura-se, nesse passado recente, uma lógica mundial dominada pelo paradigma do instante. Tal paradigma caracterizar-seia por uma ação política incapaz (ou desinteressada) em se movimentar pelas distâncias que separariam a experiência da expectativa, de modo que substituise a política direcionada para possíveis transformações qualitativas pela mera "gestão dos destroços do presente" (ARANTES 2014, p. 91).

No segundo capítulo, Arantes prossegue na construção de seu arsenal crítico, primeiramente sob a forma do nível estrutural da sociabilidade pelo trabalho como fio condutor de um novo tempo do mundo, no qual a finalidade abstrata da produção aparece como a perfeita "banalização do mal" como regra social do contemporâneo. A semelhança com a tese de Giorgio Agamben acerca do campo de concentração como paradigma político do capitalismo tardio não é mero acaso. Tal como o filósofo italiano, Arantes articula comparações entre os dois momentos históricos. O colaboracionismo nazista é colocado ao lado de um suposto colaboracionismo nas estruturas organizacionais de nosso mundo, que gravita em torno do trabalho. Se no nazismo todo mal poderia ser justificado através do elemento discursivo do inimigo; o "grande Outro" no caso de nosso tempo parece brotar de seu próprio seio, sob a forma de um "trabalho repetitivo coagido pelos cronômetros".

O interlocutor de Arantes aqui é o psicólogo e psicanalista francês Christophe Dejours que, em seu livro Souffrance en France - La banalisation de l'injustice sociale, sugeriu as conexões psíquicas e sociais entre o tipo de trabalho organizacional praticado no Ocidente contemporâneo e a intensificação de doenças ligadas ao trabalho, como a depressão e a ansiedade. Observando uma lógica de trabalho incapaz de se reproduzir positivamente em nosso mundo, já que a transformação de valor em mais-valor vê-se cada dia mais incapaz de sustentar novos ciclos econômicos produtivos, Arantes pode articular nas entrelinhas de seu texto a crítica dessa "gestão do sofrimento social" com aquela lógica temporal de um mundo que não pode ser nada além de um reflexo de si mesmo. O fundamento do que ele chama de "tempo intemporal" não pode senão naturalizar uma ideia de humanidade cuja única função é garantir a reprodução da lógica do presente. 
A segunda parte do capítulo, intitulada "Zonas de Espera: uma digressão sobre o tempo morto da onda punitiva contemporânea", propõe a reflexão sobre outra forma de banalização do mal em nosso tempo: a transformação em regra social de lógicas punitivas típicas das sociedades de mercado. E aqui as exemplificações possíveis levantadas pelo autor são múltiplas, de modo que talvez valha a pena debruçarmo-nos principalmente sobre o ponto focal de sua argumentação, a saber, que a valorização do tempo (na verdade, valorização da espera) em nosso mundo aparece como sintoma primordial da mesma lógica de um tempo engessado. A consolidação de estruturas de controle jurídicopunitivas funciona como paradigma conceitual para Arantes, como se uma sociedade com um apreço pela punição como fim em si mesmo fosse também efeito de um tempo histórico morto, no qual todo futuro só é compreendido pela régua do presente. Mas esse tempo morto da espera punitiva é entendido pelo autor como uma questão de classe, já que afeta cada vez menos o topo da pirâmide social (não só a prisão como paradigma, mas o trato com os refugiados desterritorializados ou o sujeito preso nas estruturas burocráticas do poder).

O efeito disso é a valorização de uso das categorias de tempo. A paciência, o tempo em si, a lentidão se transformam em categorias de luxo, categorias mercantilizáveis, disponíveis apenas para aqueles que possam comprá-las. Mobilizando a partir disso o conceito de "atualismo", Paulo Arantes define que a caracterização de nosso presente desarticularia as dimensões koselleckianas de "espaço de experiência" e "horizonte de expectativa", já que em nosso mundo todo chamado à ação responderia por uma injunção imediata do instante, pois, "por mais frívolo que possa parecer o apelo presentista atual, seu protagonista é um personagem submerso por obrigações temporais exigíveis à queima-roupa" (ARANTES 2014, p. 159).

O segundo capítulo finaliza com uma reflexão paralela acerca da instauração da ordem e da exceção como medida protetiva nas democracias modernas, tomando as insurreições nos subúrbios franceses em 2005 como chave de leitura para sua hipótese de uma administração do medo da insegurança como paradigma normativo das democracias contemporâneas. Nessa altura do livro, Arantes parece estar preocupado em oferecer evidências históricas para a validação de sua hipótese, de modo que as revoltas no gueto francês e as medidas protetivas de segurança efetivadas para sua pacificação surgem como local de demonstração empírica acerca de como as relações entre tempo e ação são hoje rearticuladas a partir de uma temporalidade inscrita na ideia de segurança e, portanto, uma temporalidade que é filha do instante securitário. Os motins franceses funcionam para o autor também como exemplo do modo como o desespero, enquanto categoria psicológica das massas, representa um efeito a mais do que ele chama de um "curto-circuito da semântica da história" contemporânea (ARANTES 2014, p. 253).

O terceiro capítulo aparece segmentado em duas partes: "1964" (publicado originalmente no livro organizado por Vladimir Safatle e Edson Telles, $O$ que resta da ditadura: a exceção brasileira, de 2010) e "Tempos de exceção" (entrevista do autor publicada na revista Trans/Form/Ação em 2008). No 
primeiro, preocupado com as continuidades do regime de exceção brasileiro na sociedade pós-ditadura, Arantes refaz o caminho de uma transição incompleta, em que a antiga dominação pela coerção política se estabelece na sociedade democratizada como dominação via financeirização do social. A opressão desloca-se de medida preventiva de ordem e se intensifica como técnica de governo. Consciente de fáceis mal entendidos dessa hipótese, Arantes nota que a tese da continuidade não significa reiterar a existência de uma repetição incessante do período ditatorial. Se tais continuidades caracterizariam um regime jurídico-político em que a constitucionalidade é terreno sólido para as "classes confortáveis", o tratamento paternalista-punitivo de nosso tempo sobrevive para a "ralé". Na entrevista que se segue, Arantes avança na hipótese de um "estado de exceção permanente" na realidade brasileira. O termo, que à primeira vista pode ser lido como uma sintaxe contraditória, tem a potência de demonstrar a contradição existente nas próprias relações políticas e sociais. A hipótese aqui descortina as possíveis relações entre a figura constitucional do estado de exceção com a irrupção de novas lógicas de desenvolvimento econômico à brasileira. A transformação de uma economia industrial periférica em uma recente plataforma de valorização financeira exige a existência desse poder soberano sempre passível de ser ativado.

Ao fim, Arantes apresenta o que talvez seja o núcleo político mais imediato do seu argumento, com suas considerações acerca das "jornadas de junho" de 2013. Reconstituindo a gênese de Junho pelo prisma de uma insurgência cidadã gestada nos anos Lula, mostra-se preocupado em compreender os nós que ligam a fundamentação dessa cidadania ascendente, inscrita socialmente pela ascensão via consumo e casa própria típicas da última década, ao redor do urbano. O projeto carioca das Unidades de Polícia Pacificadora funcionam, na analítica de Arantes, como um aviso de incêndio do que estava por vir: o controle social, a pacificação, o adestramento de comunidades não estáveis aparece como efeito de uma gestão de territórios que pretendeu, em última estância, produzir indivíduos reduzidos à lógica nacional do consumo-produção (e permitir, no contexto específico dos megaeventos, uma circulação segura para alguns). O controle social da cidade aparece como momento essencial na conformação dessa nova ordem, é a sua negação ou sua positivação, em diferentes níveis, que aparecem como o fundamento de novas inscrições de participações políticas na análise de Arantes (as UPP, o financiamento estatal de moradias, a arte urbana, etc.), indivíduos que se tornam parte do mundo da cidadania. Entretanto, tais políticas falharam em levar em conta a igual necessidade de uma inclusão na mobilidade urbana ou na participação de constituição da cidade como lugar do plural - ou talvez essa fosse mesmo a sua função "natural", já que o argumento não fica tão claro; mas, "aí veio Junho" (ARANTES 2014, p. 387).

O fenômeno massivo de junho de 2013 aparece assim como um ponto de inflexão de uma história originária brasileira não reativa. É que, pela primeira vez, os cidadãos "entrincheirados" tornam-se cidadãos "insurgentes", sem a coreografia pré-determinada das Diretas Já ou dos caras-pintadas. As reivindicações em jogo, concentradas todas inicialmente na exigência de um 
direito à cidade, inscreve na semântica das lutas populares o próprio conceito da "insurgência", pois os sujeitos não são mais subversivos ou indignados. O efeito dessa transformação semântica, na hipótese do autor, desestabilizaria as próprias coordenadas temporais em jogo.

Após um desenvolvimento textual que poderia facilmente ser confundido com uma espécie de crítica negativa (para não dizer puro pessimismo) das opções políticas em jogo no contemporâneo, o final do livro apresenta possíveis horizontes de positividade na crítica do autor. A figura espectral de Junho aparece nesse momento como "ato profanatório", uma brecha possível na era das expectativas decrescentes. Se a doutrina contra insurgente da exceção e da pacificação cotidiana produz uma espécie de vácuo político, repetindo o gesto foucaultiano que dizia que onde há poder, há resistência, Arantes analisa as movimentações de massa de 2013, a despeito de seus problemas de origem inscritos numa politização que é filha da institucionalidade, como momento de liberação de uma carga de energia utópica, em que aquele horizonte remoto do não-contemporâneo produz a potência de transformar-se em utopia real. Junho passa a ser o horizonte de um mundo sem horizonte que, negando os dispositivos de controle da pacificação e dos pactos sociais das últimas décadas, apresentou novas formas e novos conteúdos do fazer-política.

Mas, como quase todo exercício dialético do autor, esse também tem um lado contrário. Ao invés de lançar uma positivação neutra às multidões de Junho, Arantes toma consciência dos perigos inscritos em sua própria natureza, pois,

146 por um lado, esse poder coletivo dos corpos na rua desafia o teórico preocupado com o caráter ético-político da mobilização coletiva. Restaria saber, ainda, se a insurgência da Multidão (a referência à Toni Negri e Michael Hardt é do autor) seria capaz de garantir, por si só, uma virada pragmática dessas ondas incendiárias em utopias políticas reais capazes de transformar o extraordinário em cotidiano, para remetermos aos termos do livro.

Munido de uma heterodoxia materialista crítica, o mérito da obra de Paulo Arantes parece ser-a conjugação da semântica dos tempos históricos de Koselleck e de seus predecessores com um engajamento crítico anticapitalista por excelência (confirmado pelas referências recorrentes a Anselm Jappe, Robert Kurz, Moishe Postone, etc.), recriando um fio que, no fundo, nunca deixou de estar ali - a relação entre tempo e dominação econômica. O livro denota, ainda, importantes sinais de que há processos de subjetivação em nosso mundo que tornam essa rede do tempo dominado pela lógica do presente dominante sempre passível de ser rasgada, recriada e ultrapassada.

\section{Referências bibliográficas}

ADORNO, Theodor. Terminologia filosófica. Tradução de Ricardo Sanchez Ortiz de Urbina. Madrid: Taurus Ediciones, 1983. t. 1.

ARANTES, P. E. Hegel: a ordem do tempo. São Paulo: Polis, 1981.

O novo tempo do mundo: e outros estudos sobre a era da emergência. São Paulo: Boitempo, 2014. 
. Ressentimento da dialética. São Paulo: Paz e Terra, 1996.

. Um departamento francês de ultramar. São Paulo: Paz e Terra, 1994.

O fio da meada. São Paulo: Paz e Terra, 1996.

FAUSTO, Ruy. A esquerda encapuçada. Revista Piauí, n. 99, p. 42-50, 2014. 


\section{Mundo Rural e Historiografia Brasileira}

Rural World and Brazilian Historiography

MOTTA, Márcia Maria Menendes. O Rural à la Gauche: campesinato e latifúndio nas interpretações de esquerda (1955-1996). Niterói: Editora da UFF, 2014. 278 p.

\section{Marcos Nestor Stein}

mancha36@hotmail.com

Professor do curso de graduação em História e do PPGH

Universidade Estadual do Oeste do Paraná

Rua Pernambuco, 1777

85960-000 - Marechal Cândido Rondon - Paraná

Brasil

Palavras-chave

Historiografia; Marxismo; História do Brasil.

Keywords

Historiography; Marxism; Brazilian History. 
A despeito da fala proferida pela senadora Kátia Abreu, em janeiro de 2015 - logo após assumir o cargo de ministra da Agricultura Pecuária e Abastecimento - na qual afirmava que o "latifúndio não existe mais" em nosso país, ${ }^{1}$ a história rural mantém-se firme na reflexão crítica em torno do mundo agrário e de suas relações atavicamente desiguais, tanto no Brasil quanto na América Latina. É nesse panorama que o livro "O Rural à La Gauche" da historiadora Márcia Maria Menendes Motta apresenta-se como uma leitura fundamental para a historiografia sobre o tema.

Redigido originalmente como tese para a ascensão de sua autora ao cargo de Professora Titular da Universidade Federal Fluminense, "O Rural à la Gauche" é um livro que apresenta uma pertinente análise de obras de cinco autores fundamentais - Nelson Werneck Sodré, Alberto Passos Guimarães, Caio Prado Junior, Maria Yedda Linhares e Ciro Flamarion Cardoso - para se compreender os debates e interpretações que envolvem a história do mundo rural brasileiro, bem como a constituição e consolidação da História Agrária como um importante campo científico.

A autora, Márcia Maria Menendes Motta, é atualmente uma das principais expoentes desse campo. Publicações de sua autoria como os livros "Nas Fronteiras do Poder" e "Dicionário da Terra", assim como o recém-lançado "O Rural à la Gauche", devem ser encaradas como leituras obrigatórias para todos aqueles que pretendem se embrenhar nos estudos sobre as dinâmicas presentes nas constituições dos espaços rurais brasileiros e as aventuras e desventuras de pessoas - camponeses, colonos, posseiros, agregados, meeiros, boias frias, etc.,- que buscaram e buscam viver de forma digna nestes espaços, marcados por constantes conflitos e onde ainda hoje o latifúndio é a regra.

A análise de interpretações sobre o mundo rural brasileiro e de propostas para a superação e/ou transformação de suas mazelas, produzidas entre 1955 e 1996 por intelectuais afinados e/ou inspirados em ideias comunistas, são o objetos centrais da narrativa de "O Rural à la Gauche". Em sua introdução são apresentados os autores com quem a autora dialoga e a seguinte linha de raciocínio que permeia as análises dos intelectuais acima citados:

[...] Quais eram as concepções que cada autor tinha acerca do universo rural brasileiro, em particular sobre campesinato e latifúndio. [...] Procuro também esquadrinhar como eles olharam o passado para conferir um sentido para os seus presentes. E mais: em que medida esses olhares eram possíveis no contexto da visão? (MOTTA 2014, p. 11)

Tais questões dão o tom da narrativa. Trata-se de uma linguagem clara e envolvente que, ao mesmo tempo, por meio do uso dessa chave de análise, permite ao leitor perceber o posicionamento teórico e político da autora, o rigor adotado no trato com os conceitos e o diálogo com a bibliografia - o que pode

\footnotetext{
${ }^{1}$ Kátia Abreu foi ministra da Agricultura, Pecuária e Abastecimento entre janeiro de 2015 e maio de 2016, durante o segundo governo de Dilma Rouseff. Atualmente é senadora pelo Tocantins, pecuarista e uma das maiores defensoras do agronegócio brasileiro. Para mais detalhes sobre a sua afirmação, ver: http:// www1.folha.uol.com.br/poder/2015/01/1570557-nao-existe-mais-latifundio-no-brasil-diz-nova-ministra-daagricultura.shtml.
} 
ser percebido, por exemplo, na introdução, quando chama a atenção para os "múltiplos marxismos" que constituem o pensamento comunista no Brasil e para a "[...] legitimidade do engajamento político como parte da formação do historiador" (MOTTA 2014, p. 22). ${ }^{2}$

A discussão que se segue está organizada em três partes. A primeira, intitulada "O Latifúndio na Perspectiva de um Brasil Feudal", está dividida em dois capítulos. No primeiro, a reflexão enfoca os escritos de Nelson Werneck Sodré (1911-1999), que advogava a tese de que o Brasil apresentava traços do sistema feudal que seriam originários de seu passado colonial. Os textos analisados são: "Oeste: Ensaio Sobre a Propriedade Pastoril", de 1941, "Formação Histórica do Brasil", cuja primeira versão é de 1944, "O que se deve ler para conhecer o Brasil", de 1943, e "As Razões da Independência", publicado em 1965.

Antes de iniciar a análise de seus escritos, Motta alerta para que não se encare a trajetória e o pensamento de Sodré de forma monolítica, ou somente como um autor "marxista", mas como um intelectual que produziu reflexões inspiradas em autores não marxistas e que são marcadas por descontinuidades e por rupturas. Tais considerações nos remetem às reflexões de Pierre Bourdieu (2002) acerca do caráter fragmentário das trajetórias de homens e mulheres, para as quais, muitas vezes por meio da narrativa biográfica, intenta-se constituir um sentido único, linear, totalmente coerente e ausente de hesitações, de dúvidas e de contradições.

Tomando esse cuidado, Motta sintetiza o pensamento de Sodré da seguinte forma:

Para Sodré, a formação do Brasil estaria assentada em duas contradições; internamente aquela que opunha senhores e escravos; externamente a que se expressava na relação entre metrópole e colônia. A articulação dialética entre ambas as contradições formaram o país e explicam a manutenção de relações atrasadas, de tipo feudal (MOTTA 2014, p. 36).

Trata-se, portanto, de um intelectual que encara o universo rural brasileiro como o lugar do atraso. De acordo com Motta, essa interpretação de Sodré perpassa inclusive os episódios de revolta dos pobres do campo, os quais são rotulados como fanatismos e/ou banditismo.

Ao final do capítulo, o leitor encontrará uma interessante análise acerca das leituras de Sodré que basearam seus textos mais importantes. Motta deixa claro que nem todos os autores, cujos escritos serviram de base para o autor construir sua tese, comungavam de sua visão. É o caso, por exemplo, de Roberto Simonsen e Caio Prado Junior, que rejeitavam a ideia da existência de um feudalismo no Brasil preconizada por Sodré, o que demonstra, portanto, o caráter plural de seu pensamento.

\footnotetext{
2 Esse posicionamento teórico e político - em grande parte inspirado no marxismo inglês, em especial nas reflexões de $\mathrm{E}$. P. Thompson - também está presente em sua produção bibliográfica, como no livro intitulado "Nas Fronteiras do Poder" (2008), na qual aborda os conflitos agrários no Brasil e as interpretações da legislação referente à posse e propriedade da terra, efetuadas por fazendeiros e trabalhadores rurais, e iniciativas em conjunto com outros pesquisadores brasileiros, como a criação da Rede Proprietas, um espaço dedicado ao debate acerca da noção de propriedade individual como algo natural e absoluta.
} 
O capítulo seguinte discute outro autor, Alberto Passos Guimarães (19081993), cuja interpretação, nas palavras de Motta, "[...] viria a dar uma visão mais acabada do feudalismo brasileiro [...]" (MOTTA 2014, p. 57). Ao analisar a obra de Passos Guimarães, a autora chama a atenção, inicialmente, para o pouco conhecimento acerca a importância de seus escritos, em especial o livro "Quatro Séculos de Latifúndio", publicado em 1963.

Na sequência, Motta realiza um minucioso exame do referido livro, analisando os argumentos e autores que Passos Guimarães utilizou para construir sua explicação de que o universo rural brasileiro, baseado na grande propriedade, constituiu-se a partir de um modelo transplantado de Portugal: o feudalismo. Para ele, essa estrutura manteve-se no Brasil com algumas modificações, em especial com a introdução do escravo em substituição ao servo.

Para Motta, essa intepretação, publicada um ano antes do golpe de 1964, deve ser vista também como um mecanismo de ação política, pois "[...] Guimarães acreditava que nominar de feudalismo a experiência colonial brasileira era a melhor forma de defender a reformulação da estrutura fundiária no país [...]" (MOTTA 2014, p. 63). Motta também incorpora em sua análise a edição de 1968 de "Quatro Séculos de Latifúndio", na qual Passos Guimarães anexou um capítulo sobre o Estatuto da Terra, e os estudos publicados no início da década de 1980, que abordam o desenvolvimento agrícola e a questão da violência no campo. Ao final, o leitor encontra um panorama detalhado dos autores citados por Passos Guimarães em cada capítulo de "Quatro Séculos de Latifúndio".

A segunda parte do livro, constituída por um capítulo, é dedicada ao pensamento de Caio Prado Junior (1907-1990), um grande crítico da tese do feudalismo brasileiro. Para investigar os argumentos de Caio Prado sobre o homem do campo e o latifúndio, Motta enfoca primeiramente a Revista Brasiliense, fundada em 1955, e que veio a se constituir em um espaço privilegiado da crítica à tese feudal preconizada pelo Partido Comunista Brasileiro. A partir dos artigos e da lista de colaboradores da revista, ela elenca e demonstra a importante dimensão que o tema relacionado à questão agrária teve na revista.

Na sequência, a análise se detém principalmente em três livros de Caio Prado Junior: "Formação do Brasil Contemporâneo", escrito em 1942, "História Econômica do Brasil", de 1945, e "A Revolução Brasileira", de 1966. Em sua investigação desse conjunto de textos, Motta revela os argumentos que o autor utilizou em seu embate com defensores da tese feudal acerca de temas envolvendo a colonização do Brasil, o latifúndio e os homens livres e pobres, estes caracterizados de forma depreciativa por Caio Prado Junior.

Ao final, na seção intitulada "Sodré, Passos Guimarães e Caio Prado: das recepções das obras", o leitor encontrará uma discussão que engloba tais autores, acompanhada por quatro quadros com informações sobre o número de edições, indicação do ano e das editoras. A apresentação das edições abre caminho para mais pesquisas sobre a recepção e as apropriações, os usos que cientistas sociais fizeram do pensamento desses intelectuais - tema que, sem dúvida, merece um livro a parte. 
A terceira parte do livro, dividida em quatro capítulos, enfoca de forma densa as trajetórias e obras de Maria Yedda Linhares (1921-2011) e Ciro Flamarion Cardoso (1942-2013), bem como a constituição e afirmação do campo científico da História Agrária. A análise inicia com informações sobre o trabalho de Linhares, em conjunto com outros intelectuais, durante período final da ditadura militar, quando da criação no Rio de Janeiro de um Centro de Pós-Graduação em Desenvolvimento Agrícola, de caráter interdisciplinar, cujo objetivo central era produzir conhecimentos sobre a agricultura brasileira e sua relação com o desenvolvimento do país. Em seguida, Motta faz um interessante mapeamento das publicações de Linhares que registram essa experiência, detendo-se no livro "História da Agricultura: combates e controvérsias", publicado em 1981, o qual também leva a assinatura de Francisco Carlos Teixeira.

O segundo capítulo dessa seção trata das reflexões de Jacob Gorender, seguida das de Ciro Flamarion Cardoso, ambos dedicados à construção de explicações acerca do sistema escravista no Brasil colonial. Em relação a Jacob Gorender, a análise de Motta enfoca as interpretações sobre os homens livres pobres, que na visão do autor ocupariam um lugar secundário na sociedade escravocrata. A discussão envolvendo as publicações de Ciro Flamarion Cardoso, em especial o livro "Agricultura, Escravidão e Capitalismo", de 1979, permite ao leitor compreender o processo de construção do conceito de modo de produção escravista-colonial e os debates envolvendo o conceito de modo de produção e a visão do autor acercado lugar dos camponeses - a "brecha camponesa" - nesse sistema/conceito.

Nos dois últimos capítulos, o leitor entrará em contato com uma análise acerca dos impactos dos livros de Linhares e Cardoso, a repercussão que o tema da questão agrária teve no Programa de Pós-graduação em História da UFF e o processo que viria a constituir o campo científico da história agrária. A narrativa é acompanhada por gráficos e de uma pertinente análise da conjuntura dessa produção: o processo de abertura política e os debates relacionados à reforma agrária travados por ocasião da elaboração da constituinte de 1988.

Trata-se, portanto, de um livro muito bem escrito, o qual, por um lado, não deixa de apontar as contradições e deficiências presentes nos textos dos autores analisados, e, por outro lado, também não deixa de reconhecer as suas contribuições para "[...] desnudar os caminhos e as mazelas da história rural do país" (MOTTA 2014, p. 250). Enfim, "O Rural à la Gauche" é um convite para a reflexão sobre esse seleto grupo de pesquisadores que, em diferentes momentos, interpretou a história do universo rural brasileiro e, sobretudo, merece ser lido em função do atual debate acerca da necessária transformação da estrutura fundiária do Brasil.

\section{Referências bibliográficas}

BOURDIEU, Pierre. A ilusão biográfica. In: AMADO, Janaína. FERREIRA, Marieta. (org.) Usos \& abusos da História Oral. Rio de Janeiro: Editora da FGV. 2002, p. 183-191. 
MOTTA, Márcia Maria Menendes. Nas fronteiras do poder. Conflito e direito à terra no Brasil do século XIX. Rio de Janeiro: Vício de Leitura; Arquivo Público do Estado do Rio de Janeiro, 1998.

. O Rural à la Gauche: campesinato e latifúndio nas interpretações de esquerda (1955-1996). Niterói: Editora da UFF, 2014. 


\section{Pareceristas deste número reviewers of this issue}




\section{Pareceristas deste número}

Alessander Mario Kerber (UFRGS)

Alexander Martins Vianna (UFRRJ)

Alexandre Avelar (UFU)

Alexia Helena de Araujo Shellard (UFRJ)

Allan Oliveira (UNIOESTE)

Ana Lucia Mandacaru Lobo (École Pratique des Hautes Etudes - França)

Ana Maria Mauad (UFF)

André da Silva Ramos (UFOP)

Andréa Lisly Gonçalves (UFOP)

Arnaldo Zangelmi (UFOP)

Arthur Lima de Avila (UFRGS)

Artur Alfaix Assis (UnB)

Carlos Henrique Armani (UFSM)

Clovis Mendes Gruner (UFPR)

Daniel Faria (UnB)

Daniel Lvovich (Universidad Nacional de General Sarmiento - Argentina)

Daniel Palma Alvarado (Universidad Alberto Hurtado - Chile)

Danilo José Zioni Ferretti (UFSJ)

Dominichi Miranda de Sá (Fundação Oswaldo Cruz)

Edmar Checon de Freitas (UFF)

Fábio Franzini (UNIFESP)

Fabrício Oliveira (UFV)

Francisco Cosentino (UFV)

Gabriela Jaquet (UFRGS)

Gilberto Loaiza Cano (Universidad del Valle - Colômbia)

Giselle Venancio (UFF)

Ignacio Martinez (Universidad Nacional de Rosario - Argentina)

Igor Klain Belchior (UFOP)

Igor Salomão Teixeira (UFRGS)

Isabel Cristina Leite (UFMG)

Kaori Kodama (Fundação Oswaldo Cruz)

Lidiane S. Rodrigues (USP)

Luiza Larangeira da Silva Mello (UFRJ)

Marçal de Menezes Paredes (PUC-Rio)

Marcelo de Mello Rangel (UFOP)

Marcelo Gantus Jasmin (PUC-Rio)

Marcelo Teo (USP)

Marco Antonio Silveira (UFOP)

María Eugenia Albornoz (École des Hautes Études en Sciences Sociales - França)

María Inés Mudrovcic (Universidad nacional del Comahue - CONICET - Argentina)

Mariana Canavesse (Universidad de Buenos Aires - Argentina)

Mariana Martins Villaça (UNIFESP)

Marina Corrêa da Silva de Araujo (UFRGS) 
Marta Maria de Carvalho (USP)

Mateus Pereira (UFOP)

Miranda Lida (Universidad Torcuato Di Tella - Argentina)

Paula Bruno (Universidad de Buenos Aires - Argentina)

Pedro Telles da Silveira (UFRGS)

Rafael Faraco Benthien (UFPR)

Rafael Rosa Hagemeyer (UDESC)

Rebeca Gontijo (UFRRJ)

Renato Viana Boy (UFFS)

Ricardo Salles (UERJ)

Roberto Pittaluga (Universidad de Buenos Aires - Argentina)

Rodrigo de Faria (UnB)

Sebastian Malecki (Universidad Nacional de Córdoba - Argentina)

Sérgio Araújo Sérgio Xavier Gomes de Araújo (UNIFESP)

Sérgio Ricardo da Mata (UFOP)

Susana Debattista (Instituto de Investigaciones Lingüísticas y Literarias de la

Patagonia - Argentina)

Tâmis Peixoto Parron (USP)

Tatiana Ribeiro (UFRJ)

Temístocles Cezar (UFRGS)

Tiago Luís Gil (UnB)

Verónica Tozzi (Universidad de Buenos Aires - Argentina) 


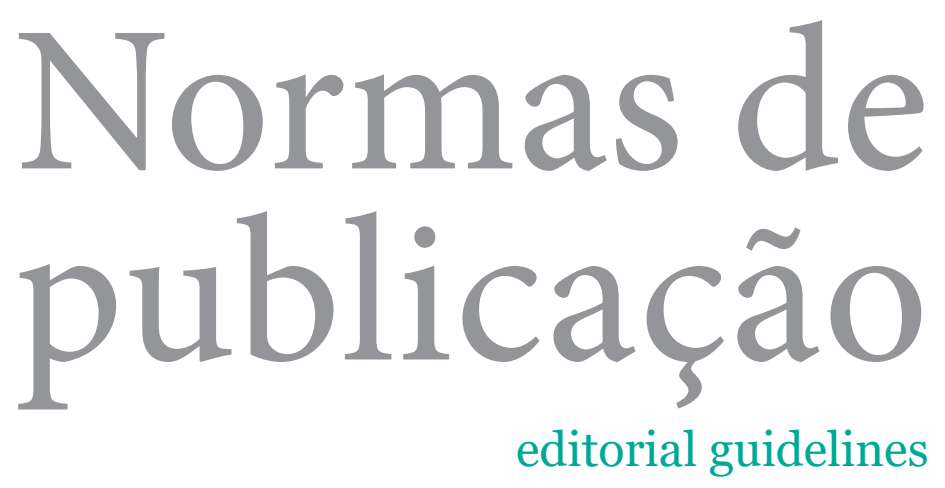


1) As colaborações poderão ser feitas sob as seguintes formas:

1.1. Artigo inédito e original (entre 28.000 e 54.000 caracteres com espaço, incluindo as notas e as referências bibliográficas).

1.2. Resenha de livro (máximo de 18.000 caracteres com espaço). As resenhas devem ter título, seguido pela referência bibliográfica completa da obra. Caso seja necessário, a bibliografia deve vir ao final da resenha, e as notas devem seguir os padrões editoriais da revista. Recomenda-se que as resenhas de livro escrito por um só autor apresentem uma avaliação crítica do trabalho à luz da literatura previamente existente sobre o tema.

1.3. Textos e documentos historiográficos. Os documentos devem ser antecedidos por um pequeno texto de apresentação, escrito pelo autor da submissão. O conjunto (apresentação + documento) não deve ultrapassar os 80.000 caracteres com espaço. Recomenda-se entrar em contato com os editores antes de preparar a submissão.

1.4. Entrevistas. Devem contar com um texto introdutório acerca do entrevistado. O conjunto (apresentação + entrevista) deve conter de 27.000 a 54.000 caracteres com espaços. Recomenda-se entrar em contato com os editores antes de preparar a submissão.

2) A revista aceita três tipos de resenha:

2.1. Resenha resumo: texto que se limita a resumir ou descrever o conteúdo 158 de um livro, sem qualquer crítica ou julgamento de valor, sem a preocupação de relacionar a obra resenhada a outras do mesmo gênero. Objetivo principal é informar o leitor e divulgar a obra.

2.2. Resenha crítica: além de resumir a obra, faz uma avaliação da mesma, apontando aspectos positivos e negativos, além de procurar situá-la em relação a outras do gênero ou que tratam do mesmo tema. Trata-se de um texto de opinião, também conhecido como recensão crítica. O objetivo da resenha crítica não é apenas informar o leitor sobre a obra, mas guiar o leitor no conjunto da produção historiográfica sobre um dado assunto, indicando parâmetros para o estudo de um tema, ao situar a obra em relação aos estudos e apontar suas contribuições e lacunas. Exige que o resenhista tenha conhecimentos da área e erudição suficiente para poder situar a obra em um contexto de estudos.

2.3. Resenha temática: trata de vários textos que tenham um assunto comum; é uma espécie de balanço bibliográfico sobre um tema. Tem caráter necessariamente crítico, pois demanda análise e opinião sobre os estudos tratados. Assim como no caso da resenha crítica de uma obra, a resenha temática também tem por objetivo guiar os leitores no conjunto dos estudos sobre um dado tema.

3) Os artigos devem conter, no início, resumo (de 700 a 1.050 caracteres com espaço) e três palavras-chave, ambos seguidos de traduções para língua inglesa.

4) Recomenda-se que os autores dividam os artigos em seções, que devem consistir em títulos explicativos, em negrito e com maiúscula apenas no início 
(ou, se nele houver, substantivo próprio). Em hipótese alguma será aceita a divisão de seções por algarismo.

5) Serão aceitas resenhas de livros que tenham sido publicados, no máximo, há três anos ou então títulos há muito esgotados e com reedição recente. Recebemos, excepcionalmente, resenhas de obras publicadas em anos anteriores, desde que haja justificativa, considerando a relevância do livro e a atualidade das questões que aborda.

6) A contribuição deve ser original e inédita, não estar sendo avaliada por outra publicação e não ter indicação de autoria. Os autores devem excluir todas as informações do arquivo que possam identificá-los como tal.

7) Quando houver financiamento da pesquisa, o autor deve indicar, em nota de rodapé ligada ao título da contribuição, a instituição financiadora.

8) As resenhas, os textos e documentos historiográficos e as entrevistas deverão conter três palavras-chave em português e em inglês, assim como os respectivos títulos nos dois idiomas.

9) As citações em língua estrangeira devem ser traduzidas. O original constará em nota de rodapé, com a informação sobre a autoria da tradução.

10) Todos os artigos, inclusive os submetidos para publicação em dossiê, serão analisados por, pelo menos, dois membros do Conselho Consultivo ou assessores ad hoc, que podem, mediante consideração da temática abordada, seu tratamento, clareza da redação e concordância com as normas da revista, recusar a publicação ou sugerir modificações. Os pareceres têm caráter sigiloso. Ao Conselho Editorial fica reservado o direito de publicar ou não os textos enviados de acordo com a pertinência em relação à programação dos temas da revista.

11) Os artigos, resenhas, entrevistas e textos e documentos historiográficos passarão por uma pré-seleção do Conselho Editorial que avaliará sua pertinência com relação à temática do periódico. Uma vez aprovados na pré-seleção, serão encaminhados para pareceristas.

12) As resenhas, entrevistas, e textos e documentos historiográficos serão avaliados por um membro do Conselho Editorial ou Consultivo, que levará em conta os critérios depertinência temática do material apresentado com relação à linha editorial do periódico e a qualidade e consistência do texto da resenha, entrevista ou texto e documento historiográfico.

13) As palavras-chave devem ser preferencialmente retiradas do banco de palavras-chave elaborado pelos editores da revista. Caso o autor considere recomendável inserir uma palavra-chave que não esteja contida no referido 
banco, deve expressamente pedir sua inclusão no sistema de busca. A solicitação será avaliada pelos editores.

14) As colaborações devem ser enviadas em Times New Roman, corpo 12, espaçamento 1,5 e com margens de $3 \mathrm{~cm}$. As citações com mais de três linhas devem ser destacadas do texto, sem aspas, compondo parágrafo com recuo, à direita, de $1,5 \mathrm{~cm}$, corpo 11 e espaçamento simples.

15) Todos os textos deverão ser apresentados após revisão ortográfica e gramatical. A revista publica contribuições em português, espanhol, inglês, francês e italiano.

16) As notas de rodapé devem ser apenas de caráter explicativo. As referências devem vir em corpo de texto tendo o seguinte formato:

(ABREU 2005, p. 36).

17) A referência à textos clássicos também deve ser feita no corpo do texto, com indicações do nome do autor, da primeira palavra do título da obra (em itálico) e da seção e/ou as linhas citadas, tal como nos seguintes exemplos: Aristóteles, Poética VII; Tucídides, História IV, 49. A referência completa à obra citada deve aparecer ao final do texto, na lista da bibliografia utilizada.

18) As referências bibliográficas, listadas em ordem alfabética, devem estar no 160 final do texto e seguirem os modelos abaixo:

Livro

KOSELLECK, Reinhart. Futuro passado: contribuição à semântica dos tempos históricos. Rio de Janeiro: Contraponto; Editora PUC-Rio, 2006.

Capítulo de livro

CASSIRER, Ernst. A linguagem. Introdução e exposição do problema. In:

A filosofia das formas simbólicas. São Paulo: Martins Fontes, 2001, p. 9-74.

Coletânea

CARDOSO, Ciro Flamarion; MALERBA, Jurandir (orgs.). Representações: contribuições a um debate transdisciplinar. Campinas: Papirus, 2000.

Artigos em periódico

RIGOLOT, François. The Renaissance Crisis of Exemplarity. Journal of the History of Ideas, v. 59, n. 4, p. 557-563, 1998.

Texto disponível na internet

HEGEL, Georg W. F. Filosofia da História. 2. ed. Brasília: Editora UnB, 1995. Disponível em: http://gutenberg.spiegel.de/buch/1657/1. Acesso em: 20 set. 2013. 
Trabalho publicado em anais eletrônicos

ARAÚJO, Rodrigo Cardoso Soares de. O polêmico Corsário, um pasquim da Corte Imperial (1880-1883). In: SEMINÁRIO DIMENSÕES DA POLÍTICA NA HISTÓRIA: ESTADO, NAÇÃO, IMPÉRIO, I, 2007, Juiz de Fora. Anais... Juiz de Fora: Clio Edições, 2007, p. 500-501.

Tese acadêmica

RIBEIRO, Tatiana O. A apódexis herodotiana: um modo de dizer o passado. Tese (Doutorado em Letras Clássicas) - Programa de Pós-Graduação em Letras Clássicas, Universidade Federal do Rio de Janeiro, Rio de Janeiro, 2010.

Artigo de jornal

GLEISER, Marcelo. Newton, Einstein e Deus. Folha de S. Paulo, 13 jun. 2010. Ilustrada, p. A23.

Pede-se os autores que indiquem, nas referências bibliográficas, a primeira edição de livros com várias reedições, seguindo o padrão: CROCE, Benedetto. Teoria e storia della storiografia. Bari: Laterza, 1973 [1913].

19) Desde o seu terceiro número, a revista História da Historiografia adotou a nova ortografia estabelecida no Novo Acordo Ortográfico da Língua Portuguesa. Recomenda-se aos colaboradores a adoção da nova ortografia nos materiais enviados para avaliação e publicação na revista.

20) O envio de manuscritos implica a cessão de direitos autorais e de publicação à História da Historiografia, que não se compromete com a devolução das colaborações recebidas. Os textos publicados na revista não podem ser republicados em outros meios e/ou formatos sem a autorização expressa dos editores. Os dados, conceitos e opiniões apresentados nos trabalhos, bem como a exatidão das referências documentais e bibliográficas, são de inteira responsabilidade dos autores.

21) Todas as colaborações devem ser enviadas exclusivamente pelo site da revista: http://www.historiadahistoriografia.com.br. 


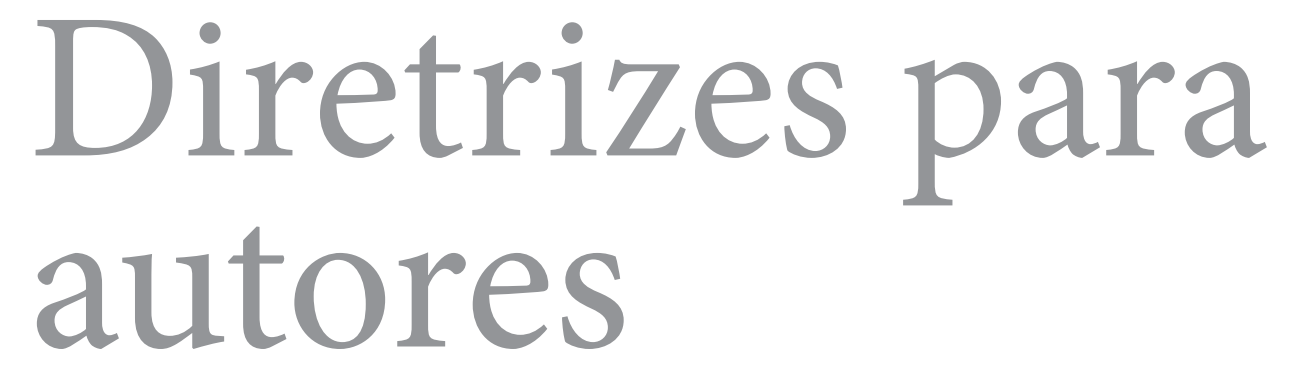

guidelines for authors 
1) Sugestões para a elaboração de resumo:

O resumo é um breve sumário do artigo. Ele não deve ser uma introdução do texto, mas uma descrição completa e sintética do conteúdo do artigo, indicando os objetivos e os aspectos centrais do argumento, a forma de abordagem do tema e as conclusões e/ou hipóteses do estudo. As informações devem ser expostas em um parágrafo, com narrativa contendo introdução (tema central do estudo e objetivos), meio (forma de abordagem do tema e fontes utilizadas) e fim (conclusões ou hipóteses principais).

\subsection{Detalhamento das partes do resumo:}

Introdução: a parte inicial do resumo deve fornecer uma introdução ao tema ou problema do estudo. Ela deve identificar a questão central do trabalho. É preciso dizer em poucas palavras sobre o que é o artigo. A introdução deve ser seguida pelos objetivos (gerais e específicos) do estudo, sendo possível eliminar a introdução e expor os objetivos no início de forma mais direta.

Meio: apresenta de forma clara as questões, os objetivos, os argumentos centrais e a forma de abordagem do tema.

Fim: indica a conclusão principal do estudo ou a hipótese (quando houver).

\subsection{O resumo deve poder responder às seguintes questões:}

Do que o texto trata?

Quais os objetivos?

Como o estudo foi conduzido?

Quais foram os resultados ou as conclusões da pesquisa?

Lembramos aos autores que o resumo é o primeiro contato do leitor com o estudo e pode ser o único elemento recuperado nas bases de dados científicos sobre um determinado tema. Além disso, se o resumo for bem escrito poderá auxiliar os avaliadores do artigo, esclarecendo possíveis dúvidas sobre os objetivos e conclusões do autor. Também poderá atrair leitores para o texto.

2) Sobre as palavras-chave

As palavras-chave devem comunicar os conceitos e/ou categoriais centrais do estudo. A seleção criteriosa das palavras-chave facilitará a recuperação das pesquisas, uma vez que tais palavras são utilizadas na indexação e busca de estudos nas bases de dados científicos. 